UNIVERSIDADE DE SÃO PAULO

ESCOLA DE ENGENHARIA DE SÃO CARLOS

PROGRAMA DE PÓS GRADUAÇÃO EM ENGENHARIA HIDRÁULICA E SANEAMENTO

IRINA MONCAYO BRAVO

\title{
INFLUÊNCIA DA CARGA ORGÂNICA NA PRODUÇÃO DE BIOHIDROGÊNIO EM ANSBBR COM RECIRCULAÇÃO DA FASE LÍQUIDA TRATANDO O EFLUENTE DO PROCESSO DE PRODUÇÃO DE BIODIESEL
}

VERSÃO CORRIGIDA

SÃo CARLOS, SP 


\section{INFLUÊNCIA DA CARGA ORGÂNICA NA PRODUÇÃO DE BIOHIDROGÊNIO EM ANSBBR COM RECIRCULAÇÃO DA FASE LÍQUIDA TRATANDO O EFLUENTE DO PROCESSO DE PRODUÇÃO DE BIODIESEL}

Dissertação apresentada à Escola de Engenharia de São Carlos, da Universidade de São Paulo, como parte dos requisítos para obtenção do título de Mestre em Ciências: Engenharia Hidráulica e Saneamento.

Orientador: $\quad$ Prof. Dr. José Alberto Domingues Rodrigues

VERSÃO CORRIGIDA

SÃo CARLOS, SP

2014 
AUTORIZO A REPRODUÇÃO TOTAL OU PARCIAL DESTE TRABALHO, POR QUALQUER MEIO CONVENCIONAL OU ELETRÔNICO, PARA FINS DE ESTUDO E PESQUISA, DESDE QUE CITADA A FONTE.

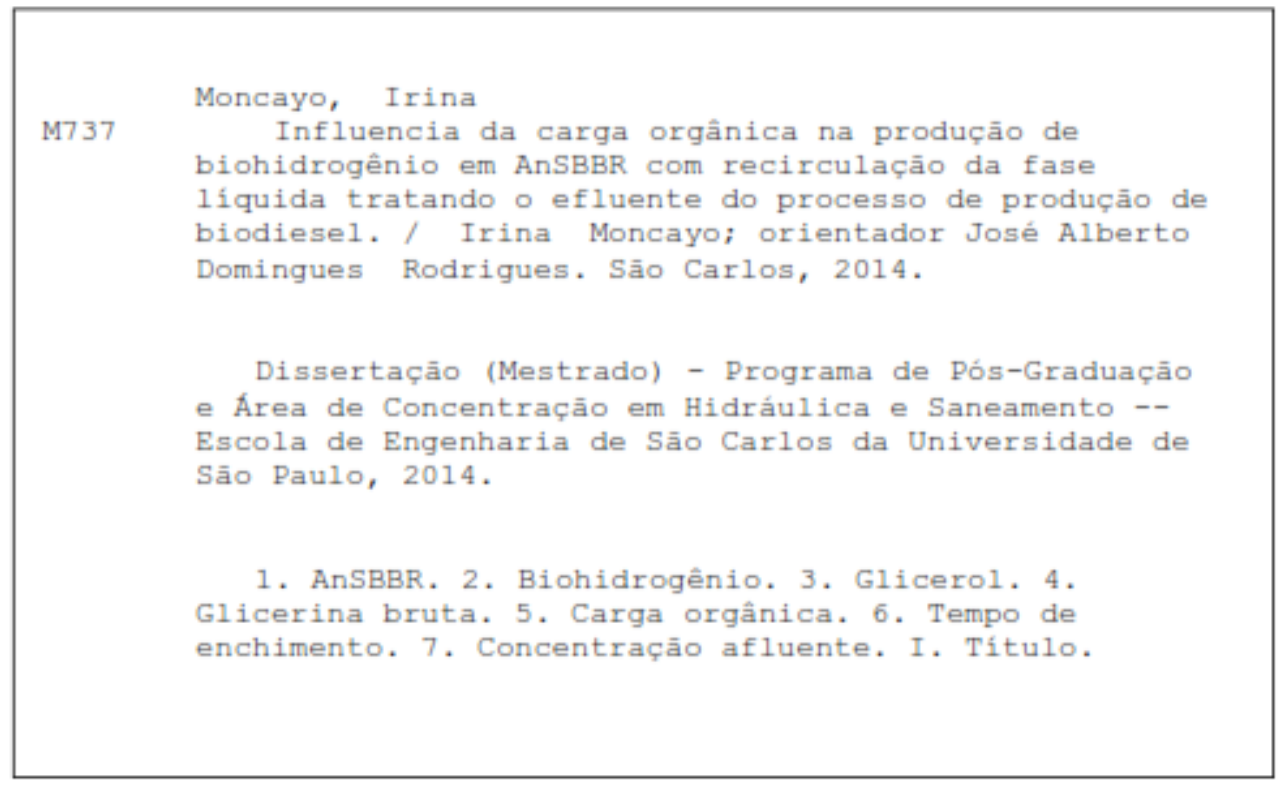




\section{FOLHA DE JULGAMENTO}

Candidata: Engenheira IRINA SORAYA MONCAYO BRAVO.

Título da dissertação: "Influência da carga orgânica na produção de biohidrogênio em ansbbb com recirculação da fase líquida tratando o efluente do processo de produção de biodiesel".

Data da defesa: $14 / 03 / 2014$

\section{Comissão Julgadora:}

Prof. Dr. José Alberto Domingues Rodrigues (Orientador) (Escola de Engenharia de Mauá/EEM)

Profa. Dra. Suzana Maria Ratusznei

(Escola de Engenharia de Mauá/EEM)

Profa. Dra. Simone Damasceno Gomes

(Universidade Estadual do Oeste do Paraná/UNIOESTE)
Resultado:
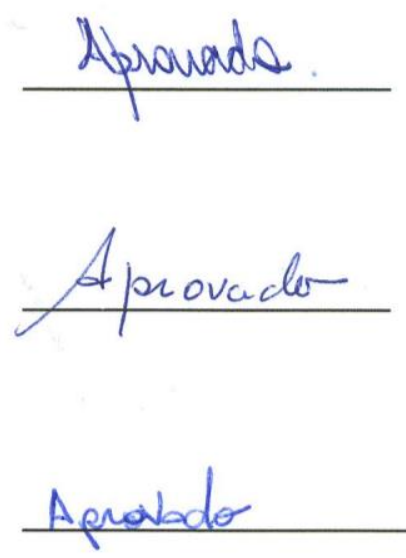

Coordenadora do Programa de Pós-Graduação em Engenharia Hidráulica e Saneamento:

Profa. Associada Maria Bernadete A. Varesche Silva

Presidente da Comissão de Pós-Graduação:

Prof. Titular Denis Vinicius Coury 


\section{DEDICATÓRIA}

A Elsa Beatriz (in memorian) 


\section{AGRADECIMENTOS}

Primeiramente, quero agradecer a Deus por suas bênçãos infinitas.

À minha família pelo amor e apoio. Ao meu noivo Gabriel pela companhia, amor e compromisso mostrado durante estes dois anos.

Aos amigos que sempre estiveram comigo a pesar da distancia. Aos novos amigos feitos no Brasil, em especial a Andrea Pineda cujo comportamento foi o de uma irmã.

A Marlene da Silva e aos Sres. Neusa e Toninho Michelon que abriram seus lares para me acolher. Sempre os levarei no meu coração.

Um especial agradecimento aos colegas de laboratório. A Giovanna Lovato pelo companheirismo e mutua colaboração no desenvolvimento da pesquisa e a Daniel Lima que além de sua grandiosa amabilidade foi de gram ajuda na revisão do português do presente trabalho.

Ao Prof. José Rodrigues pela orientação na presente pesquisa, a atenção continua no trabalho e seu alto nível de compromisso fazendo todo o que for necessário no tempo requerido, com uma pontualidade e organização destacada.

Ao Departamento de Hidráulica e Saneamento da Escola de Engenharia de São Carlos da Universidade de São Paulo e a Escola de Engenharia Mauá do Instituto Mauá de Tecnologia que disponibilizaram o espaço e o apoio necessário à realização deste projeto

A este maravilhoso país por me acolher e a todas as pessoas que contribuíram de uma ou outra forma no desenvolvimento do programa de mestrado.

Um especial agradecimento à Secretaría Nacional de Educación Superior, Ciencia y Tecnología del Ecuador (SENESCYT) pela bolsa de estudos outorgada a través da qual foi possível a consecução desta meta. 


\section{RESUMO}

MONCAYO, I. Influencia da carga orgânica na produção de biohidrogênio em AnSBBR com recirculação da fase líquida tratando o efluente do processo de produção de biodiesel. Dissertação (Mestrado) - Escola de Engenharia de São Carlos - Departamento de Hidráulica e Saneamento, Universidade de São Paulo, 2014.

O presente trabalho de pesquisa teve como objetivo principal avaliar o efeito da carga orgânica volumétrica aplicada (COVA) na produção de hidrogênio usando o reator AnSBBR com recirculação operado em batelada e biomassa imobilizada. Para este efeito, o reator foi operado a $30^{\circ} \mathrm{C}$ com dois tempos de ciclo $(3$ e $4 \mathrm{~h}$ ), alimentado com três concentrações afluentes (3000,

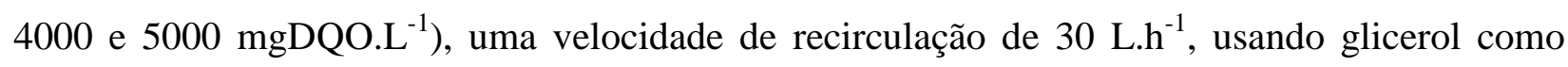
única fonte de carbono e a biomassa de uma estação de tratamento de abatedouro de aves. A combinação destes fatores fez com que o reator fosse operado com seis cargas orgânicas volumétricas aplicadas diferentes (7565, 9764, 12911, 10319, 13327 e 16216 mgDQO.L $\left.\mathrm{L}^{-1} \cdot \mathrm{d}^{-1}\right)$. Os resultados mostraram que não existiu uma tendência clara entre a carga orgânica aplicada e a produção de hidrogênio. Porém, os melhores resultados quanto à produção de hidrogênio foram atingidos quando o reator foi operado com 4 horas de tempo de ciclo e alimentado com uma concentração afluente de $5000 \mathrm{mgDQO} . \mathrm{L}^{-1}$ (COVA de $12911 \mathrm{mgDQO} . \mathrm{L}^{-1} \cdot \mathrm{d}^{-1}$ ), sendo sua produtividade molar média de hidrogênio $(\operatorname{PrM})$ de $67,5 \mathrm{molH}_{2} \cdot \mathrm{m}^{-3} \cdot \mathrm{d}^{-1}$. Esta condição também atingiu o melhor rendimento molar de hidrogênio por carga orgânica aplicada $\mathrm{RMCA}_{\mathrm{S}, \mathrm{m}}$ e o melhor rendimento molar de hidrogênio por carga orgânica removida $\left(\mathrm{RMCR}_{\mathrm{S}, \mathrm{m}}\right)$, sendo estes de 5,2 e 21,1 $\mathrm{molH}_{2} \cdot \mathrm{kgDQO}^{-1}$, respectivamente. Adicionalmente foi estudada a diferença na produção de hidrogênio entre o uso de biomassa pré-tratada e não tratada termicamente, cuja análise de variância (ANOVA) mostrou que a diferença não foi estatisticamente significativa. Finalmente o reator foi operado usando glicerina bruta industrial para comparar os resultados com aqueles obtidos operando com glicerol, observando-se uma clara desvantagem na produção de hidrogênio quando foi usada glicerina bruta. Em geral, o reator AnSBBR operado em batelada sequencial apresentou resultados promissores na produção de hidrogênio usando glicerol como fonte de carbono, porém estudos mais profundos ainda são necessários no intuito de otimizar o sistema para a utilização de glicerina bruta. 
Palavras chave: AnSBBR; biohidrogênio; glicerol; glicerina bruta; carga orgânica; tempo de ciclo; concentração afluente. 


\begin{abstract}
MONCAYO, I. Influence of organic loading rate on bio-hydrogen production in an AnSBBR with recirculation of the liquid face treating the wastewater from biodiesel production. Dissertation (Master's degree). School of Engineering of São Carlos - Department of Hydraulics and Sanitation, University of São Paulo, 2014.
\end{abstract}

This study evaluated the influence of applied volumetric organic load on biohydrogen production in an anaerobic sequencing batch biofilm reactor (AnSBBR) with $3.5 \mathrm{~L}$ of liquid medium and treating $1.5 \mathrm{~L}$ of glycerin based wastewater per cycle at $30^{\circ} \mathrm{C}$. The reactor was operated with two cycle periods ( 3 and 4 hours), three influent concentrations (3000, 4000 and $5000 \mathrm{mgCOD} . \mathrm{L}^{-1}$ ), recirculation rate of $30 \mathrm{~L} \cdot \mathrm{h}^{-1}$ and an inoculum from a poultry slaughterhouse. Six applied volumetric organic loads $\left(\mathrm{AVOL}_{\mathrm{CT}}\right)$ were generated from the combination of cycle period and influent concentrations $\left(7565,9764,12911,10319,13327\right.$ e 16216 mgCOD.L $\left.{ }^{-1} \cdot \mathrm{d}^{-1}\right)$. There was not a clear relation between the applied volumetric organic load and hydrogen production. However, the highest hydrogen molar production (MPr: $67.5 \mathrm{molH}_{2} \cdot \mathrm{m}^{-3} . \mathrm{d}^{-1}$ ) was reached when the reactor was operated with a cycle period of $4 \mathrm{~h}$ and an influent concentration of $5000 \mathrm{mgCOD} \cdot \mathrm{L}^{-1}\left(\mathrm{AVOL}_{\mathrm{CT}}: 12911 \mathrm{mgCOD} \cdot \mathrm{L}^{-1} \cdot \mathrm{d}^{-1}\right)$. This condition also reached the highest molar yield per removed load based on organic matter $\left(\mathrm{MYRL}_{\mathrm{C}, \mathrm{m}}: 5.2 \mathrm{molH}_{2} \cdot \mathrm{kgCOD}^{-1}\right)$ and the highest molar yield per applied load based on organic matter $\left(\mathrm{MYAL}_{\mathrm{C}, \mathrm{m}}: 21.1 \mathrm{molH}_{2} \cdot \mathrm{kgCOD}^{-1}\right)$. In addition, it was studied whether existed or not a statistical significant difference on molar productivity averages pre-treating and not pre-treating the inoculum. It was observed that this was not statistically significant $(\mathrm{p}>0.05)$. Finally, the reactor was operated using crude glycerol as a sole source of carbon to evaluate hydrogen production. The disadvantage on hydrogen production when crude glycerol was used comparing to pure glycerol was clearly observed. The AnSBBR used on hydrogen production experiments operated with pure glycerol as a sole carbon 
source showed an important potential. Nevertheless, additional studies are required in order to optimize results.

Key words: AnSBBR; bio-hydrogen; pure glycerol; crude glycerol; organic loading; influent concentration; cycle period. 


\section{RESUMEN}

MONCAYO, I. Influencia de la carga orgánica en la producción de bio-hidrógeno en un reactor AnSBBR con recirculación de la fase líquida, tratando el efluente del proceso de producción de biodiesel. Tesis de Maestría - Escuela de Ingeniería de São Carlos - Departamento de Hidráulica y Saneamiento, Universidad de São Paulo, 2014.

El presente trabajo de investigación tuvo como objetivo principal evaluar el efecto de la carga orgánica volumétrica aplicada (COVA) en la producción de hidrógeno usando un reactor AnSBBR operado en sistema discontinuo con recirculación de la fase líquida. Para el efecto, el reactor fue operado a $30^{\circ} \mathrm{C}$ con dos tiempos de ciclo ( 3 y 4 h), alimentado con tres concentraciones afluentes $\left(3000,4000\right.$ y $\left.5000 \mathrm{mgDQO} . \mathrm{L}^{-1}\right)$, una velocidade de recirculación de 30 L. ${ }^{-1}$, usando glicerol como única fuente de carbono y la biomasa proveniente de una estación de tratamiento de un matadero de aves. La combinación de estos factores generó seis cargas volumétricas diferentes $\left(7565,9764,12911,10319,13327\right.$ e $\left.16216 \mathrm{mgDQO} . \mathrm{L}^{-1} . \mathrm{d}^{-1}\right)$. No existió una tendencia clara entre carga orgánica aplicada y producción de hidrógeno. Sin embargo, los mejores resultados en cuanto a la producción de hidrógeno fueron alcanzados cuando el reactor fue operado con 4 horas de tiempo de ciclo y alimentado con una concentración afluente de 5000 mgDQO.L $\mathrm{L}^{-1}$ (COVA de $12911 \mathrm{mgDQO} . \mathrm{L}^{-1} \cdot \mathrm{d}^{-1}$ ), siendo la productividad molar promedio de hidrógeno (PrM) igual a 67,5 $\mathrm{molH}_{2} \cdot \mathrm{m}^{-3} \cdot \mathrm{d}^{-1}$. Esta condición también alcanzó el mejor rendimiento molar de hidrógeno por carga orgánica aplicada ( $\mathrm{RMCA}_{\mathrm{s}, \mathrm{m}}: 5,2 \mathrm{molH}_{2} \mathrm{kgDQO}^{-1}$ ) y el mejor rendimiento molar de hidrógeno por carga orgánica removida $\left(\mathrm{RMCR}_{\mathrm{s}, \mathrm{m}}: 21,1 \mathrm{molH}_{2}\right.$. $\left.\mathrm{kgDQO}^{-1}\right)$. Adicionalmente fue estudiada la diferencia entre producción de hidrógeno alcanzada pre-tratando y no pre-tratando térmicamente la biomasa utilizada. El análisis de varianza (ANAVA) mostró que la diferencia observada no fue estadísticamente significativa. Finalmente el reactor fue operado usando glicerina bruta de una industria de biodiesel para comparar los resultados entre el uso de glicerol y glicerina bruta en la producción de hidrógeno. El uso de glicerina bruta tuvo un efecto marcadamente negativo en la producción de hidrógenio. En general, el reactor AnSBBR operado en sistema discontinuo presento resultados promisorios en la

producción de hidrógeno usando glicerol como fuente de carbono, sin embargo estudios más profundos son necesarios para optimizar el proceso. 
Palabras clave: AnSBBR; bio-hidrógenio; glicerol; glicerina bruta; carga orgánica; tiempo de ciclo, concentración afluente. 


\section{LISTA DE FIGURAS}

Figura 3.1 - Processos e microrganismos envolvidos na digestão de matéria orgânica complexa (Kumar, 2008).

Figura 3.2 - Rota metabólica seguida por microrganismos procariontes e eucariontes na produção de hidrogênio (Adaptado de Chatzifragkou e Papanikolaou, 2012). 48

Figura 3.3 - Efeito da pressão parcial de hidrogênio na produção de biohidrogênio (Angelent $e t$ al.,2004). .58

Figura 4.1 - Esquema do reator. 68

Figura 4.2 - Fotografia do sistema utilizado.

Figura 4.3 - Fotografia dos grânulos do material suporte sem e com biomassa .70

Figura 4.4 - Etapas da "Fase preliminar". .85

Figura 4.5 - Sequência lógica seguida durante o desenvolvimento do projeto.

Figura 5.1 - Variáveis de estudo na produção de hidrogênio da "Fase preliminar". .93

Figura 5.2 - Produção de hidrogênio nas condições da "Fase preliminar".

Figura 5.3 - Produtividade molar de hidrogênio e produção de AVT das condições em estudo da "Fase preliminar". .99

Figura 5.4 - Composição do biogás para cada condição em estudo da "Fase preliminar" 100

Figura 5.5 - Concentrações de matéria orgânica do afluente $\mathrm{C}_{\mathrm{ST}}$ Afluente $(\rightarrow)$, efluente sem filtrar $\mathrm{C}_{\mathrm{ST} \text { Efluente }}(-)$, efluente filtrado $\mathrm{C}_{\mathrm{SF} \text { Efluente }}(\rightarrow)$ e eficiência de remoção do efluente filtrado $\varepsilon_{\mathrm{SF}}(\stackrel{*}{*})$ ao longo das seis condições da "Fase experimental". 104

Figura 5.6 - Perfil de DQO das condições CI $\left(\triangle^{๑}\right)$ CII ( $\left.\bullet\right)$ e CIII ( $(-)$ ),operadas com 4 horas de tempo de ciclo. 104

Figura 5. 7 - Perfil de DQO das condições CIV. 104 
Figura $5.8-\mathrm{pH}_{\text {Afluente }}(\bullet-), \mathrm{pH}_{\text {Efluente }}(-)$, Alcalinidade total do afluente $(\neg)$, Alcalinidade total do efluente $(\triangle)$ ao longo das seis condições da "Fase experimental". 107

Figura 5.9 - Concentração de AVT do afluente $(\bullet)$ e do efluente $(\bullet)$ ao longo das condições da "Fase experimental".

Figura 5.10 - Perfil de ácidos voláteis produzidos ao longo de cada ciclo das condições da "Etapa de experimentação". 108

Figura 5.11 - Perfil de pH, AT e AVT das condições CI $\left({ }^{\bullet}\right)$, CII $\left(\bullet^{-}\right)$e CIII $(-\bullet)$ operadas com 4 horas de tempo de ciclo.

Figura 5.12 - Perfil de pH, AT e AVT das condições CIV $\left(\neg^{-}\right)$, CV $\left(\bullet^{-}\right)$e CVI $(\bullet-)$ operadas com 3 horas de tempo de ciclo.

Figura 5.13 - Volume produzido nos ciclos monitorados de gás $\mathrm{V}_{\mathrm{G}}(-)$, volume de $\mathrm{H}_{2}(\bullet)$, volume de $\mathrm{CO}_{2}(\neg)$, volume de $\mathrm{CH}_{4}($ ( ) das condições da "Fase Experimental". 114

Figura 5.14 - Volumes acumulados produzidos ao longo dos ciclos das condições da "Fase experimentação" 115

Figura 5.15 - Composição porcentual de gases no biogás das condições da "Fase experimental" 117

Figura 5.16 - Produtividade molar média de cada condição da "Fase experimental". 117

Figura 5.17 - Produção molar acumulada de hidrogênio $(\rightarrow \bullet)$ e metano $(\rightarrow-)$, e concentração molar de ácido acético $\left({ }^{+}\right)$, ácido butírico $\left({ }^{*}\right)$, butanol $\left({ }^{\star}\right)$ ao longo do ciclo das condições da "Fase experimental".

Figura 5.18 - Concentrações de matéria orgânica do afluente $C_{S T}$ Afluente $(\neg)$, efluente sem filtrar $\mathrm{C}_{\mathrm{ST} \text { Efluente }}(-)$, efluente filtrado $\mathrm{C}_{\mathrm{SF}}$ Efluente $(-)$ e eficiência de remoção do efluente filtrado $\varepsilon_{\mathrm{SF}}(\stackrel{*}{*})$ ao longo da condição a) CBST e b) CGB. 137 
Figura 5.19 - Concentração de AVT do afluente $(\bullet-)$ e do efluente $(\bullet-)$ ao longo da condição a) CBST e b) CGB

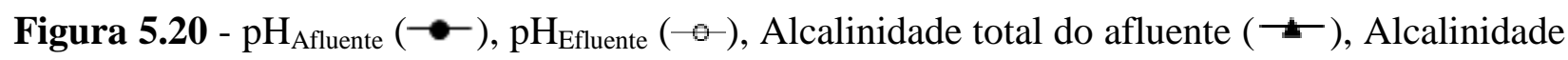
total do efluente $\left(\triangle^{\bullet}\right)$ ao longo da condição a) CBST e b) CGB. 138

Figura 5.21 - Volume produzido nos ciclos monitorados de gás $\mathrm{V}_{\mathrm{G}}\left({ }^{-}\right)$, volume de $\mathrm{H}_{2}(-\bullet)$, volume de $\mathrm{CO}_{2}(\neg)$, volume de $\mathrm{CH}_{4}$ da condição a) CBST e b) CGB 138

Figura 5.22 - Perfis ao longo do ciclo de a) matéria orgânica na forma de DQO, b) concentração de ácidos voláteis totais, c) $\mathrm{pH}$ e d) alcalinidade total das condições CIII $(-\odot)$, CBST $(\rightarrow$ * $)$ e CGB (--)

Figura 5.23 - Perfil de ácidos voláteis produzidos ao longo de cada ciclo das condições a) CBST,

b) CIII e c) CGB.

Figura 5.24 - Composição percentual do biogás produzido pelas condições CBST e CIII. .......142

Figura 5.25 - Produtividades molares de hidrogênio, metano e dióxido de carbono das condições CBST e CIII.

Figura 5.26 - Resultados da ANAVA aplicada gerados pelo programa InfoStat.

Figura 5.27 - Concentração molar de hidrogênio $(-\bullet)$, metano $(-\bullet)$, ácido acético $\left(-{ }^{+}\right)$,

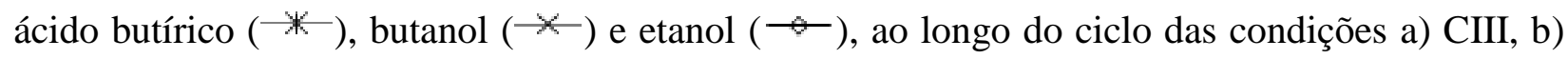
CBST e c) CGB. 


\section{LISTA DE TABELAS}

Tabela 3.1 - Processos biológicos de produção de biohidrogênio (Adaptado de Kumar, 2008). 40

Tabela 3.2 - Estratégias de enriquecimento de cultivo com bactérias produtoras de hidrogênio.43 Tabela 3.3 - Produção de hidrogênio a partir de amido - influência do $\mathrm{pH}$, temperatura e concentração de substrato (Lee et al., 2008).

Tabela 3.4 - Elementos (mg. $\left.\mathrm{L}^{-1}\right)$ e relações DQO:N e DQO:P usados em alguns estudos para produção de hidrogênio (Hawkes et al., 2007). 56

Tabela 3.5 - Condições e rendimentos obtidos em trabalhos de pesquisa desenvolvidos para obter bio- hidrogênio a partir de glicerina. 63

Tabela 4.1- Características do material suporte inerte. 69

Tabela 4.2 - Inóculos usados nas fases de experimentação 70

Tabela 4.3 - Composição da água residuária sintética utilizada nos ensaios de produção de biohidrogênio em AnSBBR com recirculação. 72

Tabela 4.4 - Frequência do monitoramento 73

Tabela 4.5 - Equações bioquímicas e equivalente-grama dos compostos em DQO 81

Tabela 4.6 - Rendimentos molares por carga aplicada potenciais por vias biológicas 83

Tabela 4.7 - Parâmetros operacionais do biorreator. 83

Tabela 4.8 - Variáveis estudadas na "fase preliminar" 86

Tabela 4.9 - Resumo das condições estudadas na "fase de experimentação". 87

Tabela 5.1 - Valores médios dos parâmetros monitorados na "Fase preliminar". .92 
Tabela 5.2 - Valores médios de indicadores de produção de hidrogênio, cargas orgânicas volumétricas e eficiências de remoção de matéria orgânica calculados na "Fase preliminar"......93

Tabela 5.3 - Resultados das variáveis estudadas na "Fase preliminar". ...................................94

Tabela 5.4 - Valores médios dos parâmetros monitorados na "Fase preliminar"...................... 103

Tabela 5.5 - Volumes acumulados de hidrogênio, metano e dióxido de carbono ao longo do ciclo das condições da "Fase Experimental". 114

Tabela 5.6 - Médias de indicadores de produção de hidrogênio e das cargas orgânicas envolvidas na operação do reator durante a "Fase experimental". 116

Tabela 5.7 - Porcentagem dos compostos intermediários das condições da "Fase experimental"

Tabela 5.8 - Fator de rendimento entre hidrogênio produzido e glicerina consumida, e porcentagens médios de glicerol consumido considerando a totalidade dos produtos intermediários nas condições da "Fase experimental". 125

Tabela 5.9 - Rendimentos molares por carga orgânica aplicada na forma de glicerol e desempenho porcentual em função dos potenciais teóricos 127

Tabela 5.10 - Comparação entre as condições e rendimentos de hidrogênio de várias pesquisas com o presente trabalho.

Tabela 5.11 - Médias da massa total de biomassa no reator e dos rendimentos molares de hidrogeno por matéria orgânica removida na "Fase experimental". 131

Tabela 5.12 - Indicadores de produção de hidrogênio para todas as condições da "Fase experimental" 132

Tabela 5.13 - Valores médios dos parâmetros monitorados da condição CBST e CIII. 136 
Tabela 5.14 - Medias de indicadores de produção de hidrogênio e das cargas orgânicas envolvidas na operação do reator durante a "Fase experimental".

Tabela 5.15 - Produção volumétrica de biogás ao longo da experimentação das condições CIII, CBST e CGB. 143

Tabela 5.16 - Porcentagem e concentração total dos compostos intermediários das condições CBST, CGB e CIII. 146

Tabela 5.17 - Fator de rendimento entre hidrogênio produzido e glicerina consumida, e porcentagens médias de glicerol consumido das condições CIII, CBST e CGB. 148 Tabela 5.18 - Massa total de biomassa no reator, produtividade molar específica e rendimento $\mathrm{H}_{2}$ /glicerina das condições CBST e CIII. 150

Tabela 5.19 - Pesquisas que usaram o reator AnSBBR em batelada com biomassa imobilizada em suporte inerte para a obtenção de hidrogênio. 153 


\section{LISTA DE ABREVIATURAS E SIGLAS}

\begin{tabular}{|c|c|}
\hline Abreviatura/Símbolo & Denominação \\
\hline \multirow[t]{3}{*}{ AnSBBR } & Reator Anaeróbio Operado em Batelada Sequencial com Biomassa \\
\hline & Imobilizada em Suporte Inerte \\
\hline & (Anaerobic Sequencing Batch Biofilm Reactor) \\
\hline CNTP & Condições Normais de Temperatura e Pressão $\left(0^{\circ} \mathrm{C}\right.$ e $\left.1 \mathrm{~atm}\right)$ \\
\hline DQO & Demanda Química de Oxigênio (matéria orgânica DQO) \\
\hline EEM & Escola de Engenharia Mauá \\
\hline EESC & Escola de Engenharia de São Carlos \\
\hline IMT & Instituto Mauá de Tecnologia \\
\hline PEBD & Polietileno de baixa densidade \\
\hline PU & Poliuretano \\
\hline USP & Universidade de São Paulo \\
\hline GB & Glicerina consumida \\
\hline TB & Tempo da batelada \\
\hline $\mathrm{DQO}_{\mathrm{GC}}$ & Equivalente em demanda química de oxigênio do glicerol consumido \\
\hline $\mathrm{EG}$ & Equivalente grama \\
\hline PI & Produtos Intermediários \\
\hline HAc & Ácido Acético \\
\hline GC & Glicerol ou glicerina bruta consumida \\
\hline GBI & Glicerina bruta industrial \\
\hline GBL & Glicerina bruta sintetizada no laboratório \\
\hline GPA & Glicerol-PA \\
\hline
\end{tabular}




\section{LISTA DE SÍMBOLOS}

\begin{tabular}{|c|c|c|}
\hline Símbolo & Denominação & Unidade \\
\hline AP & Alcalinidade parcial & $\left(\mathrm{mgCaCO}_{3} \cdot \mathrm{L}^{-1}\right)$ \\
\hline AI & Alcalinidade intermediária & $\left(\mathrm{mgCaCO}_{3} \cdot \mathrm{L}^{-1}\right)$ \\
\hline AT & Alcalinidade total & $\left(\mathrm{mgCaCO}_{3} \cdot \mathrm{L}^{-1}\right)$ \\
\hline $\mathrm{AB}$ & Alcalinidade a bicarbonato & $\left(\mathrm{mgCaCO}_{3} \cdot \mathrm{L}^{-1}\right)$ \\
\hline AVT & Ácidos voláteis totais & $\left(\mathrm{mgHAc} \cdot \mathrm{L}^{-1}\right)$ \\
\hline ST & Sólidos totais & $\left(\mathrm{mgST} . \mathrm{L}^{-1}\right)$ \\
\hline SVT & Sólidos voláteis totais & $\left(\operatorname{mgSVT} . L^{-1}\right)$ \\
\hline SST & Sólidos suspensos totais & $\left(\operatorname{mgSST} . L^{-1}\right)$ \\
\hline SSV & Sólidos suspensos voláteis & $\left(\operatorname{mgSSV} . L^{-1}\right)$ \\
\hline $\mathrm{pH}$ & Potencial hidrogeniônico & (u) \\
\hline $\mathrm{pH} \mathrm{A}$ & Potencial hidrogeniônico do afluente & (u) \\
\hline $\mathrm{pH} \mathrm{E}$ & Potencial hidrogeniônico do efluente & (u) \\
\hline $\mathrm{V}_{\mathrm{M}-\mathrm{i}}$ & Volume obtido pelo medidor de biogás & $(\mathrm{mL})$ \\
\hline $\mathrm{V}_{\mathrm{N}}$ & Volume de biogás nas CNTP & (mL-CNTP) \\
\hline $\mathrm{V}_{\mathrm{i}}$ & Volume de biogás a ser convertido & $(\mathrm{mL})$ \\
\hline $\mathrm{P}_{\mathrm{a}}$ & Pressão do ar no local da medição & (mbar) \\
\hline$P_{V}$ & Pressão parcial de vapor d’água & (mbar) \\
\hline $\mathrm{P}_{\mathrm{L}}$ & $\begin{array}{l}\text { Pressão da coluna líquida acima da câmara de } \\
\text { medição }\end{array}$ & (mbar) \\
\hline$P_{N}$ & Pressão normal (1013,25 mbar) & (mbar) \\
\hline $\mathrm{T}_{\mathrm{N}}$ & Temperatura normal $(273,15 \mathrm{~K})$ & $(\mathrm{K})$ \\
\hline $\mathrm{T}_{\mathrm{a}}$ & Temperatura no local da medição & $(\mathrm{K})$ \\
\hline $\mathrm{M}_{\mathrm{T}-\mathrm{SI}+\mathrm{B}}$ & Massa de suporte inerte e biomassa do reator & $(\mathrm{g})$ \\
\hline $\mathrm{M}_{\mathrm{A}-\mathrm{SI}+\mathrm{B}}$ & $\begin{array}{c}\text { Massa da amostra de suporte inerte e biomassa do } \\
\text { reator }\end{array}$ & (g) \\
\hline $\mathrm{M}_{\mathrm{A}-\mathrm{ST}}$ & Massa de sólidos totais (ST) da amostra de biomassa & $(\mathrm{g})$ \\
\hline $\mathrm{M}_{\mathrm{A}-\mathrm{SVT}}$ & $\begin{array}{l}\text { Massa de sólidos voláteis totais (SVT) da amostra de } \\
\text { biomassa }\end{array}$ & (g) \\
\hline
\end{tabular}




\begin{tabular}{|c|c|c|}
\hline & reator & \\
\hline $\mathrm{C}_{\mathrm{X}}$ & $\begin{array}{l}\text { Massa de sólidos voláteis totais (SVT) por volume de } \\
\text { meio líquido }\end{array}$ & $\left(\mathrm{g} \cdot \mathrm{L}^{-1}\right)$ \\
\hline $\mathrm{C}_{\mathrm{X}}^{\prime}$ & $\begin{array}{c}\text { Massa de sólidos voláteis totais (SVT) por massa de } \\
\text { material suporte }\end{array}$ & $\left(\mathrm{mg} \cdot \mathrm{g}^{-1}\right)$ \\
\hline $\mathrm{C}_{\mathrm{H} 2}$ & $\begin{array}{c}\text { Produção molar acumulada de hidrogênio a condições } \\
\text { normais de temperatura e pressão }\end{array}$ & $\left(\mathrm{mmolH}_{2}-\mathrm{CNTP}\right)$ \\
\hline $\mathrm{C}_{\mathrm{CH} 4}$ & $\begin{array}{c}\text { Produção molar acumulada de metano a condições } \\
\text { normais de temperatura e pressão }\end{array}$ & $\left(\mathrm{mmolCH}_{4}-\mathrm{CNTP}\right)$ \\
\hline $\mathrm{V}_{\mathrm{A}}$ & Volume de água residuária alimentado por ciclo & (L) \\
\hline $\mathrm{V}_{\mathrm{R}}$ & Volume de meio líquido total no reator & (L) \\
\hline $\mathrm{V}_{\text {Res }}$ & $\begin{array}{l}\text { Volume de meio líquido residual no reator após a } \\
\qquad \text { etapa de descarga }\end{array}$ & (L) \\
\hline $\mathrm{V}_{\mathrm{u}}$ & Volume útil do reator & (L) \\
\hline $\mathrm{F}_{\mathrm{AFL}}$ & $\begin{array}{l}\text { Vazão de alimentação do período em batelada } \\
\text { alimentada }\end{array}$ & $\left(\mathrm{L} \mathrm{h}^{-1}\right)$ \\
\hline $\mathrm{N}$ & Número de ciclos por dia & $\left(\operatorname{ciclos} . d^{-1}\right)$ \\
\hline $\mathrm{C}_{\mathrm{SAFL}}$ & $\begin{array}{c}\text { Concentração de matéria orgânica não filtrada no } \\
\text { afluente na forma de DQO }\end{array}$ & $\left(\mathrm{mgDQO} \cdot \mathrm{L}^{-1}\right)$ \\
\hline $\mathrm{C}_{\mathrm{S} 0}$ & $\begin{array}{c}\text { Concentração de matéria orgânica filtrada no tempo } \\
\text { inicial do ciclo na forma de DQO (perfis) }\end{array}$ & $\left(\mathrm{mgDQO} \cdot \mathrm{L}^{-1}\right)$ \\
\hline $\mathrm{C}_{\mathrm{ST}}$ & $\begin{array}{c}\text { Concentração de matéria orgânica não filtrada na } \\
\text { forma de DQO }\end{array}$ & $\left(\mathrm{mgDQO} \cdot \mathrm{L}^{-1}\right)$ \\
\hline $\mathrm{C}_{\mathrm{SF}}$ & $\begin{array}{l}\text { Concentração de matéria orgânica filtrada na forma } \\
\qquad \text { de DQO }\end{array}$ & $\left(\mathrm{mgDQO} \cdot \mathrm{L}^{-1}\right)$ \\
\hline $\mathrm{C}_{\mathrm{GC}}$ & Concentração molar de glicerina consumida & $\left(\operatorname{molGC} . L^{-1}\right)$ \\
\hline$\varepsilon_{\mathrm{ST}}$ & $\begin{array}{c}\text { Eficiência de remoção de matéria orgânica não } \\
\text { filtrada na forma de DQO }\end{array}$ & $(\%)$ \\
\hline$\varepsilon_{\mathrm{SF}}$ & $\begin{array}{l}\text { Eficiência de remoção de matéria orgânica filtrada na } \\
\text { forma de DQO }\end{array}$ & $(\%)$ \\
\hline $\mathrm{COVA}_{\mathrm{s}}$ & $\begin{array}{c}\text { Carga orgânica volumétrica aplicada em termos de } \\
\text { matéria orgânica na forma de DQO }\end{array}$ & $\left(\mathrm{mgDQO} \cdot \mathrm{L}^{-1} \cdot \mathrm{d}^{-1}\right)$ \\
\hline $\mathrm{COEA}_{\mathrm{S}}$ & Carga orgânica específica aplicada em & $\left(\mathrm{mgDQO} \mathrm{gSVT}^{-1} \cdot \mathrm{d}^{-1}\right)$ \\
\hline
\end{tabular}




\begin{tabular}{|c|c|c|}
\hline & matéria orgânica na forma de DQO & \\
\hline $\mathrm{COVR}_{\mathrm{S}}$ & $\begin{array}{c}\text { Carga orgânica volumétrica removida em termos de } \\
\text { matéria orgânica na forma de DQO }\end{array}$ & $\left(\operatorname{mgDQO} \cdot \mathrm{L}^{-1} \cdot \mathrm{d}^{-1}\right)$ \\
\hline $\mathrm{COER}_{\mathrm{S}}$ & $\begin{array}{c}\text { Carga orgânica específica removida em termos de } \\
\text { matéria orgânica na forma de DQO }\end{array}$ & $\left(\mathrm{mgDQO} \cdot \mathrm{gSVT}^{-1} \cdot \mathrm{d}^{-1}\right)$ \\
\hline $\mathrm{n}_{\mathrm{H} 2}$ & Vazão molar de hidrogênio diária & $\left(\mathrm{molH}_{2} \cdot \mathrm{d}^{-1}\right)$ \\
\hline PrM & Produtividade molar de hidrogênio volumétrica & $\left(\mathrm{molH}_{2} \cdot \mathrm{m}^{-3} \cdot \mathrm{d}^{-1}\right)$ \\
\hline PrME & Produtividade molar de hidrogênio específica & $\left(\mathrm{molH}_{2} \cdot \mathrm{kgSVT}^{-1} \cdot \mathrm{d}^{-1}\right)$ \\
\hline $\mathrm{RMCA}_{\mathrm{S}, \mathrm{m}}$ & $\begin{array}{l}\text { Rendimento entre hidrogênio (molar) produzido e } \\
\text { matéria orgânica (massa) aplicada na forma de DQO }\end{array}$ & $\left(\mathrm{molH}_{2} \cdot \mathrm{kgDQO}^{-1}\right)$ \\
\hline $\mathrm{RMCA}_{\mathrm{G}, \mathrm{m}}$ & $\begin{array}{l}\text { matéria orgânica (massa) aplicada na forma de } \\
\text { glicerina }\end{array}$ & $\left(\mathrm{molH}_{2} \cdot \mathrm{kg} \mathrm{glicerol}^{-1}\right)$ \\
\hline $\mathrm{RMCR}_{\mathrm{S}, \mathrm{m}}$ & $\begin{array}{l}\text { Rendimento entre hidrogênio (molar) produzido e } \\
\text { matéria orgânica (massa) removida na forma de DQO }\end{array}$ & $\left(\mathrm{molH}_{2} \cdot \mathrm{kGDQO}^{-1}\right)$ \\
\hline RMSR & $\begin{array}{l}\text { Rendimento entre hidrogênio (molar) produzido e } \\
\text { substrato (massa em termos de DQO equivalente) } \\
\text { removido. }\end{array}$ & $\left(\mathrm{molH}_{2} \cdot \mathrm{kgDQO}^{-1}\right)$ \\
\hline $\mathrm{C}_{\mathrm{G}}$ & $\begin{array}{l}\text { Concentração de um componente do biogás }\left(\mathrm{H}_{2}, \mathrm{CH}_{4}\right. \\
\left.\text { ou } \mathrm{CO}_{2}\right) \text { da amostra retirada do "head-space" do } \\
\text { reator }\end{array}$ & $\left(\mathrm{mmol} . \mathrm{L}^{-1}\right)$ \\
\hline $\mathrm{V}_{\mathrm{G}}$ & Volume na CNTP de biogás total produzido por ciclo & $\left(\mathrm{mL}-\mathrm{CNTP} \cdot \mathrm{ciclo}^{-1}\right)$ \\
\hline $\mathrm{V}_{\mathrm{H} 2}$ & Volume na CNTP de hidrogênio produzido por ciclo & $\left(\mathrm{mL}-\mathrm{CNTP} \cdot \mathrm{ciclo}^{-1}\right)$ \\
\hline $\mathrm{N}_{\mathrm{G}}$ & $\begin{array}{l}\text { Vazão molar de cada componente do biogás }\left(\mathrm{H}_{2}, \mathrm{CH}_{4}\right. \\
\left.\qquad \text { ou } \mathrm{CO}_{2}\right) \text { produzido durante o ciclo }\end{array}$ & $(\mathrm{mmol})$ \\
\hline
\end{tabular}




\section{SUMÁRIO}

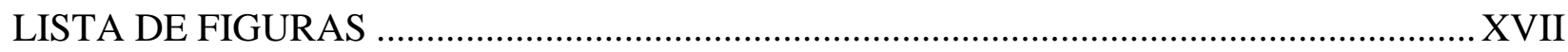

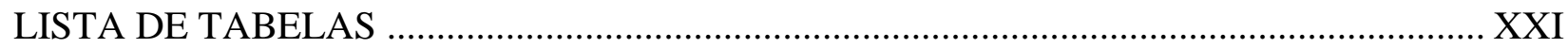

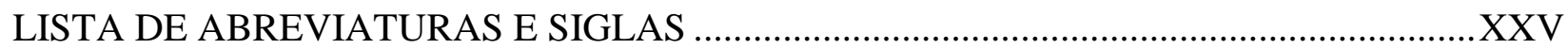

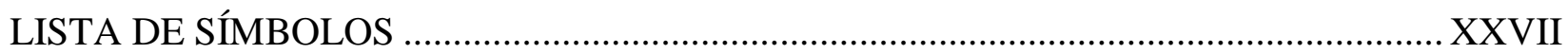

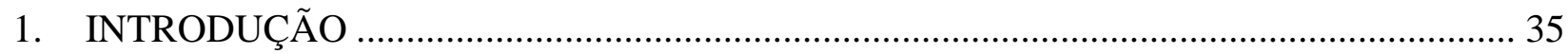

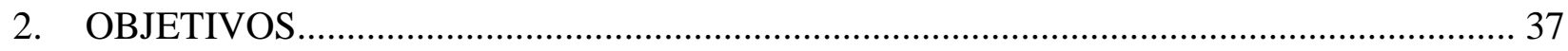

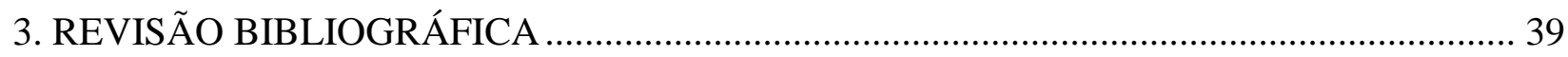

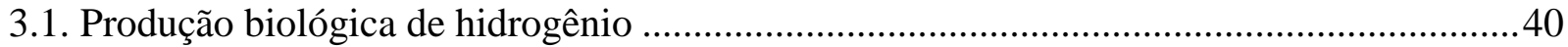

3.2. Microbiologia da fermentação escura para a produção de hidrogênio ................................. 41

3.3. Substratos usados na produção de biohidrogênio por fermentação escura............................ 45

3.4. Reator anaeróbio em batelada sequencial com biomassa imobilizada em suporte inerte... 48

3.5. Fatores de influência na produção de biohidrogênio ............................................................4

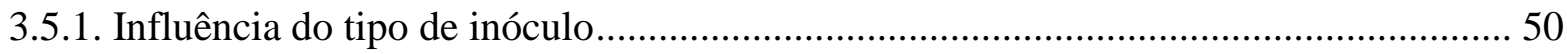

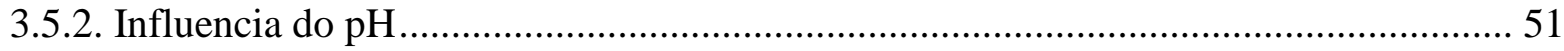

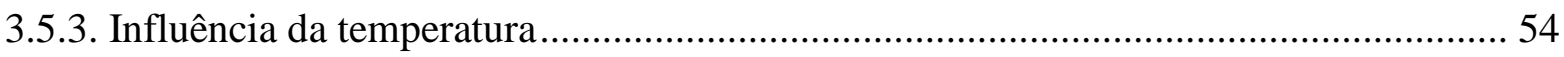

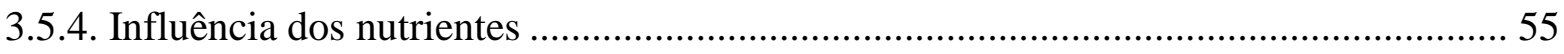

3.5.5. Influência da pressão parcial do hidrogênio........................................................... 56

3.5.6. Influência do tempo de ciclo ou tempo de detenção hidráulica .................................... 58

3.5.7. Influência da configuração do reator.......................................................................... 60

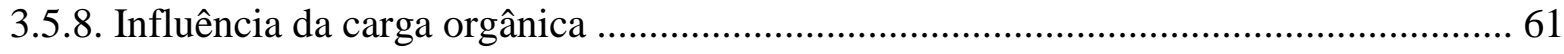

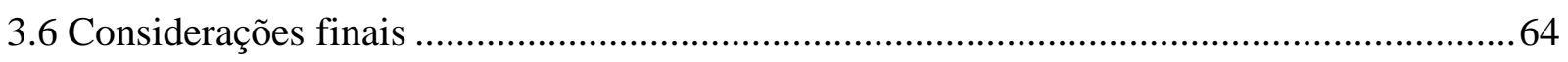

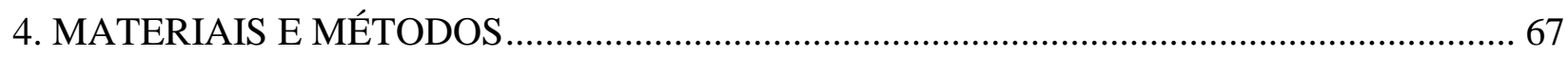

4.1. AnSBBR com biomassa imobilizada e recirculação da fase líquida ....................................67

4.2 Inóculo e imobilização da biomassa anaeróbia.....................................................................69

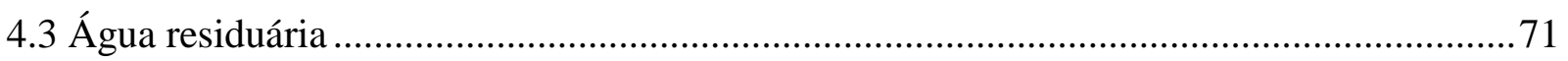

4.4 Análises físico-químicas ..............................................................................................

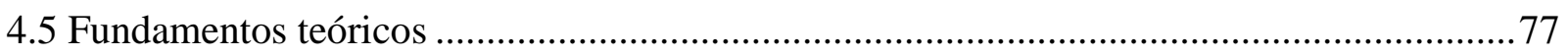

4.6 Procedimento experimental da operação do reator ............................................................. 83

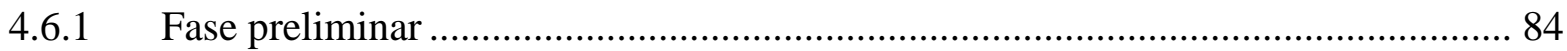

4.6.2 Fase de experimentação .................................................................................... 86 


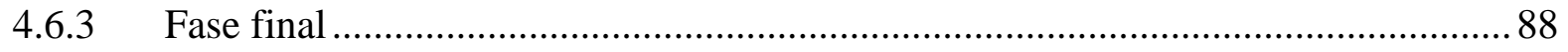

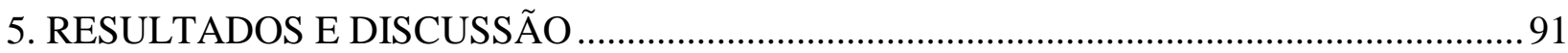

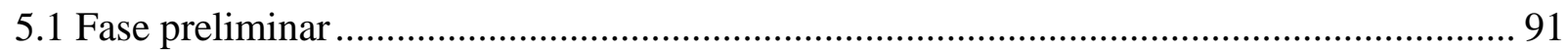

a) $\mathrm{pH}$

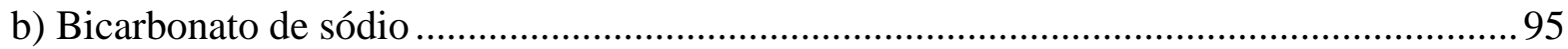

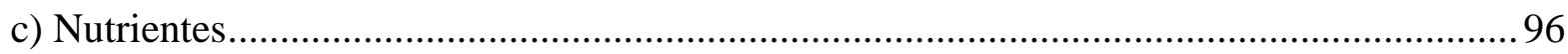

d) Tipo de glicerina, carga orgânica aplicada e tempo de ciclo...............................................97

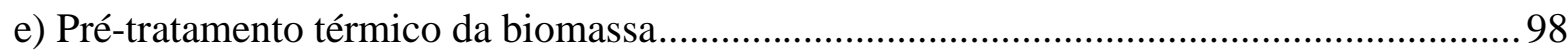

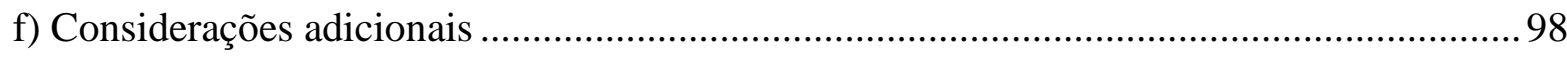

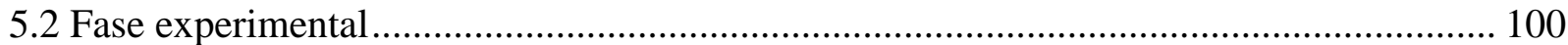

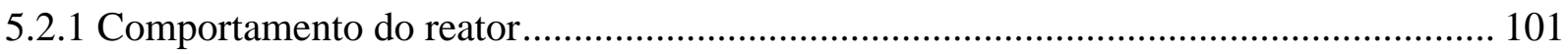

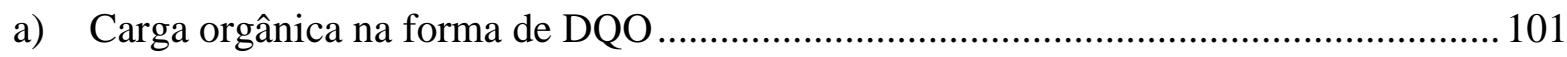

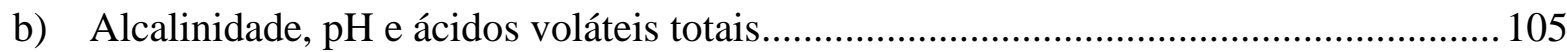

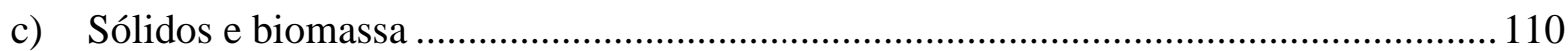

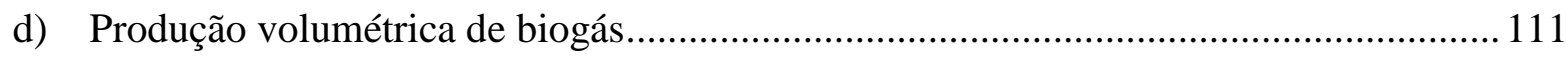

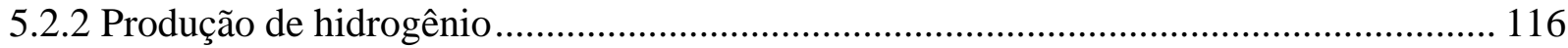

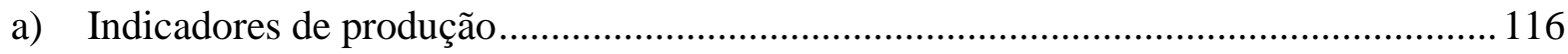

b) Produtos intermediários na produção de hidrogênio ........................................................ 121

c) Aproveitamento da glicerina na produção de hidrogênio ................................................125

d) Concentração de biomassa e produção de hidrogênio.................................................... 130

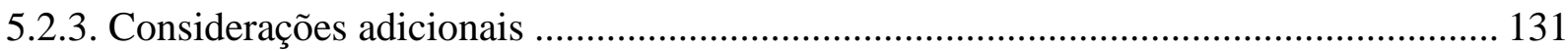

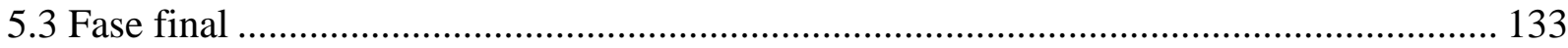

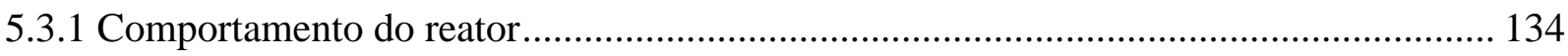

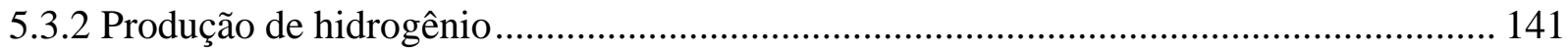

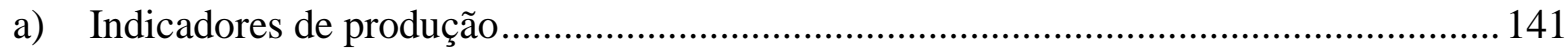

b) Produtos intermediários na produção de hidrogênio ..................................................... 144

c) Aproveitamento da glicerina na produção de hidrogênio .................................................. 147

d) Concentração biomassa e produção de hidrogênio ........................................................ 148

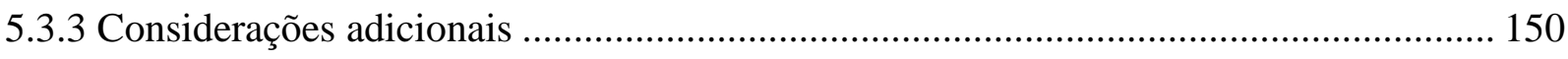

5.4 O reator AnSBBR em batelada na obtenção de hidrogênio usando glicerol como substrato 


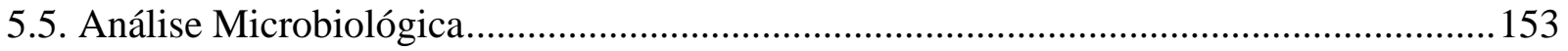

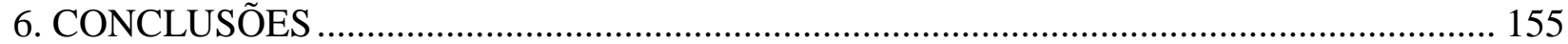

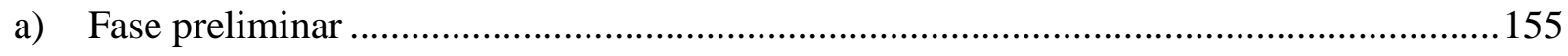

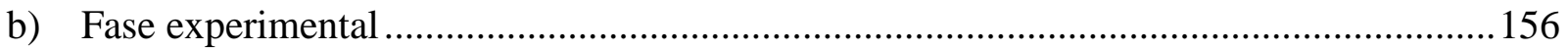

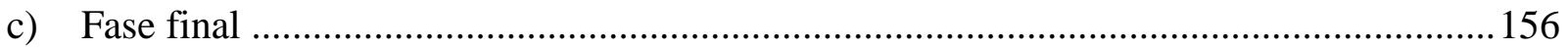

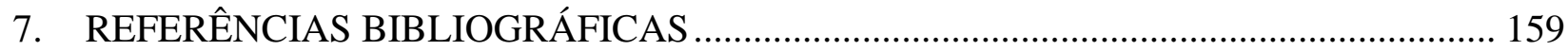


XXXIV 


\section{INTRODUÇÃO}

A demanda energética mundial cresce paralelamente com o desenvolvimento da economia global, tanto que para o ano 2025 calcula-se um crescimento de 50\% (Kumar, 2008). A dependência dos combustíveis fósseis, a instabilidade política dos países produtores e as consequências ambientais de anos de uso têm constituído uma forte motivação para encontrar fontes alternativas de energia que supram a crescente demanda.

Nesta procura de fontes alternativas de energia, o Brasil é um dos países pioneiros na produção de biocombustíveis como etanol e biodiesel. No ano de 2004, começou-se a fomentar o uso do biodiesel através do Programa Nacional para a Produção de Biodiesel (PROBIDIESEL) e no ano de 2005 aprovou-se uma lei que regulou a mistura obrigatória de biodiesel-diesel em 2\%, 5\% e 20\% para os anos 2007, 2013 e 2020 respetivamente (Duffey, 2010). No ano de 2012, o Brasil produziu 2,7 bilhões de litros (Ruralcentro, 2013) sendo que a nível mundial a produção no ano 2013 foi de 28,8 bilhões de litros (www.fedebiocombustibles.com). A produção de biodiesel aumenta anualmente para satisfazer as demandas estabelecidas pela lei.

O biodiesel é o resultado do processo de transesterificação de óleos e gorduras. Paralelamente ao combustível gera-se glicerina bruta, uma mistura de sais, metanol e glicerol em uma proporção de $10 \mathrm{~kg}$ de glicerina por cada $100 \mathrm{~kg}$ de biodiesel produzidos (Chatzifragkou e Papanikolaou, 2012). A glicerina de alta pureza é amplamente usada na indústria cosmética e de alimentos, porém, devido ao crescimento acelerado da produção de biodiesel, prevê-se que em um futuro de médio prazo a oferta de glicerina superará a demanda. Encontrar usos alternativos de esta glicerina já é uma necessidade importante para que seja evitada a sua conversão em um passivo ambiental. 
Uma aplicação atrativa de uso para esta glicerina é sua utilização como fonte de carbono em processos fermentativos anaeróbios orientados à obtenção de biohidrogênio; um combustível de poder calorífico 2,75 vezes maior que os combustíveis fósseis (Kapdan e Kargi, 2006), e que gera unicamente água na sua combustão. Além de constituir uma das diversas opções na resolução do problema de oferta excedente de glicerina, esta alternativa também faz um aporte no campo da pesquisa por novas fontes de energia e na disposição adequada de um efluente industrial valorizando o despejo.

Atualmente, os grupos de pesquisa da Escola de Engenharia de São Carlos da Universidade de São Paulo (EESC/USP) e da Escola de Engenharia Mauá do Instituto Mauá de Tecnologia (EEM/IMT) trabalham conjuntamente em projetos de pesquisa na adequação de efluentes poluentes para a obtenção de bioenergia usando reatores com biomassa imobilizada e recirculação de fase líquida. Um dos objetivos fundamentais desses projetos é valorizar os poluentes ambientais presentes nas águas residuárias utilizando-os como matéria prima. Nesse sentido, o presente trabalho de pesquisa teve como objetivo, avaliar o efeito da carga orgânica aplicada usando glicerol como única fonte de carbono, no reator anaeróbio AnSBBR para a obtenção de biohidrogênio. O sistema foi operado em batelada sequencial com biomassa imobilizada em suporte inerte com recirculação da fase líquida. Várias pesquisas previas realizadas pelo grupo previas demostram a viabilidade do processo.

O presente trabalho por tanto constitui uma contribuição à ciência na procura de opções adequadas de disposição de efluentes industriais valorizando despejos, conjuntamente com a procura de combustíveis alternativos que em um futuro possam formar parte da matriz energética. 


\section{OBJETIVOS}

O presente projeto teve como objetivo principal avaliar a aplicação do reator anaeróbio operado em batelada sequencial com biomassa imobilizada em suporte inerte e recirculação da fase líquida (AnSBBR) na produção de biohidrogênio usando glicerol e glicerina bruta (obtida como subproduto do processo de produção de biodiesel).

Os objetivos específicos foram:

- Avaliar o efeito da carga orgânica volumétrica, implementada pelo uso de diferentes tempos de ciclo e concentrações afluente, no AnSBBR sobre a produção de hidrogênio usando como indicadores a produtividade molar, a produtividade molar específica, o rendimento molar de hidrogênio por carga orgânica aplicada e o rendimento molar de hidrogênio por carga orgânica removida.

- Avaliar o comportamento do sistema quanto à composição do biogás, em relação ao hidrogênio, ao metano e ao dióxido de carbono, e do efluente em relação aos ácidos voláteis e álcoois gerados em cada condição experimental. 


\section{REVISÃO BIBLIOGRÁFICA}

A humanidade enfrenta diversos problemas ambientais graves os quais são produto de anos de uso não sustentável dos recursos naturais. Os sistemas de tratamento de efluentes poluídos gerados desse uso, geralmente se resumem à passagem de um estado da matéria (líquido, sólido e gasoso) para outro. O tratamento de efluentes líquidos, especificamente, constitui a concentração dos contaminantes presentes neste líquido em um sólido carregado que dependendo da origem, do destino ou do pós-tratamento, transforma-se em um passivo ambiental com consequências ambientais iguais ou maiores do que o despejo original.

Nas últimas décadas, a ciência em diferentes áreas, tem tentado contribuir tanto com tecnologias mais limpas como com processos de tratamento de despejos sólidos, gasosos e líquidos mais eficientes, que lhes outorguem valor agregado. Nesse contexto, a biotecnologia anaeróbia apresenta-se como uma tecnologia atrativa, porque além de fornecer soluções no campo do tratamento de poluentes ambientais é geradora de produtos de alto valor calórico de aplicação direta como fontes de energia alternativa.

Dentro da gama dos combustíveis alternativos, o hidrogênio aparece com grande destaque por suas várias vantagens: o hidrogênio é altamente energético $\left(143 \mathrm{~kJ} . g^{-1} \mathrm{H}_{2}\right)$ com 2,75 vezes mais poder energético do que qualquer outro hidrocarboneto e pode ser usado diretamente em células combustíveis (Kapdan e Kargi, 2006). Também, tem valor comercial agregado como matéria prima para a produção de amônia, etanol, a síntese de aldeídos e hidrogenação de óleos comestíveis e combustíveis fósseis, é utilizado para a produção de aparelhos eletrônicos, no processamento do aço e na dessulfurização e re-formulação da gasolina em refinarias. Além das 
suas vantagens comerciais, está a sua vantagem ambiental: gerar unicamente água como produto da combustão (Kumar, 2008, Kapdan e Kargi, 2006).

\subsection{Produção biológica de hidrogênio}

O hidrogênio é gerado basicamente por três processos: o físico, o químico e o biológico. O primeiro consiste na separação da água em hidrogênio e oxigênio por eletrólise; o segundo corresponde ao craqueamento de hidrocarbonetos. Os dois processos são efetivos, mas de alto custo energético. O hidrogênio obtido por processos biológicos recebe o nome de biohidrogênio e existem três possíveis caminhos para sua produção: fotossínteses, foto-fermentação e fermentação escura. Cada um com microrganismos e processos específicos, vantagens e desvantagens próprias que os caracterizam. A Tabela 3.1 apresenta um resumo dos processos biológicos envolvidos na obtenção de biohidrogênio.

Tabela 3.1 - Processos biológicos de produção de biohidrogênio (Kumar, 2008).

\begin{tabular}{|c|c|c|c|}
\hline Processo biológico & Grupo microbiano & Descrição do processo & Desvantagens \\
\hline Fotossíntese & Cianobactérias & $\begin{array}{l}\text { Microrganismos } \\
\text { autótrofos que usam } \mathrm{CO}_{2} \\
\text { como fonte de carbono. } \\
\text { Quebram a água em } \mathrm{H}_{2} \text { e } \\
\mathrm{O}_{2} \text { em presença de luz. }\end{array}$ & $\begin{array}{l}\text { O processo requer luz } \\
\text { como energia. Requer } \\
\text { um gás de arrastre do gás } \\
\text { gerado no processo. A } \\
\text { separação do oxigênio e } \\
\text { do nitrogênio limita o } \\
\text { processo. }\end{array}$ \\
\hline Fotofermentação & $\begin{array}{l}\text { Bactérias fototróficas } \\
\text { roxas não sulfurosas. }\end{array}$ & $\begin{array}{l}\text { Microrganismos } \\
\text { heterótrofos que usam } \\
\text { matéria orgânica simples } \\
\text { como fonte de carbono e } \\
\text { luz como fonte de } \\
\text { energia em condições } \\
\text { anaeróbias. }\end{array}$ & $\begin{array}{l}\text { A turbidez do meio } \\
\text { dificulta a penetração e } \\
\text { distribuição da luz. Os } \\
\text { microrganismos podem } \\
\text { usar anicamente } \\
\text { substratos orgânicos } \\
\text { simples. }\end{array}$ \\
\hline Fermentação escura & $\begin{array}{l}\text { Bactérias fermentativas } \\
\text { não fototróficas }\end{array}$ & $\begin{array}{l}\text { Microrganismos } \\
\text { heterótrofos que usam } \\
\text { matéria orgânica } \\
\text { complexa tanto como } \\
\text { fonte de carbono como } \\
\text { fonte de energia em } \\
\text { condições anaeróbias. }\end{array}$ & $\begin{array}{l}\text { A quantidade } \\
\text { hidrogênio gerada é } \\
\text { relativamente baixa. A } \\
\text { pressão parcial do } \\
\text { hidrogênio precisa ser } \\
\text { altamente controlada } \\
\text { para atingir bons níveis } \\
\text { de produção. }\end{array}$ \\
\hline
\end{tabular}


Dos diferentes bio-processos produtores de hidrogênio, a fermentação escura exibe uma clara vantagem econômica: baixa demanda energética porque não precisa de luz. Esta distinção viabiliza seu uso em escalas maiores como processo gerador de energia.

\subsection{Microbiologia da fermentação escura para a produção de hidrogênio}

Todo processo de digestão anaeróbia começa com a hidrólise ou liquefação de matéria orgânica complexa em produtos solúveis menores como aminoácidos, açucares, ácidos graxos de cadeia comprida e glicerina. Essa digestão é feita por enzimas extra-celulares excretadas por bactérias fermentativas (grupo 1 da Figura 3.1). O mesmo grupo de bactérias fermenta os produtos solúveis da hidrólise gerando uma mistura de ácidos orgânicos, hidrogênio e dióxido de carbono. O processo de geração desses ácidos (ácidos graxos voláteis AGV) é conhecido como acidogênese. Um segundo grupo de microrganismos chamado de bactérias acetogênicas produtoras de hidrogênio (grupo 2 da Figura 3.1) convertem os ácidos graxos voláteis em acetato, hidrogênio e dióxido de carbono. O processo envolvido é conhecido como acetogênese e é termodinamicamente desfavorável a menos que a pressão parcial do hidrogênio seja mantida em menos de $10^{-3} \mathrm{~atm}$. Essa pressão normalmente é conservada pelos microrganismos consumidores de hidrogênio como é o caso das arqueias metanogênicas hidrogenotróficas (grupo 4) e das bactérias homoacetogênicas (grupo 3). O acetato, o hidrogênio e o dióxido de carbono são os substratos primários para o processo de metanogênese. Os microrganismos formadores de metano a partir de acetato são conhecidos como acetrotróficos ou mentanogênicos acetoclásticos (grupo 5). O metano restante é gerado a partir do hidrogênio e dióxido de carbono pelos microrganismos metanogênicos hidrogenotróficos (grupo 4) (Rittman e McCarty, 2001; Kumar, 2008). 


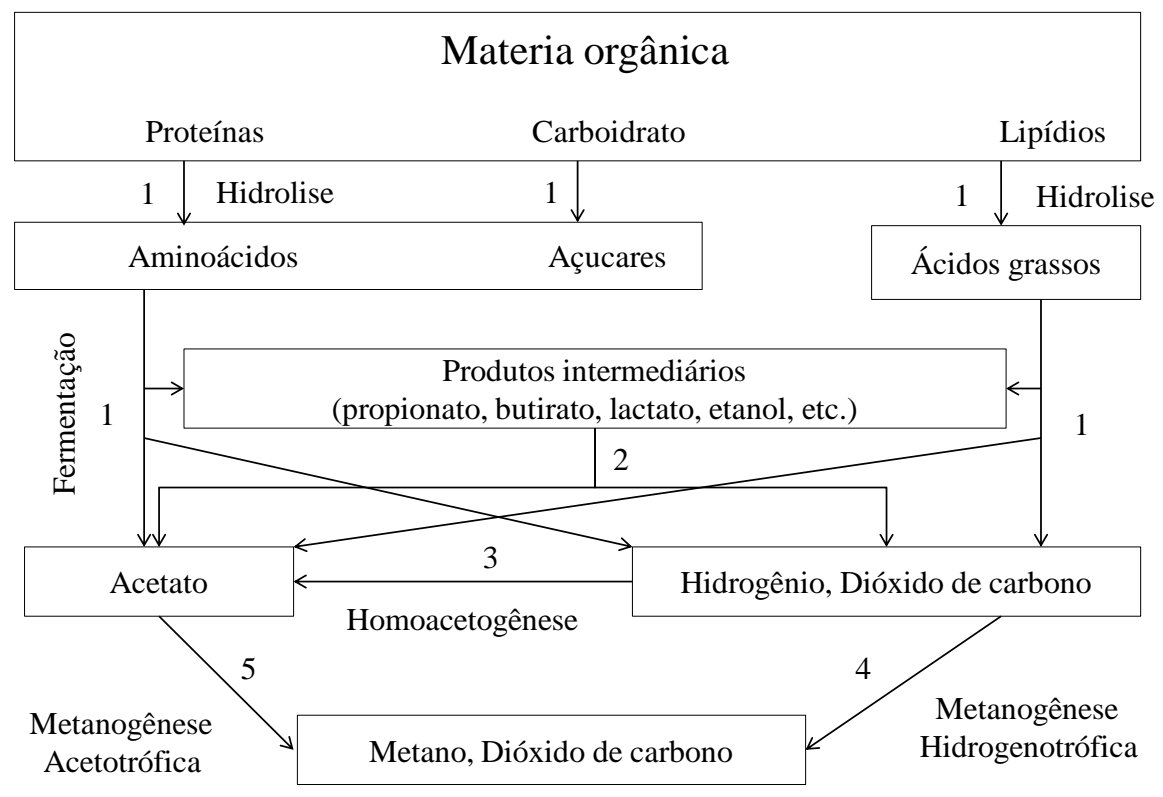

Figura 3.1 - Processos e microrganismos envolvidos na digestão de matéria orgânica complexa (Kumar, 2008).

Como se observa na Figura 3.1, em um sistema tradicional de digestão anaeróbia, o hidrogênio produzido é imediatamente consumido por microrganismos metanogênicos hidrogenotróficos para a produção de metano e por microrganismos homoacetogênicos para a produção de acetato. Esse consumo mantém a pressão parcial do hidrogênio baixa, favorecendo a manutenção de um ambiente termodinamicamente favorável que permite às bactérias produtoras de hidrogênio, produzirem acetato, hidrogênio e dióxido de carbono a partir do propionato, butirato, benzoato e etanol. Adicionalmente, o hidrogênio é consumido também como um doador de elétrons no processo de redução de sulfato, de desnitrificação autotrófica e/ou de redução de ferro no caso de que sulfatos, nitratos e ferro, respectivamente, estejam presentes no substrato (Kumar, 2008). 
Quando o objetivo é obter hidrogênio, a rota metabólica de oxidação anaeróbia completa da matéria deve ser interrompida antes do consumo do gás. Nesse intuito, têm-se desenvolvido várias estratégias de eliminação de bactérias consumidoras de hidrogênio para obter culturas ricas em bactérias produtoras deste gás. O fundamento da maior parte das estratégias está na capacidade dos microrganismos produtores de hidrogênio de formar esporos em condições desfavoráveis. Na Tabela 3.2 apresenta-se um resumo das diversas estratégias usadas com este fim.

Tabela 3.2 - Estratégias de enriquecimento de cultivo com bactérias produtoras de hidrogênio. Inibição seletiva de consumidores de hidrogênio usando químicos

Tratamento térmico da biomassa

- Aplicação a $80^{\circ} \mathrm{C}$ por $10 \min ($ Doyle, 1989)

- Ferver a biomassa por 15 min (Okamoto et al, 2000)

- Cozimento a $104^{\circ} \mathrm{C}$ por $2 \mathrm{~h}$ (van Ginkel et al, 2001)

Tratamento ácido/base

- Acidificação da biomassa a pH 3

- Uso de condições alcalinas a pH 10 (Chen et al, 2002)

Controle de $\mathrm{pH}$

- Operar o reator com o pH abaixo de $\mathrm{pH} 6,8$

Controle da cinética

- Uso de tempos de detenção hidráulica baixos

- Sistemas contínuos de tratamento (CSTR) com taxas de diluição (D) maiores que $0,055 \mathrm{~h}^{-1}$ (Rittman e McCarty, 2001).

Corrente elétrica

- Aplicação de corrente na biomassa (3-4,5 V) (Roychowdhury, 2000)

Os microrganismos envolvidos na produção de hidrogênio são classificados em duas categorias: 1) anaeróbios facultativos e 2) anaeróbios estritos, os quais coexistem e abundam de acordo com as condições existentes. Análises moleculares feitas em culturas mistas produtoras de hidrogênio aplicadas nos genes hya, hup e hox da enzima hidrogenase têm contribuído com a identificação desses organismos microbianos. Os gêneros identificados são principalmente Clostridium, Enterobacter e Bacillus (Kumar, 2008). 
Os microrganismos do género Clostridium são anaeróbios estritos formadores de esporos, com forma de haste de pontas redondas em alguns casos, que produzem hidrogênio durante a sua fase exponencial de crescimento. Entre as espécies de maior estudo estão C.buytricum, $C$. thermolacticum, C. pasteurianum, C.paraputrificum e C. bifermentants (Kapdan e Kargi, 2006).

As espécies do gênero Clostridium têm a capacidade de usar vários substratos orgânicos, sendo classificados em dois grupos de acordo com os compostos que fermentam: clostridios proteolíticos degradadores de proteínas e aminoácidos, e sacarolíticos fermentadores de carboidratos; porém alguns podem entrar nos dois grupos e outros em nenhum (Kumar, 2008).

Além do gênero Clostridium, o gênero Enterobacter também tem sido amplamente estudado com relação a sua capacidade geradora de hidrogênio. Caracterizam-se por sua forma redonda, por serem bactérias gram negativas e facultativas, apresentarem menor sensibilidade ao oxigênio e por sua capacidade para se recuperar da exposição ao ar (Nath e Das, 2004). Enterobacter aerogenes tem sido analisada com especial interesse porque, diferente ao gênero Clostridium, não apresenta inibição em uma atmosfera de 100\% de hidrogênio (Nakashimada et al., 2002).

O objetivo do trabalho de pesquisa foi obter hidrogênio a partir da hidrólise e acidogenesis do substrato gerando ácidos graxos voláteis, acetato, dióxido de carbono e hidrogênio, e não a partir da acetogenesis (oxidação dos ácidos gerados a partir da acidogenesis). O processo de acetogenesis é altamente produtor de hidrogênio, porém, para que sua produção seja termodinamicamente favorável (energia livre de Gibbs positiva) é importante que a pressão parcial do gás seja baixa. Esta pressão parcial é diminuída através do consumo de hidrogênio gerando produtos reduzidos como o metano (transporte inter espécies de hidrogênio) que afetam o processo de obtenção de hidrogênio (Kumar, 2008). 


\subsection{Substratos usados na produção de biohidrogênio por fermentação escura}

Uma variedade de substratos tem sido usada na produção de biohidrogênio por fermentação escura. A glicose (Fang e Lui, 2002; Zhang et al., 2004; Zoetemeyer et al., 1982; Lin e Chang, 1999; Mizuno et al., 2000) e a sacarose (Kyazze et al., 2006; Lin e Joe, 2003; Wu et al., 2006; Chang et al., 2004; Hussy et al., 2005; Chen e Lin, 2003) são os substratos mais usados na literatura, porém, sendo substratos puros de alto custo, tornam os processos pouco sustentáveis do ponte de vista econômico (Hawkes et al., 2002).

Para que o processo de produção de hidrogênio seja sustentável e competitivo quando comparado com outras fontes de energias alternativas, os substratos devem ser de baixo custo e de alta disponibilidade. É assim que despejos de várias origens valorizam-se ao serem utilizados como alimento de microrganismos fermentadores geradores de biohidrogênio. Entre estes despejos destacam-se: águas residuárias e resíduos sólidos urbanos (Lay et al., 1999; Noike e Mizuno, 2000; Wang et al., 2003 e Wang et al., 2003), águas residuárias industriais (Ueno et al., 1996;), resíduos de alimentos (Han e Shin, 2004), despejos de industrias de alimentos (Ginkel et al., 2005, Zhu et al., 1999, Yang et al., 2007; Han e Shin, 2004; Youn e Shin, 2005), entre outros.

O glicerol é considerado com um produto valioso desde meados da década de 1940. Aproximadamente dois terços da indústria o utilizam na fabricação de alimentos e bebidas (23\%), artigos de higiene pessoal (24\%), artigos de higiene bucal (16\%) e na fabricação do tabaco (Yuga-amornpitak T, 2012). Todas essas indústrias demandam glicerol com altos graus de pureza.

O processo de produção do biodiesel constitui uma fonte importante de glicerina. Assim, para cada 10 galões de combustível produzidos é gerado um galão de glicerina (Selembo et al., 2009). O crescimento da indústria do biodiesel é cada vez maior e com ela, a geração deste co- 
produto. Só nos Estados Unidos foram produzidos mais de um milhão de galões de biodiesel no ano 2012 (www.biodiesel.org). No ano 2012 a produção de biodiesel no Brasil foi de 2,7 bilhoes de litros (Ruralcentro, 2013), quantidade que está aumentando pela mistura obrigatória de biodiesel-diesel de 20\% prevista para o ano 2020 (Duffey, 2010). A nível mundial, o crescimento na produção no ano de 2011 foi de 3.000 .000 toneladas e tem uma projeção de crescimento a 4.600.00 para o ano de 2020 (Viana, 2012), registrando-se uma produção mundial de 24,4 milhões de toneladas no ano 2013 (www.fedebiocombustibles.com). Desta forma, a demanda desse biocombustível está em fase crescente.

A glicerina gerada como co-produto no processo de produção do biodiesel recebe os nomes de glicerina bruta, glicerol bruto, glicerol industrial ou glicerol com água concentrado. Dependendo da matéria prima usada para a fabricação do biocombustível, a glicerina pode estar misturada com metanol, água, sais inorgânicas residuais, ácidos graxos livres, mono, di e triaciglicerois, metil ésteres e outros matérias orgânicos. Para que essa glicerina bruta seja usada como matéria prima na fabricação de produtos, precisa passar por um processo prévio de purificação o que diminui o seu preço no mercado (Chatzifragkou e Papanikolaou, 2012).

Ainda que a glicerina seja purificada para sua comercialização, o crescimento da produção mundial do biodiesel gera volumes cada vez maiores que se agregam à oferta exagerada desse coproduto. Em um futuro em médio prazo, a oferta ultrapassará a demanda e consequentemente o glicerol bruto poderá se converter em um passivo ambiental. Encontrar usos alternativos da glicerina contribui na valorização do despejo e na prevenção de danos ambientais.

A fermentação escura aplicada à oxidação da glicerina como fonte de carbono para a obtenção de hidrogênio é uma opção interessante tanto pela valorização do despejo como pelo rendimento teórico de transformação da glicerina em hidrogênio. As equações (3.1) a (3.4) (Maru 
et al., 2012) indicam os rendimentos atingidos com a glicerina dependendo do produto final. Como se observa, o maior teor de hidrogênio é obtido com a hidrólise da glicerina em ácido acético, dióxido de carbono e hidrogênio (Equação 3.1).

$$
\begin{aligned}
\mathrm{C}_{3} \mathrm{H}_{8} \mathrm{O}_{3}+\mathrm{H}_{2} \mathrm{O} \rightarrow \mathrm{CH}_{3} \mathrm{COOH} \text { (Ácido acético) }+\mathrm{CO}_{2}+3 \mathrm{H}_{2} \\
\mathrm{C}_{3} \mathrm{H}_{8} \mathrm{O}_{3} \rightarrow \mathrm{C}_{2} \mathrm{H}_{5} \mathrm{OH} \text { (Etanol) }+\mathrm{CO}_{2}+\mathrm{H}_{2} \\
\mathrm{C}_{3} \mathrm{H}_{8} \mathrm{O}_{3} \rightarrow \frac{1}{2} \mathrm{C}_{4} \mathrm{H}_{8} \mathrm{O}_{2} \text { (Ácido butirico) }+\mathrm{CO}_{2}+2 \mathrm{H}_{2} \\
\mathrm{C}_{3} \mathrm{H}_{8} \mathrm{O}_{3} \rightarrow \frac{1}{2} \mathrm{C}_{4} \mathrm{H}_{10} \mathrm{O} \text { (Butanol) }+\mathrm{CO}_{2}+\frac{1}{2} \mathrm{H}_{2} \mathrm{O}+\mathrm{H}_{2}
\end{aligned}
$$

Alguns microrganismos têm sido amplamente estudados no intuito de obter hidrogênio. Entre eles, podem se citar a Escherichia coli (Hu e Wood, 2010; Gonzales et al., 2008), Klebsiella pneumaniae (Wu et al., 2011), Clostridium butyricum (Levin et al., 2006), Enterobacter cloacae (Ito et al., 2005), Enterobacter aerogenes (Marques et al., 2009) e Citrobacter freundi (Maru et al., 2009).

Chatzifragkou e Papanikolaou (2012) apresentam no seu trabalho a rota metabólica do glicerol seguida pelos microrganismos procariontes e eucariontes em condições tanto aeróbias como anaeróbias (Figura 3.2). De acordo com a rota, o hidrogênio produzido com esse substrato é resultado da decomposição do formiato, que por sua vez é formado pela decomposição do piruvato. Como se observa na Figura 3.2., o piruvato gera três produtos: 1) o ácido lático, 2) a Acetila Coenzima A (Acetil-CoA) que por sua vez gera solventes e ácidos graxos voláteis e 3) o formiato, cuja quebra produz dióxido de carbono e hidrogênio. 


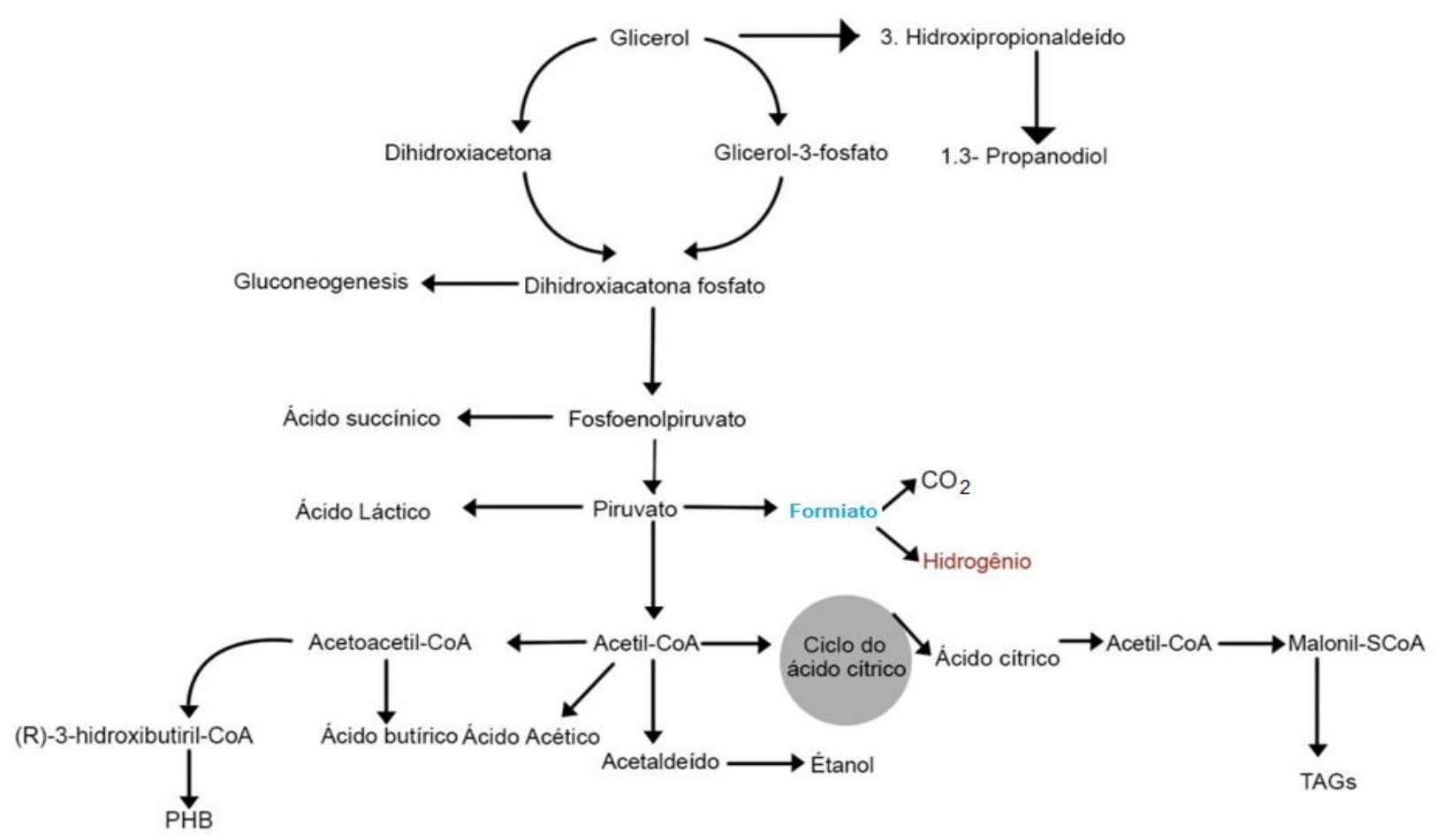

Figura 3.2 - Rota metabólica seguida por microrganismos procariontes e eucariontes na produção de hidrogênio (Adaptado de Chatzifragkou e Papanikolaou, 2012).

\subsection{Reator anaeróbio em batelada sequencial com biomassa imobilizada em suporte inerte}

De acordo a Kumar (2008), os reatores anaeróbios classificam-se em dois grupos: 1) reatores de baixa taxa e 2) reatores de alta taxa. Os reatores do primeiro grupo funcionam sem o controle das condições de operação como a temperatura e o tempo de detenção, e operam com cargas orgânicas volumétricas baixas (na ordem de 1-2 $\mathrm{kgDQO} \cdot \mathrm{m}^{-3} \mathrm{~d}^{-1}$ ). Essa configuração faz com que esses reatores sejam inadequados para a produção de bioenergia.

Os reatores do segundo grupo (de alta taxa) mantem altas concentrações de biomassa no interior, as condições de operação são controladas e funcionam com cargas orgânicas volumétricas na ordem de 5 a $30 \mathrm{kgDQO} \cdot \mathrm{m}^{-3} \mathrm{~d}^{-1}$, inclusive maiores. Dentro desse grupo está 
incluído o reator anaeróbio em batelada sequencial AnSBBR (Anaerobic Sequencing Batch Biofilm Reactor), o qual foi desenvolvido por Dague e colaboradores da Iowa State University, no inicio da década de 1990 (Dague et al., 1992).

O AnSBBR original foi desenhado para operar com biomassa em suspenção em quatro etapas bem definidas: repouso, decantação, alimentação e reação. Zaiat et al. (2001) modificaram a operação do AnSBBR, agregando um suporte inerte que facilitasse a aderência da biomassa e eliminasse a etapa de decantação. Como resultado, obteve-se o aumento do tempo de detenção celular no reator e o aumento de atividades enzimáticas (Sarti et al., 2006).

Em geral, o uso do suporte inerte para a fixação da biomassa aumenta consideravelmente a eficiência global do sistema: apresenta maiores níveis de remoção de substrato, dá estabilidade ao processo, facilita a operação do reator, aumenta a resistência a altas cargas do afluente, possui menores requerimentos de energia e reduz a produção de lodo em comparação com os sistemas que usam biomassa em suspensão (Babu et al., 2009; Jou e Huang, 2003)

O tipo de mistura efetuada no AnSBBR com biomassa imobilizada em um suporte inerte exerce uma grande influência no desenvolvimento do reator. Existem dois tipos de misturas que podem ser aplicadas: 1) por recirculação da fase líquida (Bergamo et al., 2009; Bezerra et al., 2009; Camargo et al., 2002; Brito et al., 1997) ou 2) por agitação mecânica (Angenent et al., 2002; Rodriges et al., 2003 e 2004; Damasceno et al., 2008; Michelan et al., 2009). No presente trabalho de pesquisa se usou um reservatório lateral para efetuar a mistura do meio líquido por recirculação.

\subsection{Fatores de influência na produção de biohidrogênio}


São vários os fatores que influenciam a produção de hidrogênio nos sistemas anaeróbios. A seguir são detalhados os fatores de maior relevância.

\subsubsection{Influência do tipo de inóculo}

Os microrganismos produtores de hidrogênio colocados nos reatores são originados de diferentes fontes, tanto naturais como de sistemas de tratamento implantadas pelo homem. Yuwaamornpitak (2012) isolou bactérias a partir do lodo de uma estação de tratamento de uma fábrica de leite para produção de hidrogênio usando glicerina como fonte de carbono. Com o mesmo objetivo, Bernal et al. (2013) isolaram bactérias a partir de amostras de solo e Selembo et al. (2009) obtiveram microrganismos a partir de solo de cultivos de tomate, trigo, da compostagem e do sedimentador secundário de uma planta de tratamento.

Alguns pesquisadores preferem usar lodo de estações de tratamento de esgoto municipais e estrume animal como inóculo para o start-up do reator na produção de hidrogênio (Khanal et al., 2006; Lay et al., 1999 e 2003). Outros, preferem usar cepas puras pr e-adaptadas à fonte de carbono em uso, como é o caso de Maru et al. (2012), Bernal et al. (2013) e Mangayil et al. (2012), que adaptaram as bactérias à glicerina como fonte de carbono antes de operar nas condições experimentais em estudo. Uma pré-adaptação ao substrato selecionaria aquelas bactérias com a capacidade de consumir uma fonte de carbono específica.

As famílias de bactérias Clostridiaceae, Streptococcaceae, Sporolactobacillaceae, Lacnospiraceae e Thermoanaerobacteriaceae têm sido reportadas como um grupo importante na produção de hidrogênio (Angelent et al., 2004). O uso de calor aplicado à biomassa anaeróbia (fervendo por 15 a 20 minutos) é uma estratégia útil no intuito de obter bactérias dessas famílias (Lay, 2000). Outra estratégia de utilidade é o uso de calor seco sobre amostras de solo ou 
compostagem (Khanal et al., 2004; Lay et al., 2005). Adicionalmente estão as estratégias enumeradas na Tabela 3.2 que têm como objetivo tanto enriquecer o cultivo com bactérias produtoras de hidrogênio, como eliminar às consumidoras. A eficiência da biomassa pré-tratada em comparação com a biomassa sem pré-tratamento teria uma diferença significativa na produção de hidrogênio (Kumar, 2008).

\subsubsection{Influencia do pH}

$\mathrm{O}$ pH talvez seja considerado como o fator de maior importância na produção de hidrogênio. É conhecido por pesquisadores no campo da biotecnologia anaeróbia que as bactérias acetogênicas, primeiras interventoras na digestão anaeróbia e produtoras de hidrogênio, desenvolvem-se em $\mathrm{pH}$ menores que 6,5 e que as arqueias metanogênicas produtoras de metano e consumidoras de hidrogênio crescem teoricamente numa faixa estreita de $\mathrm{pH}$ compreendida entre 7,5-6,5 (Rittman e McCarty, 2001).

A produção de hidrogênio é então altamente dependente do $\mathrm{pH}$ do meio pela seleção de bactérias. De acordo a Kumar (2008) o pH de operação é importante por três motivos:

1. Possui efeito direto na atividade da enzima hidrogenase que governa a produção de hidrogênio.

2. Direciona as rotas metabólicas para a produção de hidrogênio ou para a produção de solventes.

3. Permite inibir o crescimento dos microrganismos consumidores de hidrogênio. 
Ainda que o pH de operação para a produção de hidrogênio teoricamente estejam bem definidos, a bibliografia discorda muito no estabelecimento de valores ótimos, como se observa na Tabela 3.3 obtida de Lee et al. (2008). A faixa de experimentação vai de 4 a 9, e os valores de pH determinados como os melhores para a produção de hidrogênio variam de 4,5 a 8. Porém, pH levemente inferiores à neutralidade têm sido definidos como os mais viáveis (Hawkes et al., 2007).

Como se pode observa na Tabela 3.3., o pH está ligado a outros fatores como a temperatura, a concentração do substrato, a fonte de cultura e o tipo de sistema (batelada ou contínuo). Não existe um $\mathrm{pH}$ específico que possa ser extrapolado para todos os sistemas como um $\mathrm{pH}$ ótimo, porém é um fator decisivo. 
Tabela 3.3 - Produção de hidrogênio a partir de amido - influência do pH, temperatura e concentração de substrato (Lee et al.,2008).

\begin{tabular}{|c|c|c|c|c|c|c|c|c|c|c|c|}
\hline \multirow[b]{2}{*}{$\begin{array}{l}\text { Produtor de } \\
\qquad \mathrm{H}_{2}\end{array}$} & \multirow[b]{2}{*}{$\begin{array}{l}\text { Tipo de } \\
\text { cultura }\end{array}$} & \multirow[b]{2}{*}{ Substrato } & \multirow[b]{2}{*}{$\begin{array}{l}\text { Temperatura } \\
\text { Ensaiada }\end{array}$} & \multirow[b]{2}{*}{$\begin{array}{c}\text { pH } \\
\text { Ensaiado }\end{array}$} & \multirow{2}{*}{$\begin{array}{c}\text { Concentração } \\
\text { de substrato } \\
\text { ensaiado } \\
\left(\text { g.L. }{ }^{-1}\right)\end{array}$} & \multicolumn{3}{|c|}{ Melhores condições } & \multirow{2}{*}{$\begin{array}{c}\text { Máx. } \\
\text { Rendimento } \\
\left(\text { mmol } \mathbf{H}_{2 \cdot} \mathrm{g}^{-1}\right. \\
\text { amido) }\end{array}$} & \multirow{2}{*}{$\begin{array}{c}\text { Máx. taxa } \\
\text { de } \\
\text { produçãa } \\
\left(\text { ml. }^{-1} \cdot \mathbf{h}^{-1}\right)\end{array}$} & \multirow[b]{2}{*}{ Referência } \\
\hline & & & & & & $\begin{array}{c}\text { Temperatura } \\
\left({ }^{\circ} \mathrm{C}\right)\end{array}$ & pH & $\begin{array}{l}\text { Concentração de } \\
\text { substrato }\left(\text { g.L }^{-1}\right)\end{array}$ & & & \\
\hline $\begin{array}{c}\text { Lodo de } \\
\text { digestor } \\
\text { anaeróbio }\end{array}$ & Batelada & $\begin{array}{l}\text { Pasta de } \\
\text { arroz }\end{array}$ & 37 e 55 & $4,0-7,0$ & $2,7-22,1^{\mathrm{a}}$ & 37 & 4,5 & $5,5^{\mathrm{a}}$ & $14,12^{\mathrm{b}}$ & $\mathrm{NE}$ & $\begin{array}{l}\text { Fang et al. } \\
\text { (2006) }\end{array}$ \\
\hline Compostagem & Batelada & Amido & 37 & $4,5-6,5$ & 10 & $\mathrm{NE}$ & $\begin{array}{c}4,5 \\
\text { (inicial) }\end{array}$ & $\mathrm{NE}$ & 6,05 & $\mathrm{NE}$ & $\begin{array}{l}\text { Khanal et al, } \\
\quad \text { (2004) }\end{array}$ \\
\hline Lodo & $\begin{array}{c}\text { CSTR } \\
\text { (TRH: } \\
17 \mathrm{~h})\end{array}$ & $\begin{array}{l}\text { Amido } \\
\text { solúvel }\end{array}$ & 37 & $4,0-7,0$ & 4,25 & $\mathrm{NE}$ & 5,2 & $\mathrm{NE}$ & $\mathrm{NE}$ & 67 & Lay (2000) \\
\hline \multirow[t]{2}{*}{$\begin{array}{c}\text { Mistura } \\
\text { bacteriana }\end{array}$} & \multirow[t]{2}{*}{ Batelada } & \multirow[t]{2}{*}{$\begin{array}{l}\text { Amido de } \\
\text { milho }\end{array}$} & \multirow[t]{2}{*}{35} & \multirow[t]{2}{*}{$4,0-9,0$} & \multirow[t]{2}{*}{$2-32$} & \multirow[t]{2}{*}{$\mathrm{NE}$} & \multirow[t]{2}{*}{$\begin{array}{c}8,0 \\
\text { (inicial) }\end{array}$} & 2 & 7,92 & 4 & \multirow{2}{*}{$\begin{array}{l}\text { Liu e Shen } \\
\text { (2004) }\end{array}$} \\
\hline & & & & & & & & 24 & 4,33 & 53 & \\
\hline \multirow[b]{2}{*}{ Lodo de esgoto } & \multirow[b]{2}{*}{ Batelada } & \multirow[b]{2}{*}{$\begin{array}{l}\text { Amido de } \\
\text { mandioca }\end{array}$} & \multirow[b]{2}{*}{37 e 55} & \multirow[b]{2}{*}{$5,5-7,0$} & $4,6-36,6$ & 55 & $\begin{array}{c}6,0 \\
\text { (inicial) } \\
7,0 \\
\text { (inicial) }\end{array}$ & 4,6 & $\begin{array}{l}3,76 \\
2,73\end{array}$ & $\begin{array}{l}3,1 \\
5,8\end{array}$ & $\begin{array}{l}\text { Zhang et al. } \\
\text { (2003) }\end{array}$ \\
\hline & & & & & $\begin{array}{c}6,75-27 \\
\left(8-32 \text { gDQO.L } L^{-1}\right)\end{array}$ & 37 & 6,0 & $\begin{array}{c}20,3 \\
\left(24 \mathrm{gDQO} . \mathrm{L}^{-1}\right) \\
27 \\
\left(32 \mathrm{gDQO} . \mathrm{L}^{-1}\right)\end{array}$ & 11,25 & $\begin{array}{c}119 \\
1069\end{array}$ & $\begin{array}{l}\text { Lee } e t a l . \\
\text { (2008) }\end{array}$ \\
\hline
\end{tabular}

Notação: NE - não especificado; ${ }^{\mathrm{a}}$ - gcarboidrato. $\mathrm{L}^{-1} ;{ }^{\mathrm{b}} \mathrm{mmolH}_{2} \cdot \mathrm{g}$-carboidrato ${ }^{-1}$ 


\subsubsection{Influência da temperatura}

A temperatura, assim como o $\mathrm{pH}$, determina a seleção de microrganismos, a atividade da enzima hidrogenase, a taxa de transferência de massa, a hidrólise dos substratos e a pressão parcial do hidrogênio no meio (Kumar, 2008). Os estudos da influência da temperatura na produção de hidrogênio consideram basicamente duas faixas de temperatura do crescimento microbiano: faixa mesófila $\left(30-40^{\circ} \mathrm{C}\right)$ e termófila $\left(40-70^{\circ} \mathrm{C}\right)$. Porém, tem-se atribuído às condições hiper-termófilas $\left(70-80^{\circ} \mathrm{C}\right)$ melhores cinéticas de reação e a capacidade de operar a altas pressões parciais de hidrogênio (van Groenestijn et al., 2002).

Não existe uma temperatura estabelecida como a mais conveniente para a produção de hidrogênio. A temperatura parece estar ligada a outros fatores que determinam uma produção específica. Zhang e Shen (2006), por exemplo, encontraram que temperaturas entre 25 e $40^{\circ} \mathrm{C}$ são favoráveis, porém temperaturas superiores a $45^{\circ} \mathrm{C}$ teriam um efeito negativo. Wang et al. (2005) estudaram o efeito da temperatura na produção de hidrogênio testando temperaturas entre 20 e $40^{\circ} \mathrm{C}$. A temperatura que atingiu melhores resultados na produção de hidrogênio foi $35^{\circ} \mathrm{C}$. Mu et al. (2006) conseguiram aumentar a produção em $72 \%$ subindo $2^{\circ} \mathrm{C}$ periodicamente de 33 a $41^{\circ} \mathrm{C}$

e finalmente, $\mathrm{Yu}$ et al. (2002) reportaram $55^{\circ} \mathrm{C}$ como a temperatura ótima usando um reator UASB e água residuária de uma fábrica de arroz como substrato. Como se observa, a faixa que teoricamente proporcionaria os melhores resultados de produção de hidrogênio é bastante ampla.

Com relação às temperaturas usadas na produção de hidrogênio usando glicerina como substrato, a maioria de trabalhos consultados operou em condições mesófilas. Os efeitos da temperatura, porém, dependem adicionalmente de outros fatores paralelamente como será exemplificado mais na frente. 


\subsubsection{Influência dos nutrientes}

Tendo em vista que o processo de obtenção de biohidrogênio tem como protagonistas organismos vivos, os nutrientes presentes no meio são determinantes para sua existência. Os nutrientes considerados de maior importância pela porcentagem da constituição física dos microrganismos são o $\mathrm{C}, \mathrm{N}$ e o $\mathrm{P}$. Varias relações $\mathrm{C} / \mathrm{N}$ têm sido estudadas no intuito de estabelecer um valor ótimo. Lin e Lay, (2004), por exemplo, ensaiaram as relações C/N de 130, 98, 47 e 40 para a produção de hidrogênio. A máxima produção foi reportada na relação C/N de 47 usando hexoses como fonte de carbono. Morimoto et al. (2004) reportaram um valor de 10 como a melhor relação usando glicose como fonte de carbono e extrato de levedura como fonte de nitrogênio.

Para a relação C/P, alguns estudos estabelecem como ótimas as compreendidas entre 120 e 130 (Hawkes et al., 2002; Lin e Lay, 2004). De acordo a Hawkes et al. (2007), Ren et al. (1995) reportaram ter produzido hidrogênio usando açúcar ou amido de milho como fonte de carbono adicionando unicamente sais de nitrogênio e fósforo, porém, na maioria dos estudos utiliza-se uma mistura mais complexa de sais. Hawkes et al. (2007) mencionam que a presença do enxofre e do ferro teriam igual importância do que o nitrogênio e o fósforo, pela constituição da enzima hidrogenase. De acordo a Lee et al. (2001) um meio limitado em ferro tem uma baixa produção de hidrogênio e uma mudança na rota metabólica de produção de ácidos (gerador de hidrogênio) para geração de solventes (consumidor de hidrogênio).

Na Tabela 3.4 obtida de Hawkes et al. (2007), apresenta-se uma lista de macro e micro elementos considerados importantes na produção de hidrogênio, e as relações DQO:N e DQO:P usadas pelos autores mencionados. É importante realçar que todos eles usaram hexoses como fonte de carbono, o que permite comparar as relações com maior facilidade. 
Tabela 3.4 - Elementos (mg. $\mathrm{L}^{-1}$ ) e relações DQO:N e DQO:P usados em alguns estudos para produção de hidrogênio (Hawkes et al., 2007).

\begin{tabular}{ccccccc}
\hline Elemento & $\begin{array}{c}\text { Fang e Liu } \\
(\mathbf{2 0 0 2})\end{array}$ & $\begin{array}{c}\text { Lin e Chang } \\
(\mathbf{1 9 9 9 )}\end{array}$ & $\begin{array}{c}\text { Mizuno } \text { et al. } \\
(\mathbf{( 2 0 0 0 )}\end{array}$ & $\begin{array}{c}\text { Zoetemeyer } \text { et al. } \\
(\mathbf{1 9 8 2})\end{array}$ & $\begin{array}{c}\text { Hussy } \text { et al. } \\
(\mathbf{2 0 0 3})\end{array}$ & $\begin{array}{c}\text { Mu e Yu } \\
(\mathbf{2 0 0 6})\end{array}$ \\
\hline $\mathrm{N}$ & 131 & 929 & 680 & 351 & 680 & 72,9 \\
$\mathrm{~K}$ & 112 & 56 & 113 & 97 & 183,7 & 53 \\
$\mathrm{~S}$ & 42 & 5,5 & 0,6 & 12,8 & 9,9 & - \\
$\mathrm{Mg}$ & 32 & 13 & 32 & 3,6 & 37,8 & 12,0 \\
$\mathrm{Ni}$ & 12 & - & 0,13 & - & 12,05 & 1,23 \\
$\mathrm{Ca}$ & 14 & - & - & 0,20 & 18,0 & 18,02 \\
$\mathrm{~B}$ & 0,4 & - & 0,07 & - & 1,36 & 0,69 \\
$\mathrm{Mo}$ & 0,01 & - & 0,20 & - & 7,61 & 8,66 \\
$\mathrm{Zn}$ & 11 & - & 0,24 & 0,40 & 11,04 & 2,4 \\
$\mathrm{Co}$ & 6,2 & 0,04 & 0,74 & - & 3,72 & 1,24 \\
$\mathrm{Cu}$ & 3,7 & 1,3 & - & - & 3,73 & 1,42 \\
$\mathrm{Mn}$ & 8,3 & - & 0,69 & - & 6,95 & 1,39 \\
$\mathrm{I}$ & - & - & 1,91 & - & - & - \\
$\mathrm{Fe}$ & 17,2 & 5,03 & 1,0 & 2,9 & 17,3 & 11,0 \\
$\mathrm{P}$ & 102,3 & 22,0 & 44,5 & 76,2 & 101,5 & 21,03 \\
$\mathrm{DQO}: \mathrm{N}$ & $57: 1$ & $23: 1$ & $16: 1$ & $30: 1$ & $11,4: 1$ & $73: 1$ \\
DQO:P & $73: 1$ & $970: 1$ & $240: 1$ & $140: 1$ & $77: 1$ & $253: 1$ \\
\hline
\end{tabular}

Como se observa na Tabela 3,4, uma vez mais, não existem relações nutricionais específicas que possam ser estabelecidas como absolutas para a produção de hidrogênio. Assim como os fatores apresentados anteriormente, a produção de hidrogênio dependerá de uma ação conjunta entre a relação nutricional e os demais fatores.

\subsubsection{Influência da pressão parcial do hidrogênio}

De acordo a Angelent et al. (2004) e a Mandal e Nath (2006), a produção de hidrogênio através da fermentação escura é governada pela atividade da enzima hidrogenase, que catalisa a transferência de elétrons desde as moléculas transportadoras intracelulares aos prótons. Os prótons caracterizam-se por serem aceptores pobres de elétrons, fato evidenciado por seu baixo potencial redox $\left(\mathrm{Eh}_{\mathrm{H} 2}=-414 \mathrm{mV}\right)$. Os transportadores de elétrons, que são a ferrodoxina reduzida e o cofator NADH (Nicotinamida Adenina Denucleotídeo, forma reduzida) têm potenciais redox 
baixos (-400 e -320 mV, respectivamente) e são capazes de reduzir os prótons a hidrogênio dependendo do potencial redox da condição atual.

Assumindo uma concentração intracelular igual de formas oxidadas e reduzidas de ferrodoxina e NADH, a produção de hidrogênio é termodinamicamente desfavorável quando a pressão parcial do hidrogênio segue a Equação (3.5) apresentada por Angelent et al., (2004).

$$
\mathrm{P}_{\mathrm{H} 2, \max } \leq \exp \left[\frac{2 F\left(E_{H 2}^{o^{\prime}}-E_{x}^{o^{\prime}}\right)}{R T}\right]
$$

Na qual:

$\mathrm{P}_{\mathrm{H} 2 \text {,máx }}$ é a pressão parcial máxima do hidrogênio

$\mathrm{E}_{\mathrm{H} 2}{ }^{\mathrm{o}^{\prime}}$ é o potencial redox de prótons de hidrogênio

$\mathrm{E}_{\mathrm{x}}{ }^{\mathrm{o}^{\prime}}$ é o potencial redox do doador de elétrons

F é a constante de Faraday

$\mathrm{R}$ é a constante dos gases em condições ideais

T é a temperatura absoluta.

A produção de hidrogênio através da ferrodoxina reduzida será possível sempre que a pressão parcial do hidrogênio for menor a $0,3 \mathrm{~atm}$. (ou $3 \times 10^{4} \mathrm{~Pa}$.). No caso do cofator NADH, a pressão parcial do gás deveria ser mantida a níveis extremamente baixos (menores a 6 × $10^{-4}$ atm ou $60 \mathrm{~Pa}$ ) para que a redução dos prótons a hidrogênio seja viável. Os valores foram calculados considerando concentrações iguais das formas de doadores de elétrons reduzidas e oxidadas. A Figura 3.3 mostra como a produção de hidrogênio por via do cofator NADH é maior quando a pressão parcial é menor a $60 \mathrm{~Pa}$. 

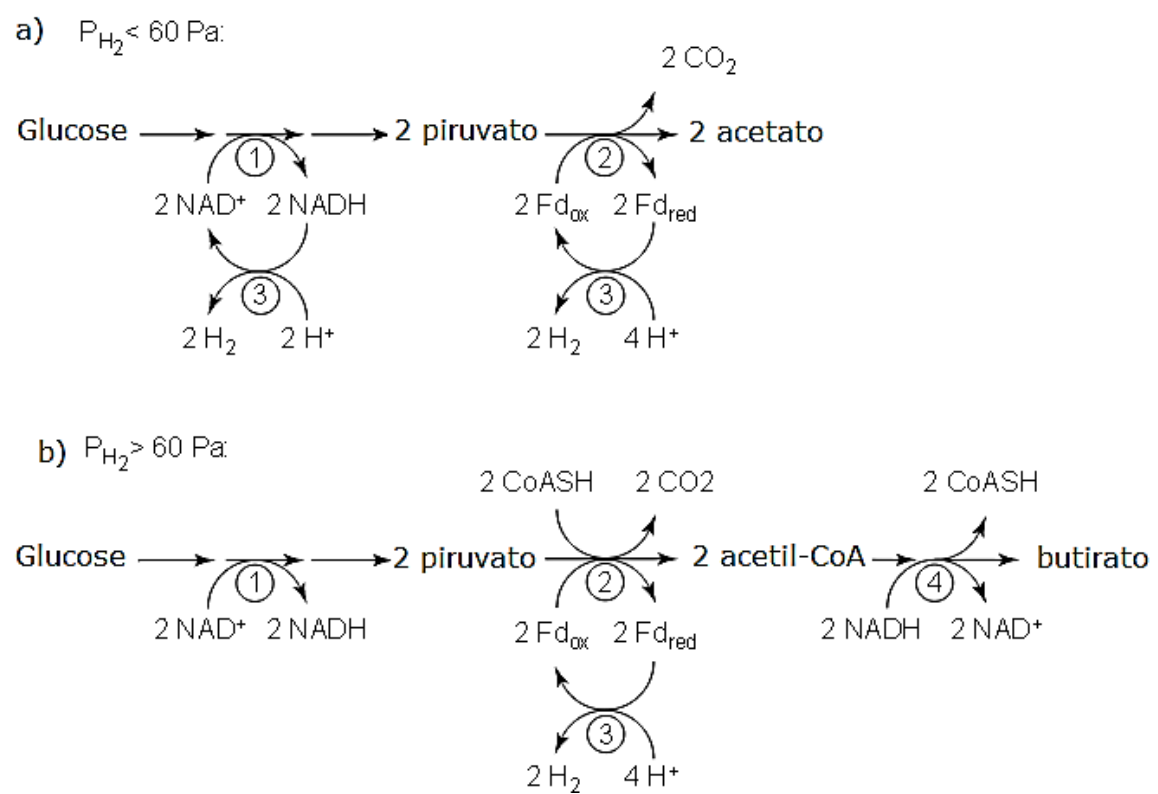

Figura 3.3 - Efeito da pressão parcial de hidrogênio na produção de biohidrogênio. a) Oxidação de NADH acontece pela redução do próton H+ quando a pressão parcial de hidrogênio é menor a $60 \mathrm{~Pa}$; caso contrario b) outros produtos são formados (Angelent et al.,2004).

No intuito de diminuir a pressão parcial do hidrogênio no sistema os pesquisadores têm adotado estratégias específicas. Lay (2000) reportou um aumento na produção de hidrogênio quando modificou a velocidade de agitação de 100 a 700 rpm em um reator CSTR em escala de laboratório. Hussy et al. (2005) gaseificaram o meio de reação com nitrogênio, obtendo uma aumento no rendimento de $60 \%$ quando comparado ao experimento sem gaseificação. Porém, Li e Fang (2007) não melhoraram a sua produção quando aplicaram vácuo, nem com o uso de uma membrana permeável a hidrogênio.

\subsubsection{Influência do tempo de ciclo ou tempo de detenção hidráulica}

De acordo a Kumar (2008), a produção de hidrogênio é afetada pelo tempo de detenção hidráulica (TDH) devido basicamente a duas razões: 
1) Exerce efeito de diluição do substrato e dos produtos, e subsequentemente na carga orgânica;

2) Permite seletivamente lavar os microrganismos de lento crescimento, como é o caso das metanogênicas consumidoras de hidrogênio.

A segunda razão está intimamente relacionada com o controle do processo produtor de hidrogênio, pela baixa velocidade máxima de crescimento dos microrganismos metanogênicos $\left(\mu_{\max }=0,0167 \mathrm{~h}^{-1}\right)($ van Haandel e Lettinga, 1994) comparada com as bactérias produtoras de hidrogênio $\left(\mu_{\max }=0,140-0,330 \mathrm{~h}^{-1}\right)$ (Horiunchi et al, 2002).

O estabelecimento de um TDH específico quando o objetivo é obter hidrogênio deve ser fixado tomando em consideração a velocidade de crescimento dos microrganismos produtores e consumidores, e também a eficiência de remoção da matéria orgânica. Diminuir excessivamente o TDH para evitar a presença de metanogênicas poderia se traduzir em baixas eficiências de consumo de substrato. Já que as variações no TDH têm um efeito direto na carga orgânica aplicada (COVA), desvincular esses dois fatores é pouco provável (Kumar, 2008).

É importante ressaltar que trabalhar com TDH curtos, tanto como trabalhar com $\mathrm{pH}$ menores que 6,5, não garante a ausência de metanogênicas no meio. Fang e Liu (2002) observaram produção de metano em um reator CSTR submetido a um pH de 6 de um TDH de apenas $6 \mathrm{~h}$. Contrariamente, Lin et al. (2006), operaram também um CSTR com um pH de 6,8 e um TDH entre 2 a 12 h, e encontraram metano não detectável para todas as condições.

Para reatores anaeróbios operados em batelada sequencial, que é o reator usado na presente pesquisa, o conceito do tempo de reação que melhor se adapta é o chamado tempo de ciclo correspondente ao tempo de permanência da água residuária no reator, contabilizado desde a 
carga até a descarga. Santos (2012) usou o mesmo sistema com o objetivo de obter hidrogênio a partir de sacarose ensaiando com tempos de ciclo de 2, 3 e 4 horas (os mesmos tempos de ciclo avaliados nesse trabalho) e duas concentrações afluente de sacarose (3600 e 5400 mgDQO.L ${ }^{-1}$ ). O melhor rendimento de hidrogênio $\left(3,66 \mathrm{molH}_{2} \cdot \mathrm{kgDQO}^{-1}\right)$ foi atingido com a menor concentração de DQO e o maior tempo de ciclo.

\subsubsection{Influência da configuração do reator}

A maioria de estudos desenvolvidos com o objetivo de produzir hidrogênio é conduzida em sistemas contínuos usando reatores CSTR. Como já foi mencionado no item 3.5.6, os sistemas contínuos permitem controlar com mais facilidade a reprodução de metanogênicas consumidoras de hidrogênio.

Uma distinção importante que a bibliografia ressalta é a pouca viabilidade do uso de biomassa em suporte para a produção de hidrogênio. Os tempos de detenção celular longos contribuiriam na reprodução de bactérias consumidoras de hidrogênio de lento crescimento. Porém, os reatores com biomassa imobilizada produtora de hidrogênio teriam a capacidade de suportar maiores cargas orgânicas volumétricas e como consequência atingir maiores níveis de produção de hidrogênio (Hawkes et al., 2007).

Uma comparação interessante feita por Hawkes et al. (2007) é estabelecida a partir dos trabalhos de Lin e Jo (2003) e Kyazze et al. (2006). Os primeiros trabalharam com um reator em batelada sequencial a $35^{\circ} \mathrm{C}$, pH 6,7 e com uma COVA de 82 g-sacarose. $\mathrm{L}^{-1} \cdot \mathrm{d}^{-1}$, obtendo um rendimento de 1,3 $\mathrm{molH}_{2}$.molhexose ${ }^{-1}$. Os segundos trabalharam com um reator CSTR com uma COVA similar e obtiveram um rendimento de $1,15 \mathrm{molH}_{2} \cdot \mathrm{molhexose}^{-1}$. Esses resultados são 
evidência de que um sistema em batelada pode ser tanto ou mais eficiente na produção de hidrogênio do que um CSTR.

Adicionalmente à configuração do reator, a operação do sistema é uma variável de grande influencia na produção de hidrogênio. Khanal et al. (2006) por exemplo, operaram um reator em batelada sequencial usando sacarose como substrato e re-inserindo no reator uma porção do efluente depois de aplicar um tratamento térmico. Os autores sugerem que um reator operado em batelada sequencial no modo denominado "feast and fast" favoreceria a germinação de esporos e adicionalmente eliminariam do sistema os ácidos não ionizados inibitórios.

Como mencionado anteriormente, dois fatores de grande impacto sobre a produção de hidrogênio são a pressão parcial de hidrogênio e a supressão de consumidores de hidrogênio. A configuração e operação dos reatores produtores de hidrogênio devem então ser orientados para satisfazer esses dois requisitos fundamentais (Kumar, 2008).

\subsubsection{Influência da carga orgânica}

Um fator importante e cuja avaliação é um dos objetivos do presente trabalho é a carga orgânica aplicada ao sistema. Com o objetivo de aperfeiçoar o sistema produtor de hidrogênio é importante estabelecer a carga orgânica que o sistema consegue suportar e na qual, maiores rendimentos são atingidos (Hafez et al., 2010).

A carga orgânica tem uma influencia ligada a outros fatores que afetam a produção de hidrogênio. Em algumas pesquisas o aumento da carga levou ao aumento da produção de hidrogênio e em outros a queda. Van Ginkel e Logan (2005), por exemplo, realizaram

experimentos com 10, 20, 30 e 40 g.L $\mathrm{L}^{-1}$ de glicose em um pH 5,5 e TDH de 10 h em um sistema 
contínuo obtendo o maior rendimento com a menor carga $\left(2,2 \pm 0,2 \mathrm{molH}_{2} \cdot\right.$ molglucose $\left.^{-1}\right)$. Zhang et al. (2004) pelo contrario, atingiram a maior produção com a maior concentração $(0,14$ $\mathrm{LH}_{2}$.gglicose ${ }^{-1}$ a 80 gDQO.L $\left.1 \cdot \mathrm{d}^{-1}\right)$. As quedas na produção de hidrogênio quando a carga é elevada poderiam estar intimamente relacionada com a pressão parcial do hidrogênio no meio devido a uma rápida formação do gás que afetaria negativamente o resultado total (Hafez et al., 2010).

Com relação ao uso da glicerina bruta como substrato, tanto Mangayil et al. (2012) como Ito et al. (2005) operaram com varias concentrações. Os primeiros trabalharam com cinco concentrações $\left(0.5,1,2.5,3.5,5\right.$ g. $\left.\mathrm{L}^{-1}\right)$ a $40^{\circ} \mathrm{C}$ em frascos para cultivo de soro. $\mathrm{O}$ maior rendimento foi atingido com 1 g-glicerina. $\mathrm{L}^{-1}$. Ito et al. (2005) testaram quatro concentrações $\left(1.7,3.3,10\right.$ e 25 g.L $\left.\mathrm{L}^{-1}\right)$ em um reator de leito fixo em sistema continuo, obtendo o maior rendimento com uma carga similar ao trabalho de Mangayil et el. (2012), sendo esta a menor concentração ensaiada.

Os trabalhos de pesquisa consultados utilizando glicerina como fonte de carbono para a obtenção de hidrogênio, testaram uma variedade de cargas orgânicas que foram de 1 a 50 g.L ${ }^{-1}$. Os rendimentos obtidos foram variados em conjunto com outros fatores como o $\mathrm{pH}$, a temperatura, o tipo de reator e os microrganismos usados. A Tabela 3.5 apresenta um resumo dos trabalhos consultados que trabalham com glicerina como fonte de carbono, especificando as condições de operação com os respetivos rendimentos. Unicamente apresentam-se os melhores resultados. Como se observa, a produção de hidrogênio dependerá da combinação de fatores. 
Tabela 3.5 - Condições e rendimentos obtidos em trabalhos de pesquisa desenvolvidos para obter biohidrogênio a partir de glicerin a.

\begin{tabular}{|c|c|c|c|c|c|c|c|c|c|c|c|}
\hline Reator & $\begin{array}{l}\text { Volume de } \\
\text { reação (L) }\end{array}$ & $\begin{array}{l}\text { TB } \\
\text { (h) }\end{array}$ & pH & $\begin{array}{c}\mathrm{T}^{\mathbf{0}} \\
\left({ }^{\circ} \mathrm{C}\right) \\
\end{array}$ & Biomassa & $\begin{array}{c}\text { Pre-tratamento } \\
\text { biomassa }\end{array}$ & Adicionais & $\begin{array}{c}\text { Concentração } \\
\text { glicerina }\end{array}$ & $\begin{array}{c}\text { Tipo de } \\
\text { glicerina }\end{array}$ & Rendimento & Autores \\
\hline $\begin{array}{l}\text { Batelada com } \\
\text { agitação }\end{array}$ & 1 & - & 7 & 35 & E.coli HB41 & $\begin{array}{l}\text { Ativação previa } \\
\text { em meio com } \\
\text { glicerina }\end{array}$ & Minerais, $\mathrm{NH}_{4} \mathrm{Cl}$ & $2 \%$ & $\begin{array}{l}\text { Glicerina bruta } \\
\text { pre tratada }\end{array}$ & $\approx 2 \mathrm{mM} \cdot \mathrm{L}^{-1}$ & $\begin{array}{l}\text { Yuwa-amornpitak } \\
\text { (2012) }\end{array}$ \\
\hline $\begin{array}{l}\text { Batelada com } \\
\text { agitação }\end{array}$ & 1,2 & 72 & 6,3 & 37 & $\begin{array}{c}\text { Enterobacter } \\
\text { spH1 } \\
\text { Enterobacter } \\
\text { spH2 } \\
\text { Citrobacter } \\
\text { freundii } \mathrm{H} 3 \\
\text { Mistura } \\
(1: 1: 1)\end{array}$ & $\begin{array}{l}\text { Ativação previa } \\
\text { em meio com } \\
\text { glicerina }\end{array}$ & $\begin{array}{l}\text { Uso de extrato de } \\
\text { malte, extrato de } \\
\text { levedura }\end{array}$ & $20 \mathrm{~g} \cdot \mathrm{L}^{-1}$ & Glicerina pura & $\begin{array}{l}\text { 0,85 } \mathrm{mol} \mathrm{H}_{2} \mathrm{~mol}^{-1} \text { gli. } \\
0,95 \mathrm{~mol} \mathrm{H}_{2} \mathrm{~mol}^{-1} \text { gli. } \\
0,94 \mathrm{~mol} \mathrm{H}_{2} \mathrm{~mol}^{-1} \text { gli. } \\
0,76 \mathrm{~mol} \mathrm{H}_{2} \mathrm{~mol}^{-1} \text { gli. }\end{array}$ & Maru et al. (2012) \\
\hline RALF & 4 & 72 & 7 & $\mathrm{NE}$ & $\begin{array}{c}\text { Clostridium } \\
s p . \text { (IBUN } \\
18 \mathrm{~S})\end{array}$ & $\begin{array}{l}\text { Ativação previa } \\
\text { em meio com } \\
\text { glicerina }\end{array}$ & $\begin{array}{l}\text { Uso de extrato de } \\
\text { levedura }\end{array}$ & $50 \mathrm{~g} \cdot \mathrm{L}^{-1}$ & $\mathrm{NE}$ & $\begin{array}{l}0,1962 \mathrm{~mol} \\
\mathrm{H}_{2} \cdot \mathrm{mol}^{-1} \mathrm{gli} .\end{array}$ & Bernal et al. (2013) \\
\hline $\begin{array}{l}\text { Frascos para } \\
\text { cultivo de soro }\end{array}$ & 0,5 & 72 & 6,2 & 30 & $\begin{array}{l}\text { Solo cultivo } \\
\text { de trigo }\end{array}$ & $105^{\circ} \mathrm{C}, 2 \mathrm{~h}$ & $\begin{array}{l}\text { Uso de vitaminas } \\
\text { e minerais }\end{array}$ & 3 g..$L^{-1}$ & $\begin{array}{l}\text { Glicerina ultra } \\
\text { pura } \\
\text { Glicerina bruta }\end{array}$ & $\begin{array}{l}\text { 0,28 } \mathrm{mol} \mathrm{H}_{2} \cdot \mathrm{mol}^{-1} \\
\text { gli. } \\
\begin{array}{c}\text { 0,31 } \\
\mathrm{mol} \mathrm{H}\end{array} \mathrm{mol}^{-1} \\
\text { gli. }\end{array}$ & $\begin{array}{l}\text { Selembo et al. } \\
\quad(2009)\end{array}$ \\
\hline Batelada & 2,25 & $\approx 85$ & 6,3 & $\mathrm{NE}$ & E. coli K12 & $\begin{array}{l}\text { Ativação previa } \\
\text { em meio com } \\
\text { glicerina }\end{array}$ & $\begin{array}{c}\text { Uso de extrato de } \\
\text { levedura e } \\
\text { triptona. }\end{array}$ & $25 \mathrm{~g} \cdot \mathrm{L}^{-1}$ & $\mathrm{NE}$ & $1,140 \mathrm{mmol} \mathrm{H}_{2} \mathrm{~L}^{-1}$ meio & $\begin{array}{c}\text { Chaundhary et al. } \\
\text { (2011) }\end{array}$ \\
\hline $\begin{array}{c}\text { Frascos para } \\
\text { cultivo de soro }\end{array}$ & 0,160 & $\mathrm{NE}$ & 6,5 & 35 & $\begin{array}{c}\text { Cultura } \\
\text { anaeróbia }\end{array}$ & $100^{\circ} \mathrm{C}, 15 \mathrm{~min}$ & $\begin{array}{c}\text { Uso de extrato de } \\
\text { levedura }\end{array}$ & $8,3 \mathrm{~g} \mathrm{DQO} . \mathrm{L}^{-1}$ & Glicerina pura & $\begin{array}{c}26,26 \mathrm{mLH}_{2} \cdot \mathrm{g}^{-1} \\
\mathrm{DQO}_{\text {aplicada }}\end{array}$ & Vlassis et al. (2012) \\
\hline $\begin{array}{l}\text { Frascos para } \\
\text { cultivo de soro }\end{array}$ & 0,04 & 197 & $\begin{array}{c}6,8 \\
- \\
7,5 \\
\end{array}$ & 75 & $\begin{array}{c}\text { Thermotoga } \\
\text { neapolitana } \\
\text { DSM } 4359\end{array}$ & - & $\begin{array}{c}\text { Gasificação com } \\
\mathrm{N}_{2} \text { do espaço livre } \\
\text { e controle de pH }\end{array}$ & 5 g.. $\mathrm{L}^{-1}$ & $\begin{array}{l}\text { Glicerina bruta } \\
\text { pré- tratada }\end{array}$ & $\begin{array}{l}2,06 \mathrm{~mol} \mathrm{H}_{2} \cdot \mathrm{mol}^{-1} \\
\text { gli.consumida }\end{array}$ & Ngo et al. (2011) \\
\hline Quimiostato & 0,5 & 14 & 6,3 & 37 & $\begin{array}{c}\text { Enterobacter } \\
\text { aerogenes- } \\
\text { HU-101 }\end{array}$ & $\begin{array}{l}\text { Pré- ativação de } \\
\text { inóculo }\end{array}$ & - & $10 \mathrm{~g} \cdot \mathrm{L}^{-1}$ & $\mathrm{NE}$ & 6,69 mmol.g ${ }^{1}$ gli. & $\underset{\text { (2002) }}{\text { Nakashimada }}$ et al. \\
\hline $\begin{array}{l}\text { Reator de leito } \\
\text { fixo em sistema } \\
\text { continuo }\end{array}$ & 0,6 & 10 & - & 37 & $\begin{array}{c}\text { Enterobacter } \\
\text { aerogenes- } \\
\text { HU-101 }\end{array}$ & $\begin{array}{l}\text { Pré- ativação de } \\
\text { inóculo }\end{array}$ & $\begin{array}{l}\text { Uso de extrato de } \\
\text { levedura e triptona }\end{array}$ & $1,7 \mathrm{~g} \cdot \mathrm{L}^{-1}$ & $\begin{array}{l}\text { Glicerina de } \\
\text { biodiesel de } \\
\text { laboratório }\end{array}$ & 1,12 mol.mol ${ }^{-1} \mathrm{gli}$ & Ito et al. (2005) \\
\hline $\begin{array}{l}\text { Frascos para } \\
\text { cultivo de soro }\end{array}$ & 0,120 & $\mathrm{NE}$ & 6,5 & 40 & $\begin{array}{l}\text { Biomassa de } \\
\text { PTAR }\end{array}$ & $\begin{array}{l}\text { Pré-ativação de } \\
\text { inóculo em } \\
\text { meio com } \\
\text { glicerina }\end{array}$ & - & $1 \mathrm{~g} \cdot \mathrm{L}^{-1}$ & Glicerina bruta & $\begin{array}{c}1,1 \mathrm{~mol} \mathrm{H}_{2} \cdot \mathrm{mol}^{-1} \\
\text { gli.consumida }\end{array}$ & $\begin{array}{l}\text { Mangayil et al. } \\
\quad \text { (2012) }\end{array}$ \\
\hline Batelada & 2 & 0,5 & 5,5 & 25 & $\begin{array}{c}\text { De um reator } \\
\text { de leito fixo } \\
\text { usando } \\
\text { sacarose }\end{array}$ & - & $\begin{array}{l}\text { Gasificação com } \\
\text { Argônio do } \\
\text { espaço livre }\end{array}$ & 3,7 g.L $\mathrm{L}^{-1} \mathrm{DQO}$ & Glicerina bruta & $\begin{array}{c}200 \mathrm{~mL} \mathrm{H}_{2} \cdot \mathrm{g} \\
\mathrm{DQO}_{\text {glicerina }}\end{array}$ & $\begin{array}{l}\text { Fernandes et al. } \\
\quad(2010)\end{array}$ \\
\hline $\begin{array}{l}\text { Batelada com } \\
\text { agitação }\end{array}$ & 0,670 & $\mathrm{NE}$ & 6,5 & 30 & $\begin{array}{c}\text { Enterobacter } \\
\text { aerogenes }\end{array}$ & $\begin{array}{c}\text { Pré- ativação da } \\
\text { biomassa }\end{array}$ & $\begin{array}{c}\text { Uso de triptona e } \\
\text { extrato de } \\
\text { levedura. } \\
\text { Gasificação com } \\
\mathrm{N}_{2}\end{array}$ & $20 \mathrm{~g} \cdot \mathrm{L}^{-1}$ & Glicerina bruta & 2,5 $\mathrm{L} \mathrm{H}_{2} \cdot \mathrm{L}^{-1}$ medio & $\begin{array}{l}\text { Marques et al. } \\
\quad \text { (2009) }\end{array}$ \\
\hline
\end{tabular}

NE: Não especificado 
Adicionalmente à carga, um fator intimamente relacionado à produção de hidrogênio é o tipo de substrato. O glicerol, por exemplo, apresenta um rendimento máximo teórico de 3 molH $_{2} \cdot$ molglicerol $^{-1}$ (Maru et al., 2012), menor que outros substratos puros como a glicose e a sacarose com rendimentos de 4 molH $_{2} \cdot$ molglicose $^{-1}$ (Selembo et al., 2009) e 8 $\mathrm{molH}_{2} \cdot$ molsacarose $^{-1}$ (Santos, 2012) respetivamente, se apenas acetato é obtido como produto final. Assim, teoricamente é esperada uma maior produção em reatores que trabalhem com os substratos puros mencionados em comparação com o glicerol. Porém, como se observou na Tabela 3.5, a obtenção de hidrogênio usando glicerina como fonte de carbono é totalmente possível.

\subsection{Considerações finais}

Atualmente, os grupos de pesquisa da Escola de Engenharia de São Carlos da Universidade de São Paulo (EESC/USP) e da Escola de Engenharia Mauá do Instituto Mauá de Tecnologia (EEM/IMT) trabalham conjuntamente em projetos de pesquisa na adequação de efluentes poluentes para a obtenção de bioenergia usando reatores com biomassa imobilizada e recirculação de fase líquida. Um dos objetivos fundamentais desses projetos é valorizar os poluentes ambientais presentes nas águas residuárias utilizando-os como matéria prima. Nesse sentido, o presente trabalho de pesquisa teve como objetivo, avaliar o efeito da carga orgânica aplicada no reator anaeróbio operado em batelada sequencial com biomassa imobilizada em suporte inerte e recirculação de fase líquida (AnSBBR) na produção de hidrogênio, usando a glicerina como única fonte de carbono no metabolismo anaeróbio. Em base à informação anteriormente apresentada observa-se que o objetivo do trabalho é totalmente viável. 
O presente trabalho por tanto constitui uma contribuição à ciência na procura de opções adequadas de disposição de efluentes industriais valorizando despejos, conjuntamente com a procura de combustíveis alternativos que em um futuro possam formar parte da matriz energética. Adicionalmente, constitui uma contribuição à procura de opções de uso da glicerina que devido ao acelerado crescimento da indústria do biodiesel, tem um grande potencial de se converter em um passivo ambiental. O presente trabalho experimenta com condições amplamente estudadas pelos grupos de pesquisa da USP e o IMT na obtenção de hidrogênio, visando otimizar o processo de aproveitamento do mencionado substrato. 


\section{MATERIAIS E MÉTODOS}

\subsection{AnSBBR com biomassa imobilizada e recirculação da fase líquida}

A Figura 4.1 mostra o esquema do sistema proposto para a produção de biohidrogênio usando glicerina como fonte de carbono. O reator, com capacidade para $2 \mathrm{~L}$ de meio líquido além do suporte inerte e biomassa, foi constituído por um frasco de acrílico, cilíndrico, com as seguintes dimensões: $490 \mathrm{~mm}$ de altura, $100 \mathrm{~mm}$ de diâmetro externo e 3,5 $\mathrm{mm}$ de espessura de parede. Foi utilizada uma unidade de controle para automatizar as operações de carga, descarga e recirculação.

O suporte de imobilização da biomassa foi acondicionado entre telas de aço Inox - 314, dividindo a altura de $490 \mathrm{~mm}$ do reator em 5 estágios para evitar a compactação do leito. Na parte inferior do reator havia um compartimento de $20 \mathrm{~mm}$ de altura destinado a favorecer a distribuição da água residuária e, na parte superior, um compartimento com 90 mm de altura que funcionou como câmara coletora de biogás $\left(\mathrm{H}_{2}, \mathrm{CH}_{4} \mathrm{e} \mathrm{CO}_{2}\right)$.

O sistema de recirculação foi composto por: (i) um reservatório lateral, o qual conteve um volume de meio de 1,67 L, constituído por um frasco de acrílico, cilíndrico, com as seguintes dimensões: $430 \mathrm{~mm}$ de altura, $100 \mathrm{~mm}$ de diâmetro externo e 3,5 $\mathrm{mm}$ de espessura de parede (volume total de 2,9 L); e (ii) bomba peristáltica marca Ismatec ${ }^{\circledR}$ modelo MCP, com capacidade de até $30 \mathrm{~L} \cdot \mathrm{h}^{-1}$. Uma bureta de $100 \mathrm{~mL}$ foi interligada ao sistema de recirculação para medir a vazão de recirculação. O volume total de meio reacional, resultante da soma do volume de meio contido no reator (2 L) e no reservatório paralelo (1,67 L) foi de 3,67 L. 
A alimentação e descarga foram realizadas por bombas tipo diafragma marca Prominent ${ }^{\circledR}$,

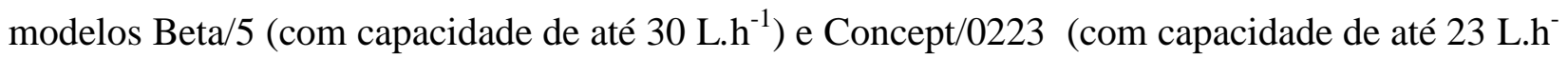
${ }^{1}$ ), respectivamente, auxiliadas por um sistema de automação composto por temporizadores marca Coel $^{\circledR}$, modelo RTST/20.

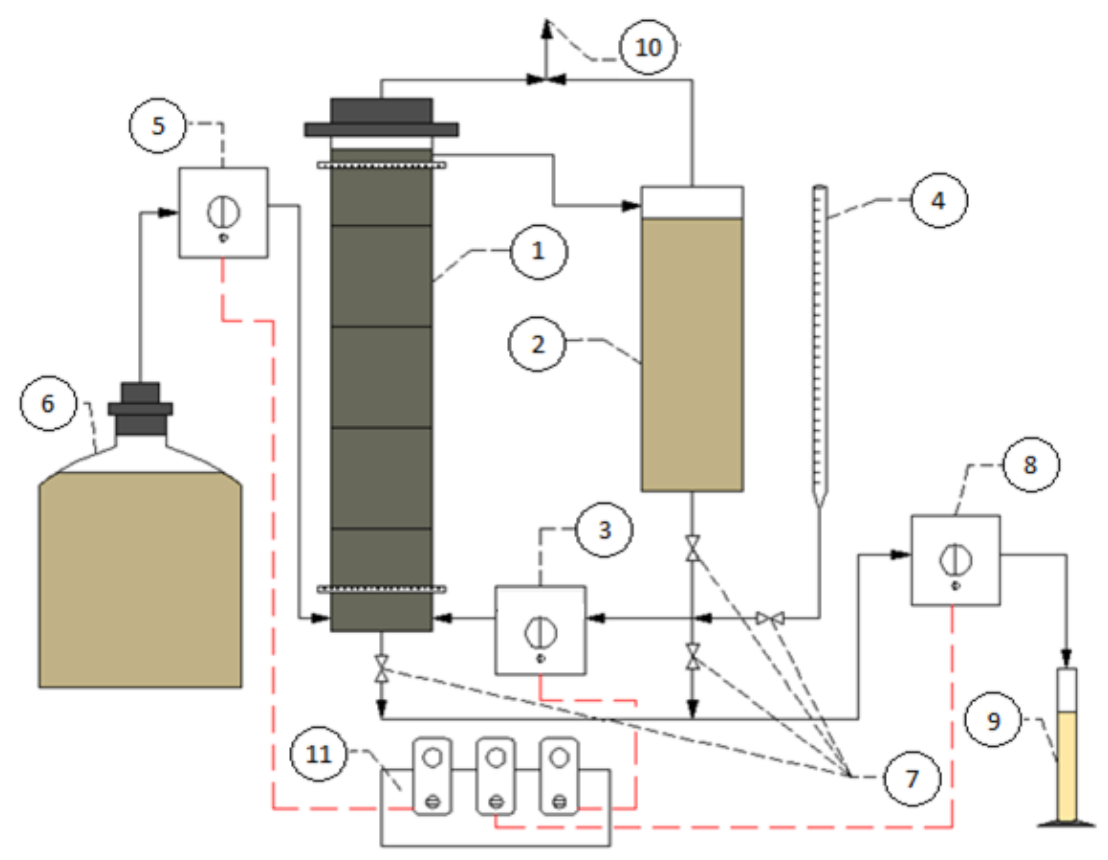

Figura 4.1 - Esquema do reator.

[Notação: 1 - reator contendo biomassa imobilizada; 2 - reservatório lateral; 3 - bomba de reciclo; 4 - medidor de vazão; 5 - bombas de alimentação; 6 - reservatório de água residuária; 7 - válvulas de descarga; 8 - bomba de descarga; 9 - saída do efluente; 10 - saída de biogás; 11 - unidade de controle; —— ligações hidráulicas; - - - ligações elétricas].

O reator foi colocado em uma câmara mantida a $30 \pm 1{ }^{\circ} \mathrm{C}$ por um sistema composto de sensor, controlador (Novus ${ }^{\circledR}$, modelo N480), ventilador e resistência elétrica.

A Figura 4.2 mostra uma fotografia do sistema completo utilizado na experimentação, com as partes constituintes. 


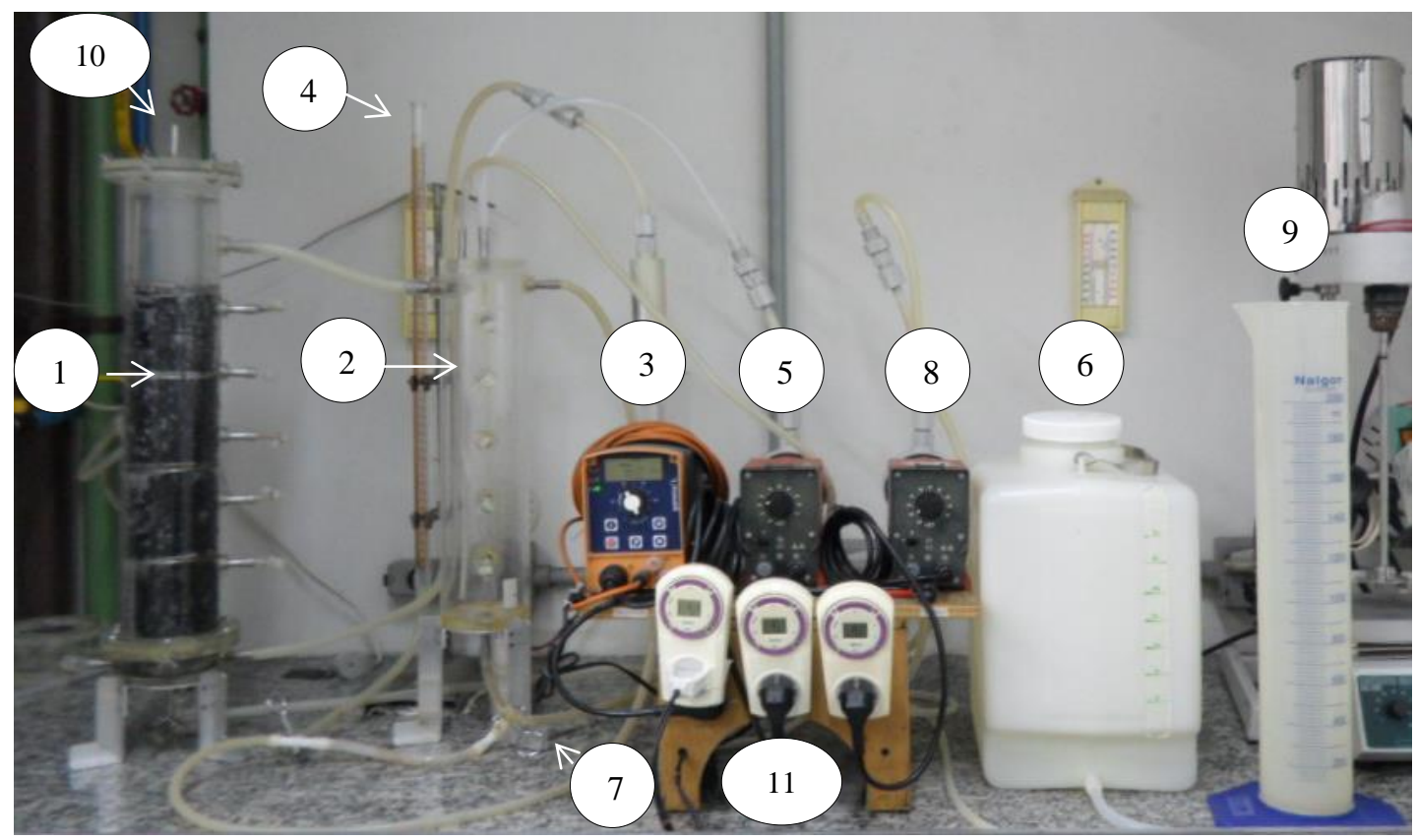

Figura 4.2 - Fotografia do sistema utilizado.

[Notação: 1 - reator contendo biomassa imobilizada; 2 - reservatório lateral; 3 - bomba de reciclo; 4 - medidor de vazão; 5 - bombas de alimentação; 6 - reservatório de água residuária; 7 - válvulas de descarga; 8 - bomba de descarga; 9 - saída do efluente; 10 - saída de biogás;

11 - unidade de controle].

\subsection{Inóculo e imobilização da biomassa anaeróbia}

O meio suporte utilizado para aderência da biomassa foram grânulos de polietileno de baixa densidade (PEBD) produto intermediário do processo de reciclagem de plásticos de resíduos domésticos, cuja empresa doadora localiza-se em São Carlos, SP. As características do material são apresentadas na Tabela 4.1.

Tabela 4.1- Características do material suporte inerte

\begin{tabular}{cc}
\hline Propriedades & Valor / Descrição \\
\hline Composição & Polietileno de baixa densidade \\
Diâmetro de um grânulo & $3 \mathrm{~mm}$ \\
Comprimento de um grânulo & $6 \mathrm{~mm}$ \\
Massa utilizada & $1,34 \mathrm{~kg}$ \\
Porosidade do leito & 0,43 \\
Comportamento & Flutuante/Auto compactante \\
\hline
\end{tabular}


Na Figura 4.3 é apresentada uma fotografia dos grânulos de polietileno de baixa densidade (PEBD) onde se observa o tamanho aproximado.
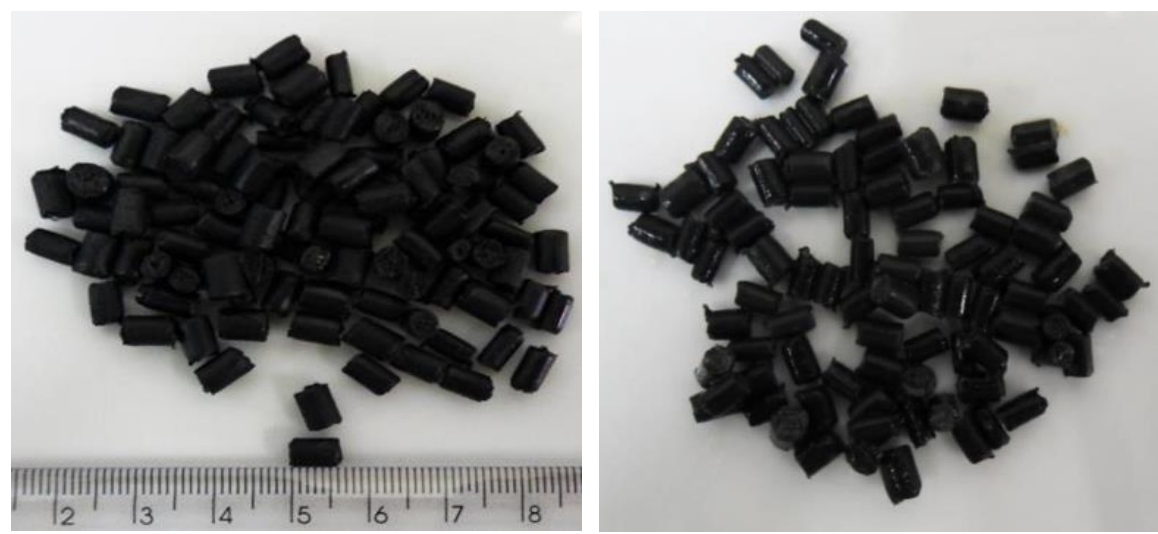

Figura 4.3 - Fotografia dos grânulos do material suporte sem (esquerda) e com (direita) biomassa

Algumas condições experimentais da fase preliminar da pesquisa foram operadas usando como suporte inerte uma mistura de PEBD com poliuretano como será explicado posteriormente.

Durante a pesquisa foram utilizados os inóculos especificados na Tabela 4.2.

Tabela 4.2 - Inóculos usados nas fases de experimentação

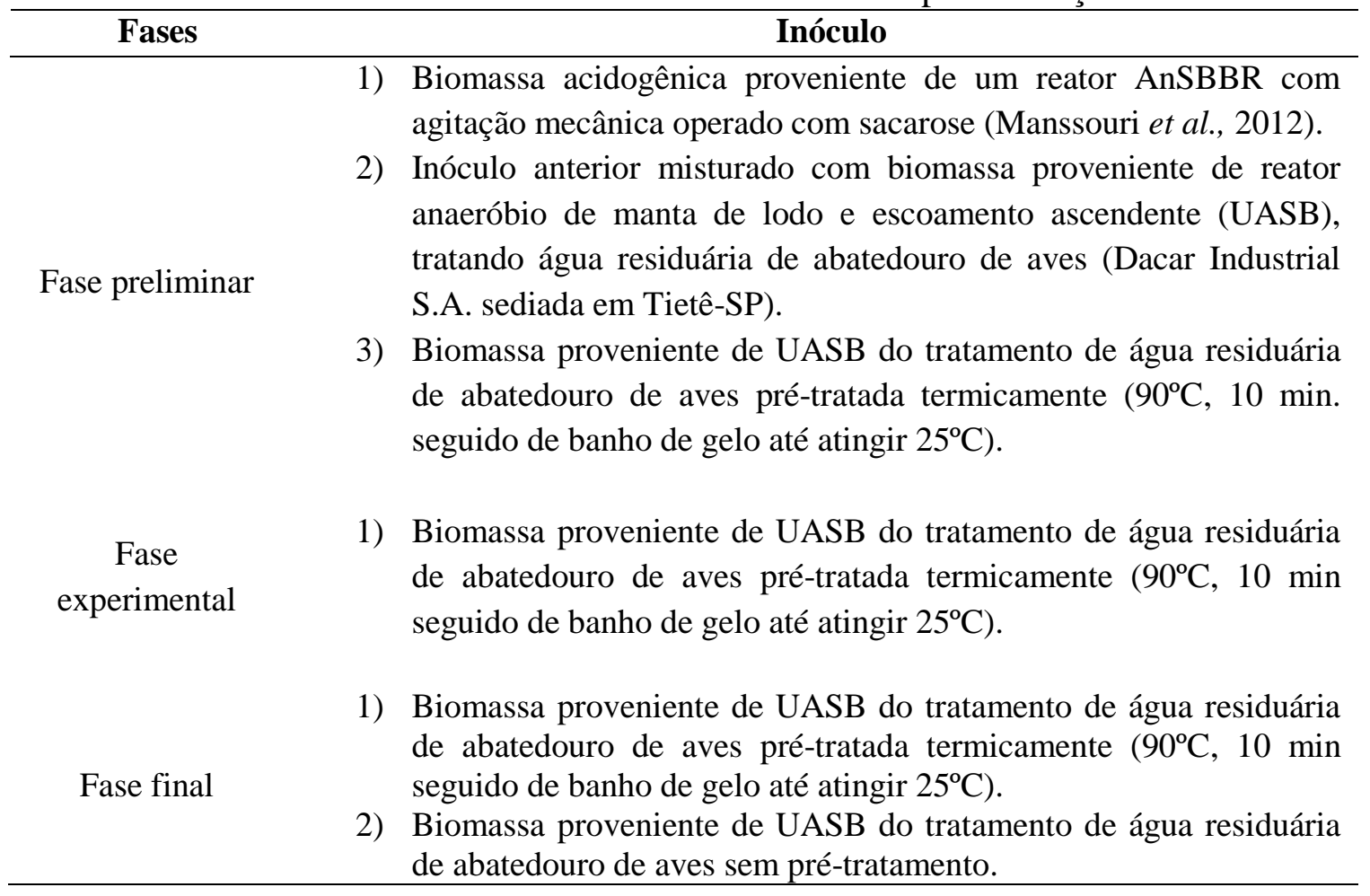


A biomassa acidogênica usada estava fixada a grânulos de PEBD armazenados em refrigeração. A inoculação do suporte foi feita por mistura dos grânulos de PEBD limpos com aqueles contendo a biomassa acidogênica imobilizada.

Em aquelas condições experimentais nas que foi usada biomassa proveniente do UASB do tratamento de água residuária do abatedouro de aves, a inoculação foi feita através da mistura de 150 mL de biomassa liquidificada com os grânulos de PEBD. Posteriormente, os grânulos inoculados foram colocados dentro do reator pela parte superior. Finalmente, o reator foi fechado com parafusos e selado com silicone para evitar a saído do biogás.

\section{3 Água residuária}

A água residuária sintética utilizada teve como base a composição apresentada na Tabela 4.3 (adaptado Del Nery, 1987). Usou-se glicerina bruta industrial (GBI), glicerina bruta sintetizada no laboratório (GBL) e glicerol-PA (GPA), cada uma em diferentes condições experimentais como fonte de carbono, e ureia como fonte de nitrogênio, em uma razão C/N imposta de aproximadamente 110 e a razão DQO/P menor que 500 (1000:2). A composição foi modificada em diferentes etapas da fase preliminar tal como será explicado posteriormente. 
Tabela 4.3 - Composição da água residuária sintética utilizada nos ensaios de produção de biohidrogênio em AnSBBR com recirculação.

\begin{tabular}{cc}
\hline Composto & Concentração $\left(\mathrm{mg} . \mathrm{L}^{-1}\right)$ \\
\hline Glicerina & 822 \\
(relação teórica: $1000 \mathrm{mgDQO}=822 \mathrm{mgglicerina})$ & $\left(1000 \mathrm{mgDQO} . \mathrm{L}^{-1}\right)$ \\
Ureia $\left(\mathrm{CH}_{4} \mathrm{~N}_{2} \mathrm{O}\right)$ & 5,8 \\
Sulfato de níquel $\left(\mathrm{NiSO}_{4} \cdot 6 \mathrm{H}_{2} \mathrm{O}\right)$ & 0,50 \\
Sulfato ferroso $\left(\mathrm{FeSO}_{4} \cdot 7 \mathrm{H}_{2} \mathrm{O}\right)$ & 2,50 \\
Cloreto férrico $\left(\mathrm{FeCl}_{3} \cdot 6 \mathrm{H}_{2} \mathrm{O}\right)$ & 0,25 \\
Cloreto de cálcio $\left(\mathrm{CaCl}_{2} \cdot 2 \mathrm{H}_{2} \mathrm{O}\right)$ & 2,06 \\
Cloreto de cobalto $\left(\mathrm{CoCl}_{2} \cdot 6 \mathrm{H}_{2} \mathrm{O}\right)$ & 0,04 \\
Dióxido de selênio $\left(\mathrm{SeO}_{2}\right)$ & 0,04 \\
Fosfato de potássio monobásico $\left(\mathrm{KH}_{2} \mathrm{PO}_{4}\right)$ & 5,36 \\
Fosfato de potássio dibásico $\left(\mathrm{K}_{2} \mathrm{HPO}_{4}\right)$ & 1,30 \\
Fosfato de sódio dibásico $\left(\mathrm{Na}_{2} \mathrm{HPO}_{4}\right)$ & 2,70 \\
Bicarbonato de sódio $\left(\mathrm{NaHCO}_{3}\right)$ & Variável \\
\hline
\end{tabular}

$\mathrm{O} \mathrm{pH}$ do efluente foi controlado em valores menores do que 5 mediante a adição de bicarbonato de sódio.

A relação $\mathrm{C} / \mathrm{N}(\mathrm{g}-\mathrm{C} / \mathrm{g}-\mathrm{N})$ foi calculada de acordo com a porcentagem em massa de carbono e nitrogênio dos elementos que constituíram parte do meio: glicerina (glicerina $-\mathrm{C}_{3} \mathrm{H}_{8} \mathrm{O}_{3}$ - 36gC/92g.glicerina) e uréia $\left(\mathrm{CH}_{4} \mathrm{~N}_{2} \mathrm{O}-28 \mathrm{~g}-\mathrm{N} / 60 \mathrm{~g}\right.$-uréia). Assim, a relação $\mathrm{C} / \mathrm{N}$ utilizada nesse estudo foi: $822 / 5,8=(822 \cdot 36 / 92) /(5,8 \cdot 28 / 60)=321,7 / 2,7=118,8 \mathrm{gC} / \mathrm{gN}$.

A relação C/P (g-C/g-P) foi calculada de acordo com a porcentagem em massa de carbono e fósforo dos elementos que constituíram parte do meio: glicerina (glicerina $-\mathrm{C}_{3} \mathrm{H}_{8} \mathrm{O}_{3}-36 \mathrm{gC} / 92$ gglicerina) e sais de fósforo $\left(\mathrm{KH}_{2} \mathrm{PO}_{4}-31 \mathrm{gP} / 136 \mathrm{gKH}_{2} \mathrm{PO}_{4} ; \mathrm{K}_{2} \mathrm{HPO}_{4}-31 \mathrm{gP} / 174 \mathrm{gK}_{2} \mathrm{HPO}_{4}\right.$; $\mathrm{Na}_{2} \mathrm{HPO}_{4}-31 \mathrm{gP} / 142 \mathrm{gNa}_{2} \mathrm{HPO}_{4}$ ). Assim, a relação C/P utilizada nesse estudo foi (i) em termos de $\mathrm{C}:(822 \cdot 36 / 92) /(5,36 \cdot 31 / 136+1,30 \cdot 31 / 174+2,70 \cdot 31 / 142)=321,7 / 2,04=134,0 \mathrm{gC} / \mathrm{gP} ;$ e (ii) em termos de DQO: $(1000) /(5,36 \cdot 31 / 136+1,30 \cdot 31 / 174+2,70 \cdot 31 / 142)=1000 / 2,04=490,2$ gDQO/gP. 


\subsection{Análises físico-químicas}

O monitoramento do reator foi efetuado medindo-se, em amostras do afluente e do efluente, as concentrações de matéria orgânica nas formas não filtrada $\left(\mathrm{C}_{\mathrm{ST}}\right.$ e $\left.\mathrm{C}_{\mathrm{CT}}\right)$ e filtrada $\left(\mathrm{C}_{\mathrm{SF}}\right.$ e $\mathrm{C}_{\mathrm{CF}}$ ) (como demanda química de oxigênio - método de DQO), alcalinidade parcial (AP), alcalinidade intermediária (AI), alcalinidade total (AT), alcalinidade a bicarbonato (AB), ácidos voláteis totais (AVT), sólidos totais (ST), sólidos totais voláteis (SVT), sólidos suspensos totais (SST) e sólidos suspensos voláteis (SSV), além da medida do $\mathrm{pH}$ e do volume de meio alimentado/descarregado por ciclo $\left(\mathrm{V}_{\mathrm{A}}\right)$. Tais análises foram realizadas de acordo com o Standard Methods for the Examination of Water and Wastewater (1995), considerando também o método proposto por Dilallo e Albertson (1961), o qual foi modificado por Ripley et al. (1986) na determinação da alcalinidade. A Tabela 4.4 apresenta a frequência com que foram realizadas as análises.

Tabela 4.4 - Frequência do monitoramento

\begin{tabular}{cccc}
\hline Análise & Amostra & Frequência & Método \\
\hline DQO & Afluente e Efluente & Diariamente & Standard Methods (1995) \\
Alcalinidade/AVT & Afluente e Efluente & Diariamente & Ripley et al. (1986) \\
Série de sólidos & Afluente e Efluente & 2 vezes por semana & Standard Methods (1995) \\
Ácidos e álcoois & Efluente & 1 vez por condição & Cromatografia gasosa \\
Volume de gás & Saída de gás & Diariamente & Medidor de gás Ritter \\
Composição do gás & Saída de gás & Diariamente & Cromatografia gasosa \\
\hline
\end{tabular}

Os compostos intermediários do metabolismo anaeróbio (solventes: acetona, metanol, etanol, n-butanol; ácidos voláteis: ácidos acético, propiônico, butírico, iso-butírico, valérico, iso-valérico e capróico) foram analisados por cromatografia em fase gasosa com padrão externo (iso-butanol para os solventes e ácido crotônico para os ácidos voláteis) utilizando-se um 
cromatógrafo Hewlett Packard ${ }^{\circledR}$ modelo 7890 equipado com detector de ionização de chama e coluna HP-Innowax com $30 \mathrm{~m} \times 0,25 \mathrm{~mm} \times 0,25 \mu \mathrm{m}$ de espessura do filme. O gás de arraste utilizado foi o hidrogênio com vazão de 1,56 mL. $\mathrm{min}^{-1}$ (velocidade linear constante de 41,8 $\mathrm{cm} . \mathrm{s}^{-1}$ ), a temperatura do injetor foi de $250^{\circ} \mathrm{C}$, a razão de "split" de 10 ("head-space") e o volume de injeção de $400 \mu \mathrm{L}$, utilizando-se injetor automático. A temperatura do forno foi programada da seguinte forma: de $35^{\circ} \mathrm{C}$ à $38^{\circ} \mathrm{C} \mathrm{em} 2^{\circ} \mathrm{C} \cdot \mathrm{min}^{-1}$, de $38^{\circ} \mathrm{C}$ à $75^{\circ} \mathrm{C} \mathrm{em} 10^{\circ} \mathrm{C} \cdot \mathrm{min}^{-1}$, de $75^{\circ} \mathrm{C}$ à $120^{\circ} \mathrm{C}$ em $35^{\circ} \mathrm{C} \cdot \mathrm{min}^{-1}$, em $120^{\circ} \mathrm{C}$ por $1 \mathrm{~min}$, de $120^{\circ} \mathrm{C}$ à $170^{\circ} \mathrm{C}$ em $10^{\circ} \mathrm{C} \cdot \mathrm{min}^{-1}$ e em $170^{\circ} \mathrm{C}$ por 2 min ("head-space”). A temperatura do detector foi de $280^{\circ} \mathrm{C}$ ("head-space”) com fluxo de hidrogênio (combustível) de $30 \mathrm{~mL} \cdot \mathrm{min}^{-1}$, de ar sintético (comburente) de $300 \mathrm{~mL} \cdot \mathrm{min}^{-1}$ e vazão de "make up" de nitrogênio de $30 \mathrm{~mL} \cdot \mathrm{min}^{-1}$. Foi utilizado nessa análise o método por "headspace".

A composição do biogás formado pelo metabolismo anaeróbio (hidrogênio, metano e dióxido de carbono) foi analisada por cromatografia em fase gasosa utilizando-se um cromatógrafo Agilent ${ }^{\circledR}$ modelo 7890 equipado com detector de condutividade térmica e coluna GS-Carbonplot com $30 \mathrm{~m} \times 0,53 \mathrm{~mm} \times 3,0 \mu \mathrm{m}$ de espessura do filme. O gás de arraste utilizado foi o argônio com vazão de 3,67 mL. $\mathrm{min}^{-1}$, a temperatura do injetor foi de $185^{\circ} \mathrm{C}$, a razão de "split" de 10 e o volume de injeção de $200 \mu \mathrm{L}$. A temperatura do forno foi programada em $40^{\circ} \mathrm{C}$ isotérmico em 5 min. A temperatura do detector foi de $150^{\circ} \mathrm{C}$, com vazão de "make up" de argônio de 8,33 $\mathrm{mL} \cdot \mathrm{min}^{-1}$.

A produção total do biogás durante o ciclo $\left(\mathrm{V}_{\mathrm{G}}\right)$ foi quantificada por medidor de gás Ritter modelo Milligas Counter, sendo que tais medições foram realizadas na forma de perfis ao longo do ciclo em medida acumulada de volume. Em cada ciclo essa medição foi feita a cada 30 min. Quando foi feito o perfil, antes que fosse realizada a medição do biogás, foi feita uma limpeza do 
"headspace" do reator (local onde o biogás se acumula antes de ser liberado) com nitrogênio, no intuído de eliminar todo o hidrogênio e dióxido de carbono do último ciclo.

Uma vez quantificada o volume de gás foi necessária à conversão desse volume para as CNTP, ja que o volume depende das condições de operação existentes no momento em que é realizada a medição. A conversão foi feita de acordo com a lei geral dos gases através da Equação (4.1), que se encontra no manual do equipamento, sendo $V_{N}$ o volume nas CNTP, $V_{i} o$ volume de biogás a ser convertido, $\mathrm{P}_{\mathrm{a}}$ a pressão do ar no local da medição, $\mathrm{P}_{\mathrm{V}}$ a pressão parcial de vapor de água, $\mathrm{P}_{\mathrm{L}}$ a pressão da coluna líquida acima da câmara de medição ( 2 mbar), $\mathrm{P}_{\mathrm{N}}$ a pressão normal $\left(1013,25\right.$ mbar), $T_{N}$ a temperatura normal $(273,15 \mathrm{~K})$ e $\mathrm{T}_{\mathrm{a}}$ a temperatura no local da medição.

$$
V_{N}=V_{i} \frac{\left(P_{a}-P_{V}+P_{L}\right)}{P_{N}} \frac{T_{N}}{T_{a}}
$$

Ao final de cada condição experimental foi realizada a quantificação da biomassa no interior do reator. Primeiramente foi feita a drenagem do sistema, sendo verificado o volume de meio líquido do reator $\left(V_{R}\right)$. Em seguida, todo o suporte inerte junto com a biomassa foram retirados do reator e quantificados $\left(\mathrm{M}_{\mathrm{T}-\mathrm{SI}+\mathrm{B}}\right)$, esse material foi homogeneizado e uma amostra (suporte inerte com biomassa) coletada e quantificada $\left(\mathrm{M}_{\mathrm{A}-\mathrm{SI}+\mathrm{B}}\right)$. Posteriormente, a amostra foi lavada do suporte obtendo uma fase sólida apenas com os grânulos de PEBD e uma fase líquida contendo a biomassa. A partir da fase sólida foi realizada a análise de ST e da fase líquida as análises de ST e SVT. Uma vez obtida a quantidade de ST dos grânulos de PEBD (M $\left.\mathrm{M}_{\mathrm{A}-\mathrm{ST}}\right)$ e da quantidade de SVT da amostra $\left(\mathrm{M}_{\mathrm{A}-\mathrm{SVT}}\right)$, foi calculada a quantidade de biomassa do reator e apresentada em três diferentes formas: 
(i) Na quantidade total de biomassa do reator $\left(\mathrm{M}_{\mathrm{SVT}}\right)$, calculada pela Equação (4.2).

$$
M_{S V T}=\frac{M_{A-S V T} \cdot M_{T-S I+B}}{M_{A-S I+B}}
$$

A quantidade total de biomassa do reator $\left(\mathrm{M}_{\mathrm{SVT}}\right)$ permite medir a capacidade do reator na retenção da biomassa. Adicionalmente é uma variável utilizada no cálculo da carga orgânica específica aplicada (COEA), da carga orgânica específica removida (COER) e da produtividade molar específica (PrME);

(ii) Na relação entre a quantidade de biomassa e o volume de meio líquido do reator $\left(\mathrm{C}_{\mathrm{X}}\right)$, calculada pela Equação (4.3).

$$
C_{X}=\frac{M_{S V T}}{V_{R}}
$$

A concentração de biomassa no reator por volume de meio líquido tratado por ciclo $\left(\mathrm{C}_{\mathrm{X}}\right)$ mede a relação entre a quantidade de meio líquido disponível ao tratamento e a biomassa envolvida nas biotransformações inerentes ao processo biológico em estudo;

(iii) Na relação entre a quantidade de biomassa e a quantidade de suporte inerte presente no reator $\left(\mathrm{C}_{\mathrm{X}}{ }^{\prime}\right)$, calculada pela Equação (4.4).

$$
C_{X}^{\prime}=\frac{M_{A-S V T}}{M_{A-S I}}
$$


A concentração de biomassa no reator por massa de suporte inerte presente no reator $\left(C_{X}{ }^{\prime}\right)$ mede a relação entre a quantidade de suporte inerte disponível para a imobilização/retenção da biomassa e a biomassa envolvida nas biotransformações inerentes ao processo biológico em estudo.

Foram retiradas também amostras de biomassa para exame microbiológico do reator alimentado com glicerina bruta. As amostras foram examinadas em lâminas de vidro, por microscopia óptica comum, utilizando o microscópio Olympus ${ }^{\circledR}$ modelo BX41, com sistema de câmera digital Optronics e aquisição de imagens feita pelo software Image Pro-Plus® versão 4.5.0.

\subsection{Fundamentos teóricos}

As eficiências de remoção de matéria orgânica na forma de DQO em amostras filtradas e não filtradas no sistema foram calculadas pelas Equações (4.5) e (4.6), nas quais $\mathrm{C}_{\mathrm{SAFL}}$ é a concentração de matéria orgânica no afluente em amostras não filtradas e $\mathrm{C}_{\mathrm{ST}}$ e $\mathrm{C}_{\mathrm{SF}}$ são as concentrações de matéria orgânica em amostras não filtradas e filtradas, respectivamente, do efluente.

$$
\begin{aligned}
& \varepsilon_{\mathrm{ST}}(\%)=\frac{\mathrm{C}_{\mathrm{SAFL}}-\mathrm{C}_{\mathrm{ST}}}{\mathrm{C}_{\mathrm{SAFL}}} .100 \\
& \varepsilon_{\mathrm{SF}}(\%)=\frac{\mathrm{C}_{\mathrm{SAFL}}-\mathrm{C}_{\mathrm{SF}}}{\mathrm{C}_{\mathrm{SAFL}}} .100
\end{aligned}
$$


A porosidade do leito do reator $(\varphi)$ é definida como o volume de vazios no interior do reator $\left(\mathrm{V}_{\text {Vazios }}\right)$ dividido pelo volume total do reator $\left(\mathrm{V}_{\text {Total }}\right)$, segundo Equação (4.7).

$$
\varphi=\frac{V_{\text {Vazios }}}{V_{\text {Total }}}
$$

A área real utilizada pelo reator $\left(A_{R}\right)$ é igual à multiplicação da área da seção transversal nominal do reator (A) pela porosidade do leito $(\varphi)$, segundo Equação (4.8). O volume real utilizado do reator $\left(\mathrm{V}_{\mathrm{R}}\right)$ é dado pela multiplicação da área real utilizada pelo reator e a altura nominal do reator, segundo Equações (4.9).

$$
\begin{gathered}
A_{R}=\text { A. } \varphi \\
V_{R}=A_{R} \cdot h
\end{gathered}
$$

A velocidade ascensional do líquido no interior do reator (v) é dada pela vazão de recirculação (Q) dividida pela área real utilizada, como mostrado na Equação (4.10).

$$
\mathrm{v}=\frac{Q}{A_{R}}
$$

A carga orgânica volumétrica aplicada (COVA) é definida como sendo a quantidade de matéria orgânica aplicada ao reator por unidade de tempo e por volume de meio do reator $\left(\mathrm{gDQO} . \mathrm{L}^{-1} \cdot \mathrm{d}^{-1}\right)$. Para reatores operados em batelada pode ser calculada pela Equação (4.11), na qual $\mathrm{V}_{\mathrm{A}}$ é o volume de água residuária alimentada no ciclo, $\mathrm{N}$ é o número de ciclos por dia, $\mathrm{C}_{\mathrm{SAFL}}$ é a concentração de matéria orgânica no afluente $e V_{R}$ é o volume de água residuária no reator. 


$$
\operatorname{COVA}=\frac{\left(\mathrm{V}_{\mathrm{A}} \cdot \mathrm{N}\right) \cdot \mathrm{C}_{\mathrm{SAFL}}}{\mathrm{V}_{\mathrm{R}}}
$$

A carga orgânica específica aplicada (COEA) é definida como a quantidade de matéria orgânica aplicada ao reator por unidade de tempo e por massa de sólidos totais voláteis no reator (gDQO.gSVT $\left.{ }^{-1} \cdot \mathrm{d}^{-1}\right)$. Para reatores operados em batelada é calculada pela Equação (4.12).

$$
\mathrm{COEA}=\frac{\left(\mathrm{V}_{\mathrm{A}} \cdot \mathrm{N}\right) \cdot \mathrm{C}_{\mathrm{SAFL}}}{\mathrm{M}_{\mathrm{SVT}}}
$$

A carga orgânica volumétrica removida (COVR), para amostras filtradas, é definida como a quantidade de matéria orgânica removida pelo reator por unidade de tempo e por volume de meio do reator $\left(\mathrm{gDQO} . \mathrm{L}^{-1} \cdot \mathrm{d}^{-1}\right)$. Para reatores operados em batelada é calculada pela Equação (4.13).

$$
\operatorname{COVR}=\frac{\left(\mathrm{V}_{\mathrm{A}} \cdot \mathrm{N}\right) \cdot\left(\mathrm{C}_{\mathrm{SAFL}}-\mathrm{C}_{\mathrm{SF}}\right)}{\mathrm{V}_{\mathrm{R}}}
$$

A carga orgânica específica removida (COER), para amostras filtradas, é definida como a quantidade de matéria orgânica removida pelo reator por unidade de tempo e por massa de sólidos totais voláteis no reator $\left(\mathrm{gDQO} \cdot \mathrm{gSVT}^{-1} \cdot \mathrm{d}^{-1}\right)$. Para reatores operados em batelada é calculada pela Equação (4.14).

$$
\operatorname{COER}=\frac{\left(\mathrm{V}_{\mathrm{A}} \cdot \mathrm{N}\right) \cdot\left(\mathrm{C}_{\mathrm{SAFL}}-\mathrm{C}_{\mathrm{SF}}\right)}{\mathrm{M}_{\mathrm{SVT}}}
$$


A produtividade molar volumétrica $(\mathrm{PrM})$ é definida pela quantidade de hidrogênio $\left(\mathrm{H}_{2}\right)$ produzida por unidade de tempo e por volume útil do reator $\left(\mathrm{molH}_{2} \cdot \mathrm{m}^{-3} \cdot \mathrm{d}^{-1}\right)$, calculada pela Equação (4.15), onde $n_{H 2}$ é a quantidade molar de hidrogênio produzido por dia e $\mathrm{V}_{\mathrm{R}}$ é o volume total de água residuária contida no reator por ciclo.

$$
\operatorname{PrM}=\frac{\mathrm{n}_{\mathrm{H} 2}}{\mathrm{~V}_{\mathrm{R}}}
$$

A produtividade molar específica (PrME) é definida pela quantidade de hidrogênio $\left(\mathrm{H}_{2}\right)$ produzida por unidade de tempo e por massa de sólidos voláteis totais no interior do reator $\left(\mathrm{molH}_{2} \cdot \mathrm{kgSVT}^{-1} \cdot \mathrm{d}^{-1}\right)$, calculada pela Equação (4.16).

$$
\operatorname{PrME}=\frac{\mathrm{n}_{\mathrm{H} 2}}{\mathrm{M}_{\mathrm{SVT}}}
$$

O rendimento entre hidrogênio (molar) produzido e matéria orgânica (massa) aplicada (RMCA) é definido pela quantidade de hidrogênio $\left(\mathrm{H}_{2}\right)$ produzida (em mol) pela quantidade de matéria orgânica aplicada (em massa) $\left(\mathrm{molH}_{2} \cdot \mathrm{kgDQO}^{-1}\right)$, calculado pela Equação (4.17).

$$
\mathrm{RMCA}=\frac{\mathrm{n}_{\mathrm{H} 2}}{\mathrm{~N} \cdot \mathrm{V}_{\mathrm{A}} \cdot \mathrm{C}_{\mathrm{SAFL}}}
$$

O rendimento entre o hidrogênio molar produzido e a matéria orgânica removida em massa (RMCR) é definido pela quantidade de hidrogênio $\left(\mathrm{H}_{2}\right)$ produzida pela quantidade de matéria orgânica removida $\left(\mathrm{molH}_{2} \cdot \mathrm{kgDQO}^{-1}\right)$, calculada segundo Equação (4.18). 


$$
\mathrm{RMCR}=\frac{\mathrm{n}_{\mathrm{H} 2}}{\mathrm{~N} \cdot \mathrm{V}_{\mathrm{A}} \cdot\left(\mathrm{C}_{\mathrm{SAFL}}-\mathrm{C}_{\mathrm{SF}}\right)}
$$

A quantidade de glicerina consumida na forma de DQO foi calculada através do balanço de massa em DQO do sistema, como é apresentado nas equações (4.19), (4.20), (4.21), (4.22).

$$
\begin{gathered}
\mathrm{DQO}_{\text {Afluente }}-\mathrm{DQO}_{\text {Efluente }}=\mathrm{DQO}_{\text {Consumida }} \\
\mathrm{DQO}_{\mathrm{Glicerina} \mathrm{total}}-\left(\mathrm{DQO}_{\mathrm{Glicerina} \text { não consumida }}+\mathrm{DQO}_{\mathrm{PI}}\right)=\mathrm{DQO} \text { Consumida } \\
\mathrm{DQO}_{\mathrm{Glicerina} \text { consumida }}=\mathrm{DQO}_{\text {Consumida }}+\mathrm{DQO}_{\mathrm{PI}} \\
\mathrm{DQO}_{\text {glicerina consumida }}=\mathrm{DQO}_{\mathrm{Afl}}-\mathrm{DQO}_{\mathrm{Efl}}+\mathrm{DQO}_{\mathrm{PI}}
\end{gathered}
$$

O equivalente em DQO dos produtos intermediários foi calculado a partir das equações bioquímicas apresentadas na Tabela 4.5 .

Tabela 4.5 - Equações bioquímicas e equivalente-grama dos compostos em DQO

\begin{tabular}{ccc}
\hline Componente & Equação bioquímica & $\begin{array}{c}\text { Equivalente- } \\
\text { grama }(\mathbf{g O} / \mathbf{g})\end{array}$ \\
\hline Glicerol & $\mathrm{C}_{3} \mathrm{H}_{8} \mathrm{O}_{3}+\frac{7}{2} \mathrm{O}_{2} \rightarrow 3 \mathrm{CO}_{2}+4 \mathrm{H}_{2} \mathrm{O}$ & 1,217 \\
Etanol & $\mathrm{C}_{2} \mathrm{H}_{6} \mathrm{O}+2 \mathrm{O}_{2} \rightarrow 2 \mathrm{CO}_{2}+3 \mathrm{H}_{2} \mathrm{O}$ & 1,391 \\
n-Butanol & $\mathrm{C}_{4} \mathrm{H}_{10} \mathrm{O}+6 \mathrm{O}_{2} \rightarrow 4 \mathrm{CO}_{2}+5 \mathrm{H}_{2} \mathrm{O}$ & 2,590 \\
Ácido acético & $\mathrm{CH}_{3} \mathrm{COOH}+2 \mathrm{O}_{2} \rightarrow 2 \mathrm{CO}_{2}+2 \mathrm{H}_{2} \mathrm{O}$ & 1,006 \\
Ácido propiônico & $\mathrm{CH}_{3} \mathrm{CH}_{2} \mathrm{COOH}+\frac{7}{2} \mathrm{O}_{2} \rightarrow 3 \mathrm{CO}_{2}+3 \mathrm{H}_{2} \mathrm{O}$ & 1,514 \\
Ácido isobutírico & $\mathrm{CH}_{3} \mathrm{CH}_{2} \mathrm{CH}_{2} \mathrm{COOH}+5 \mathrm{O}_{2} \rightarrow 4 \mathrm{CO}_{2}+4 \mathrm{H}_{2} \mathrm{O}$ & 1,818 \\
Ácido butírico & $\mathrm{CH}_{3} \mathrm{CH}_{2} \mathrm{CH}_{2} \mathrm{COOH}+5 \mathrm{O}_{2} \rightarrow 4 \mathrm{CO}_{2}+4 \mathrm{H}_{2} \mathrm{O}$ & 1,818 \\
Ácido valérico & $\mathrm{CH}_{3} \mathrm{CH}_{2} \mathrm{CH}_{2} \mathrm{CH}_{2} \mathrm{COOH}+\frac{13}{2} \mathrm{O}_{2} \rightarrow 5 \mathrm{CO}_{2}+5 \mathrm{H}_{2} \mathrm{O}$ & 2,036 \\
Ácido iso-valérico & $\mathrm{CH}_{3} \mathrm{CH}_{2} \mathrm{CH}_{2} \mathrm{CH}_{2} \mathrm{COOH}+\frac{13}{2} \mathrm{O}_{2} \rightarrow 5 \mathrm{CO}_{2}+5 \mathrm{H}_{2} \mathrm{O}$ & 2,036 \\
Ácido capróico & $\mathrm{CH}_{3} \mathrm{CH}_{2} \mathrm{CH}_{2} \mathrm{CH}_{2} \mathrm{CH}{ }_{2} \mathrm{COOH}+8 \mathrm{O}_{2} \rightarrow 6 \mathrm{CO}_{2}+6 \mathrm{H}_{2} \mathrm{O}$ & 2,196 \\
Biomassa & $\mathrm{C}_{5} \mathrm{H}_{9} \mathrm{O}_{3} \mathrm{~N}+\frac{11}{2} \mathrm{O}_{2} \rightarrow 5 \mathrm{CO}_{2}+\frac{9}{2} \mathrm{H}_{2} \mathrm{O}$ & 1,343 \\
\hline
\end{tabular}


A partir da quantidade de glicerina consumida na forma de DQO, foi calculado o fator de rendimento entre hidrogênio produzido e glicerina consumida $\left(\mathrm{Y}_{\mathrm{H} 2}\right)$ em $\mathrm{molH}_{2} \cdot \mathrm{molGC}$. Para este efeito o valor de glicerina consumida em DQO foi convertido em concentração molar de glicerina consumida $\left(\mathrm{C}_{\mathrm{GC}}\right)$. $\mathrm{O}$ fator $\mathrm{Y}_{\mathrm{H} 2}$ foi calculado dividindo a produtividade molar $\operatorname{PrM}$ em $\mathrm{molH}_{2} \cdot \mathrm{L}^{-}$ ${ }^{1} \cdot \mathrm{d}^{-1}$ pelo o consumo molar diário de glicerina $\left(\mathrm{C}_{\mathrm{GC}}\right)$ em molGC. $\mathrm{L}^{-1} \cdot \mathrm{d}^{-1}$, como é apresentado na Equação (4.23).

$$
\mathrm{Y}_{\mathrm{H} 2}=\frac{\operatorname{PrM}}{\mathrm{C}_{\mathrm{GC}}}
$$

$\mathrm{O}$ rendimento entre o hidrogênio molar produzido e o substrato consumido na forma de DQO equivalente (RMSC) é definido pela quantidade de hidrogênio $\left(\mathrm{H}_{2}\right)$ produzida pela quantidade de substrato consumido na forma de DQO $\left(\mathrm{molH}_{2} \cdot \mathrm{kgDQO}_{\mathrm{GC}}{ }^{-1}\right)$, calculado pela Equação (4.24), onde PM é o peso em gramas de uma mol do substrato e EG é o equivalente grama de oxigênio por grama de substrato.

$$
\mathrm{RMSC}=\frac{\mathrm{Y}_{\mathrm{H} 2}}{\mathrm{PM} . \mathrm{EG}}
$$

Na Tabela 4.6 são apresentados os rendimentos molares de hidrogênio por carga orgânica aplicada em glicerina considerando as principais rotas metabólicas. Os rendimentos molares teóricos apresentados foram comparados com os experimentais, obtendo-se os desempenhos porcentuais de produção molar. 
Tabela 4.6 - Rendimentos molares por carga aplicada potenciais por vias biológicas.

\begin{tabular}{|c|c|c|c|}
\hline Metabólito & Rota Metabólica & $\begin{array}{c}\text { RMCA teórico } \\
\text { molH }_{2} \cdot \text { molglicerina }\end{array}$ & $\begin{array}{c}\text { RMCA teórico } \\
\text { molH }_{2} \cdot \text { kgglicerina }\end{array}$ \\
\hline Ácido Acético & $\mathrm{C}_{3} \mathrm{H}_{8} \mathrm{O}_{3}+\mathrm{H}_{2} \mathrm{O} \rightarrow \mathrm{CH}_{3} \mathrm{COOH}+\mathrm{CO}_{2}+3 \mathrm{H}_{2}$ & 3 & 32,6 \\
\hline Ácido Butírico & $2 \mathrm{C}_{3} \mathrm{H}_{8} \mathrm{O}_{3} \rightarrow \mathrm{C}_{4} \mathrm{H}_{8} \mathrm{O}_{2}+2 \mathrm{CO}_{2}+4 \mathrm{H}_{2}$ & 2 & 21,7 \\
\hline
\end{tabular}

\subsection{Procedimento experimental da operação do reator}

A operação do reator foi realizada da seguinte maneira: no final do ciclo eram descarregados 1,5 L de meio em 10 min e 2,17 L de meio (volume residual) eram mantidos no reator, sendo o volume total de meio no sistema de 3,67 L. Logo após a descarga, um novo ciclo tinha início alimentando o reservatório com 1,5 L em 10 minutos. Na sequência depois a recirculação era ligada. Ao término do ciclo, a recirculação era interrompida e, em seguida, iniciava-se a descarga e, assim, o ciclo era repetido, caracterizando as bateladas sequenciais. $\mathrm{Na}$ Tabela 4.7 apresentam-se os parâmetros operacionais do biorreator.

Tabela 4.7 - Parâmetros operacionais do biorreator.

\begin{tabular}{cc}
\hline Parâmetro & Valor \\
\hline Volume da fase líquida (reator e reservatório) & $3,67 \mathrm{~L}$ \\
Volume do inóculo com suporte inerte (reator) & $1,6 \mathrm{~L}$ \\
Volume da fase líquida (reator) & $2,0 \mathrm{~L}$ \\
Volume da fase líquida (reservatório) & $1,67 \mathrm{~L}$ \\
Volume alimentado/descarregado por ciclo (reservatório) & $1,5 \mathrm{~L}$ \\
Volume da fase líquida residual entre ciclos (reator) & $2,17 \mathrm{~L}$ \\
Tempo total de ciclo & $4 \mathrm{~h}, 3 \mathrm{~h}$ \\
Tempo de alimentação & $10 \mathrm{~min}$ \\
Tempo de descarga & $10 \mathrm{~min}$ \\
Vazão da recirculação & $10,20 \mathrm{e} 30 \mathrm{~L} \cdot \mathrm{h}^{-1}$ \\
Volume do inóculo & $0,15 \mathrm{~L}$ \\
\hline
\end{tabular}


A presente pesquisa foi dividida em três fases de ensaios na sequência: 1) Fase preliminar, 2) Fase de experimentação e 3) Fase final. Cada fase é detalhada a seguir.

\subsubsection{Fase preliminar}

A denominada "Fase preliminar" foi composta por cinco etapas, cada uma com objetivos específicos, tanto como etapa individual quanto como conjunto. Cada etapa começou com a inoculação do suporte e continuou com a variação de diversas condições que são especificadas na Figura 4.4. Para todas as etapas utilizou-se a agua residuária exposta na Tabela 4.3 com algumas modificações como variáveis de estudo. A velocidade de recirculação foi modificada durante as etapas, operando a $20 \mathrm{~L} \cdot \mathrm{h}^{-1}$ durante a primeira etapa $\left(\mathrm{v}=7,05 \mathrm{~m} \cdot \mathrm{h}^{-1}\right)$, a $10 \mathrm{~L} \cdot \mathrm{h}^{-1}\left(\mathrm{v}=3,53 \mathrm{~m} \cdot \mathrm{h}^{-1}\right)$ durante as etapas dois, três e quatro, e a $30 \mathrm{~L}^{-\mathrm{h}^{-1}}\left(\mathrm{v}=10,58 \mathrm{~m} \cdot \mathrm{h}^{-1}\right)$ durante a etapa cinco. No começo da etapa cinco, os grânulos de PEBD foram submetidos a um pré-tratamento físico colocando lhes no liquidificador por 30 segundos para aumentar a superfície de contato.

É importante destacar que as etapas foram realizadas de forma consecutiva com base nos resultados atingidos na etapa prévia. Assim, a etapa dois foi planejada com base nos resultados obtidos na etapa um, a etapa três com base na etapa dois e assim sucessivamente. Na Figura 4.4 apresenta-se um diagrama que especifica todas as ações feitas em cada etapa. Como foi mencionado anteriormente, antes do começo de cada etapa, o reator foi desmontado, lavado e novamente inoculado. 

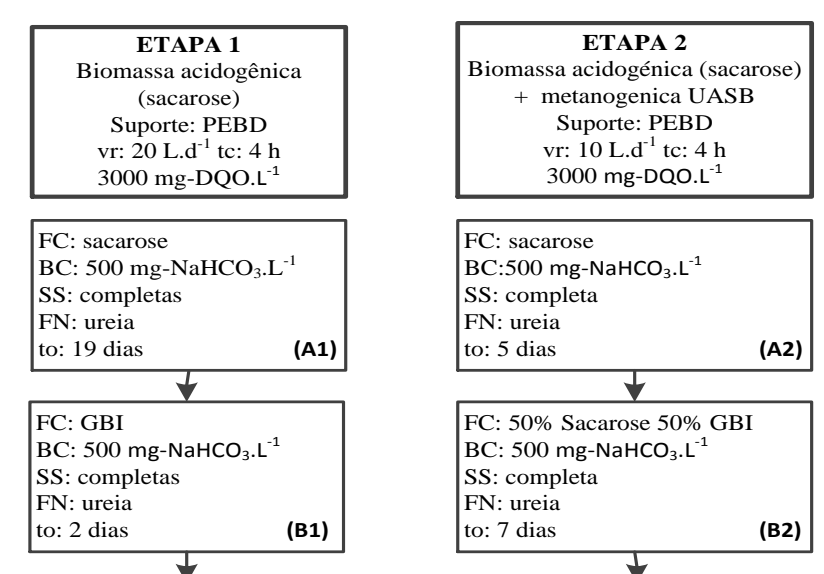

\begin{tabular}{|l|}
\hline FC: GBI \\
BC: 200 mg-NaHCO \\
SS: completas \\
FN: ureia \\
to: 2 dias \\
\hline
\end{tabular}

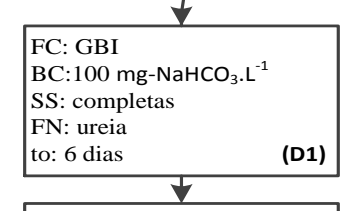

\begin{tabular}{|l|}
\hline FC: GBI \\
BC: sem $\mathrm{NaHCO}_{3}$ \\
SS: sem sais \\
FN: ureia \\
to: 7 dias \\
\hline
\end{tabular}

$$
\begin{aligned}
& \text { FC: } \mathrm{GBI} \\
& \text { BC: } \mathrm{sem} \mathrm{NaHCO}_{3} \\
& \text { SS: sem enxofre } \\
& \text { FN: ureia }
\end{aligned}
$$

to: 7 dias

\section{FC:GBL \\ BC: sem $\mathrm{NaHCO}_{3}$ \\ SS: sem enxofre}

FN: nenhum
to: 1 dias

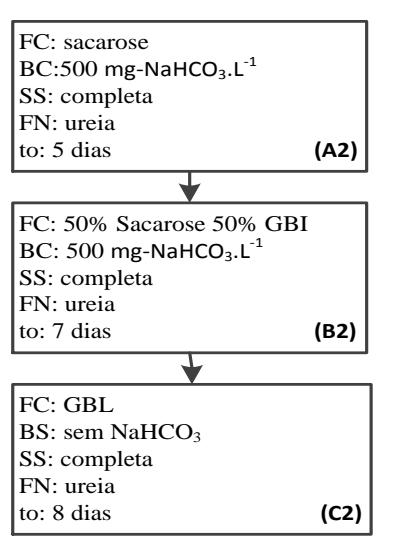
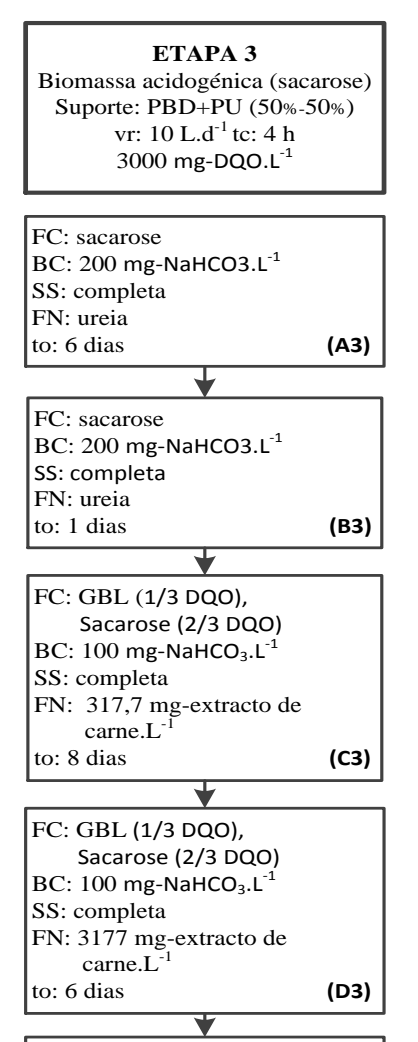

\begin{tabular}{|l|}
\hline FC: GPA (1/3 DQO), \\
Sacarose (2/3 DQO) \\
BC: $100 \mathrm{mg}-\mathrm{NaHCO} . \mathrm{L}^{-1}$ \\
SS: completa \\
FN: $3177 \mathrm{mg}$-extracto de \\
carne.. \\
to: 4 dias \\
\hline
\end{tabular}

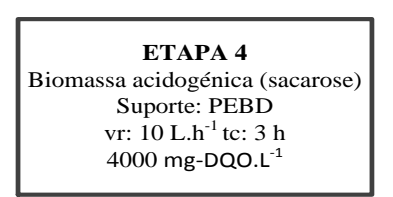

FC: sacarose 50\% GPA 50\%

FC: $100 \mathrm{mg}-\mathrm{NaHCO}_{3} \cdot \mathrm{L}^{-1}$

SS: completa

FN: ureia

to: 9 dia

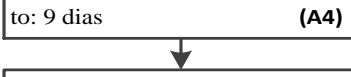

FC: GPA

BC: $100 \mathrm{mg}-\mathrm{NaHCO}_{3} \cdot \mathrm{L}^{-1}$

SS: completa

FN: ureia
to: 2 dias

(B4)

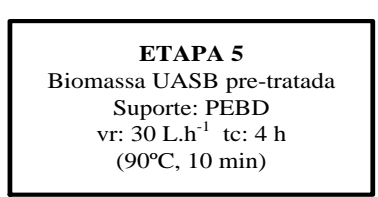

FC: GPA (1000 mg-DQO..-1 $)$ BC: $100 \mathrm{mg}-\mathrm{NaHCO}_{3} \cdot \mathrm{L}^{-1}$

SS: completa

FN: ureia

to: 8 dias (A5)

FC: GPA (2000 mg-DQO..-1)

BC: $100 \mathrm{mg}-\mathrm{NaHCO}_{3} \cdot \mathrm{L}^{-1}$

SS: completa

to: 2 dias

(B5)

Figura 4.4 - Etapas da "Fase preliminar". Notaçao: FC: fonte de carbono, BC: concentração de bicarbonato, SS: solução de sais da Tabela 4.3, FN: fonte de nitrogênio. 
A "Fase preliminar" permitiu estudar o efeito das variáveis que são apresentadas na Tabela 4.8. A partir dos resultados atingidos nesta fase foram estabelecidas as condições experimentais da fase seguinte, denominada de "Fase preliminar".

Tabela 4.8 - Variáveis estudadas na "Fase preliminar".

\begin{tabular}{|c|c|}
\hline Variável & Tratamento \\
\hline Tipo de glicerina & $\begin{array}{ll}\text { - } & \text { Glicerina bruta industrial. } \\
\text { - } & \text { Glicerina bruta de laboratório. } \\
\text { - } & \text { Glicerol-PA. }\end{array}$ \\
\hline Tempo de ciclo & $\begin{array}{l}\text { - } \quad 4 \mathrm{~h} \\
\text { - } \quad 3 \mathrm{~h}\end{array}$ \\
\hline $\begin{array}{l}\text { Concentração de DQO } \\
\text { no afluente }\end{array}$ & $\begin{array}{l}\text { - } 3000 \text { e } 4000 \mathrm{mgDQO} . \mathrm{L}^{-1} \text { de glicerina bruta de laboratório. } \\
\text { - } 1000 \text { e } 2000 \mathrm{mgDQO} . \mathrm{L}^{-1} \text { de glicerol-PA. }\end{array}$ \\
\hline Inóculo & $\begin{array}{l}\text { - Biomassa acidogênica proveniente de um AnSBBR operado } \\
\text { com sacarose. } \\
\text { - Biomassa anterior misturada com biomassa de UASB do } \\
\text { tratamento de água residuária de abatedouro de aves. } \\
\text { - Biomassa UASB pre-tratada termicamente }\left(90^{\circ} \mathrm{C} \text { durante } 10\right. \\
\text { min.) }\end{array}$ \\
\hline Outros & $\begin{array}{l}\text { - Efeito do pH do afluente e do efluente. } \\
\text { - Efeito da concentração de bicarbonato de sódio. } \\
\text { - Efeito do enxofre e dos sais completos na água residuária } \\
\text { sintética. } \\
\text { - Efeito do suporte. } \\
\text { - Velocidade de recirculação. }\end{array}$ \\
\hline
\end{tabular}

\subsubsection{Fase de experimentação}

A denominada "Fase de experimentação" foi planejada com base nos resultados obtidos na última etapa (Etapa 5) da "Fase preliminar". A biomassa utilizada em toda esta fase foi obtida a partir do tratamento térmico $\left(90^{\circ} \mathrm{C}\right.$ durante 10 minutos $)$ aplicado à biomassa do UASB tratando 
água residuária do abatedouro de aves. Para cada condição testada, o suporte foi esterilizado em autoclave a $120^{\circ} \mathrm{C}$ durante 15 minutos e posteriormente inoculado e recolocado no reator.

Durante a "Fase de experimentação" dois tempos de ciclo ( 3 e 4 h) e três concentrações de DQO foram ensaiadas, em um total seis condições experimentais que são apresentadas na Tabela 4.9. A velocidade de recirculação do liquido foi de $3 \mathrm{~L}^{-h^{-1}}$. As condições experimentais foram desenvolvidas na ordem exposta.

Tabela 4.9 - Resumo das condições estudadas na "Fase de experimentação".

\begin{tabular}{|c|c|c|c|c|}
\hline Condição & $\begin{array}{c}\text { Concentração afluente } \\
\left(\mathrm{mg.L}^{-1}\right)\end{array}$ & $\begin{array}{l}\text { Tempo de ciclo } \\
\text { (h) }\end{array}$ & $\begin{array}{l}\text { Número de ciclos } \\
\quad\left(\text { Ciclos.d }^{-1}\right)\end{array}$ & $\begin{array}{c}\text { COVA } \\
\left(\text { gDQO.L }^{-1} \cdot \mathrm{d}^{-1}\right)\end{array}$ \\
\hline I & 3000 & 4 & 6 & 7,7 \\
\hline II & 4000 & 4 & 6 & 10,3 \\
\hline III & 5000 & 4 & 6 & 12,9 \\
\hline IV & 3000 & 3 & 8 & 10,3 \\
\hline V & 4000 & 3 & 8 & 13,7 \\
\hline VI & 5000 & 3 & 8 & 17,1 \\
\hline
\end{tabular}
Obs.: $\mathrm{V}_{\mathrm{A}}=1,5 \mathrm{~L} ; \mathrm{V}_{\mathrm{R}}=3,67 \mathrm{~L}$

Uma vez atingida a estabilidade nas condições experimentais, foram obtidos perfis ao longo do ciclo de operação. Nestes perfis foram retiradas amostras $(25 \mathrm{~mL})$ ao longo do tempo de operação de um ciclo (na primeira meia hora e depois a cada hora). As variáveis de interesse foram: concentrações de matéria orgânica na forma filtrada, de alcalinidade a bicarbonato, de ácidos voláteis totais, de metabólitos intermediários (acetona, ácidos voláteis e álcoois), de biogás (composição e produção), além do pH. Desta forma, foi possível obter uma melhor compreensão das rotas metabólicas ao longo de um ciclo. 


\subsubsection{Fase final}

Uma vez terminada a "Fase de experimentação" foi determinada a condição denominada de “ótima”, na qual ocorreu maior produção de hidrogênio com relação à produtividade molar volumétrica (PrM), à produtividade molar específica (PrME), ao rendimento entre hidrogênio (molar) produzido e matéria orgânica (massa) aplicada (RMCA) e ao rendimento entre hidrogênio (molar) produzido e matéria orgânica (massa) removida (RMCR).

Esta condição "ótima" foi repetida mais duas vezes na denominada "Fase final”, uma das quais utilizando glicerina bruta como fonte de carbono e a outra utilizando o inóculo proveniente do UASB do tratamento de abatedouro de aves sem pré-tratamento térmico.

Assim, esta fase teve o objetivo de determinar a influência na produção de hidrogênio do tipo de glicerina como substrato (glicerina bruta ou glicerol-PA) e do pré-tratamento térmico da biomassa.

Na Figura 4.5. é apresentado um diagrama que explica a lógica seguida durante todo o projeto para melhor entendimento geral do estudo. 


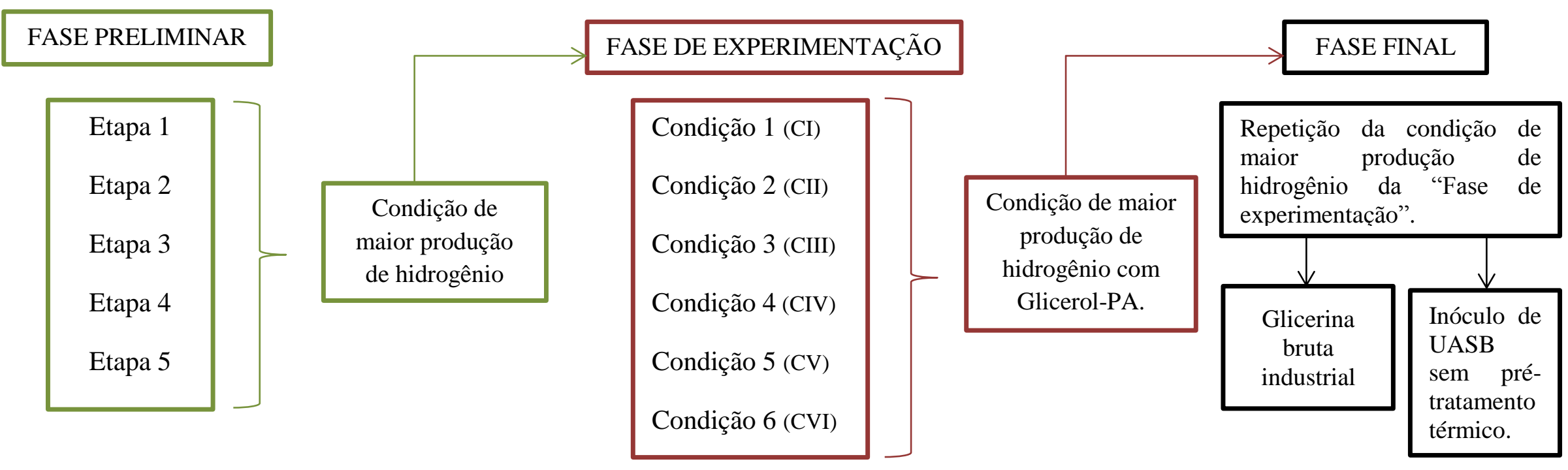

\section{Características:}

Fonte de carbono: GBI, GBL e GPA.

Inóculo: acidogênico e de reator UASB sem pré-tratamento.

Sacarose como fonte de carbono nos primeiros dias de operação do reator das primeiras quatro etapas.

Características:
Fonte de carbono: GPA.
Inóculo: biomassa de reator UASB
pré-tratado termicamente.
GPA como única fonte de carbono
durante toda a experimentação.

Características:

Fonte de carbono: GBI e GPA.

Inóculo: biomassa pré-tratada e não pré-tratada terminacamente.

Glicerina como única fonte de carbono durante toda a experimentação.

Figura 4.5 - Sequência lógica seguida durante o desenvolvimento do projeto. 


\section{RESULTADOS E DISCUSSÃO}

\subsection{Fase preliminar}

A fase preliminar foi dividida em cinco etapas, cada uma com suas condições experimentais identificadas com letras e números, como se observa na Figura 4.4 e como foi explicado no capítulo anterior. As primeiras condições das etapas que foram usadas sacarose e mistura de sacarose com glicerina, tiveram unicamente a função de enriquecer e pré-adaptar a biomassa ao substrato, e não quantificar sua produção de hidrogênio. Por essa razão, no presente capítulo são apresentados e discutidos unicamente os valores correspondentes às médias dos parâmetros monitorados e às produtividades de hidrogênio calculadas a partir das condições experimentais nas quais foram usadas glicerina como única fonte de carbono. Os resultados são apresentados em sua totalidade nos Anexos I, II, III, IV, V e VI.

Na Tabela 5.1 são apresentadas as médias dos parâmetros monitorados. A partir desses valores foram calculados os indicadores de eficiência na produção de hidrogênio que são apresentados na Tabela 5.2. Com base nos cálculos e nos valores monitorados, foram estudadas as variáveis especificadas nas Tabelas 4.8 e 4.9 e, finalmente, determinadas as melhores condições para serem usadas na fase seguinte da pesquisa.

Para facilitar a análise dos resultados, apresentam-se na Figura 5.1 as médias calculadas a partir dos valores das variáveis de estudo conjuntamente com a produtividade molar de hidrogênio para cada condição. Na Figura 5.2 são apresentados tanto a produtividade molar de hidrogênio quanto os rendimentos por matéria orgânica aplicada e removida das etapas em estudo. 
Tabela 5.1 - Valores médios dos parâmetros monitorados na "Fase preliminar".

\begin{tabular}{|c|c|c|c|c|c|c|c|c|c|c|c|c|c|c|c|c|c|c|c|c|c|c|c|c|c|}
\hline & & \multicolumn{4}{|c|}{ Afluente } & \multicolumn{4}{|c|}{ Efluente } & \multicolumn{4}{|c|}{ Afluente } & \multicolumn{4}{|c|}{ Efluente } & \multicolumn{3}{|c|}{ Afluente } & \multicolumn{5}{|c|}{ Efluente } \\
\hline $\mathbf{C}_{\mathrm{ST}}$ & $\left(\mathrm{mgDQO} \cdot \mathrm{L}^{-1}\right)$ & 3344 & (2) & \pm & 57 & 2144 & (2) & \pm & 114 & 3449 & (2) & \pm & 0 & 2237 & (2) & \pm & 169 & 3044 & (3) & \pm & 94 & 2012 & (3) & \pm & 160 \\
\hline $\mathbf{C}_{\mathrm{SF}}$ & $\left(\operatorname{mgDQO} \cdot \mathrm{L}^{-1}\right)$ & - & & & - & 1882 & (2) & & 109 & - & & & - & 1910 & (2) & & 70 & - & & & - & 1690 & (3) & & 35 \\
\hline pH & (u) & 7,86 & (2) & \pm & 0,06 & 6,34 & (2) & \pm & 0,23 & 7,73 & (2) & \pm & 0,21 & 5,75 & (2) & \pm & 0,42 & 7,72 & (3) & \pm & 0,15 & 5,34 & (3) & \pm & 0,22 \\
\hline AVT & $\left(\operatorname{mgHAc} . \mathrm{L}^{-1}\right)$ & 105 & (2) & \pm & 3 & 285 & (2) & \pm & 109 & 96 & (2) & \pm & 4 & 397 & (2) & \pm & 0 & 95 & (3) & \pm & 6 & 379 & (3) & \pm & 42 \\
\hline AT & $\left(\mathrm{mgCaCO}_{3} \cdot \mathrm{L}^{-1}\right)$ & 473 & (2) & \pm & 3 & 345 & (2) & \pm & 8 & 283 & (2) & \pm & 35 & 207 & (2) & \pm & 31 & 255 & (3) & \pm & 32 & 152 & (3) & \pm & 11 \\
\hline $\mathbf{A P}$ & $\left(\mathrm{mgCaCO}_{3} \cdot \mathrm{L}^{-1}\right)$ & 334 & (2) & \pm & 11 & 104 & (2) & \pm & 19 & 201 & (2) & \pm & 52 & 11 & (2) & \pm & 16 & 185 & (3) & \pm & 22 & 0 & (3) & \pm & 0 \\
\hline AI & $\left(\mathrm{mgCaCO}_{3} \cdot \mathrm{L}^{-1}\right)$ & 139 & (2) & \pm & 8 & 245 & (2) & \pm & 28 & 82 & (2) & \pm & 17 & 196 & (2) & \pm & 15 & 70 & (3) & \pm & 10 & 152 & (3) & \pm & 11 \\
\hline $\mathbf{A B}$ & $\left(\mathrm{mgCaCO}_{3} \cdot \mathrm{L}^{-1}\right)$ & 398 & (2) & \pm & 5 & 0 & (2) & \pm & 0 & 214 & (2) & \pm & 32 & 0 & (2) & \pm & 0 & 188 & (3) & \pm & 29 & 0 & (3) & \pm & 0 \\
\hline $\mathbf{V}_{\mathbf{G}}$ & $\left(\right.$ mL-CNTP.ciclo $\left.{ }^{-1}\right)$ & - & & & - & 46 & (2) & \pm & 22 & - & & & - & 37 & (2) & \pm & 2 & - & & & - & 68 & (2) & \pm & 9 \\
\hline \multirow[t]{2}{*}{$\mathbf{V}_{\mathbf{A}}$} & (L) & 1,5 & (1) & \pm & - & - & & & - & 1,5 & (2) & \pm & 0,007 & - & & & - & 1,5 & & \pm & 0,03 & - & & & - \\
\hline & & \multicolumn{8}{|c|}{ E1 } & \multicolumn{8}{|c|}{ F1 } & \multicolumn{8}{|c|}{ G1 } \\
\hline $\mathrm{C}_{\mathrm{ST}}$ & $\left(\mathrm{mgDQO} \cdot \mathrm{L}^{-1}\right)$ & 3038 & (3) & \pm & 70 & 2068 & (3) & \pm & 70 & 3016 & (3) & \pm & 156 & 2159 & (3) & \pm & 222 & 3250 & (1) & & - & 1761 & (1) & & - \\
\hline $\mathbf{C}_{\mathrm{SF}}$ & $\left(\mathrm{mgDQO} . \mathrm{L}^{-1}\right)$ & & & & & 1724 & (3) & & 95 & & & & & 19134 & (3) & & 114 & & (1) & & - & 1646 & (1) & & - \\
\hline pH & (u) & 7,42 & (3) & \pm & 0,33 & 4,70 & (3) & \pm & 0,14 & 7,49 & (3) & \pm & 0,27 & 4,39 & (3) & \pm & 0,25 & 10,2 & (1) & & - & 4,20 & (1) & & - \\
\hline AVT & $\left(\mathrm{mgHAc} . \mathrm{L}^{-1}\right)$ & 81 & (3) & \pm & 8 & 384 & (3) & \pm & 17 & 73 & (3) & \pm & 8 & 406 & (3) & \pm & 11 & 27 & (1) & & - & 456 & (1) & & - \\
\hline AT & $\left(\mathrm{mgCaCO}_{3} \cdot \mathrm{L}^{-1}\right)$ & 124 & (3) & \pm & 22 & 65 & (3) & \pm & 24 & 118 & (3) & \pm & 26 & 30 & (3) & \pm & 27 & 116 & (1) & & - & 0 & (1) & & - \\
\hline AP & $\left(\mathrm{mgCaCO}_{3} \cdot \mathrm{L}^{-1}\right)$ & 96 & (3) & \pm & 15 & 0 & (3) & \pm & 0 & 82 & (3) & \pm & 14 & 0 & (3) & \pm & 0 & 101 & (1) & & - & 0 & (1) & & - \\
\hline AI & $\left(\mathrm{mgCaCO}_{3} \cdot \mathrm{L}^{-1}\right)$ & 28 & (3) & \pm & 7 & 65 & (3) & \pm & 24 & 36 & (3) & \pm & 14 & 30 & (3) & \pm & 27 & 15 & (1) & & - & 0 & (1) & & - \\
\hline AB & $\left(\mathrm{mgCaCO}_{3} \cdot \mathrm{L}^{-1}\right)$ & 67 & (3) & \pm & 17 & 0 & (3) & \pm & 0 & 66 & (3) & \pm & 21 & 0 & (3) & \pm & 0 & 97 & (1) & & - & 0 & (1) & & - \\
\hline $\mathbf{V}_{\mathbf{G}}$ & $\left(\mathrm{mL}-\mathrm{CNTP} \cdot \mathrm{ciclo}^{-1}\right)$ & - & & & & 15 & (2) & \pm & 18 & & & & & 21 & (3) & & 25 & - & & & & 26 & (1) & & - \\
\hline \multirow[t]{2}{*}{$\mathbf{V}_{\mathbf{A}}$} & (L) & 1,5 & (3) & & 0,01 & - & & & - & 1,5 & (4) & & 0,02 & - & & & - & 1,6 & (1) & & - & - & & & - \\
\hline & & \multicolumn{8}{|c|}{$\mathrm{C} 2$} & & & & & & & & & & & & & & & & \\
\hline $\mathrm{C}_{\mathrm{ST}}$ & $\left(\mathrm{mgDQO} \cdot \mathrm{L}^{-1}\right)$ & 3161 & (6) & \pm & 326 & 1984 & (6) & \pm & 289 & 3882 & (1) & & - & 3783 & (1) & & - & 1005 & (3) & \pm & 98 & 792 & (3) & \pm & 25 \\
\hline $\mathbf{C}_{\mathrm{SF}}$ & $\left(\operatorname{mgDQO} . L^{-1}\right)$ & & & & & 1583 & (6) & & 149 & & & & - & 3702 & (1) & & - & & & & & 761 & & & 23 \\
\hline pH & (u) & 9,51 & (6) & \pm & 0,19 & 4,64 & (6) & \pm & 0,18 & 7,53 & (1) & & - & 4,85 & (1) & & - & 7,58 & (3) & \pm & 0,1 & 7,09 & (3) & \pm & 0,11 \\
\hline AVT & $\left(\right.$ mgHAc. $\left.\mathrm{L}^{-1}\right)$ & 39 & (6) & \pm & 10 & 377 & (6) & \pm & 42 & 16 & (1) & & - & 156 & (1) & & - & 15 & (3) & \pm & 0,6 & 82 & (3) & \pm & 10 \\
\hline AT & $\left(\mathrm{mgCaCO}_{3} \cdot \mathrm{L}^{-1}\right)$ & 162 & (6) & \pm & 17 & 63 & (6) & \pm & 24 & 123 & (1) & & - & 56 & (1) & & - & 145 & (3) & \pm & 16 & 127 & (3) & \pm & 3 \\
\hline $\mathbf{A P}$ & $\left(\mathrm{mgCaCO}_{3} \cdot \mathrm{L}^{-1}\right)$ & 133 & (6) & \pm & 14 & 0 & (6) & \pm & 0 & 88 & (1) & & - & 0 & (1) & & - & 108 & (3) & \pm & 12 & 56 & (3) & \pm & 4 \\
\hline AI & $\left(\mathrm{mgCaCO}_{3} \cdot \mathrm{L}^{-1}\right)$ & 29 & (6) & \pm & 5 & 63 & (6) & \pm & 24 & 35 & (1) & & - & 56 & (1) & & - & 38 & (3) & \pm & 4 & 71 & (3) & \pm & 5 \\
\hline $\mathbf{A B}$ & $\left(\mathrm{mgCaCO}_{3} \cdot \mathrm{L}^{-1}\right)$ & 134 & (6) & \pm & 17 & 0 & (6) & \pm & 0 & 112 & (1) & & - & 0 & (1) & & - & 135 & (3) & \pm & 16 & 68 & (3) & \pm & 4 \\
\hline $\mathbf{V}_{G}$ & $\left(\right.$ mL-CNTP.ciclo $\left.{ }^{-1}\right)$ & - & & & & 64 & (5) & \pm & 12 & - & & & & 130 & (2) & & 16 & - & & & & 0 & (3) & & 0 \\
\hline $\mathbf{V}_{\mathbf{A}}$ & (L) & 1,5 & (6) & \pm & 0,07 & - & & & - & 1,5 & (1) & & & - & & & - & 1,6 & & & 0,03 & - & & & - \\
\hline & & & & & & & & & & & & & & & & & & & & & & & & & \\
\hline $\mathrm{C}_{\mathrm{ST}}$ & $\left(\operatorname{mgDQO} . L^{-1}\right)$ & 2030 & (2) & \pm & 42 & 1543 & (2) & \pm & 50 & & & & & & & & & & & & & & & & \\
\hline $\mathbf{C}_{\mathrm{SF}}$ & $\left(\operatorname{mgDQO} \cdot \mathrm{L}^{-1}\right)$ & & (2) & & & 1514 & (2) & & 42 & & & & & & & & & & & & & & & & \\
\hline pH & (u) & 7,78 & (2) & \pm & 0,26 & 6,11 & (2) & \pm & 0,16 & & & & & & & & & & & & & & & & \\
\hline AVT & $\left(\right.$ mgHAc. $\left.L^{-1}\right)$ & 17 & (2) & \pm & 1 & 165 & (2) & \pm & 3 & & & & & & & & & & & & & & & & \\
\hline AT & $\left(\mathrm{mgCaCO}_{3} \cdot \mathrm{L}^{-1}\right)$ & 154 & (2) & \pm & 12 & 121 & (2) & \pm & 8 & & & & & & & & & & & & & & & & \\
\hline $\mathbf{A P}$ & $\left(\mathrm{mgCaCO}_{3} \cdot \mathrm{L}^{-1}\right)$ & 118 & (2) & \pm & 8 & 9 & (2) & \pm & 5 & & & & & & & & & & & & & & & & \\
\hline AI & $\left(\mathrm{mgCaCO}_{3} \cdot \mathrm{L}^{-1}\right)$ & 36 & (2) & \pm & 2 & 112 & (2) & \pm & 3 & & & & & & & & & & & & & & & & \\
\hline $\mathbf{A B}$ & $\left(\mathrm{mgCaCO}_{3} \cdot \mathrm{L}^{-1}\right)$ & 142 & (2) & \pm & 12 & 4 & (2) & \pm & 6 & & & & & & & & & & & & & & & & \\
\hline $\mathbf{V}_{\mathbf{G}}$ & $\left(\mathrm{mL}-\mathrm{CNTP} \cdot \mathrm{ciclo}^{-1}\right)$ & - & & & & 87 & (2) & & 0 & & & & & & & & & & & & & & & & \\
\hline $\mathbf{V}_{\mathbf{A}}$ & (L) & 1,5 & (2) & \pm & 0,01 & - & & & - & & $a 1$ & & I & nd & & & & & & & & & & & \\
\hline
\end{tabular}


Tabela 5.2 - Valores médios de indicadores de produção de hidrogênio, cargas orgânicas volumétricas e eficiências de remoção de matéria orgânica calculados na "Fase preliminar".

\begin{tabular}{|c|c|c|c|c|c|c|c|c|c|c|}
\hline & $\varepsilon_{\mathrm{ST}}$ & $\varepsilon_{\mathrm{SF}}$ & COVA $_{\mathrm{ST}}$ & $\mathrm{COVR}_{\mathrm{SF}}$ & $V_{H_{2}}$ & $\mathbf{n}_{\mathrm{H} 2}$ & PrM & $\mathbf{R M C A}_{\mathrm{s}, \mathrm{m}}$ & $\mathbf{R M C R}_{\mathrm{s}, \mathrm{m}}$ & $\begin{array}{c}\text { DQO } \\
\text { GC }\end{array}$ \\
\hline Etapa & $(\%)$ & $(\%)$ & $\left(m g D Q O . L^{-1} \cdot d^{-1}\right)$ & $\left(\mathrm{mgDQO} \mathrm{L}^{-1} \cdot \mathrm{d}^{-1}\right)$ & $\left(\mathbf{m L} . d^{-1}\right)$ & $\left(\mathbf{m m o l H}_{2} \cdot \mathrm{d}^{-1}\right)$ & $\left(\mathrm{molH}_{2} \cdot \mathrm{m}^{-3} \cdot \mathrm{d}^{-1}\right)$ & $\left(\mathrm{mmolH}_{2} \cdot \mathrm{kgDQO}^{-1}\right)$ & $\left(\mathrm{mmolH}_{2} \cdot \mathrm{kgDQO}^{-1}\right)$ & $\left(\mathrm{mgDQO}^{-L^{-1}}\right)$ \\
\hline B1 & 36 & 44 & 10032 & 4385 & 0 & 0 & 0 & 0 & 0 & 1654 \\
\hline $\mathrm{C} 1$ & 35 & 46 & 10347 & 4616 & 8 & 0,4 & 0,1 & 10 & 30 & 1859 \\
\hline D1 & 34 & 45 & 9133 & 4065 & 29 & 1,3 & 0,4 & 50 & 110 & 1658 \\
\hline E1 & 32 & 43 & 9113 & 3943 & 8 & 0,4 & 0,1 & 10 & 30 & 1637 \\
\hline $\mathrm{F} 1$ & 29 & 37 & 9048 & 3306 & 2 & 0,6 & 0,2 & 20 & 60 & 1458 \\
\hline G1 & 46 & 49 & 9750 & 4812 & 0 & 0 & 0 & 0 & 0 & 2061 \\
\hline $\mathrm{C} 2$ & 38 & 52 & 9484 & 4735 & 39 & 1,8 & 0,4 & 40 & 90 & 1938 \\
\hline B4 & 3 & 5 & 15529 & 719 & 102 & 4,5 & 1,5 & 100 & 210 & 328 \\
\hline A5 & 20 & 23 & 3016 & 732 & 0 & 0 & 0 & 0 & 0 & 316 \\
\hline B5 & 24 & 25 & 6090 & 1548 & 73 & 33 & 1,1 & 180 & 700 & 674 \\
\hline
\end{tabular}

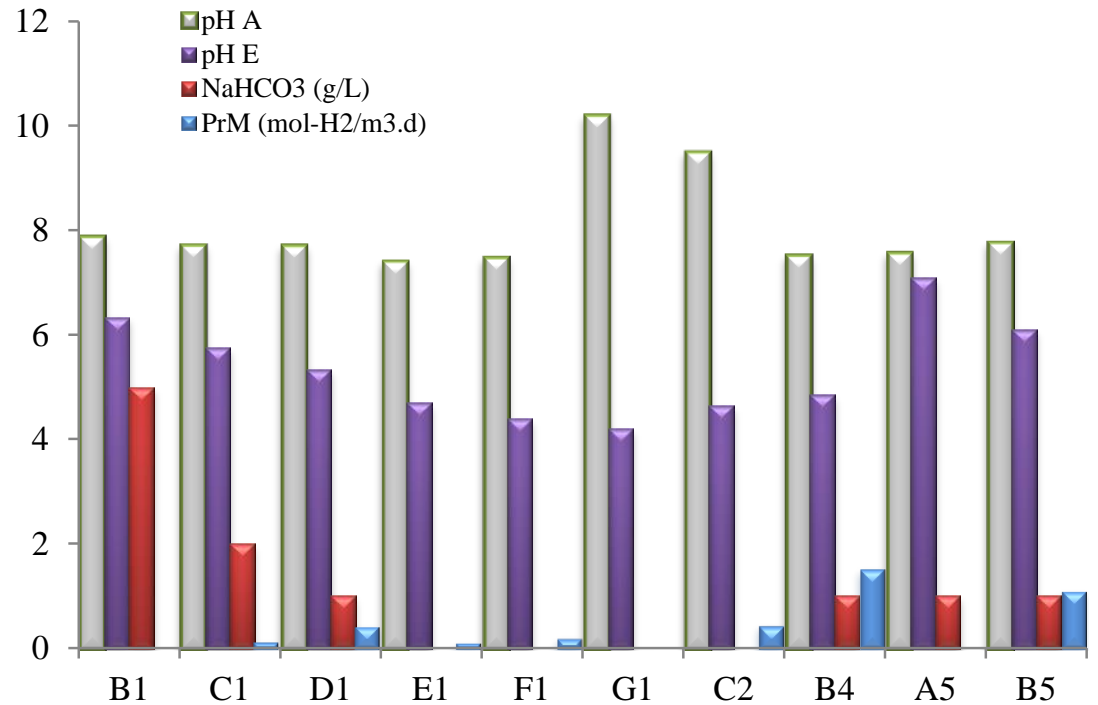

Figura 5.1 - Variáveis de estudo na produção de hidrogênio da "Fase preliminar".

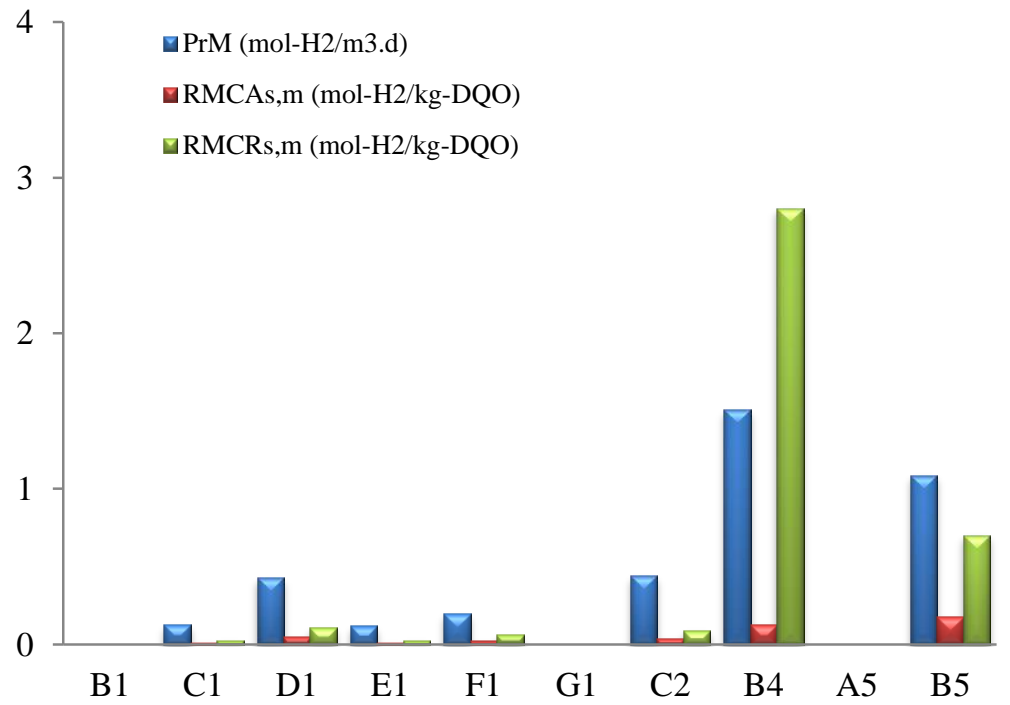

Figura 5.2 - Produção de hidrogênio nas condições da "Fase preliminar". 
A "Fase preliminar" permitiu estudar a influência de variáveis na produção de hidrogênio como pH afluente e efluente, presença de enxofre e de sais no meio de alimentação, concentração de bicarbonato de sódio, pré-adaptação da biomassa à fonte de carbono, tipo de suporte, tempo de ciclo, concentração de matéria orgânica e tipo de glicerina, como foi explicado no capítulo anterior. Os resultados obtidos especificamente para estas variáveis em cada etapa são apresentados na Tabela 5.3.

Tabela 5.3 - Resultados das variáveis estudadas na "Fase preliminar".

\begin{tabular}{|c|c|c|}
\hline Etapa & Variável de estudo & Resultados \\
\hline 1 & Presença de enxofre no meio de alimentação & $\begin{array}{l}\text { - A ausência de enxofre foi desfavorável na } \\
\text { produção de hidrogênio }\end{array}$ \\
\hline & Presença de sais no meio de alimentação & $\begin{array}{l}\text { - Na ausência dos sais, a produção de hidrogênio } \\
\text { foi próxima a zero }\end{array}$ \\
\hline & Presença de $\mathrm{NaHCO}_{3}$ no meio de alimentação & $\begin{array}{l}\text { - A maior produção de hidrogênio foi atingida } \\
\text { usando } 100 \mathrm{mg} \cdot \mathrm{L}^{-1} \text { de bicarbonato }\end{array}$ \\
\hline 2 & Adaptação gradual à glicerina & $\begin{array}{l}\text { - A adaptação gradual à glicerina não contribuiu } \\
\text { no aumentou da produção de hidrogênio }\end{array}$ \\
\hline 3 & Tipo do suporte & $\begin{array}{l}\text { - } \mathrm{O} \text { uso de } \mathrm{PU} \text { misturado com PEBD contribui } \\
\text { para a produção de metano possivelmente pela } \\
\text { retenção de microrganismos metanogênicos no } \\
\text { PU }\end{array}$ \\
\hline 4 & Glicerol-PA & $\begin{array}{l}\text { - O uso de glicerol-PA como única fonte de } \\
\text { carbono aumentou a produção de hidrogênio em } \\
\text { comparação ao uso de glicerina bruta }\end{array}$ \\
\hline & Carga orgânica de glicerol & $\begin{array}{l}\text { - O aumento da carga orgânica produziu um } \\
\text { aumento da produção de hidrogênio }\end{array}$ \\
\hline 5 & Pré-tratamento da biomassa & $\begin{array}{l}\text { - A biomassa pré-tratada com calor permitiu obter } \\
\text { hidrogênio sem necessidade do enriquecimento } \\
\text { ou pré-adaptação com sacarose, inclusive com } \\
\text { baixas cargas orgânicas aplicadas }\end{array}$ \\
\hline & Carga orgânica. & $\begin{array}{l}\text { - Quanto maior a carga orgânica aplicada, maior a } \\
\text { produção de hidrogênio }\end{array}$ \\
\hline
\end{tabular}




\section{a) pH}

De forma geral, na "Fase preliminar" se observou que o $\mathrm{pH}$ do afluente não foi um fator de influência na produção de hidrogênio. Tanto as maiores como as menores produções foram obtidas quando o $\mathrm{pH}$ do afluente esteve em uma faixa entre 7 e 8 . As condições D1 e C2 obtiveram produtividades molares de hidrogênio similares, com pH do afluente de 7,71 e 9,51 respectivamente. Com relação ao pH do efluente, se observou a mesma desvinculação. Assim, as condições que apresentaram maior $\mathrm{pH}$ do efluente foram a B1, A5 e B5, com produtividades molares de 0 e $1,09 \mathrm{molH}_{2} \mathrm{~m}^{-3} \cdot \mathrm{d}^{-1}$, respectivamente. A condição que apresentou menor $\mathrm{pH}$ do efluente foi a G1, cuja produtividade molar foi zero. Essa divergência nas faixas de pH é também mencionada na literatura, estabelecendo-se a não existência de pH ótimos que possam ser generalizados à produção de hidrogênio, como foi apresentado na Tabela 3.3.

\section{b) Bicarbonato de sódio}

$\mathrm{Na}$ primeira etapa, a maior produção de hidrogênio foi obtida utilizando 100 $\mathrm{mgNaHCO} 3 . \mathrm{L}^{-1}$ (condição D1), concentração que posteriormente foi usada nas etapas três, quatro e cinco. Na segunda etapa, não foi adicionado bicarbonato de sódio na condição C2 porque o meio de cultura apresentou $\mathrm{pH}$ perto de 10 devido ao uso de glicerina bruta feita no laboratório sem nenhum tratamento de purificação. O meio de cultura da condição C2 apresentou alcalinidade a bicarbonato similar ao meio da condição D1, sendo as produtividades molares de hidrogênio também similares.

As condições B1, C1 e D1 operaram com meio de cultura de igual composição mudando apenas a concentração de bicarbonato de sódio para 500, 200 e $100 \mathrm{mgNaHCO}_{3} \cdot \mathrm{L}^{-1}$ 
respectivamente. Esta igualdade na composição permitiu analisar o efeito da concentração de bicarbonato de sódio sobre a produção do hidrogênio. A relação de produção de hidrogênio e concentração de bicarbonato de sódio para essas três condições foi inversamente proporcional, indicando que uma excessiva alcalinidade a bicarbonato poderia ter um efeito negativo no processo em questão.

Com base nos resultados é possível inferir que a produção de hidrogênio está mais relacionada com a capacidade tampão do meio de cultura do que com o pH do mesmo.

\section{c) Nutrientes}

A condição E1 operada apenas com a fonte de carbono e de nitrogênio, atingiu a produtividade molar de hidrogênio próxima a zero. A condição F1 caracterizada pela ausência de enxofre e bicarbonato de sódio no meio de alimentação apresentou a menor produção de hidrogênio em comparação à condição D1 na qual se utilizou $100 \mathrm{mgNaHCO}_{3} \cdot \mathrm{L}^{-1}$ e solução de sais completas. A ausência de nitrogênio, bicarbonato de sódio e a solução de sais completa no meio de alimentação, e o uso apenas de glicerina na condição G1 fez com que a produção de hidrogênio fosse nula. As maiores produções de hidrogênio foram obtidas nas condições nas quais se usaram todos os nutrientes especificados na Tabela 4.3.

Todos estes resultados foram um indicativo de que a presença única de carbono no afluente é insuficiente para suprir as necessidades nutricionais dos microrganismos produtores de hidrogênio. Tanto macro-elementos adicionais (nitrogênio, fósforo e com especial importância do enxofre e ferro associado à constituição da enzima hidrogenase), como micro-elementos são de relevante importância na produção de hidrogênio, como é mencionado por Hawkes et al. (2007) e 
Kumar (2008). A presença de sulfatos no meio de alimentação podia constituir um risco de queda na produção de hidrogênio pelo possível consumo do hidrogênio por bactérias redutoras de sulfato, porém, para este caso em particular, a presença de enxofre foi benéfica.

\section{d) Tipo de glicerina, carga orgânica volumétrica aplicada}

Nas Figuras 5.1 e 5.2 observa-se que de todas as condições em estudo a que apresentou maior produção de hidrogênio tanto em produtividade molar volumétrica (PrM) como em rendimento de hidrogênio produzido por carga orgânica removida (RMCRs,m) foi a condição B4, na qual foi usado glicerol-PA como única fonte de carbono, com uma concentração de matéria orgânica de $4000 \mathrm{mgDQO} . \mathrm{L}^{-1}$ e 3 horas de tempo de ciclo (a maior carga orgânica volumétrica aplicada COVA: 15529 mgDQO. $\mathrm{L}^{-1}$ ). A segunda melhor condição foi a B5, caracterizada pelo pré-tratamento térmico aplicado à biomassa, pela ausência de enriquecimento microbiano usando sacarose como fonte de carbono, pelo uso de glicerol-PA e 4 horas de tempo de ciclo. Ainda que nesta última condição tenha sido usada uma carga orgânica volumétrica aplicada (COVA: 6090

mgDQO. $\mathrm{L}^{-1}$ ), a produção volumétrica de hidrogênio e remoção de matéria orgânica por carga aplicada foi similar e maior, respectivamente, à condição B4.

Estes últimos resultados foram claramente melhores que os obtidos usando glicerina bruta industrial e glicerina bruta sintetizada no laboratório, o que poderia ser um indicativo do efeito negativo da presença de impurezas próprias desta glicerina como metanol, ácidos graxos livres, sais inorgânicos, metil ésteres, entre outros, já estudado por Chatzifragkou e Papanikolaou (2012). 


\section{e) Pré-tratamento térmico da biomassa}

Com relação à influência do pré-tratamento térmico, o uso de calor fez com que não fosse necessário realizar um enriquecimento da biomassa com sacarose nem adaptação gradual à glicerina. Aliás, a produtividade molar de hidrogênio usando o inóculo pré-tratado termicamente com uma carga orgânica de $2000 \mathrm{mgDQO} . \mathrm{L}^{-1}$ e 4 horas de tempo de ciclo (condição B5) foi similar à obtida usando a biomassa acidogênica adaptada gradualmente à glicerina com uma carga orgânica 4000 mgDQO.L ${ }^{-1}$ e 3 horas de tempo de ciclo (condição B4), como se observa na Tabela 5.2 e na Figura 5.2. Estes resultados podem ser justificados pela capacidade dos microrganismos produtores de hidrogênio de formar esporos em condições desfavoráveis. São vários os trabalhos de pesquisa que têm estudado o efeito dos pré-tratamentos térmicos na produção de hidrogênio com favorecimento significativo desta; podendo citar a Duangmanee et al. (2007), Nissilä et al. (2011) e El-Bery et al. (2013).

\section{f) Considerações adicionais}

Ainda que as produções de hidrogênio das etapas um e dois tenham sido baixas, foram as que apresentaram maior quantidade de ácidos voláteis totais (AVT) na forma de mgHAc.L ${ }^{-1} \mathrm{e}$ maior consumo de matéria orgânica na forma de DQO correspondente à glicerina consumida, como se observa na Figura 5.3 e na Tabela 5.2, respectivamente. Estes resultados podem ser um indicativo do consumo de hidrogênio por bactérias homoacetogênicas que usam o hidrogênio e o gás carbônico para formar acetato, constituindo um fator de risco na produção de hidrogênio como têm sido estudado por Luo et al. (2011) e Dinamarca e Bakke (2009). Adicionalmente, 
estes resultados podem ser um indicativo de consumo de ácidos produzidos produzindo ácido acético por processos de acetogenesis.

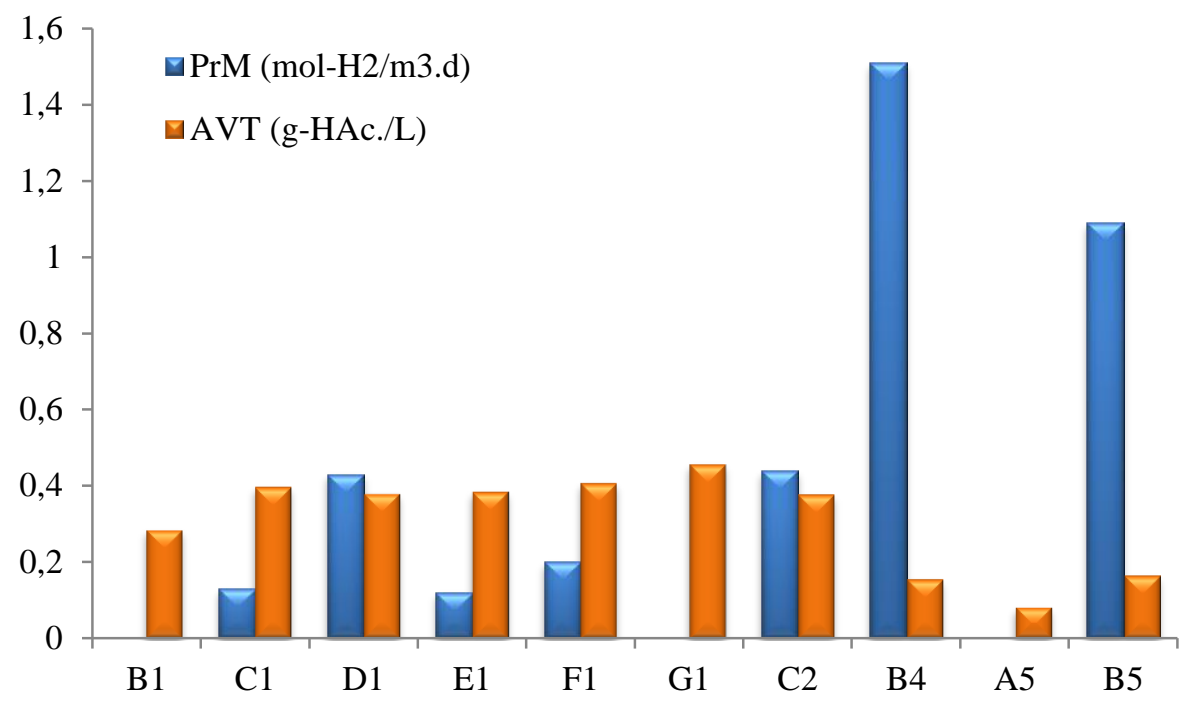

Figura 5.3 - Produtividade molar de hidrogênio e produção de AVT das condições em estudo da "Fase preliminar".

Das condições em estudo, nenhuma apresentou metano como se observa na Figura 5.4. Durante toda a "Fase preliminar" a única etapa que produziu metano foi a etapa três que teve como objetivo avaliar o efeito do suporte (mistura PU e PEBD). Os resultados desta etapa não são discutidos neste capítulo porque ela foi operada sempre em presença de sacarose. 


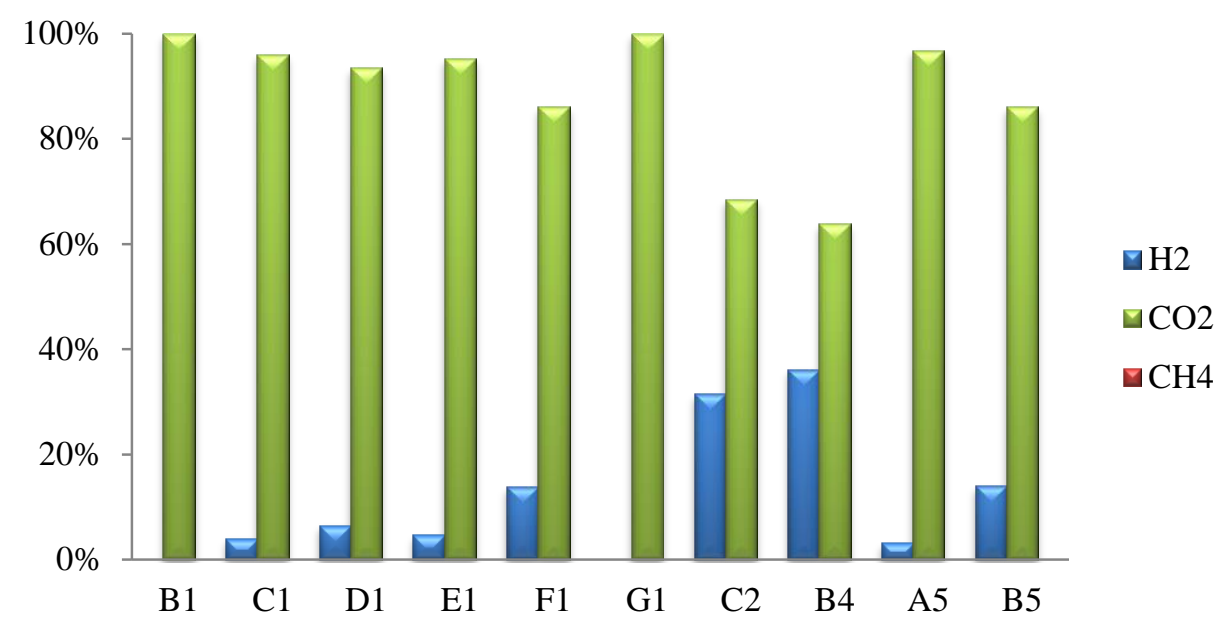

Figura 5.4 - Composição do biogás para cada condição em estudo.

Das duas condições com maior produção de hidrogênio B4 e B5 foi realizada uma mistura das variáveis que deram os melhores resultados para operar a chamada "Fase de experimentação". Assim, foi usado o meio completo exposto na Tabela 4.3., o glicerol-PA como única fonte de carbono desde o primeiro dia de operação, a biomassa proveniente do UASB do abatedouro de aves pré-tratada termicamente $\left(90^{\circ} \mathrm{C}\right.$ por 10 minutos, seguido de um choque térmico), com cargas orgânicas maiores do que 2000 mgDQO.L ${ }^{-1}$ (3000, 4000 e 5000 mgDQO.L${ }^{1}$ ) e tempos de ciclo de 3 e 4 horas. Adicionalmente, foi usado unicamente PEBD como suporte.

\subsection{Fase experimental}

A fase experimental foi composta por seis condições operadas usando glicerol-PA como única fonte de carbono e a composição completa apresentada na Tabela 4.3. O inóculo usado foi proveniente de um UASB de um abatedouro de aves, pré-tratado termicamente $\left(90^{\circ} \mathrm{C}\right.$ por 10 minutos seguido por choque térmico até atingir $25^{\circ} \mathrm{C}$ ). Antes da operação do reator em cada 
condição esterilizou-se o material suporte $\left(120^{\circ} \mathrm{C}\right.$ por 15 minutos) e lavou-se o reator. Cada condição foi operada durante 13 dias seguindo a sequência especificada na Tabela 4.10. Finalmente foi realizado o perfil. Todos os dados coletados são apresentados nos Anexos do VII a XIV, enquanto que na presente sessão são apresentados e discutidos exclusivamente as tabelas de médias e os gráficos gerados a partir dos dados originais.

\subsubsection{Comportamento do reator}

\section{a) Carga orgânica na forma de DQO}

Durante esta fase, o reator foi operado com três concentrações afluentes de DQO e dois tempos de ciclo. Na Tabela 5.4 apresentam-se as médias dos parâmetros monitorados ao longo da experimentação. As condições CI, CII e CIII operaram com tempo de ciclo de 4 horas e foram alimentadas com concentração afluente média de 3085, 3982 e 5265 mgDQO.L ${ }^{-1}$, respectivamente. As condições CIV, CV e CVI operaram com tempo de ciclo de 3 horas e afluente de concentração media de 3156, 4076 e 4959 mgDQO.L ${ }^{-1}$, respectivamente.

Como se observa na Figura 5.5, para todas as condições, as concentrações de DQO tanto do afluente como do efluente mantiveram-se quase constantes ao longo do tempo, com as eficiências de remoção de matéria orgânica apresentando comportamento semelhante. A faixa de remoção de matéria orgânica na forma de DQO variou entre 19 - 30\%, um valor baixo esperado já que o processo visa obter hidrogênio apenas a partir da hidrólise e acidogênese da glicerina e não a partir da fermentação dos ácidos voláteis gerados que contabilizam DQO ao sistema. Remoções maiores de DQO implicariam remoções desses ácidos por bactérias acetogênicas que 
exigem pressões parciais de hidrogênio baixas e por tanto o consumo de hidrogênio na forma de ácido acético e metano para tornarem as reações fermentativas termodinamicamente favoráveis, como é especificado por Kumar (2008) e Rittman e McCarty (2001).

Os dados obtidos evidenciam que a eficiência de remoção de matéria orgânica na forma de DQO não está vinculada à concentração de matéria orgânica na forma de DQO aplicada ao reator nem ao tempo de ciclo de operação. Esta observação foi relatada já por Santos et al. (2012) que operaram o mesmo reator em batelada usando sacarose como fonte de carbono. A concordância destes resultados é um indicativo de que a remoção de matéria orgânica na forma de DQO também poderia estar desvinculada ao substrato usado.

Nas Figuras 5.6 e 5.7 são apresentados os perfis de DQO realizados para todas as condições. Observa-se que mesmo sendo operadas com diferentes tempos de ciclo, aquelas condições alimentadas com a mesma concentração de DQO do afluente apresentaram comportamentos similares com relação à remoção de DQO ao longo do ciclo. Porém, as condições operadas com um tempo de ciclo de 4 horas, mantiveram concentrações maiores de DQO no reator em comparação àquelas operadas com tempo de ciclo de 3 horas, ao longo do ciclo.

Em geral, observa-se que as concentrações de DQO ao longo do ciclo mantiveram-se praticamente constantes. A diluição da concentração de DQO do afluente alimentado aconteceu aproximadamente depois de três minutos após iniciada a recirculação. Mesmo que a glicerina seja consumida ao longo do ciclo, ácidos voláteis são paralelamente produzidos aumentando a concentração de DQO no sistema e mantendo os valores deste parâmetro quase constante. 
Tabela 5.4 - Valores médios dos parâmetros monitorados na "Fase experimental".

\begin{tabular}{|c|c|c|c|c|c|c|c|c|c|c|c|c|c|c|c|c|c|}
\hline \multirow[b]{2}{*}{$\mathrm{C}_{\mathrm{ST}}$} & \multirow[b]{2}{*}{$\left(\mathrm{mgDQO} \cdot \mathrm{L}^{-1}\right)$} & \multicolumn{3}{|c|}{ Afluente } & \multicolumn{2}{|c|}{ CI } & \multicolumn{3}{|c|}{ Efluente } & \multicolumn{3}{|c|}{ Afluente } & CIV & \multicolumn{4}{|c|}{ Efluente } \\
\hline & & 3085 & (7) & \pm & 257 & 2506 & (7) & \pm & 231 & 3156 & (6) & \pm & 467 & 2304 & (6) & \pm & 137 \\
\hline $\mathbf{C}_{\mathrm{SF}}$ & $\left(\mathrm{mgDQO} \cdot \mathrm{L}^{-1}\right)$ & - & & & - & 2353 & (7) & \pm & 153 & - & & & - & 2158 & (6) & \pm & 181 \\
\hline$\varepsilon_{\mathrm{SF}}$ & $(\%)$ & - & & & - & 24 & (7) & \pm & 3 & - & & & - & 30 & (6) & \pm & 13 \\
\hline pH & (u) & 7,66 & (7) & \pm & 0,12 & 4,62 & (7) & \pm & 0,27 & 7,70 & $(6)$ & \pm & 0,14 & 4,70 & (6) & \pm & 0,07 \\
\hline AVT & $\left(\mathrm{mgHAc} . \mathrm{L}^{-1}\right)$ & 20 & (7) & \pm & 1 & 379 & (7) & \pm & 20 & 22 & (6) & \pm & 1 & 456 & (6) & \pm & 17 \\
\hline $\mathbf{A P}$ & $\left(\mathrm{mgCaCO}_{3} \cdot \mathrm{L}^{-1}\right)$ & 108 & (7) & \pm & 19 & 0,0 & (7) & \pm & 0 & 132 & (6) & \pm & 6 & 0 & (6) & \pm & 0 \\
\hline AI & $\left(\mathrm{mgCaCO}_{3} \cdot \mathrm{L}^{-1}\right)$ & 30 & (7) & \pm & 9 & 56,0 & (7) & \pm & 47 & 24 & (6) & \pm & 5 & 81 & (6) & \pm & 11 \\
\hline $\mathbf{A B}$ & $\left(\mathrm{mgCaCO}_{3} \cdot \mathrm{L}^{-1}\right)$ & 124 & (7) & \pm & 26 & 0,0 & (7) & \pm & 0 & 141 & (6) & \pm & 4 & 0 & (6) & \pm & 0 \\
\hline $\mathbf{V}_{\mathbf{G}}$ & $\left(\mathrm{mL}\right.$-CNTP.ciclo $\left.{ }^{-1}\right)$ & - & & & - & 276 & (5) & \pm & 53 & - & & & - & 590 & (6) & \pm & 89 \\
\hline ST & $\left(\mathrm{mg} \cdot \mathrm{L}^{-1}\right)$ & 385 & (3) & \pm & 67 & 505 & (4) & \pm & 78 & 476 & (3) & \pm & 98 & 533 & (4) & \pm & 66 \\
\hline SVT & $\left(\mathrm{mg} . \mathrm{L}^{-1}\right)$ & 213 & (3) & \pm & 22 & 327 & (4) & \pm & 67 & 269 & (3) & \pm & 70 & 357 & (4) & \pm & 35 \\
\hline SST & $\left(\mathrm{mg} . \mathrm{L}^{-1}\right)$ & 23 & (3) & \pm & 8 & 54 & (4) & \pm & 18 & 21 & (3) & \pm & 14 & 100 & (4) & \pm & 44 \\
\hline SSV & $\left(\mathrm{mg} . \mathrm{L}^{-1}\right)$ & 2 & (3) & \pm & 2 & 31 & (4) & \pm & 19 & 27 & (3) & \pm & 10 & 97 & (4) & \pm & 56 \\
\hline $\mathbf{C}_{\mathbf{X}}$ & $\left(\right.$ g. $\left.\mathrm{L}^{-1}\right)$ & - & & & - & 2 & & & - & - & & & - & 1 & & & - \\
\hline $\mathbf{C}_{\mathbf{X}^{\prime}}$ & (mg.g-suporte ${ }^{-1}$ ) & - & & & - & 5 & & & - & - & & & - & 3 & & & - \\
\hline \multirow[t]{2}{*}{$\mathbf{V}_{\mathrm{A}}$} & $(\mathrm{L})$ & 1,5 & $(5)$ & \pm & 0,01 & - & & & - & 1,5 & $(5)$ & \pm & 0,01 & - & & & - \\
\hline & & \multicolumn{8}{|c|}{ CII } & & & & & & & & \\
\hline $\mathrm{C}_{\mathrm{ST}}$ & $\left(\mathrm{mgDQO} \cdot \mathrm{L}^{-1}\right)$ & 3982 & (7) & \pm & 198 & 3111 & (7) & \pm & 265 & 4076 & (6) & \pm & 140 & 3225 & (6) & \pm & 186 \\
\hline $\mathrm{C}_{\mathrm{SF}}$ & $\left(\mathrm{mgDQO} \cdot \mathrm{L}^{-1}\right)$ & - & & & - & 3011 & (7) & \pm & 95 & - & & & - & 2990 & (6) & \pm & 52 \\
\hline$\varepsilon_{\mathrm{ST}}$ & $(\%)$ & - & & & - & 22 & (7) & \pm & 5 & - & & & - & 20 & (6) & \pm & 6 \\
\hline$\varepsilon_{\mathrm{SF}}$ & $(\%)$ & - & & & - & 24 & (7) & \pm & 4 & - & & & - & 26 & (6) & \pm & 4 \\
\hline pH & (u) & 7,55 & (7) & \pm & 0,07 & 4,46 & (7) & \pm & 0,08 & 7,55 & (7) & \pm & 0,07 & 4,56 & (7) & \pm & 0,14 \\
\hline AVT & $\left(\right.$ mgHAc. $\left.\mathrm{L}^{-1}\right)$ & 26 & (7) & \pm & 2 & 523 & (7) & \pm & 56 & 20 & (7) & \pm & 2 & 485 & (7) & \pm & 54 \\
\hline $\mathbf{A T}$ & $\left(\mathrm{mgCaCO}_{3} \cdot \mathrm{L}^{-1}\right)$ & 167 & (7) & \pm & 23 & 41 & (7) & \pm & 24 & 160 & (7) & \pm & 5 & 58 & (7) & \pm & 23 \\
\hline $\mathbf{A P}$ & $\left(\mathrm{mgCaCO}_{3} \cdot \mathrm{L}^{-1}\right)$ & 135 & (7) & \pm & 19 & 0 & (7) & \pm & 0 & 131 & (7) & \pm & 3 & 0 & (7) & \pm & 0 \\
\hline AI & $\left(\mathrm{mgCaCO}_{3} \cdot \mathrm{L}^{-1}\right)$ & 31 & (7) & \pm & 5 & 41 & (7) & \pm & 24 & 29 & (7) & \pm & 2 & 58 & (7) & \pm & 23 \\
\hline AB & $\left(\mathrm{mgCaCO}_{3} \cdot \mathrm{L}^{-1}\right)$ & 148 & (7) & \pm & 23 & 0 & (7) & \pm & 0 & 145 & $(7)$ & \pm & 5 & 0 & (7) & \pm & 0 \\
\hline $\mathbf{V}_{\mathbf{G}}$ & $\left(\mathrm{mL}-\mathrm{CNTP}\right.$. ciclo $\left.^{-1}\right)$ & - & & & - & 877 & (6) & \pm & 373 & - & & & - & 717 & $(5)$ & & 119 \\
\hline SST & $\left(\mathrm{mg} \cdot \mathrm{L}^{-1}\right)$ & 17 & (3) & \pm & 15 & 84 & (4) & \pm & 85 & 19 & (3) & \pm & 14 & 93 & (4) & \pm & 13 \\
\hline SSV & $\left(\mathrm{mg} \cdot \mathrm{L}^{-1}\right)$ & 27 & (3) & \pm & 2 & 81 & (4) & \pm & 28 & 27 & (3) & \pm & 7 & 92 & (4) & \pm & 21 \\
\hline $\mathbf{M}_{\text {SVT }}$ & (g) & - & & & - & 3 & & & - & - & & & - & 4 & & & - \\
\hline $\mathbf{C}_{\mathbf{X}}$ & $\left(\right.$ g. $\left.\mathrm{L}^{-1}\right)$ & - & & & - & 0,8 & & & - & - & & & - & 1 & & & - \\
\hline $\mathbf{C}_{\mathbf{X}^{\prime}}$ & (mg.g-suporte ${ }^{-1}$ ) & - & & & - & 2 & & & - & - & & & - & 3 & & & - \\
\hline $\mathbf{V}_{\mathbf{A}}$ & (L) & 1,5 & $(5)$ & \pm & 0,01 & - & & & - & 1,5 & $(4)$ & \pm & 0,03 & - & & & - \\
\hline & & & & & & & & & & & & & & & & & \\
\hline $\mathrm{C}_{\mathrm{ST}}$ & $\left(\mathrm{mgDQO} \cdot \mathrm{L}^{-1}\right)$ & 5265 & (6) & \pm & 177 & 4105 & (6) & \pm & 95 & 4959 & (6) & \pm & 146 & 3978 & (6) & \pm & 210 \\
\hline $\mathbf{C}_{\mathrm{SF}}$ & $\left(\mathrm{mgDQO} \cdot \mathrm{L}^{-1}\right)$ & - & & & - & 3972 & (6) & \pm & 78 & - & & & - & 3704 & (6) & \pm & 144 \\
\hline$\varepsilon_{\mathrm{ST}}$ & $(\%)$ & - & & & - & 22 & (6) & \pm & 5 & - & & & - & 20 & (6) & \pm & 6 \\
\hline$\varepsilon_{\mathrm{SF}}$ & $(\%)$ & - & & & - & 25 & (6) & \pm & 2 & - & & & - & 25 & (6) & \pm & 2 \\
\hline $\mathbf{P h}$ & (u) & 7,54 & (6) & \pm & 0,06 & 4,32 & (6) & \pm & 0,18 & 7,60 & $(6)$ & & 0,06 & 4,38 & (6) & \pm & 0,05 \\
\hline AVT & $\left(\right.$ mgHAc. $\left.L^{-1}\right)$ & 24 & (6) & \pm & 1 & 526 & (6) & \pm & 19 & 24 & (6) & & 2 & 627 & (6) & \pm & 43 \\
\hline $\mathbf{A T}$ & $\left(\mathrm{mgCaCO}_{3} \cdot \mathrm{L}^{-1}\right)$ & 154 & (6) & \pm & 13 & 10 & (6) & \pm & 10 & 148 & (6) & & 7 & 23 & (6) & \pm & 14 \\
\hline $\mathbf{A P}$ & $\left(\mathrm{mgCaCO}_{3} \cdot \mathrm{L}^{-1}\right)$ & 124 & (6) & \pm & 11 & 0 & (6) & \pm & 0 & 123 & (6) & & 5 & 0 & (6) & \pm & 0 \\
\hline AI & $\left(\mathrm{mgCaCO}_{3} \cdot \mathrm{L}^{-1}\right)$ & 30 & (6) & \pm & 4 & 10 & (6) & \pm & 10 & 26 & (6) & & 3 & 23 & (6) & \pm & 14 \\
\hline $\mathbf{A B}$ & $\left(\mathrm{mgCaCO}_{3} \cdot \mathrm{L}^{-1}\right)$ & 137 & (6) & \pm & 13 & 0 & (6) & \pm & 0 & 131 & (6) & & 7 & 0 & (6) & \pm & 0 \\
\hline $\mathbf{V}_{\mathbf{G}}$ & $\left(\mathrm{mL}-\mathrm{CNTP}\right.$. ciclo $\left.^{-1}\right)$ & - & & & - & 1390 & (5) & \pm & 94 & & & & & 1009 & (6) & \pm & 96 \\
\hline ST & $\left(\mathrm{mg} . \mathrm{L}^{-1}\right)$ & 549 & (3) & \pm & 72 & 812 & (4) & \pm & 39 & 520 & (3) & \pm & 16 & 935 & (4) & \pm & 71 \\
\hline SVT & $\left(\mathrm{mg} \cdot \mathrm{L}^{-1}\right)$ & 289 & (3) & \pm & 88 & 605 & (4) & \pm & 31 & 309 & (3) & \pm & 70 & 776 & (4) & \pm & 96 \\
\hline SST & $\left(\mathrm{mg} \cdot \mathrm{L}^{-1}\right)$ & 38 & (3) & \pm & 31 & 105 & (4) & \pm & 30 & 25 & (3) & \pm & 14 & 46 & (4) & \pm & 19 \\
\hline SSV & $\left(\mathrm{mg} \cdot \mathrm{L}^{-1}\right)$ & 20 & (3) & \pm & 17 & 93 & (4) & \pm & 4 & & (3) & \pm & 14 & 34 & (4) & \pm & 23 \\
\hline $\mathbf{M}_{\text {SVT }}$ & (g) & - & & & - & 3 & & & - & - & & & - & 8 & & & - \\
\hline $\mathbf{C}_{\mathbf{X}}$ & $\left(\mathrm{g} . \mathrm{L}^{-1}\right)$ & - & & & - & 1 & & & - & - & & & - & 2 & & & - \\
\hline $\mathbf{C}_{\mathbf{X}^{\prime}}$ & (mg.g-suporte ${ }^{-1}$ ) & - & & & - & 3 & & & - & - & & & - & 6 & & & - \\
\hline $\mathbf{V}_{\mathbf{A}}$ & (L) & 1,5 & (4) & \pm & 0,02 & - & & & - & 1,5 & $(4)$ & \pm & 0,03 & - & & & - \\
\hline
\end{tabular}




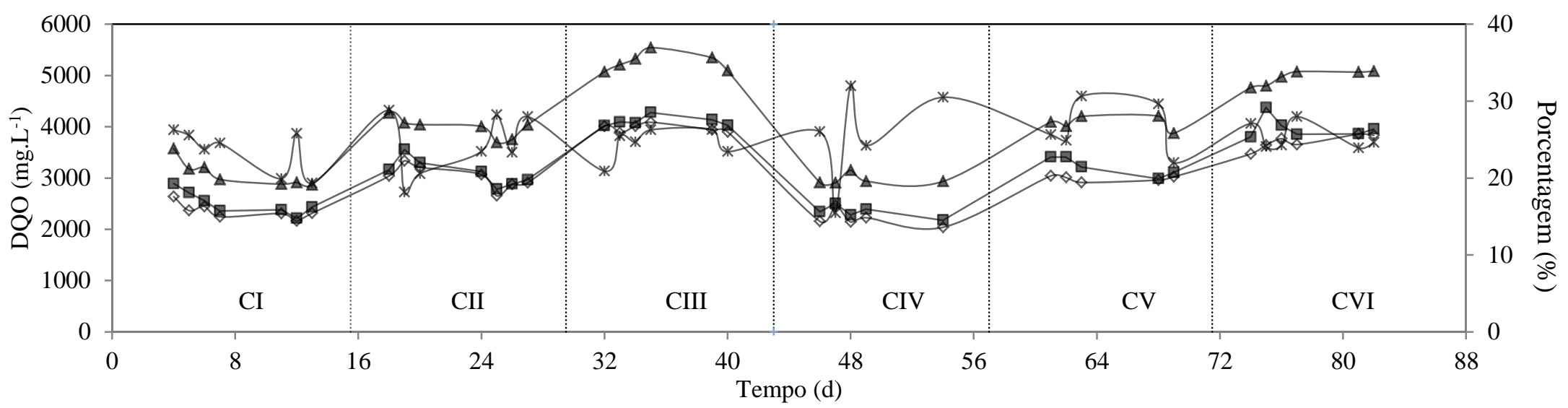

Figura 5. 5 - Concentrações de matéria orgânica do afluente $C_{\text {ST Afluente }}(-\boldsymbol{\star})$, efluente sem filtrar $C_{\text {ST Efluente }}\left(-\right.$-), efluente filtrado $C_{\text {SF Efluente }}$ $(-)$ e eficiência de remoção do efluente filtrado $\varepsilon_{\mathrm{SF}}\left({ }^{*}\right)$ ao longo das seis condições da "Fase experimental".

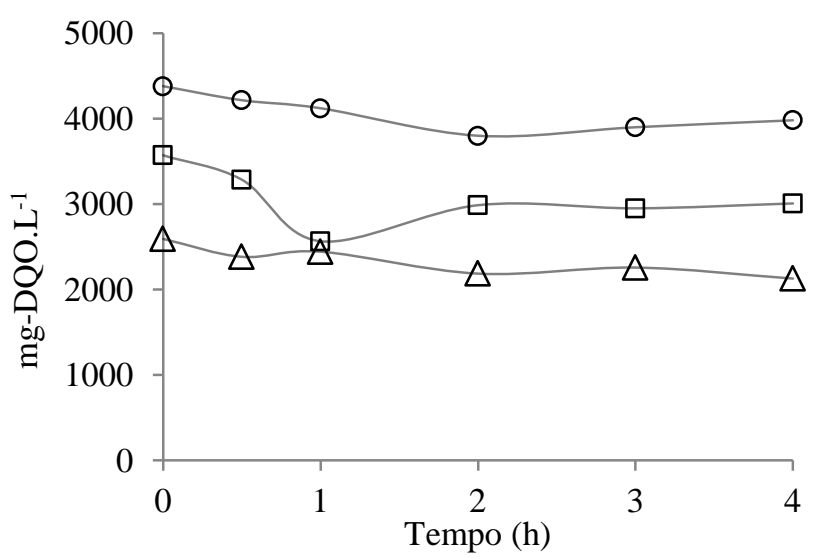

Figura 5.6 - Perfil de DQO das condições CI $(\triangle)$ CII ( $\square)$ e CIII (- - ),operadas com 4 horas de tempo de ciclo.

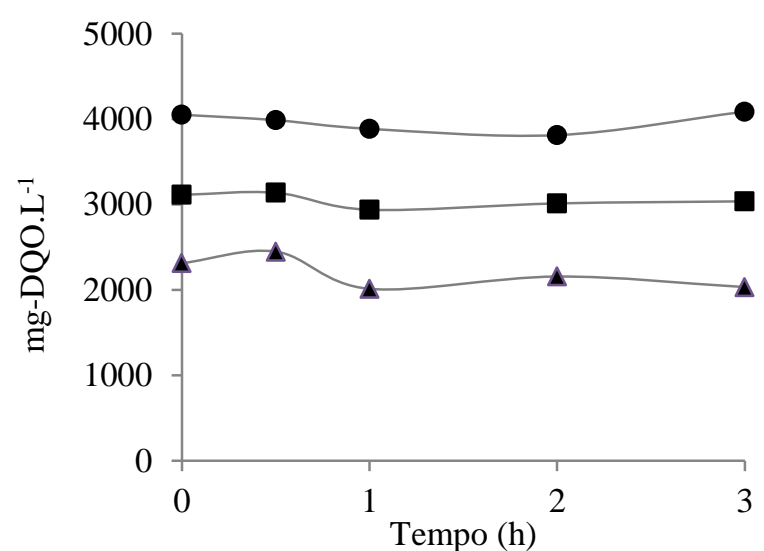

Figura 5. 7 - Perfil de DQO das condições CIV $(\neg)$, CV $(-)$ e CVI $(\bullet-)$, operadas com 3 horas de tempo de ciclo. 


\section{b) Alcalinidade, pH e ácidos voláteis totais}

$\mathrm{O}$ reator operou com um $\mathrm{pH}$ quase constante tanto do afluente como do efluente mostrando estabilidade, como é observado na Figura 5.8. Mesmo tendo diferentes cargas orgânicas, o pH do afluente foi similar. O mesmo comportamento foi observado para o efluente. O afluente de todas as condições também apresentou valores similares de alcalinidade, como se observa na Tabela 5.4 e na Figura 5.8.

As condições operadas com tempos de ciclo de 4 horas (CI, CII e CIII) perderam mais alcalinidade total do que as condições operadas com tempos de ciclo de 3 horas (CIV, CV, CIV). Entretanto, o efluente de todas as condições não apresentou alcalinidade a bicarbonato, a qual foi totalmente consumida no processo fermentativo. Assim, a alcalinidade presente no efluente correspondeu à alcalinidade intermediaria relacionada à concentração de ácidos graxos voláteis. A maior alcalinidade no efluente foi observada quando o reator foi alimentado com a maior carga orgânica, como é evidenciado na Figura 5.8.

A queda de alcalinidade no efluente esteve acompanhada pela geração de ácidos voláteis totais. Como se observa na Tabela 5.4 e na Figura 5.9, as condições operadas com as maiores concentrações de matéria orgânica (condições CIII e CVI) apresentaram as maiores concentrações de ácidos voláteis totais. Porém, em média, as concentrações de ácidos voláteis totais produzidos nas condições CII e CIII operadas com 4 horas de ciclo e alimentadas com concentrações de matéria orgánica aproximadas de 4000 e 5000 mgDQO.L ${ }^{-1}$, respectivamente, produziram praticamente a mesma quantidade de ácidos voláteis totais (523 e $526 \mathrm{mgHAc} . \mathrm{L}^{-1}$ respetivamente). $\mathrm{O}$ mesmo comportamento foi observado nas condições CIV e CV operadas com 3 horas de ciclo e concentrações aproximadas de 3000 e $4000 \mathrm{mgDQO} . \mathrm{L}^{-1}$, respectivamente. 
Na Figura 5.10 são mostrados os perfis dos ácidos voláteis e álcoois monitorados ao longo do ciclo. As condições operadas com concentrações afluente de 4000 e 5000 mgDQO.L ${ }^{-1}$ mostraram uma predominância de acido butírico, seguido pelo butanol e pelo ácido acético. Nas condições operadas com concentração afluente de $3000 \mathrm{mgDQO} \cdot \mathrm{L}^{-1}$ houve predomínio do ácido butírico seguido pelo ácido acético. 


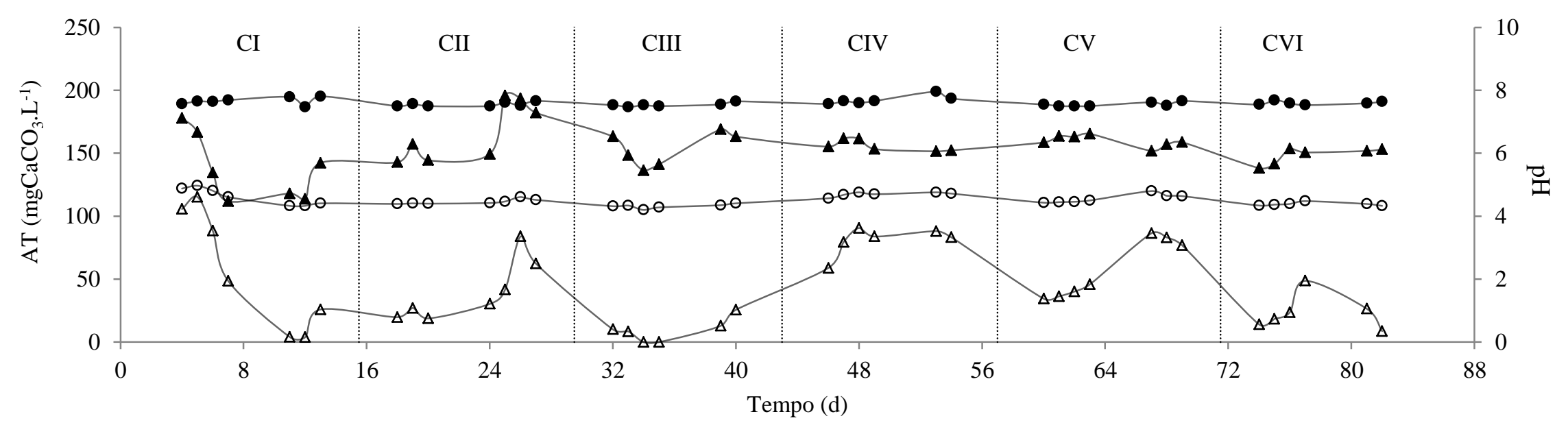

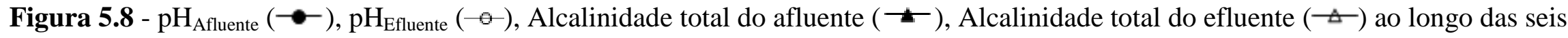
condições da "Fase experimental".

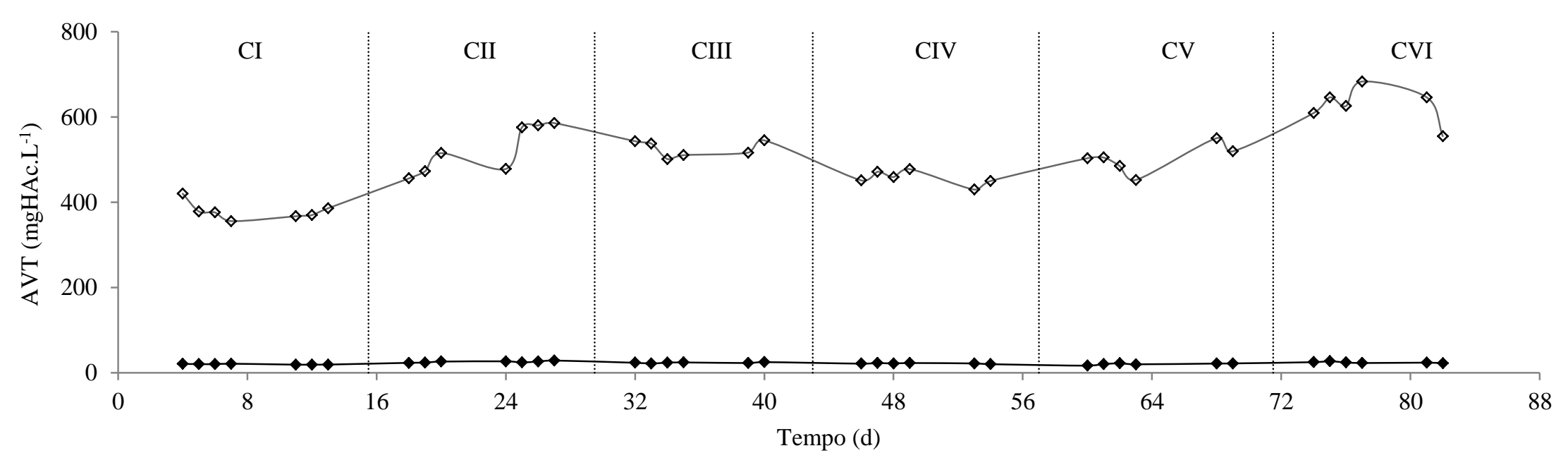

Figura 5.9 - Concentração de AVT do afluente $(\bullet)$ e do efluente $(\bullet)$ ) ao longo das condições da "Fase experimental". 
CI



CIV

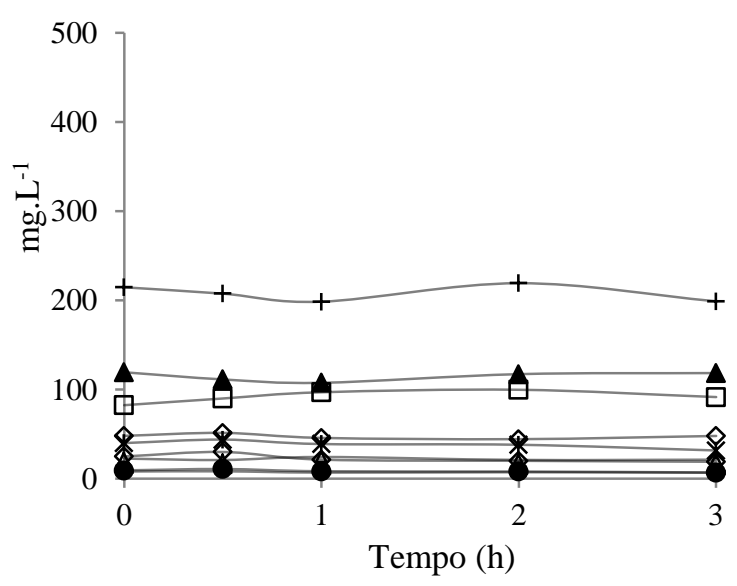

CII

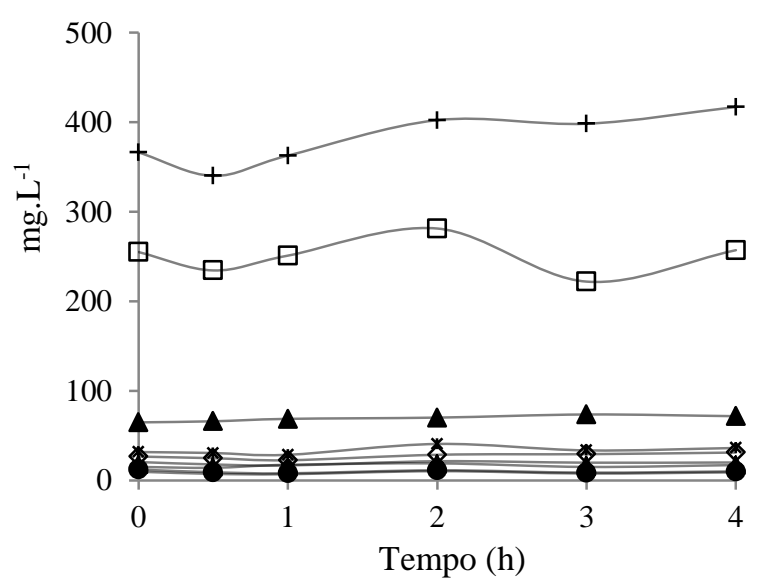

$\mathrm{CV}$

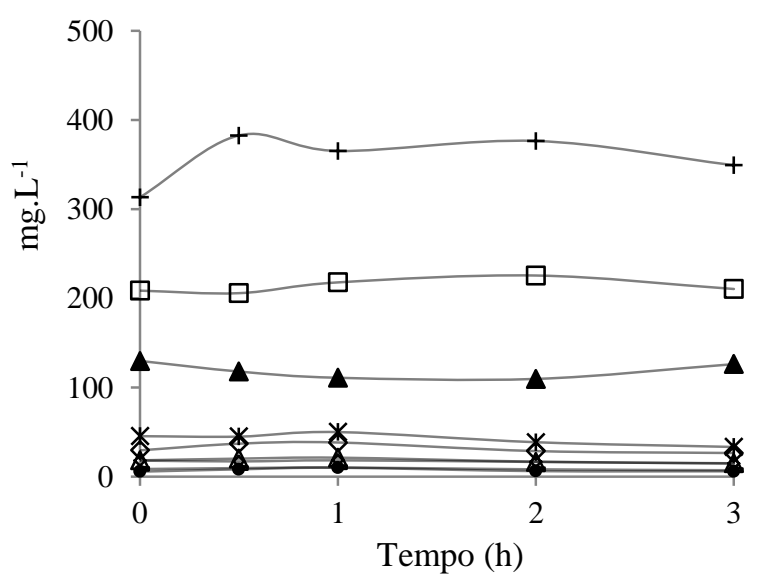

CIII

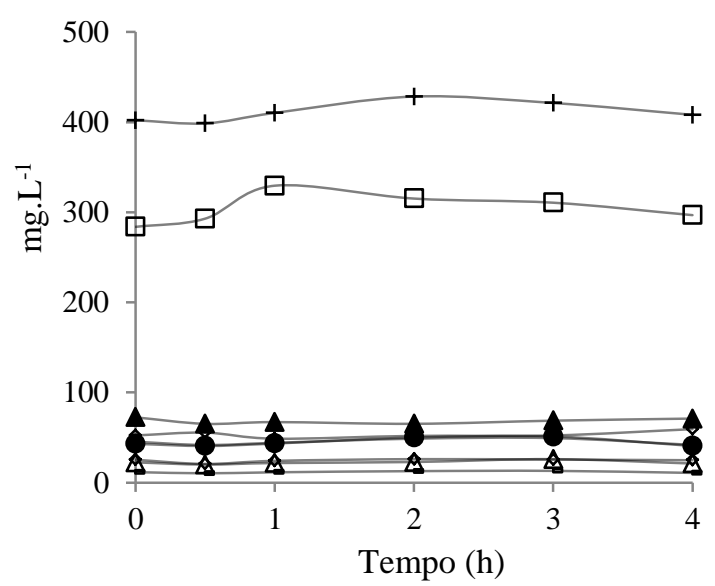

CVI

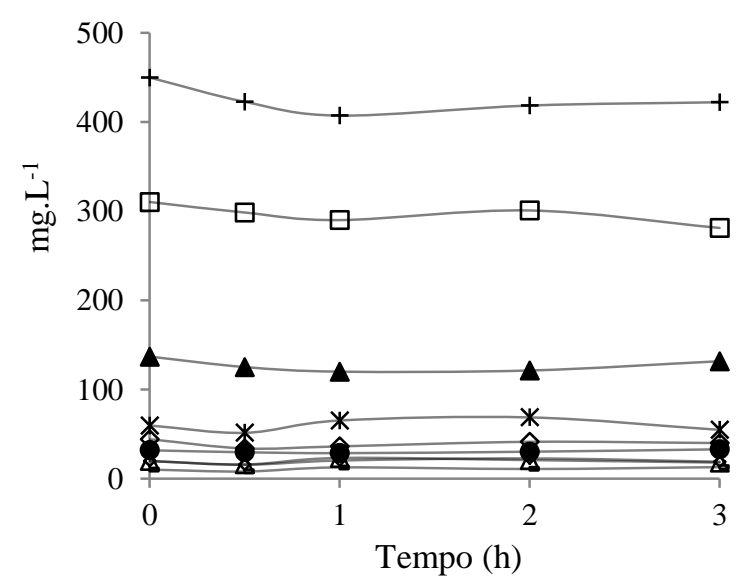

Figura 5. 10 - Perfil de ácidos voláteis produzidos ao longo de cada ciclo das condições da "Etapa de experimentação".

Notação: Etanol $(\rightarrow)$, Butanol $(\square)$, Ácido Acético $\left(\bullet^{-}\right)$, Ácido Propiônico $\left(\rightarrow^{*}\right)$, Ácido Iso-butírico $(\rightarrow-)$, Ácido Butírico $(\square)$, Ácido Iso-valérico $(-)$, Ácido Valérico $(\triangle)$, Ácido Capróico $(\longrightarrow)$. 
Nas Figuras 5.11 e 5.12 é apresentado o comportamento do reator para os parâmetros pH, AT e AVT ao longo do ciclo de 3 e 4 horas, respetivamente.
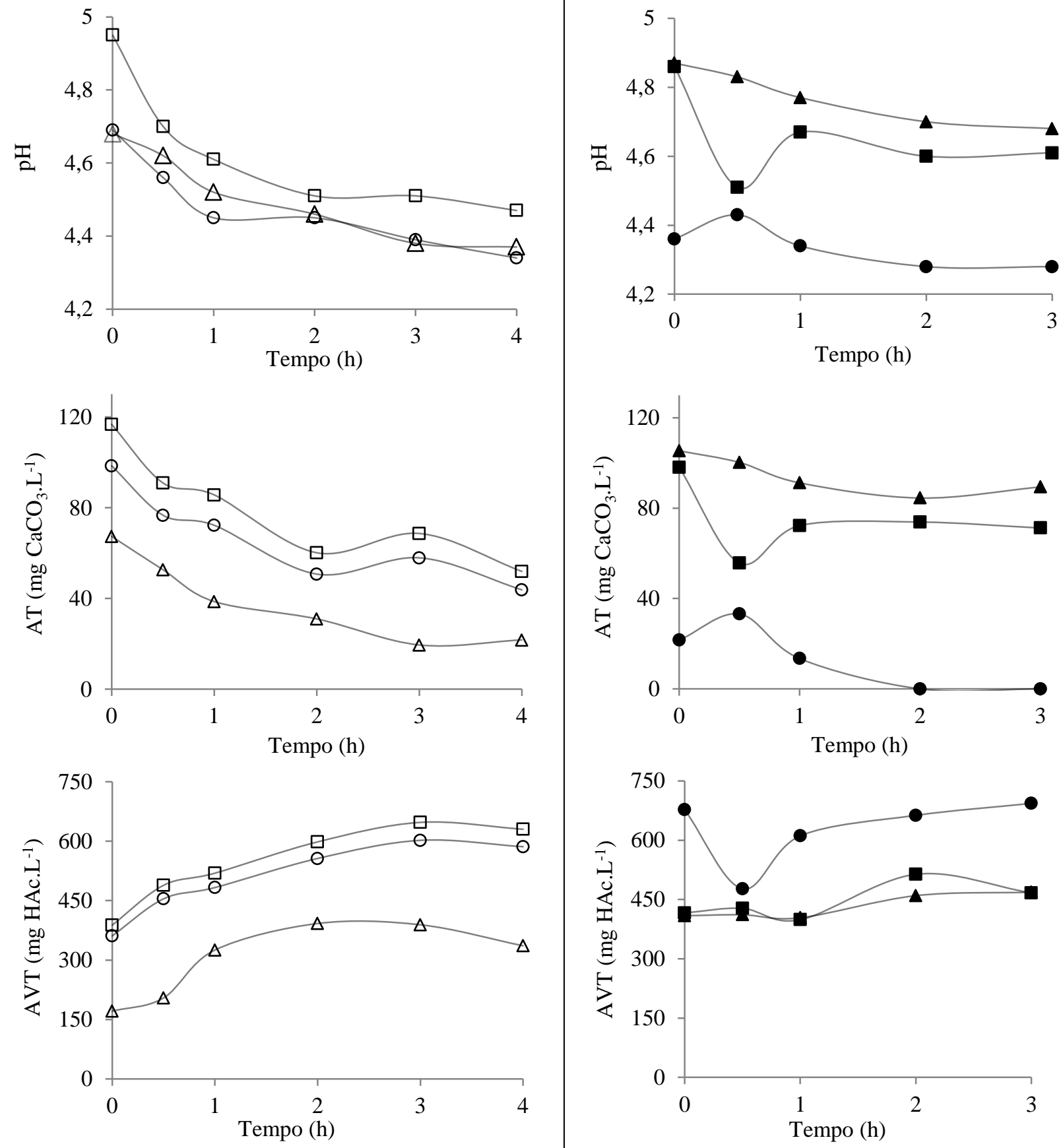

Figura 5.11 - Perfil de pH, AT e AVT das condições CI $\left(\bullet^{-}\right)$, CII $(\square)$ e CIII $(-\bullet)$ operadas com 4 horas de tempo de ciclo.

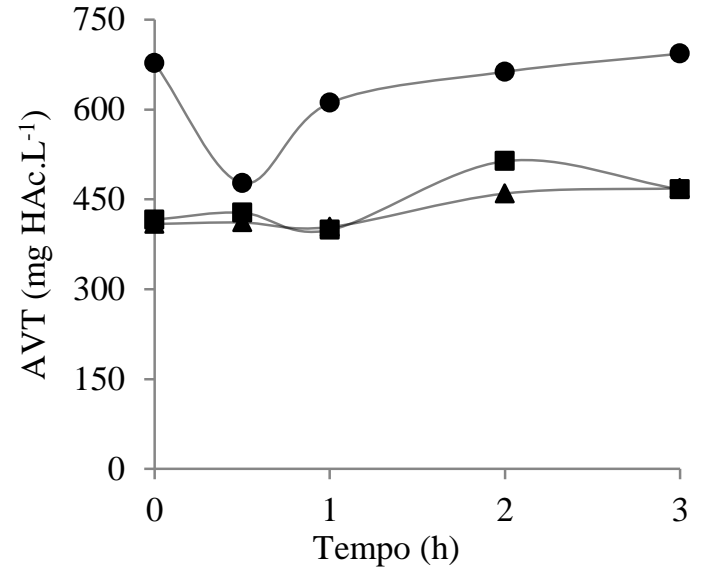

Figura 5.12 - Perfil de pH, AT e AVT das condições CIV $\left(\bullet^{-}\right), \mathrm{CV}(-)$ e CVI $(\bullet-)$ operadas com 3 horas de tempo de ciclo. 
Como se observa na Figura 5.11, para as condições operadas com tempo de ciclo de 4 horas foi observada uma queda no $\mathrm{pH}$ e na alcalinidade total enquanto a contração de ácidos voláteis aumentava ao longo do ciclo. O mesmo comportamento foi observado na condição CIV operada com 3 horas de tempo de ciclo, porém as condições CV e CVI mostraram tendências irregulares como se observa na Figura 5.12. A condição CV mostrou uma tendência de produção e consumo em sequência de ácidos voláteis totais acompanhada por uma tendência contraria para o parâmetro pH. Na condição CVI observou-se uma queda acentuada na concentração dos ácidos voláteis totais com meia hora de tempo de ciclo seguida por seu aumento continuo. A tendência contrária observou-se para os parâmetros pH e alcalinidade total, que diminuíram a medida que a concentração de AVT aumentou.

\section{c) Sólidos e biomassa}

Ainda que para todos os experimentos fosse colocada a mesma quantidade de inóculo, a carga orgânica afluente e o tempo de ciclo de operação fizeram com que as quantidades de biomassa aderidas ao suporte fossem diferentes para cada condição. Assim, como se observa na Tabela 5.4, as condições CI, CII e CIII que operaram com tempos de ciclo de 4 horas apresentaram 6, 3 e 3 g de biomassa total operando com aproximadamente 3000, 4000 e 5000

mgDQO.L ${ }^{-1}$, respectivamente. Contrariamente ao esperado, quanto menor carga aplicada maior foi a quantidade de biomassa presente no interior do reator. Este patrão de comportamento, porém, não foi observado nas condições CIV, CV e CVI que operaram com tempos de ciclo de 3 horas e concentrações afluentes aproximadas de 3000, 4000 e 5000 mgDQO.L ${ }^{-1}$, respectivamente, para as quais a maior carga apresentou a maior quantidade de biomassa total no 
suporte. Este último resultado pode ser justificado pela alta reposição de nutrientes no meio em períodos mais curtos de tempo.

Com relação à quantidade de biomassa desprendida do suporte e eliminada no efluente na forma de SSV, observou-se que para os ciclos de 4 horas a relação foi diretamente proporcional à carga, com maior desprendimento de biomassa para as maiores cargas aplicadas. Pelo contrário, nas condições que operaram com 3 horas de tempo de ciclo, a relação foi inversamente proporcional.

\section{d) Produção volumétrica de biogás}

Tanto para as condições que foram operadas com 3 horas de tempo de ciclo como para as operadas com 4 horas, observou-se uma relação diretamente proporcional entre a carga orgânica aplicada na forma de DQO e o volume de biogás produzido, como se observa na Tabela 5.4 e na Figura 5.13.

O tempo de ciclo foi um fator determinante na produção volumétrica de biogás como se observa na Figura 5.13. As condições CI e CIV operadas com afluente de concentração aproximada de $3000 \mathrm{mgDQO} . \mathrm{L}^{-1}$ apresentaram diferentes comportamentos na produção de biogás. A CI operada com um tempo de ciclo de 4 horas mostrou uma produção constante de biogás durante os primeiros dias de monitoramento e um pequeno aumento no final, sendo o volume de biogás mínimo e máximo registrado de 1,2 e 2,1 L.d ${ }^{-1}$, respectivamente.

Entretanto, a condição CIV operada com um tempo de ciclo de 3 horas, mostrou um aumento constante na produção durante os primeiros dias com uma queda acentuada no final, sendo o volume de biogás mínimo e máximo registrado de 3,9 e 6 L.d ${ }^{-1}$ respetivamente. Nas duas 
condições prevaleceu a produção de hidrogênio, seguido pelo dióxido de carbono e finalmente pelo metano. Em média as condições CI e IV mesmo alimentadas com aproximadamente a mesma concentração de DQO afluente produziram 0,6 e 2,4 L- $\mathrm{H}_{2} \cdot \mathrm{d}^{-1}$, respectivamente.

As condições CII e CV operadas com uma concentração afluente aproximada de 4000 mgDQO.L $\mathrm{L}^{-1}$ também mostraram comportamentos diferentes. A condição CII operada com um tempo de ciclo de 4 horas apresentou uma produção constante durante os primeiros dias, seguido de um pico máximo e posteriormente uma queda, sendo o volume de biogás mínimo e máximo registrado de 3,5 e 8,8 L.d ${ }^{-1}$ respectivamente. Entretanto, a condição CV operada com um tempo de ciclo de 3 horas, apresentou o seu pico máximo nos primeiros dias e posteriormente uma queda constante, sendo o volume de biogás mínimo e máximo registrado de 4,8 e 6,7 L.d ${ }^{-1}$ respetivamente. As duas condições produziram volumes médios similares de hidrogênio, sendo estes 3,2 e 3,5 L-H $\mathrm{H}_{2} \mathrm{~d}^{-1}$, respectivamente. Porém, enquanto a condição CII produziu em média apenas 0,02 $\mathrm{L}-\mathrm{CH}_{4} \cdot \mathrm{d}^{-1}$ observando-se a presença deste gás unicamente no último dia de monitoramento, a condição $\mathrm{CV}$ produziu em média $0,16 \mathrm{~L}-\mathrm{CH}_{4} \cdot \mathrm{d}^{-1}$ quantificando-se metano desde o primeiro dia de monitoramento.

Para as condições CIII e CVI operadas com concentração afluente aproximada de 5000 mgDQO.L ${ }^{-1}$, observou-se uma marcada diferença tanto no volume de gás total como na composição deste. A produção de biogás na condição CIII operada com um tempo de ciclo de 4 horas foi crescente nos primeiros dias mantendo-se quase constante no final, sendo o volume de biogás mínimo e máximo registrado de 7,5 e 9 L.d ${ }^{-1}$, respectivamente Nesta condição prevaleceu a produção volumétrica de hidrogênio que foi em média $5,6 \mathrm{~L}-\mathrm{H}_{2} \cdot \mathrm{d}^{-1}$, seguida pela produção de dióxido de carbono e metano, sendo a produção volumétrica média desde último gás de 0,15 $\mathrm{LCH}_{4} \cdot \mathrm{d}^{-1}$. A condição CVI manteve sua produção de biogás estável durante os primeiros dias 
caindo nos últimos. Esta condição se caracterizou pela alta e crescente produção de metano, produzindo em média $4,3 \mathrm{LH}_{2} \cdot \mathrm{d}^{-1}$ e $0,96 \mathrm{LCH}_{4} \cdot \mathrm{d}^{-1}$.

Na Tabela 5.5 são apresentados os volumes acumulados de hidrogênio, metano e dióxido de carbono gerados ao longo do ciclo em todas as condições. A tendência na produção pode ser visualizada mais facilmente na Figura 5.14, na qual se observa que em todas as condições, com exceção das CI e CIV, os volumes acumulados dos três gases apresentaram um aumento ao longo do ciclo. Os perfis das condições CI e CIV evidenciaram uma queda do volume acumulado de hidrogênio na primeira hora de ciclo o que coincidiu com o aumento do volume de metano. No ciclo da condição CIV observou-se o maior volume de hidrogênio com uma hora de ciclo, apresentando uma queda concomitante do volume de dióxido de carbono e um aumento do volume de metano.

Das condições em estudo, a que produziu maior volume de hidrogênio foi a CIII alimentada com uma concentração afluente de $5000 \mathrm{mgDQO} . \mathrm{L}^{-1}$ e operada com 4 horas de tempo de ciclo (COVA: $\left.12911 \mathrm{mgDQO} \cdot \mathrm{L}^{-1} \cdot \mathrm{d}^{-1}\right)$. 


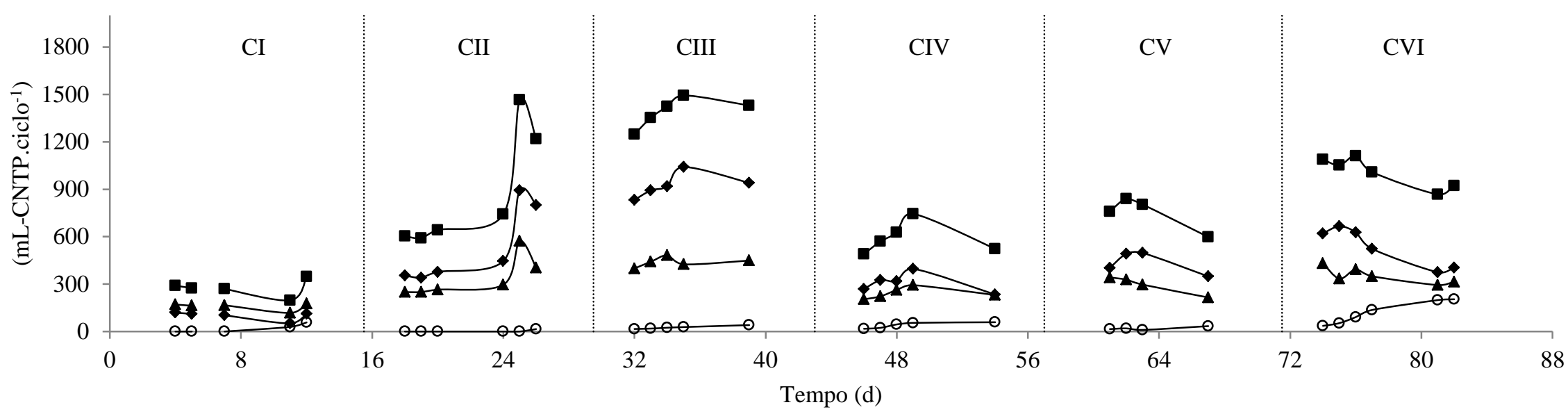

Figura 5.13 - Volume produzido nos ciclos monitorados de gás $\mathrm{V}_{\mathrm{G}}(-\boldsymbol{-})$, volume de $\mathrm{H}_{2}(\rightarrow)$, volume de $\mathrm{CO}_{2}\left({ }^{\bullet}\right)$, volume de $\mathrm{CH}_{4}$ (o) das condições da "Fase Experimental".

Tabela 5.5 - Volumes acumulados de hidrogênio, metano e dióxido de carbono ao longo do ciclo das condições da "Fase Experimental".

\begin{tabular}{|c|c|c|c|c|c|c|c|c|c|c|c|c|c|c|c|c|c|c|}
\hline \multirow[t]{2}{*}{ Tempo (h) } & \multicolumn{3}{|c|}{$\begin{array}{c}\mathrm{CI} \\
\text { (mL-CNTP) }\end{array}$} & \multicolumn{3}{|c|}{$\begin{array}{c}\text { CII } \\
\text { (mL-CNTP) }\end{array}$} & \multicolumn{3}{|c|}{$\begin{array}{c}\text { CIII } \\
\text { (mL-CNTP) }\end{array}$} & \multicolumn{3}{|c|}{$\begin{array}{c}\text { CIV } \\
\text { (mL-CNTP) }\end{array}$} & \multicolumn{3}{|c|}{$\begin{array}{c}\mathrm{CV} \\
\text { (mL-CNTP) }\end{array}$} & \multicolumn{3}{|c|}{$\begin{array}{c}\text { CVI } \\
\text { (mL-CNTP) }\end{array}$} \\
\hline & $\mathrm{V}_{\mathrm{H} 2}$ & $\mathrm{~V}_{\mathrm{CH} 4}$ & $\mathrm{~V}_{\mathrm{CO} 2}$ & $\mathrm{~V}_{\mathrm{H} 2}$ & $\mathrm{~V}_{\mathrm{CH} 4}$ & $\mathrm{~V}_{\mathrm{CO} 2}$ & $\mathrm{~V}_{\mathrm{H} 2}$ & $\mathrm{~V}_{\mathrm{CH} 4}$ & $\mathrm{~V}_{\mathrm{CO} 2}$ & $\mathrm{~V}_{\mathrm{H} 2}$ & $\mathrm{~V}_{\mathrm{CH} 4}$ & $\mathrm{~V}_{\mathrm{CO} 2}$ & $\mathrm{~V}_{\mathrm{H} 2}$ & $\mathrm{~V}_{\mathrm{CH} 4}$ & $\mathrm{~V}_{\mathrm{CO} 2}$ & $\mathrm{~V}_{\mathrm{H} 2}$ & $\mathrm{~V}_{\mathrm{CH} 4}$ & $\mathrm{~V}_{\mathrm{CO} 2}$ \\
\hline 0 & 0,0 & 0,0 & 0,0 & 0,0 & 0,0 & 0,0 & 0,0 & 0,0 & 0,0 & 0,0 & 0,0 & 0,0 & 0,0 & 0,0 & 0,0 & 0,0 & 0,0 & 0,0 \\
\hline 0,5 & 92,4 & 0,0 & 0,0 & 191,3 & 0,0 & 183,5 & 241,6 & 10,5 & 120,1 & 57,0 & 0,0 & 402,5 & 131,1 & 0,0 & 151,3 & 134,1 & 102,4 & 107,5 \\
\hline 1 & 64,5 & 14,0 & 96,1 & 479,6 & 0,0 & 275 & 519,3 & 14,3 & 23 & 434,8 & 30,1 & 279 & 278,1 & 25,9 & 247,9 & 293,7 & 190,0 & 212,1 \\
\hline 2 & 111,4 & 33,1 & 153 & 778,9 & 0,0 & 389 & 863,7 & 30,7 & 420 & 377,3 & 50,7 & 31 & 444,9 & 53,9 & 299 & 420,6 & 209,0 & 294,8 \\
\hline 3 & 112,1 & 48,0 & 181,4 & 811,6 & 0,0 & 408,0 & 946,2 & 39,0 & 444,9 & 374,2 & 62,8 & 307,7 & 459,8 & 46,2 & 297,6 & 405,0 & 204,4 & 314,9 \\
\hline & 112,9 & 57,6 & 176,1 & 799,9 & 15,3 & 404,4 & 940,4 & 40,8 & 448,9 & - & - & - & - & - & - & - & - & - \\
\hline & \multicolumn{3}{|c|}{$\mathrm{V}_{\mathrm{G}}: 346,6 \mathrm{~mL}-\mathrm{CNTP}$} & & & \multicolumn{3}{|c|}{$\mathrm{V}_{\mathrm{G}}: 744,6 \mathrm{~mL}-\mathrm{CNTP}$} & \multicolumn{3}{|c|}{$\mathrm{V}_{\mathrm{G}}: 803,6 \mathrm{~mL}-\mathrm{CNTP}$} & \multicolumn{3}{|r|}{ ENTP } \\
\hline
\end{tabular}


CI

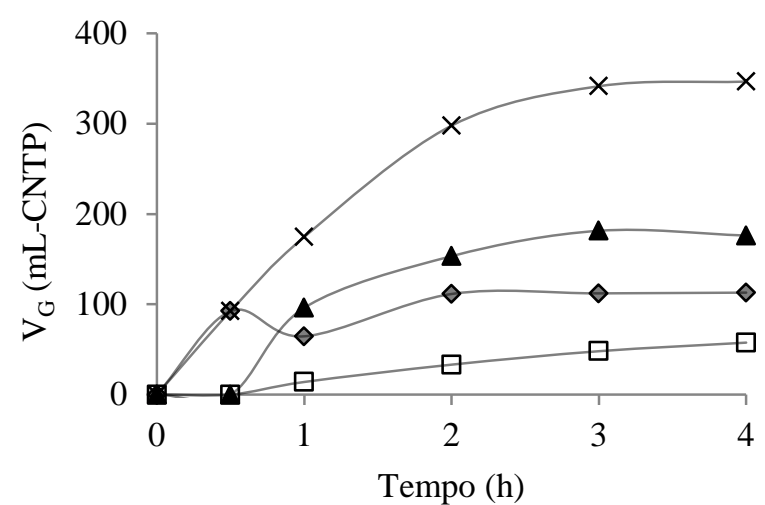

CIV

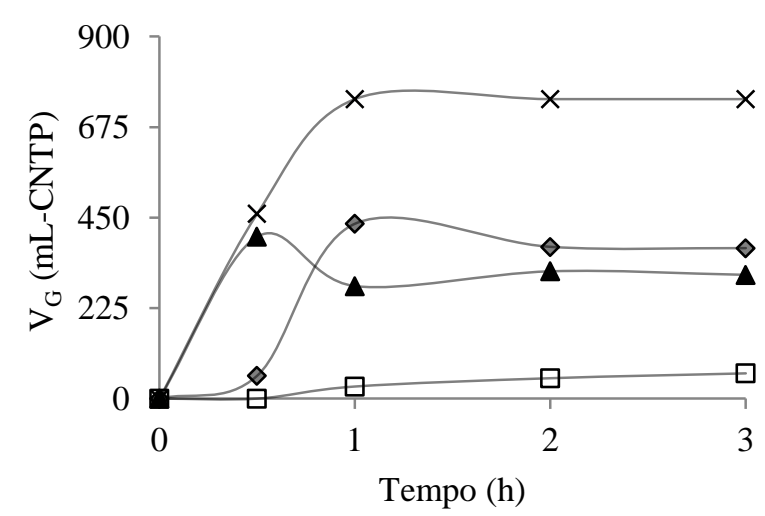

CII

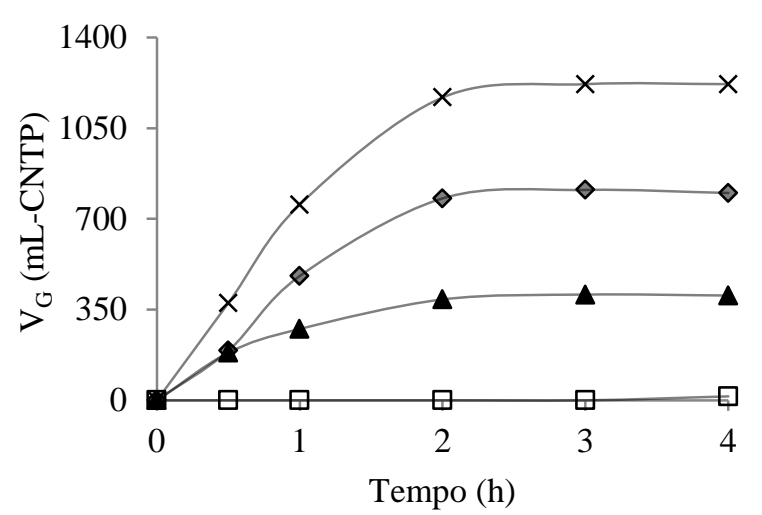

CV

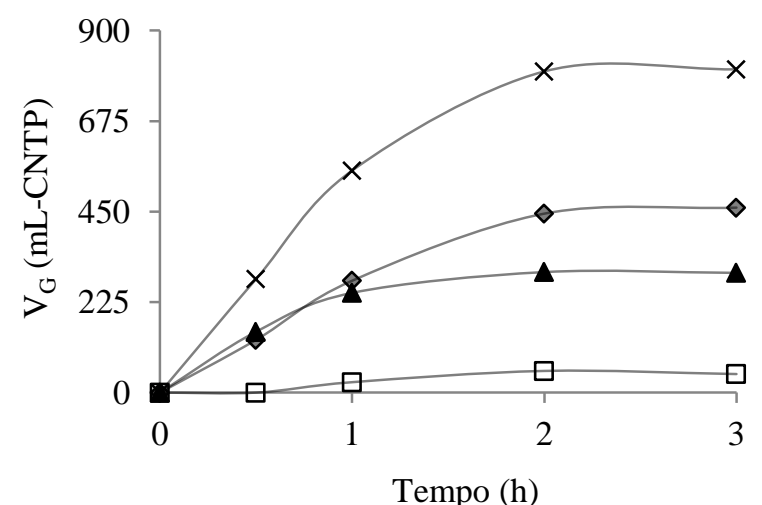

CIII

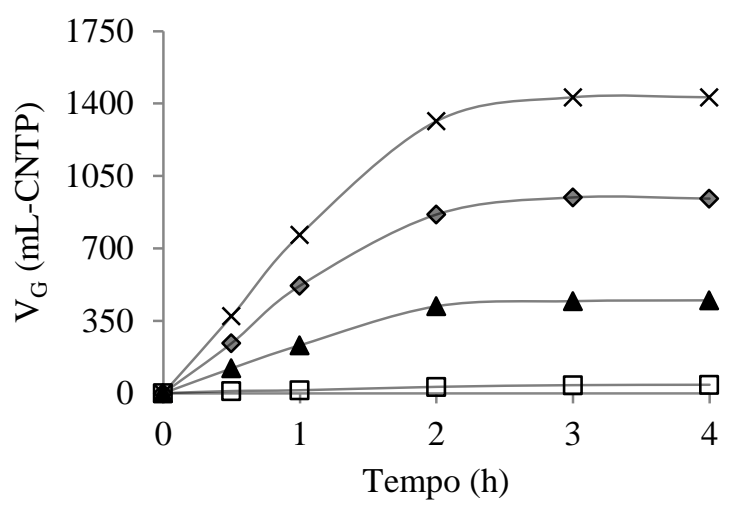

CVI

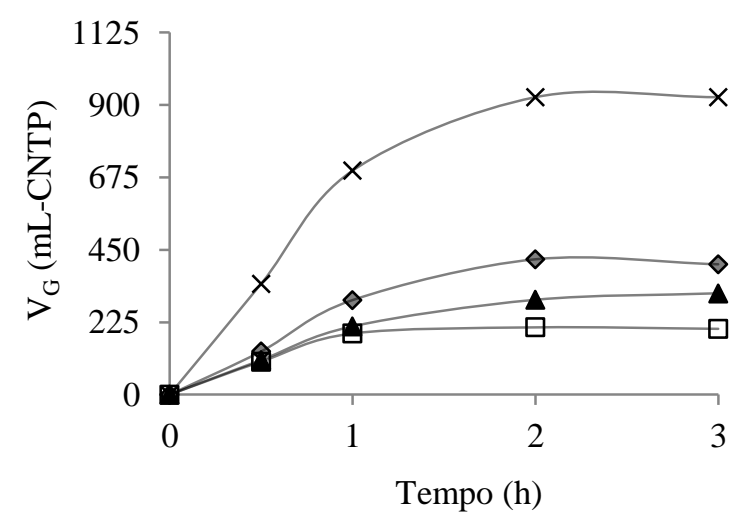

Figura 5.14 - Volumes acumulados produzidos ao longo dos ciclos das condições da "Fase experimentação".

Notação: mL-CNTP de biogás $\left({ }^{\star}\right)$, mL-CNTP de $\mathrm{H}_{2}(\bullet)$, mL-CNTP de $\mathrm{CH}_{4}\left({ }^{-}\right)$, mL-CNTP de $\mathrm{CO}_{2}\left(\bullet^{-}\right)$. 


\subsubsection{Produção de hidrogênio}

\section{a) Indicadores de produção}

Na Tabela 5.6 apresenta-se um resumo das médias dos indicadores usados na "Fase de experimentação" para avaliar a produção de hidrogênio das diferentes condições, conjuntamente com as cargas envolvidas na operação do reator.

Ainda que a concentração da DQO do afluente tenha sido a mesma para as condições CI e CIV, CII e CV, e CIII e CVI, a diminuição do tempo de ciclo de 4 para 3 horas fez como que a carga orgânica volumétrica aplicada ao reator aumentasse, já que quanto menor a duração do ciclo, maior é o número de ciclos por dia e maior é a carga aplicada diariamente. Quando se fala de concentração de matéria orgânica alimentada ao reator faz-se referência à concentração de DQO do afluente. Por outro lado, quando se fala de carga orgânica volumétrica aplicada faz-se referência à quantidade em massa de matéria orgânica aplicada ao reator por unidade de tempo e por volume de meio do reator (COVA).

Tabela 5. 6 - Médias de indicadores de produção de hidrogênio e das cargas orgânicas envolvidas na operação do reator durante a "Fase experimental".

\begin{tabular}{cccccccc}
\hline & & \multicolumn{7}{c}{ Condições } \\
\cline { 3 - 8 } Parâmetro & Unidade & CI & CII & CIII & CIV & CV & CVI \\
\hline COVA $_{\mathrm{ST}}$ & $\left(\mathrm{mgDQO} \cdot \mathrm{L}^{-1} \cdot \mathrm{d}^{-1}\right)$ & 7565 & 9764 & 12911 & 10319 & 13327 & 16216 \\
COVR $_{\mathrm{SF}}$ & $\left(\mathrm{mgDQO} \cdot \mathrm{L}^{-1} \cdot \mathrm{d}^{-1}\right)$ & 1794 & 2378 & 3171 & 3263 & 3552 & 4106 \\
COEA $_{\mathrm{ST}}$ & $\left(\mathrm{mgDQO} \cdot \mathrm{gSVT}^{-1} \cdot \mathrm{d}^{-1}\right)$ & 4627 & 11945 & 13936 & 10432 & 11988 & 7719 \\
COER $_{\mathrm{SF}}$ & $\left(\mathrm{mgDQO} \cdot \mathrm{gSVT}^{-1} \cdot \mathrm{d}^{-1}\right)$ & 1097 & 2909 & 3422 & 3299 & 3195 & 1954 \\
$\mathrm{~V}_{\mathrm{H} 2}$ & $\left(\mathrm{~L}-\mathrm{CNTP}^{-1} \mathrm{~d}^{-1}\right)$ & 0,6 & 3,2 & 5,6 & 2,4 & 3,5 & 4,3 \\
$\mathrm{n}_{\mathrm{H} 2}$ & $\left(\mathrm{mmolH}_{2} \cdot \mathrm{d}^{-1}\right)$ & 27 & 143 & 248 & 109 & 155 & 191 \\
PrM & $\left(\mathrm{molH}_{2} \cdot \mathrm{m}^{-3} \cdot \mathrm{d}^{-1}\right)$ & 7,3 & 39,0 & 67,5 & 29,8 & 42,3 & 52,1 \\
PrME & $\left(\mathrm{molH}_{2} \cdot \mathrm{kgSVT}^{-1} \cdot \mathrm{d}^{-1}\right)$ & 4,4 & 13,2 & 19,8 & 8,2 & 10,4 & 6,8 \\
$\mathrm{RMCA}_{\mathrm{S}, \mathrm{m}}$ & $\left(\mathrm{molH}_{2} \cdot \mathrm{kgDQO}^{-1}\right)$ & 0,9 & 4,1 & 5,2 & 2,9 & 3,4 & 3,4 \\
RMCR $_{\mathrm{S}, \mathrm{m}}$ & $\left(\mathrm{molH}_{2} \cdot \mathrm{kgDQO}^{-1}\right)$ & 3,8 & 17,1 & 21,1 & 11,6 & 12,5 & 13,4 \\
\hline
\end{tabular}


Como se observa na Tabela 5.6, a carga orgânica volumétrica aplicada para a qual o reator teve uma melhor resposta com relação à produção de hidrogênio foi $12911 \mathrm{mgDQO} \cdot \mathrm{L}^{-1} \cdot \mathrm{d}^{-1} \mathrm{em}$ média, correspondente à condição CIII operada com um tempo de ciclo de 4 horas. A condição apresentou a maior produção volumétrica de hidrogênio $\left(\mathrm{V}_{\mathrm{H} 2}\right)$, a maior produção molar de hidrogênio $\left(\mathrm{n}_{\mathrm{H} 2}\right)$, a maior produtividade molar (PrM), a maior produtividade molar específica (PrME), o melhor rendimento molar por carga orgânica aplicada $\left(\mathrm{RMCA}_{\mathrm{S}, \mathrm{m}}\right)$ e o melhor rendimento molar por carga orgânica removida $\left(\mathrm{RMCR}_{\mathrm{s}, \mathrm{m}}\right)$. Como se observa na Figura 5.15 o biogás gerado nesta condição apresentou a maior concentração de hidrogênio, a menor concentração de dióxido de carbono e uma baixa porcentagem de metano. A sua produtividade molar foi evidentemente maior em comparação às outras condições como se observa na Figura 5.16 .

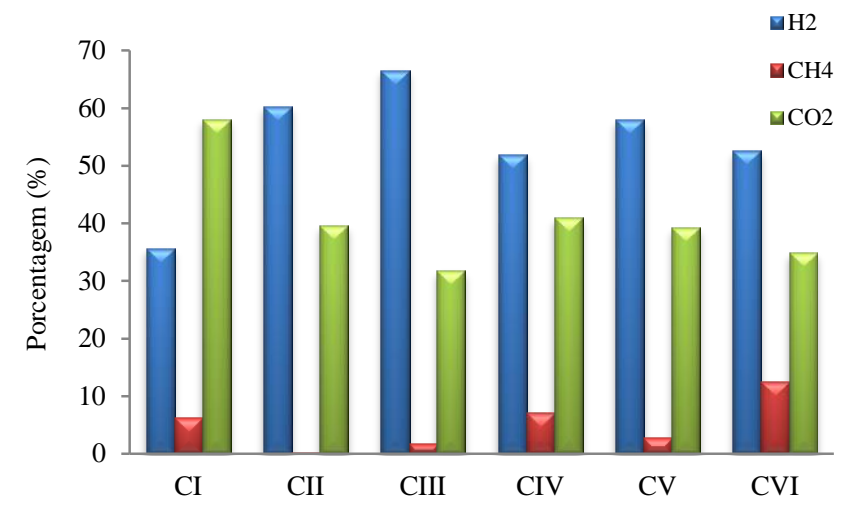

Figura 5.15 - Composição porcentual de gases das condições da "Fase experimental".

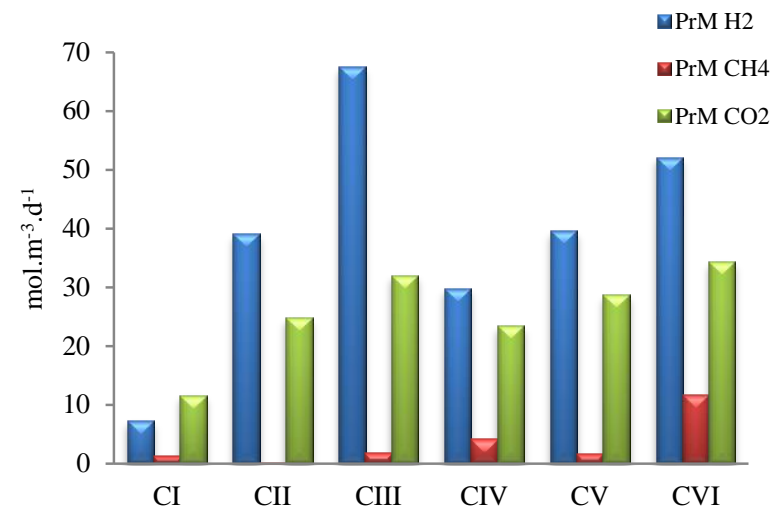

Figura 5.16 - Produtividade molar média de cada condição da "Fase experimental".

A segunda melhor condição com relação à produtividade molar de hidrogênio foi a CVI operada com uma carga orgânica volumétrica média de 16216 mgDQO.L $\mathrm{L}^{-1}$ e um tempo de ciclo de 3 horas, como se observa na Figura 5.16. Porém, esta condição também apresentou a maior porcentagem de metano no biogás de todas as condições em estudo. 
Como foi exposto no Capítulo 3, o metabolismo microbiano anaeróbio constitui uma sequência de processos interdependentes dos produtos gerados previamente. Em primeiro lugar aparecem as bactérias fermentativas encarregadas da hidrólise da matéria orgânica e da geração de ácidos voláteis, razão pela qual recebem o nome de bactérias acidogênicas. Durante esta etapa de acidogênese é gerado o hidrogênio objetivo desta pesquisa. Em uma segunda fase, aparecem as bactérias acetogênicas produtoras de hidrogênio que, como seu nome indica, produzem hidrogênio a partir dos ácidos voláteis gerados na primeira fase. Porém, as reações de oxidação dos ácidos voláteis acontecem apenas quando os níveis de pressão parcial de hidrogênio são extremamente baixos. Para que isto seja possível, estabelece-se de acordo com Hungate (1967) uma relação simbiótica entre microrganismos acetogênicos e metanogênicos, ocorrendo o processo chamado de "transferência de hidrogênio interespécies" (Kumar, 2008). Assim, os microrganismos consumidores de hidrogênio, diminuem a pressão parcial deste gás transformado às reações de oxidação dos ácidos gerados na acidogenesis, termodinamicamente favoráveis. Quando as concentrações de matéria orgânica que alimentam o reator são altas, as bactérias fermentativas dispõem de maiores quantidades de matéria para formar ácidos voláteis, hidrogênio e dióxido de carbono. Como foi observado na descrição do comportamento do reator, as condições CIII e CVI alimentadas com o afluente de $5000 \mathrm{mgDQO} . \mathrm{L}^{-1}$ apresentaram as maiores produções de AVT e de hidrogênio, um resultado esperado de acordo com a bibliografia. Porém, como se observa na Figura 5.16, a condição CVI apresentou a maior produção de metano, resultado que poderia ser um indicativo de que a produção de hidrogênio aconteceu a partir dos ácidos voláteis por acetogênesis e não unicamente do processo de acidogênese do glicerol-PA. Adicionalmente, durante o perfil da condição CVI foi observada uma queda na concentração de 
AVT com meia hora de tempo de ciclo, fato que pode ter sido ocasionado pelo consumo mencionado.

As cargas orgânicas volumétricas aplicadas às condições operadas com 4 horas de tempo de ciclo e concentrações de matéria orgânica alimentadas de 4000 e 5000 mgDQO.L ${ }^{-1}$ foram menores em comparação às operadas com 3 horas de tempo de ciclo. Como consequência a quantidade de matéria orgânica hidrolisada durante o dia foi menor tendo possivelmente um efeito positivo em relação à pressão parcial de hidrogênio, já que em quanto menor matéria orgânica a metabolizar menor hidrogênio produzido. Devido a isto, as condições CII e CIII mostraram maiores produções de hidrogênio com menores produções de metano em comparação às $\mathrm{CV}$ e CVI. Estes resultados evidenciam que o hidrogênio produzido pela oxidação de ácidos voláteis foi consideravelmente menor ao produzido pela acidogênesis a partir do glicerol.

Porém, para a condição CI que operou com a menor carga orgânica volumétrica se observou a maior produção de metano das condições operadas com 4 horas de tempo de ciclo. Este resultado pode ter acontecido devido ao maior tempo de ciclo em relação à concentração de matéria orgânica do afluente, o que facilitou a reprodução de microrganismos de lento crescimento como as aqueias metanogênicas.

Os resultados evidenciam que o sucesso no processo de obtenção de hidrogênio por fermentação do substrato estaria em encontrar um equilíbrio entre a concentração de matéria orgânica alimentada no afluente e o tempo que os microrganismos têm para fermentar essa matéria antes de atingir o nível crítico de pressão parcial de hidrogênio. Um tempo excessivamente alto para uma carga baixa poderia se traduzir no consumo de hidrogênio pela disponibilidade do gás para microrganismos consumidores de lento crescimento. Um tempo curto com uma alta concentração de matéria orgânica alimentada poderia se traduzir na excessiva 
pressão parcial de hidrogênio que também contribuiria para o seu consumo pelos mesmos organismos.

Das cargas orgânicas volumétricas ensaiadas e dos resultados obtidos observa-se que esse equilíbrio para o reator AnSBBR operado em batelada foi atingido com as cargas volumétricas de 9764 e 12911 mgDQO.L ${ }^{-1}$. A primeira correspondeu à condição CII operada com 4 horas de tempo de ciclo e alimentada com um afluente de $4000 \mathrm{mgDQO} . \mathrm{L}^{-1}$. Esta condição apresentou, em média, uma composição de $0,21 \%$ de metano. A segunda carga correspondeu à condição CIII operada também com 4 horas de tempo de ciclo e alimentada com um afluente de 5000 mgDQO.L $L^{-1}$, a qual apresentou a composição média de metano de $1,8 \%$ e produtividade molar de hidrogênio mais alta entre todas as condições. Como foi observado na Figura 5.12 do perfil de AVT ao longo do ciclo, a concentração de AVT da condição CII foi maior do que a concentração da condição CIII, possivelmente por esse consumo de ácidos. Esta seria então uma possível explicação para a última condição CVI apresentar a maior concentração de metano.

De acordo com Hawkes et al. (2007), tempos de detenção hidráulica excessivamente curtos afetam o aproveitamento do substrato na produção de hidrogênio, o que justificaria o maior rendimento de hidrogênio atingido pelas condições CII e CIII operadas com 4 horas de tempo de ciclo em comparação com as condições CV e CVI operadas com 3 horas. Os resultados evidenciam que o tempo de ciclo de 4 horas além de permitir um melhor aproveitamento do substrato provavelmente apresenta algumas vantagens em relação à pressão parcial de hidrogênio, que de acordo com Angelent et al. (2004) e Mandal e Nath (2006), constitui um fator de risco para a produção de hidrogênio. 


\section{b) Produtos intermediários na produção de hidrogênio}

De acordo com Maru et al. (2012) e Sarma et al. (2012) a geração máxima de hidrogênio de $3 \mathrm{molH}_{2} \cdot \mathrm{molglicerol}^{-1}$ é atingida pela hidrolise da glicerina em ácido acético, dióxido de carbono e hidrogênio. Esta relação é de apenas $2 \mathrm{molH}_{2} \cdot \mathrm{molglicerol}^{-1}$ quando ácido butírico e butanol são os produtos finais, e $1 \mathrm{molH}_{2} \cdot$ molglicerol $^{-1}$ quando é o etanol. De acordo com os resultados apresentados na Tabela 5.7 em sua maioria o hidrogênio foi produzido em uma relação de $2 \mathrm{molH}_{2} \cdot \mathrm{molglicerol}^{-1}$, já que os produtos intermediários de maior abundancia foram o ácido butírico e o butanol. Como

Tendo em vista que o ácido acético é gerado tanto pela fermentação da glicerina como por processos de homoacetogênese a partir de dióxido de carbono e hidrogênio no meio, estabelecer se o ácido acético quantificado foi gerador ou consumidor de hidrogênio torna se difícil. Porém, a condição de maior produção de hidrogênio CIII apresentou a menor porcentagem de ácido acético na composição dos intermediários ao longo do ciclo como se observa na Tabela 5.7. Este fato poderia constituir evidencia de que o ácido acético presente proveio também da homoacetogênese, naquelas condições que mostraram maiores produções deste ácido. Nesse sentido, um caso interessante foi observado na condição CI, a qual mostrou uma queda na concentração molar de hidrogênio acompanhada pelo aumento da concentração molar de metano e de ácido acético com uma hora de ciclo como se observa na Figura 5.17. Um comportamento similar foi observado na condição CIV. O aumento de ácido acético acompanhada da queda da produção de hidrogênio tem sido já observado na literatura e relacionado com a homoacetogênese, como são os casos apresentados por Oh et al. (2003), Hussy et al. (2003) e Ueno et al. (1996). 
Ao comparar os perfis das condições CII e CV da Figura 5.17, observa-se que a condição CII apresentou menor concentração de ácido acético, menor concentração de metano e maior concentração de ácido butírico e butanol em comparação à CV. Parte do hidrogênio observado nesta última condição poderia estar relacionada ao consumo dos ácidos voláteis por bactérias acetogênicas com participação da arqueias metanogênicas e homoacetogênicas. Em consequência estaria relacinado também à produção de hidrogênio por acetogênesis.

A condição CVI operada com a maior carga orgânica volumétrica nesta fase mostrou o maior consumo de hidrogênio na forma de metano e alta presença de ácido acético. Como foi explicado anteriormente, possivelmente este fato se deve ao efeito da pressão parcial de hidrogênio que contribuiu ao aparecimento de microrganismos consumidores do gás. Ni et al. (2011) observaram em sua experimentação que em maiores concentrações de substrato haveram maiores produções de ácido acético por homoacetogênese. Um resultado que concorda com o obtido na presente pesquisa.

Hawkes et al. (2005) assegura que a produção de hidrogênio realizada pelo gênero clostridia está relacionada à enzima hidrogenase, a qual oxida o fator NADH produzindo hidrogênio, quando a pressão parcial do hidrogênio é baixa. Porém, em condições normais de operação, a maioria dos fatores NADH do meio são oxidados quando produtos reduzidos como o ácido butírico são gerados. Esta poderia ser a explicação pela qual o ácido butírico, um produto reduzido, foi altamente observado.

De acordo com Ballongue et al. (1987) o acúmulo de ácidos no meio faz com que as rotas metabólicas mudem para a produção de solventes com o objetivo de regular o pH do meio. Esta mudança da rota metabólica aconteceria quando o $\mathrm{pH}$ é menor do que 4,5 como foi o registrado nesta fase da pesquisa. Esta poderia ser a razão pela qual foram observadas altas concentrações 
de butanol no efluente tratado. Doremus et al. (1985) também atribuíram a produção de solventes ao aumento da pressão parcial do hidrogênio devido à pobre agitação do meio de cultura. Na fasse preliminar foi observada uma melhora na produção de hidrogênio quando a velocidade de recirculação foi aumentada de $10 \mathrm{~L} \cdot \mathrm{h}^{-1}$ a $30 \mathrm{~L} \cdot \mathrm{h}^{-1}$, possivelmente relacionada à diminuição da pressar parcial de hidrogênio. Ensaios com velocidades maiores de recirculação poderia ser objeto de estudos futuros.

Tabela 5.7 - Porcentagem dos compostos intermediários das condições da "Fase experimental"

\begin{tabular}{ccccccc}
\hline Espécies & CI & CII & CIII & CIV & CV & CVI \\
\hline Acetona (\%) & 0 & 0 & 0 & 0 & 0 & 0 \\
Metanol (\%) & 0 & 0 & 0 & 0 & 0 & 0 \\
Etanol (\%) & 4 & 2 & 3 & 9 & 2 & 2 \\
Butanol (\%) & 4 & 30 & 30 & 17 & 27 & 28 \\
Ácido Acético (\%) & 24 & 8 & 7 & 22 & 16 & 13 \\
Ácido Propiônico (\%) & 8 & 4 & 4 & 6 & 4 & 5 \\
Ácido Iso-Butírico (\%) & 1 & 1 & 4 & 1 & 1 & 3 \\
Ácido Butírico (\%) & 47 & 48 & 42 & 37 & 44 & 42 \\
Ácido Iso-Valérico (\%) & 2 & 1 & 1 & 1 & 1 & 1 \\
Ácido Valérico (\%) & 4 & 2 & 2 & 4 & 2 & 2 \\
Ácido Capróico (\%) & 5 & 4 & 6 & 3 & 3 & 4 \\
Total (mg.L ${ }^{-1}$ ) & 449,5 & 870,2 & 978,9 & 544,1 & 790,8 & 1014,6 \\
\hline
\end{tabular}


CI

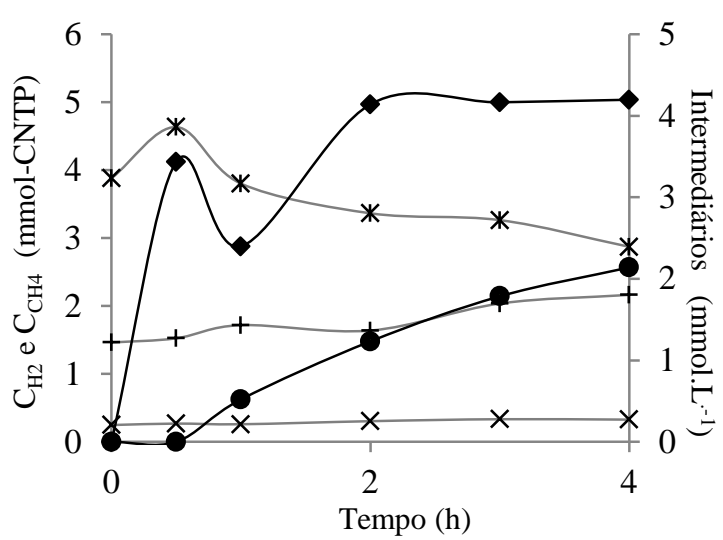

CIV

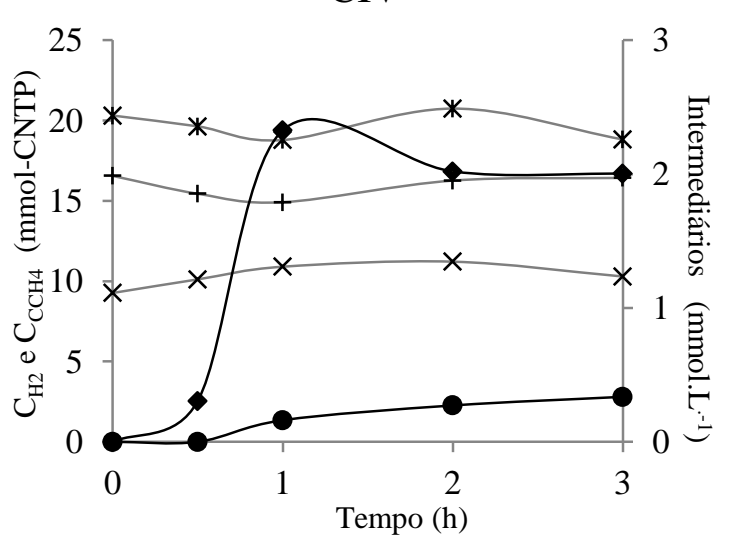

CII

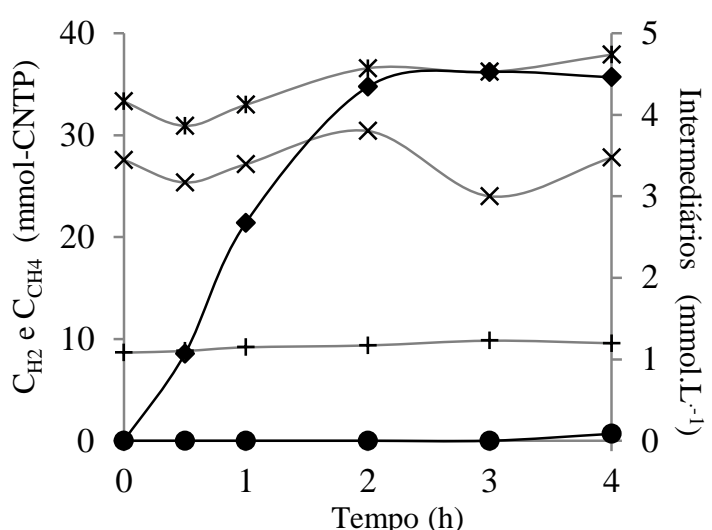

CV

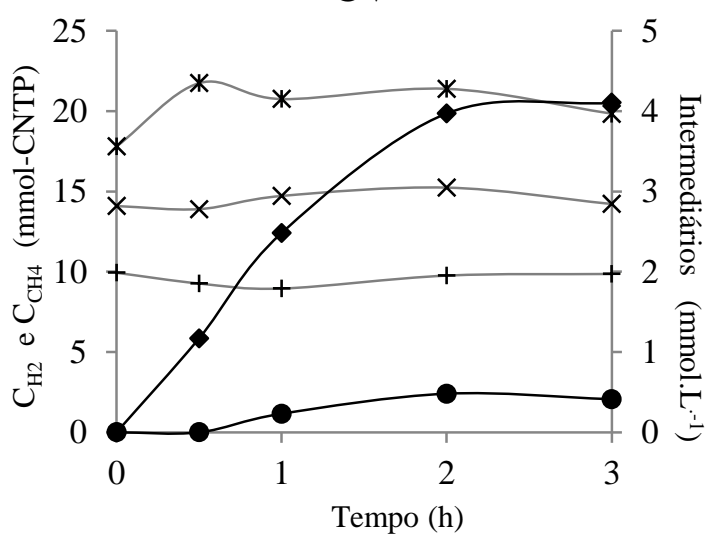

CIII

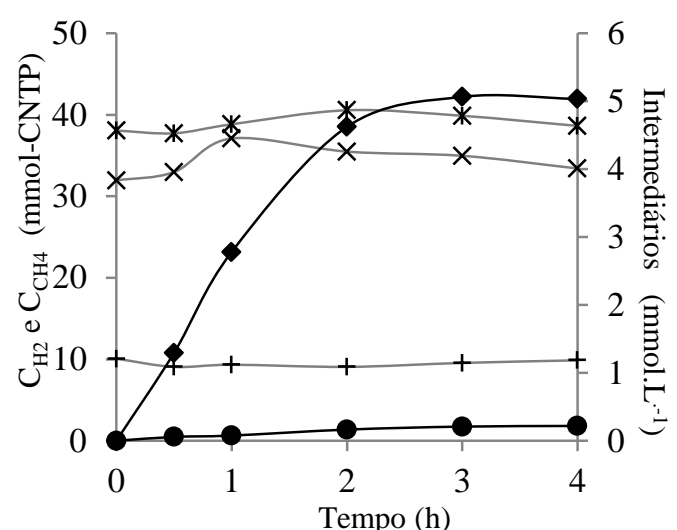

CVI

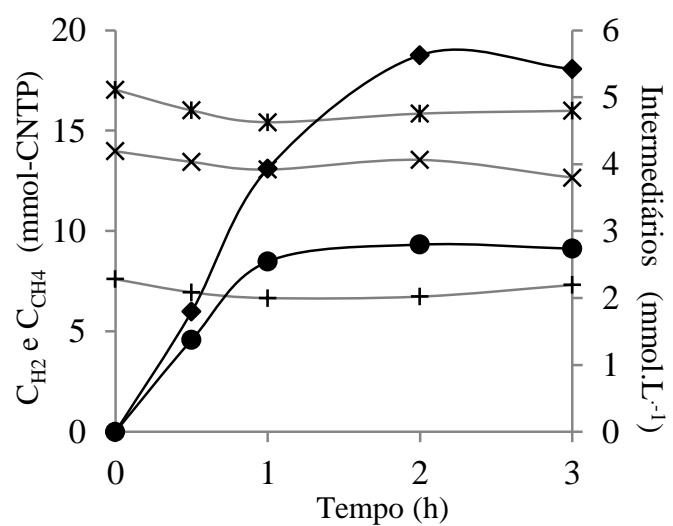

Figura 5. 17 - Produção molar acumulada de hidrogênio $(\bullet-)$ e metano $(\bullet-)$, e concentração molar de ácido acético $(\rightarrow)$, ácido butírico $\left(\stackrel{*}{*}^{*}\right)$, butanol $\left({ }^{\star}\right)$ ao longo do ciclo das condições da "Fase experimental". 


\section{c) Aproveitamento do glicerol na produção de hidrogênio}

Na Tabela 5.6 são apresentados os rendimentos molares de hidrogênio por carga orgânica aplicada $\left(\mathrm{RMCA}_{\mathrm{S}, \mathrm{m}}\right)$ e removida $\left(\mathrm{RMCR}_{\mathrm{S}, \mathrm{m}}\right)$. Estes indicadores mostraram a clara vantagem da condição CIII seguida da condição CII no aproveitamento da matéria orgânica disponível no meio para a produção de hidrogênio. Estes indicadores permitiram, como será apresentado mais tarde, avaliar o desempenho do reator na obtenção de hidrogênio, em comparação com outras pesquisas baseadas em termos de matéria orgânica.

Além dos indicadores de rendimento por matéria orgânica aplicada e removida, foram calculadas as quantidades aproximadas de glicerina consumida com o objetivo de obter um fator de rendimento que relacione a produção molar de hidrogênio e o consumo molar de glicerina. Para este efeito foi usada a equação (4.24) obtida a partir do balanço de massas da matéria orgânica no sistema. As concentrações de produtos intermediários (PI) em mgDQO.L ${ }^{-1}$ foram calculadas aplicando as equações químicas especificadas na Tabela 4.5. Uma vez calculada a quantidade de glicerol-PA consumido em $\mathrm{mgDQO} \cdot \mathrm{L}^{-1} \cdot \mathrm{d}^{-1} \mathrm{o}$ valor foi convertido em concentração molar e junto com a produtividade molar PrM em $\mathrm{molH}_{2} \cdot \mathrm{L}^{-1} \cdot \mathrm{d}^{-1}$ se calculou o fator de rendimento entre hidrogênio produzido e glicerina consumida $\mathrm{Y}_{\mathrm{H} 2}\left(\mathrm{molH}_{2} \cdot \mathrm{molGC}^{-1}\right)$. Os resultados são apresentados na Tabela 5.8.

Tabela 5.8 - Fator de rendimento entre hidrogênio produzido e glicerol consumido, e porcentagens médios de glicerol consumido considerando a totalidade dos produtos intermediários nas condições da "Fase experimental".

\begin{tabular}{|c|c|c|c|c|c|c|c|c|c|}
\hline $\mathrm{C}$ & PI & $\mathrm{C}_{\text {SAFTL }}$ & $\mathrm{C}_{\mathrm{ST}}$ & GC & $\mathrm{GC}$ & GC & GC & PrM & $\mathrm{Y}_{\mathrm{H} 2}$ \\
\hline & $\mathrm{mgDQO} . \mathrm{L}^{-1}$ & mgDQO.L - $^{-1}$ & mgDQO. $\mathrm{L}^{-1}$ & $\operatorname{mgDQO} \cdot \mathrm{L}^{-1} \cdot \mathrm{d}^{-1}$ & mg.glicerol. $\mathrm{L}^{-1} \cdot \mathrm{d}^{-1}$ & molglicero. $L^{-1} \cdot d^{-1}$ & $\%$ & $\mathrm{molH}_{2} \cdot \mathrm{L}^{-1} \cdot \mathrm{d}^{-1}$ & $\mathrm{molH}_{2} \cdot \mathrm{molGC}^{-1}$ \\
\hline CI & 740 & 3085 & 2506 & 7914 & 6504 & 0,0708 & 38 & 0,0072 & 0,103 \\
\hline CII & 1722 & 3982 & 3111 & 15558 & 12780 & 0,1386 & 65 & 0,039 & 0,281 \\
\hline CIII & 1950 & 5265 & 4105 & 18654 & 15324 & 0,1668 & 59 & 0,0678 & 0,405 \\
\hline CIV & 941 & 3156 & 2304 & 14344 & 11784 & 0,128 & 57 & 0,0296 & 0,233 \\
\hline $\mathrm{CV}$ & 1491 & 4076 & 3226 & 18728 & 15384 & 0,1672 & 57 & 0,0424 & 0,253 \\
\hline CVI & 1946 & 4959 & 3978 & 23416 & 19240 & 0,2088 & 59 & 0,052 & 0,249 \\
\hline
\end{tabular}


É importante ressaltar que o equivalente em DQO dos produtos intermediários foi calculado tomando em consideração apenas a concentração desses produtos no final do ciclo do perfil realizado para cada condição. Se em substituição do equivalente em DQO dos produtos intermediários for usado o equivalente da média da concentração de ácidos voláteis totais AVT no cálculo da quantidade de glicerina consumida, os valores obtidos do fator $\mathrm{Y}_{\mathrm{H} 2}$ são maiores sendo 0,$14 ; 0,53 ; 0,76 ; 0,33 ; 0,45$ e 0,46 para as condições CI, CII, CIII, CIV, CV e CVI, respectivamente. Esta diferença deve-se ao fato de que a análise de alcalinidade, através da qual é quantificada a concentração total de AVT, considera exclusivamente os ácidos voláteis produzidos e não aos álcoois. Entretanto, a análise cromatográfica usada na quantificação dos produtos intermediários considera alguns ácidos e alguns álcoois. Devido os cálculos da porcentagem de glicerol consumido ser um valor dependente dos produtos intermediários e dos ácidos gerados, esta porcentagem também foi diferente, sendo $31,35,32,42,33$ e $33 \%$ para as condições CI, CII, CIII, CIV, CV e CVI, respectivamente.

Se for feita uma análise lógica, os consumos mais reais de glicerol foram calculados considerando no balanço de matéria orgânica a maior quantidade de intermediários que contabilizam DQO no sistema, e que na sua formação também produziram hidrogênio. Portanto, os resultados apresentados na Tabela 5.8 estariam mais próximos à realidade.

Na Tabela 5.8 observa-se que a condição que apresentou a maior porcentagem de consumo de glicerol foi a CII, seguida pelas condições CIII e CIV. Porém o maior fator de rendimento de hidrogênio por glicerina consumida foi atingido pela condição CIII. É interessante analisar as condições CIII e CVI porque os resultados revelam informação importante que permite gerar hipóteses sobre o comportamento microbiano do reator. As duas condições 
apresentaram a mesma porcentagem de glicerol consumido, porém a condição CVI produziu menos hidrogênio e mais ácido acético que a condição CIII. Se o ácido acético está relacionado tanto com a máxima produção de hidrogênio quanto com o consumo por homoacetogênese, existe forte evidência de que o ácido acético quantificado na condição CVI originou-se principalmente do consumo do hidrogênio. Adicionalmente, de acordo com Kumar (2008) a produção de ácido propiônico, presente em maior percentagem na condição CVI do que na CIII, está relacionada às altas pressões parciais de hidrogênio. Como já foi explicado anteriormente, pressões parciais altas de hidrogênio propiciam o aparecimento de arquéias metanogênicas e homoacetogênicas consumidoras de hidrogênio que favorecem termodinamicamente a oxidação dos ácidos voláteis. Esta explicação também teria aplicação para aquelas condições de alta produção de metano e ácido acético como a CIV e CV.

Por outro lado, os resultados evidenciam que o hidrogênio produzido na condição CII originou-se na acidogênese da glicerina, cuja porcentagem de glicerol consumido foi a maior, apresentando a segunda menor produção de ácido acético, a menor produção de metano e a maior produção de ácido butírico.

Na Tabela 5.9 são mostrados os rendimentos molares por carga aplicada na forma de glicerina de todas as condições e os desempenhos percentuais em função dos potenciais teóricos apresentados na Tabela 4.6. Como se observa na Tabela 5.9, das duas principais rotas metabólicas, os maiores desempenhos porcentuais correspondem à condição III.

Tabela 5. 9 - Rendimentos molares por carga orgânica aplicada na forma de glicerol e desempenho porcentual em função dos potenciais teóricos.

\begin{tabular}{ccccccccc}
\hline & & & \multicolumn{7}{c}{ Condições } \\
Indicadores & Unidade & Via & I & II & III & IV & V & VI \\
\hline $\mathrm{RMCA}_{\mathrm{G}, \mathrm{m}}$ & $\mathrm{molH}_{2}$.kgglicerol & - & 1,17 & 4,87 & 6,36 & 4,68 & 5,15 & 5,22 \\
$\mathrm{RMCA}_{\mathrm{G}, \mathrm{m}}$ & molH $_{2}$.kgglicerol & Ácido Acético & $4 \%$ & $15 \%$ & $20 \%$ & $14 \%$ & $16 \%$ & $16 \%$ \\
$\mathrm{RMCA}_{\mathrm{G}, \mathrm{m}}$ & $\mathrm{molH}_{2}$.kgglicerol & Ácido Butírico & $5 \%$ & $22 \%$ & $29 \%$ & $22 \%$ & $24 \%$ & $24 \%$ \\
\hline
\end{tabular}


O calculo do rendimento molar de hidrogênio por mol de glicerol, permitiu comparar os resultados do presente trabalho com outras pesquisas nas quais foram usadas glicerol ou glicerina bruta como única fonte de carbono. A Tabela 5.10 apresenta um resumo das condições usadas e dos rendimentos atingidos por algumas pesquisas e o fator de rendimento médio da condição de maior produção de hidrogênio do presente trabalho. Como se observa, os maiores rendimentos são obtidos usando cepas puras, longos tempos de batelada, volumes pequenos e em consequência, cargas orgânicas volumétricas aplicadas baixas. Neste sentido, o uso do reator AnSBBR mostrou resultados promissores já que trabalha com um inóculo misto que não exige condições estritas de assepsia e admite cargas orgânicas volumétricas maiores. Adicionalmente, não foram usados adicionais nutricionais como extrato de levedura ou triptona, que como foi analisado por Sarma et al. (2013), encarecem o processo de aproveitamento da glicerina pelos altos custos implicados. 
Tabela 5. 10 - Comparação entre as condições e rendimentos de hidrogênio de várias pesquisas com o presente trabalho.

\begin{tabular}{|c|c|c|c|c|c|c|c|c|c|c|c|}
\hline Reator & $\begin{array}{l}\text { Volume } \\
\text { reação }\end{array}$ & TB & $\mathrm{pH}$ & $\mathrm{T}^{\mathrm{o}}$ & Biomassa & $\begin{array}{l}\text { Pre-tratamento } \\
\text { biomassa }\end{array}$ & Adicionais & COVA & $\begin{array}{l}\text { Tipo de } \\
\text { glicerina }\end{array}$ & $\mathrm{Y}_{\mathrm{H} 2}$ & Autores \\
\hline & (L) & (h) & (u) & $\left({ }^{\circ} \mathrm{C}\right)$ & & & & GC. $L^{-1} \cdot d^{-1}$ & & $\begin{array}{c}\left(\mathrm{molH}_{2} \cdot \mathrm{mol}\right. \\
\left.\mathrm{GC}^{-1}\right)\end{array}$ & \\
\hline $\begin{array}{l}\text { Batelada com } \\
\text { agitação }\end{array}$ & 0,5 & 72 & 6,3 & 37 & $\begin{array}{c}\text { Enterobacter } \\
\text { spH1 } \\
\text { Enterobacter } \\
\text { spH2 } \\
\text { Citrobacter } \\
\text { freundii } \mathrm{H} 3 \\
\text { Mistura }(1: 1: 1)\end{array}$ & $\begin{array}{l}\text { Ativação prévia } \\
\text { em meio com } \\
\text { glicerina }\end{array}$ & $\begin{array}{l}\text { Uso de extrato } \\
\text { de malte, } \\
\text { extrato de } \\
\text { levedura }\end{array}$ & 6,7 & Glicerol & $\begin{array}{l}0,85 \\
0,95 \\
0,94 \\
0,76\end{array}$ & $\begin{array}{l}\text { Maru et al. } \\
\quad \text { (2012) }\end{array}$ \\
\hline RALF & 4 & 72 & 7 & $\mathrm{NE}$ & $\begin{array}{l}\text { Clostridium sp. } \\
\text { (IBUN 18S) }\end{array}$ & $\begin{array}{l}\text { Ativação previa } \\
\text { em meio com } \\
\text { glicerina }\end{array}$ & $\begin{array}{l}\text { Uso de extrato } \\
\text { de levedura }\end{array}$ & 17 & Glicerol & 0,1962 & $\begin{array}{l}\text { Bernal et al. } \\
\quad \text { (2013) }\end{array}$ \\
\hline $\begin{array}{l}\text { Frascos para } \\
\text { cultivo de } \\
\text { soro }\end{array}$ & 0,5 & 72 & 6,2 & 30 & $\begin{array}{l}\text { Solo cultivo de } \\
\text { trigo }\end{array}$ & $105^{\circ} \mathrm{C}, 2 \mathrm{~h}$ & $\begin{array}{c}\text { Uso de } \\
\text { vitaminas e } \\
\text { minerais }\end{array}$ & 1 & $\begin{array}{c}\text { Glicerol } \\
\text { Glicerina } \\
\text { bruta }\end{array}$ & $\begin{array}{l}0,28 \\
0,31\end{array}$ & $\begin{array}{l}\text { Selembo et al. } \\
\quad(2009)\end{array}$ \\
\hline $\begin{array}{l}\text { Frascos para } \\
\text { cultivo de } \\
\text { soro }\end{array}$ & 0,04 & 197 & 6,8 & 75 & $\begin{array}{c}\text { Thermotoga } \\
\text { neapolitana } \\
\text { DSM } 4359\end{array}$ & - & $\begin{array}{c}\text { Gasificação } \\
\text { com } \mathrm{N}_{2} \text { do } \\
\text { espaço livre e } \\
\text { controle de pH }\end{array}$ & 0,6 & $\begin{array}{l}\text { Glicerina } \\
\text { bruta } \\
\text { pré- tratada }\end{array}$ & 2,06 & $\begin{array}{l}\text { Ngo et al. } \\
\text { (2011) }\end{array}$ \\
\hline Quimiostato & 0,5 & 14 & 6,3 & 37 & $\begin{array}{c}\text { Enterobacter } \\
\text { aerogenes-HU- } \\
101 \\
\end{array}$ & $\begin{array}{l}\text { Pre- ativação de } \\
\text { inóculo }\end{array}$ & - & 17 & $\mathrm{NE}$ & 0,62 & $\begin{array}{c}\text { Nakashimada et } \\
\text { al. (2002) }\end{array}$ \\
\hline $\begin{array}{l}\text { Frascos para } \\
\text { cultivo de } \\
\text { soro }\end{array}$ & 0,05 & 72 & 6,5 & 40 & $\begin{array}{l}\text { Biomassa de } \\
\text { PTAR }\end{array}$ & $\begin{array}{l}\text { Pre-ativação de } \\
\text { inóculo em } \\
\text { meio com } \\
\text { glicerina }\end{array}$ & - & 0,8 & $\begin{array}{c}\text { Glicerina } \\
\text { bruta }\end{array}$ & 1,1 & $\begin{array}{l}\text { Mangayil et al. } \\
\text { (2012) }\end{array}$ \\
\hline Batelada & 0,7 & 31 & 6,5 & 30 & $\begin{array}{c}\text { Klebsiella } \\
\text { pneumoniae } \\
\text { DSM2026 }\end{array}$ & - & - & 13,5 & Glicerol & 0,61 & $\begin{array}{l}\text { Bielb et al. } \\
\quad(1998)\end{array}$ \\
\hline AnSBBR & 3,67 & 4 & 7,5 & 30 & $\begin{array}{c}\text { UASB } \\
\text { abatedouro }\end{array}$ & $90^{\circ} \mathrm{C}, 15 \mathrm{~min}$ & - & 10,5 & Glicerol & 0,405 & $\begin{array}{l}\text { Presente } \\
\text { trabalho }\end{array}$ \\
\hline
\end{tabular}




\section{d) Concentração de biomassa e produção de hidrogênio}

De acordo com Hawkes et al. (2007), sistemas que usam biomassa imobilizada em suportes inertes têm a capacidade de suportar maiores cargas orgânicas volumétricas aplicadas do que sistemas com biomassa em suspenção. Ao comparar as cargas orgânicas volumétricas aplicadas nos trabalhos bibliográficos consultados e a presente pesquisa, se observa que esta é uma clara vantagem do sistema usado.

Porém, qualitativamente foi observado um constante crescimento de biomassa aderida no suporte ao longo do tempo de cada condição experimental e com esse crescimento uma perda de eficiência na produção de hidrogênio. Assim, os maiores rendimentos molares de hidrogênio por matéria orgânica removida $\mathrm{RMCR}_{\mathrm{S}, \mathrm{m}}$ foram obtidos com as menores quantidades de biomassa no reator naquelas condições operadas com 4 horas de tempo de ciclo.

Entretanto, naquelas condições operadas com 3 horas de tempo de ciclo, a relação observada foi inversamente proporcional. Uma maior quantidade total de biomassa no reator resultou em menor rendimento molar de hidrogênio por matéria orgânica removida, como se observa na Tabela 5.11. Nestas condições também se evidenciam maiores consumos de hidrogênio na forma de ácido acético e metano.

Em consequência observa-se uma clara vantagem na produção molar específica hidrogênio das condições CIII e CII, que com pouca biomassa mostraram melhor aproveitamento do substrato. 
Tabela 5.11 - Médias da massa total de biomassa no reator e dos rendimentos molares de hidrogeno por matéria orgânica removida na "Fase experimental".

\begin{tabular}{cccc}
\hline Condição & $\mathrm{M}_{\mathrm{SVT}}$ & PrME & $\mathrm{RMCR}_{\mathrm{S}, \mathrm{m}}$ \\
\hline & $(\mathrm{g})$ & $\left(\mathrm{molH}_{2} \cdot \mathrm{kgSVT}^{-1} \cdot \mathrm{d}^{-1}\right)$ & $\left(\mathrm{molH}_{2} \cdot \mathrm{kgDQO}^{-1}\right)$ \\
\hline CI & 6,0 & 4,4 & 3,8 \\
$\mathrm{CII}$ & 3,0 & 13,2 & 17,1 \\
$\mathrm{CIII}$ & 3,4 & 19,8 & 21,1 \\
$\mathrm{CIV}$ & 3,6 & 8,2 & 11,6 \\
$\mathrm{CV}$ & 4,1 & 10,4 & 12,5 \\
$\mathrm{CVI}$ & 7,7 & 6,8 & 13,4 \\
\hline
\end{tabular}

Como foi exposto anteriormente, para todas as condições foi colocada a mesma quantidade de inóculo inicial, porém, os efeitos combinados dos fatores tempo de ciclo e concentração de matéria orgânica no afluente fizeram com que a biomassa se reproduzisse mais em umas condições do que em outras.

São necessários estudos mais profundos sobre a relação entre quantidade de biomassa e produção de hidrogênio, porém, os dados obtidos na presente pesquisa evidenciam que a relação poderia ser inversamente proporcional.

\subsubsection{Considerações adicionais}

O objetivo principal do presente trabalho foi avaliar o efeito da carga orgânica aplicada na produção de hidrogênio usando o reator AnSBBR em batelada. Depois da análise dos resultados se evidencia que não existe uma relação específica entre carga orgânica volumétrica aplicada e produção de hidrogênio que possa ser tomada como absoluta. Como se observa na Tabela 5.12, a condição apresentou a maior produtividade molar foi a condição CIII seguida pela condição CVI. 
Porém, ao analisar o fator de rendimento de hidrogênio produzido por glicerol consumido e considerando fatores adicionais como a produção de metano, a condição CVI foi uma das piores. A segunda melhor condição com relação ao aproveitamento do substrato foi realmente a CII, apresentando o segundo melhor rendimento molar por carga orgânica aplicada (RMCA $\left.\mathrm{R}_{\mathrm{S}, \mathrm{m}}\right) \mathrm{e}$ removida $\left(\mathrm{RMCR}_{\mathrm{S}, \mathrm{m}}\right)$, o segundo melhor fator de rendimento entre o hidrogênio produzido e a glicerina consumida $\mathrm{Y}_{\mathrm{H} 2}$ e a maior porcentagem media de glicerol consumido. Adicionalmente nesta condição foi quantificado metano unicamente no último dia de monitoramento.

Ao analisar a Tabela 5.12 observa-se que a relação entre COVA e $\mathrm{Y}_{\mathrm{H} 2}$ não é clara, porém os melhores resultados foram gerados por uma ação conjunta entre o tempo de ciclo e a concentração afluente. O objetivo do presente trabalho foi obter hidrogênio por fermentação escura a partir da fermentação da glicerina evitando a produção de gases consumidores. Como foi discutido ao longo desta seção esse objetivo foi atingido operando o reator com 4 horas de tempo de ciclo e alimentando o reator com concentrações afluentes de 4000 e 5000 mgDQO.L ${ }^{-1}$ (condição CII e CIII respectivamente).

Tabela 5.12 - Indicadores de produção de hidrogênio para todas as condições da "Fase experimental"

\begin{tabular}{cccccccc}
\hline & & \multicolumn{7}{c}{ Condições } \\
\cline { 3 - 7 } Parâmetro & Unidade & $\mathrm{CI}$ & $\mathrm{CII}$ & $\mathrm{CIII}$ & $\mathrm{CIV}$ & $\mathrm{CV}$ & $\mathrm{CVI}$ \\
\hline $\mathrm{COVA}_{\mathrm{ST}}$ & $\left(\mathrm{mgDQO} \cdot \mathrm{L}^{-1} \cdot \mathrm{d}^{-1}\right)$ & 7565 & 9764 & 12911 & 10319 & 13327 & 16216 \\
PrM & $\left(\mathrm{molH}_{2} \cdot \mathrm{m}^{-3} \cdot \mathrm{d}^{-1}\right)$ & 7,3 & 39,0 & 67,5 & 29,8 & 42,3 & 52,1 \\
$\mathrm{RMCA}_{\mathrm{S}, \mathrm{m}}$ & $\left(\mathrm{molH}_{2} \cdot \mathrm{kgDQO}^{-1}\right)$ & 0,9 & 4,1 & 5,2 & 2,9 & 3,4 & 3,2 \\
$\mathrm{RMCR}_{\mathrm{S}, \mathrm{m}}$ & $\left(\mathrm{molH}_{2} \cdot \mathrm{kgDQO}^{-1}\right)$ & 3,8 & 17,1 & 21,1 & 11,6 & 12,5 & 13,4 \\
$\mathrm{Y}_{\mathrm{H} 2}$ & $\left(\mathrm{molH}_{2} \cdot \mathrm{molGC}^{-1}\right)$ & 0,103 & 0,281 & 0,405 & 0,233 & 0,252 & 0,249 \\
\hline
\end{tabular}

Finalmente, a partir dos resultados obtidos, observa-se a necessidade de futuras pesquisas usando 4 horas de tempo de ciclo e cargas orgânicas de alimentação maiores na procura de informação que permita estabelecer uma relação específica de comportamento. Estudos sobre o 
efeito da pressão parcial do hidrogênio e o consumo de ácidos voláteis também são necessários para esclarecer as rotas metabólicas envolvidas na produção de hidrogênio, visando otimizar o processo.

\subsection{Fase final}

A presente fase da pesquisa teve dois objetivos específicos:

1) Estabelecer se o pré-tratamento térmico aplicado à biomassa foi um fator que influenciou na produção de hidrogênio.

2) Estabelecer se existe diferença na obtenção de hidrogênio usando o glicerol ou a glicerina bruta como única fonte de carbono.

Para este efeito o reator foi operado usando o tempo de ciclo e a concentração afluente da condição que apresentou melhores resultados de produção de hidrogênio durante a "Fase experimental". Assim o reator foi operado com 4 horas de tempo de ciclo e alimentado com concentração afluente de 5000 mgDQO.L ${ }^{-1}$ em duas condições denominadas CBST (condição com biomassa sem tratamento térmico) e CGB (condição operada com glicerina bruta).

Assim como na "Etapa Experimental", antes da montagem do reator para cada condição esterilizou-se o suporte $\left(120^{\circ} \mathrm{C}\right.$ por $\left.15 \mathrm{~min}\right)$ e lavou-se o reator. No primeiro ensaio desta fase (condição CBST), a biomassa de uma estação de tratamento da água residuária de um abatedouro de aves foi batida no liquidificador por 30 segundos e misturada com o suporte sem prétratamento térmico. O segundo ensaio (condição CGB) foi operado usando a mesma biomassa, porém pré-tratada termicamente. Todos os dados obtidos nestes dois ensaios são apresentados nos 
Anexos XV e XVI. No presente capitulo são mostrados apenas as tabelas das médias dos parâmetros monitorados, dos indicadores de produção de hidrogênio, e os gráficos gerados com base nos dados experimentais.

\subsubsection{Comportamento do reator}

Durante os experimentos das duas condições (CBST e CGB) foi observada estabilidade em relação à concentração da DQO do afluente, efluente e do efluente filtrado, como é observado na Figura 5.18. A mesma estabilidade foi observada na produção de ácidos voláteis totais, alcalinidade total e $\mathrm{pH}$ do afluente e do efluente, como é observado nas Figuras 5.19 e 5.20. Com relação à produção volumétrica de biogás a condição CBST apresentou um aumento contínuo da produção, estabilizando-se nos últimos dias de monitoramento, como é observado na Figura 5.21 (a). A condição CGB mostrou estabilidade na produção durante quase toda a experimentação, observando-se um leve aumento no final seguido de uma queda, como se observa na Figura 5.21 (b). As duas condições mostraram uma prevalência do hidrogênio na composição do biogás.

Na Tabela 5.13 são apresentadas as médias dos parâmetros monitorados nas condições CBST e CGB conjuntamente com a condição CIII, permitindo assim uma comparação entre as três. Observa-se que as duas condições foram alimentadas com um afluente em média levemente menor em relação à condição CIII. As eficiências de remoção atingidas foram similares para as condições CBST e CIII. A condição CGB mostrou um importante aumento na eficiência de remoção de matéria orgânica filtrada, sendo em média de $43 \%$.

Com relação ao pH e a alcalinidade, observa-se na Tabela 5.13 que as condições CIII e CBST operaram com caraterísticas similares. A condição CGB mostrou grandes diferenças destes 
parâmetros em comparação às duas condições mencionadas, destacando-se as altas alcalinidades do meio. Em relação ao efluente, às condições CIII e CBST mostraram valores similares dos parâmetros em discussão. A condição CGB mostrou mais uma vez valores médios de pH e alcalinidades maiores. A concentração média de ácidos voláteis totais do efluente da condição CBST foi maior do que as outras duas condições.

Como é possível observar na Tabela 5.13, as condições CIII e CBST operaram com características similares. Porém, foi observada uma reprodução e aderência maior da biomassa na condição CBST em comparação à condição CIII, sendo a massa total de biomassa quantificada maior que o dobro. A condição CGB apresentou uma massa total de biomassa quase doze vezes maior do que a condição CIII.

Na Figura 5.22 são apresentados os perfis de concentração de DQO, AVT, pH e alcalinidade total dos ciclos das três condições analisadas. Observa-se que para todos os parâmetros a tendência de comportamento foi similar. A condição CBST apresentou concentrações de DQO levemente menores do que a condição CIII. Já as concentrações de DQO observadas durante o ciclo da condição CGB foram visivelmente menores.

Com relação à concentração de ácidos voláteis totais (AVT), observa-se que as tendências de comportamento também foram similares para as condições em análise. A condição CGB apresentou uma maior semelhança com a condição CBST, com uma queda na concentração no final do ciclo. Durante o ciclo da condição CGB, a concentração de AVT foi maior do que nas outras duas condições em análise apresentando, porém, uma queda acentuada no final.

$\mathrm{O}$ pH e a alcalinidade total foram similares nas condições CIII e CBST, porém a condição CGB mostrou um pH e uma alcalinidade maiores ao longo do ciclo devido à alta alcalinidade do afluente alimentado. 
Tabela 5.13 - Valores médios dos parâmetros monitorados da condição CBST e CIII.

\begin{tabular}{|c|c|c|c|c|c|c|c|c|c|c|c|c|c|c|c|c|c|c|c|c|c|c|c|c|c|}
\hline \multirow[b]{3}{*}{$\mathrm{C}_{\mathrm{ST}}$} & \multirow[b]{3}{*}{$\left(\mathrm{mgDQO} \cdot \mathrm{L}^{-1}\right)$} & \multicolumn{8}{|c|}{ CIII } & \multicolumn{8}{|c|}{ CBST } & \multicolumn{8}{|c|}{ CGB } \\
\hline & & \multicolumn{4}{|c|}{ Afluente } & \multicolumn{4}{|c|}{ Efluente } & \multicolumn{4}{|c|}{ Afluente } & \multicolumn{4}{|c|}{ Efluente } & \multicolumn{4}{|c|}{ Afluente } & \multicolumn{4}{|c|}{ Efluente } \\
\hline & & 5265 & (6) & \pm & 177 & 4105 & (6) & \pm & 95 & 5028 & (6) & \pm & 46 & 3821 & (6) & \pm & 156 & 5211 & (8) & \pm & 293 & 3208 & (8) & \pm & 285 \\
\hline $\mathrm{C}_{\mathrm{SF}}$ & $\left(\operatorname{mgDQO} \cdot \mathrm{L}^{-1}\right)$ & - & & & - & 3972 & (6) & \pm & 78 & - & & & - & 3678 & (6) & \pm & 206 & - & & & - & 2953 & (8) & \pm & 255 \\
\hline$\varepsilon_{\mathrm{ST}}$ & $(\%)$ & - & & & - & 22 & (6) & \pm & 5 & - & & & - & 24 & (6) & \pm & 4 & - & & & - & 39 & (8) & \pm & 3 \\
\hline$\varepsilon_{\mathrm{SF}}$ & $(\%)$ & - & & & - & 25 & (6) & \pm & 2 & - & & & - & 27 & (6) & \pm & 4 & - & & & - & 43 & (8) & \pm & 3 \\
\hline $\mathrm{pH}$ & (u) & 7,54 & (6) & \pm & 0,06 & 4,32 & (6) & \pm & 0,18 & 7,73 & (6) & \pm & 0,02 & 4,32 & (6) & \pm & 0,02 & 8,10 & (8) & \pm & 0,12 & 5,46 & (8) & \pm & 0,3 \\
\hline AVT & $\left(\operatorname{mgHAc} . \mathrm{L}^{-1}\right)$ & 24 & (6) & \pm & 1 & 526 & (6) & \pm & 19 & 25 & (6) & \pm & 2 & 738 & (6) & \pm & 80 & 127 & (8) & \pm & 6 & 597 & (8) & \pm & 29 \\
\hline $\mathrm{AT}$ & $\left(\mathrm{mgCaCO}_{3} \cdot \mathrm{L}^{-1}\right)$ & 154 & (6) & \pm & 13 & 10 & (6) & \pm & 10 & 145 & (6) & \pm & 12 & 10 & (6) & \pm & 9 & 145 & (8) & \pm & 12 & 227 & (8) & \pm & 28 \\
\hline $\mathrm{AP}$ & $\left(\mathrm{mgCaCO}_{3} \cdot \mathrm{L}^{-1}\right)$ & 124 & (6) & \pm & 11 & 0 & (6) & \pm & 0 & 120 & (6) & \pm & 12 & 0 & (6) & \pm & 0 & 213 & (8) & \pm & 22 & 0 & (8) & \pm & 0 \\
\hline AI & $\left(\mathrm{mgCaCO}_{3} \cdot \mathrm{L}^{-1}\right)$ & 30 & (6) & \pm & 4 & 10 & (6) & \pm & 10 & 25 & (6) & \pm & 4 & 10 & (6) & \pm & 9 & 285 & (8) & \pm & 20 & 227 & (8) & \pm & 28 \\
\hline $\mathrm{AB}$ & $\left(\mathrm{mgCaCO}_{3} \cdot \mathrm{L}^{-1}\right)$ & 137 & (6) & \pm & 13 & 0 & (6) & \pm & 0 & 128 & (6) & \pm & 11 & 0 & (6) & \pm & 0 & 194 & (8) & \pm & 18 & 0 & (8) & \pm & 0 \\
\hline $\mathrm{V}_{\mathrm{G}}$ & $\left(\mathrm{mL}-\mathrm{CNTP} \cdot \mathrm{ciclo}^{-1}\right)$ & - & & & - & 1390 & (5) & \pm & 94 & & & & & 1301 & (5) & \pm & 398 & & & & & 284 & (7) & \pm & 60 \\
\hline ST & $\left(\mathrm{mg} \cdot \mathrm{L}^{-1}\right)$ & 549 & (3) & \pm & 72 & 812 & (4) & \pm & 39 & 475 & (3) & \pm & 74 & 942 & (4) & \pm & 24 & 2070 & (4) & \pm & 240 & 1079 & (4) & \pm & 140 \\
\hline SVT & $\left(\mathrm{mg} \cdot \mathrm{L}^{-1}\right)$ & 289 & (3) & \pm & 88 & 605 & (4) & \pm & 31 & 249 & (3) & \pm & 110 & 743 & (4) & \pm & 34 & 1486 & (4) & \pm & 258 & 1630 & (4) & \pm & 108 \\
\hline SST & $\left(\mathrm{mg} \cdot \mathrm{L}^{-1}\right)$ & 38 & (3) & \pm & 31 & 105 & (4) & \pm & 30 & 33 & (3) & \pm & 19 & 29 & (4) & \pm & 4 & 332 & (4) & \pm & 82 & 93 & (4) & \pm & 15 \\
\hline SSV & $\left(\mathrm{mg} \cdot \mathrm{L}^{-1}\right)$ & 20 & (3) & \pm & 17 & 93 & (4) & \pm & 4 & 29 & (3) & \pm & 15 & 37 & (4) & \pm & 22 & 305 & (4) & \pm & 86 & 72 & (4) & \pm & 14 \\
\hline $\mathrm{M}_{\mathrm{SVT}}$ & (g) & - & (6) & & - & 3,4 & & & - & - & & & - & 8 & & & - & - & & & - & 40 & & & - \\
\hline $\mathrm{Cx}$ & $\left(\mathrm{g} . \mathrm{L}^{-1}\right)$ & - & & & - & 1 & & & - & - & & & - & 2 & & & - & - & & & - & 11 & & & - \\
\hline $\mathrm{Cx}^{\prime}$ & (mg.g-suporte ${ }^{-1}$ ) & - & & & - & 3 & & & - & - & & & - & 6 & & & - & - & & & - & 32 & & & - \\
\hline $\mathrm{V}_{\mathrm{A}}$ & (L) & 1,5 & (4) & \pm & 0,02 & - & & & - & 1,5 & (3) & \pm & 0,01 & - & & & - & 1,5 & (4) & \pm & 0,02 & - & & & - \\
\hline $\mathrm{V}_{\mathrm{R}}$ & $(\mathrm{L})$ & - & & & - & 3,67 & (1) & & - & - & & & - & 3,67 & (1) & & - & - & & & - & 3,67 & (1) & & - \\
\hline
\end{tabular}



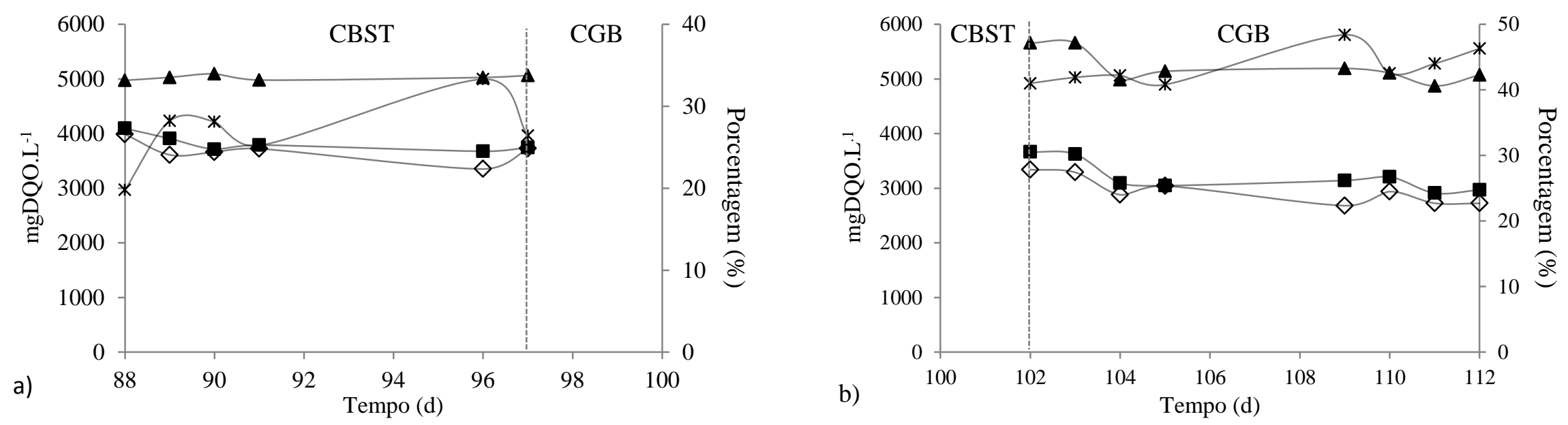

Figura 5.18 - Concentrações de matéria orgânica do afluente $\mathrm{C}_{\mathrm{ST}}$ Afluente $(\boldsymbol{\bullet})$, efluente sem filtrar $\mathrm{C}_{\mathrm{ST}}$ Efluente $(-\boldsymbol{-})$, efluente filtrado $\mathrm{C}_{\mathrm{SF}}$ Efluente $(-)$ e eficiência de remoção do efluente filtrado $\varepsilon_{\mathrm{SF}}\left({ }^{*}\right)$ ao longo da condição a) CBST e b) CGB.
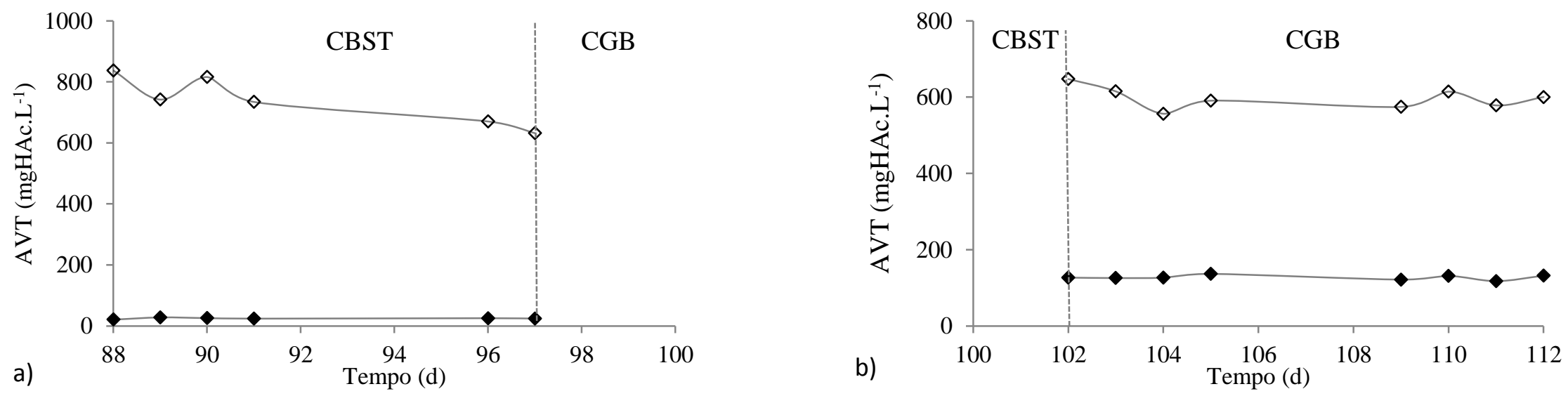

Figura 5.19 - Concentração de AVT do afluente $(\bullet \bullet)$ e do efluente $(\bullet-)$ ao longo da condição a) CBST e b) CGB. 

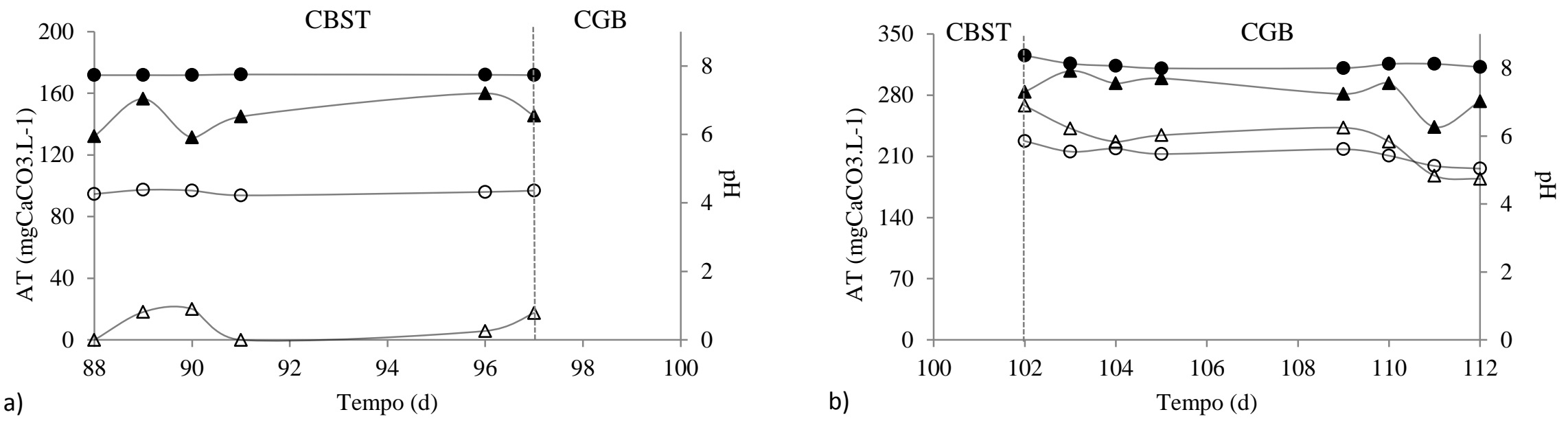

Figura 5.20 - $\mathrm{pH}_{\text {Afluente }}(\bullet-), \mathrm{pH}_{\text {Efluente }}(\bullet)$, Alcalinidade total do afluente $(\neg)$, Alcalinidade total do efluente $(\neg)$ ao longo da condição a) CBST e b) CGB.
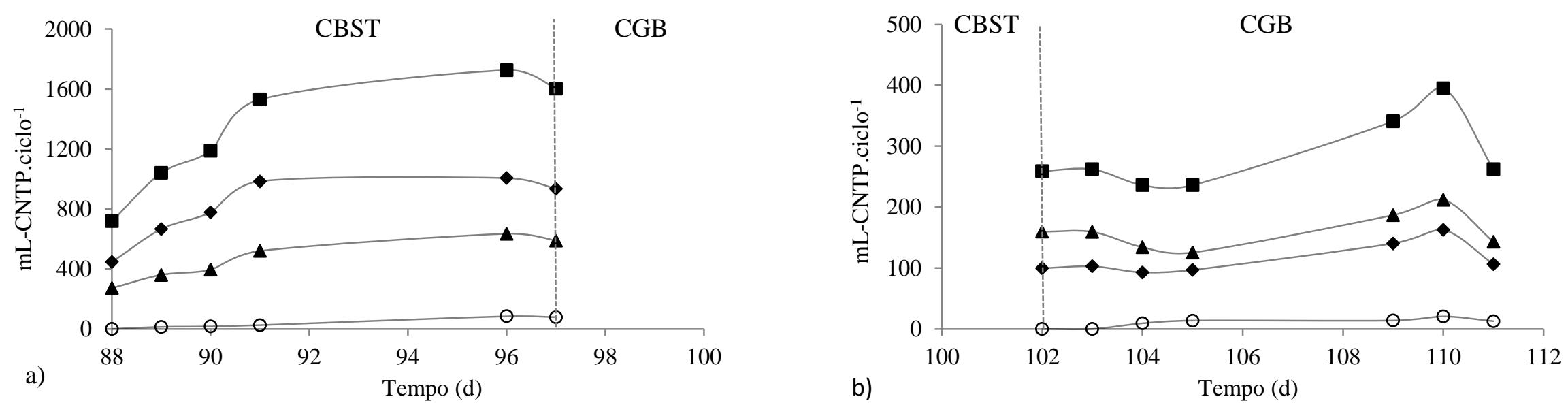

Figura 5.21 - Volume produzido nos ciclos monitorados de gás $\mathrm{V}_{\mathrm{G}}(-\bullet)$, volume de $\mathrm{H}_{2}(-\bullet)$, volume de $\mathrm{CO}_{2}\left({ }^{\star}\right)$, volume de $\mathrm{CH}_{4}(-\odot)$ da condição a) CBST e b) CGB. 

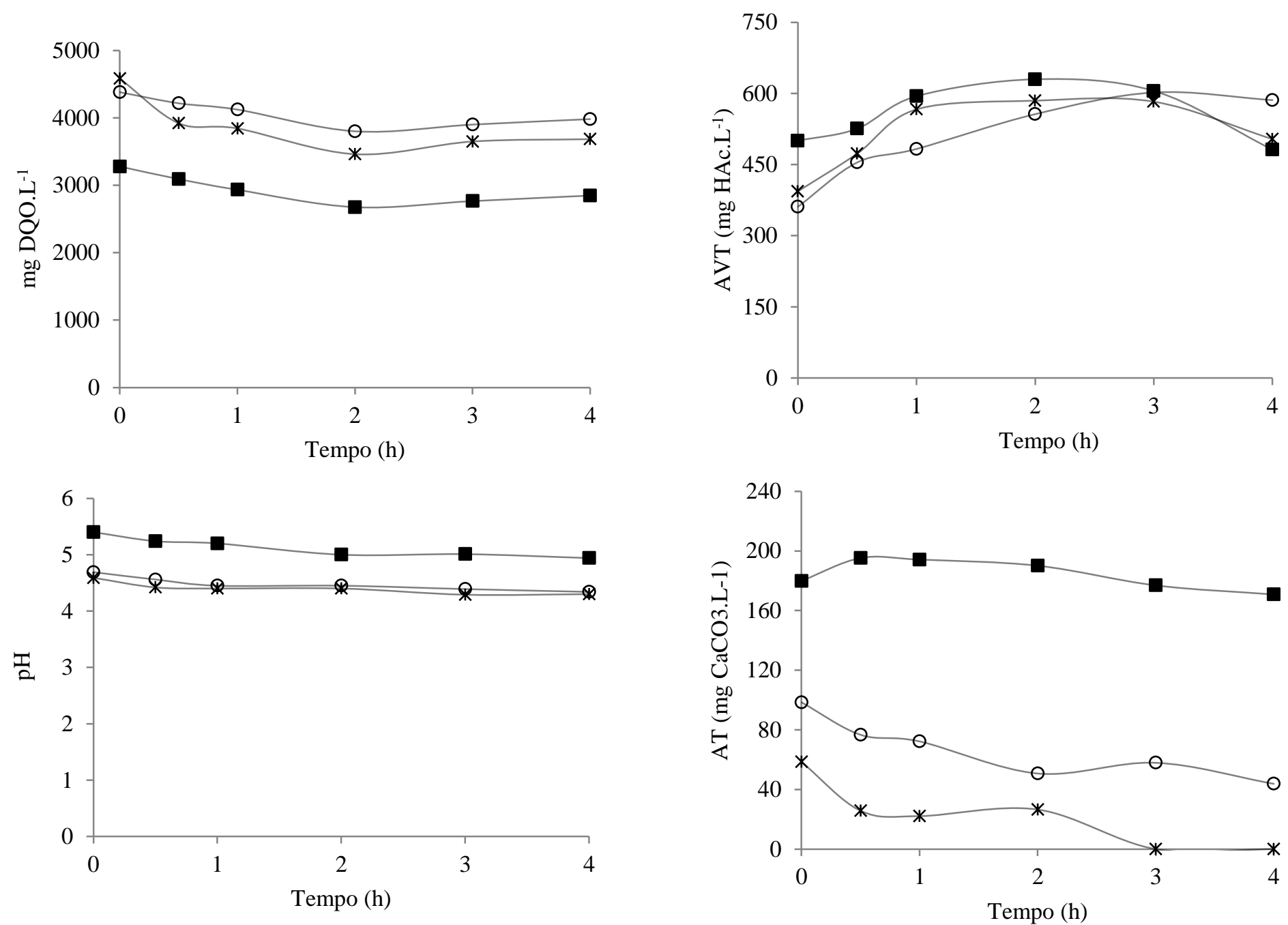

Figura 5.22 - Perfis ao longo do ciclo de a) matéria orgânica na forma de DQO, b) concentração de ácidos voláteis totais, c) pH e d) alcalinidade total das condições CIII (-๑), CBST $\left({ }^{*}\right)$ e CGB $(-\bullet)$ 
Na figura 5.23 são apresentados os perfis dos produtos intermediários quantificados ao longo do ciclo das três condições. Enquanto que na condição CIII predominou a produção de ácido butírico seguida do butanol, na condição CBST predominou a produção de butanol, seguida de ácido butírico e ácido acético. Já na condição CGB predominou a produção de ácido acético seguida pelo ácido propiônico e etanol.
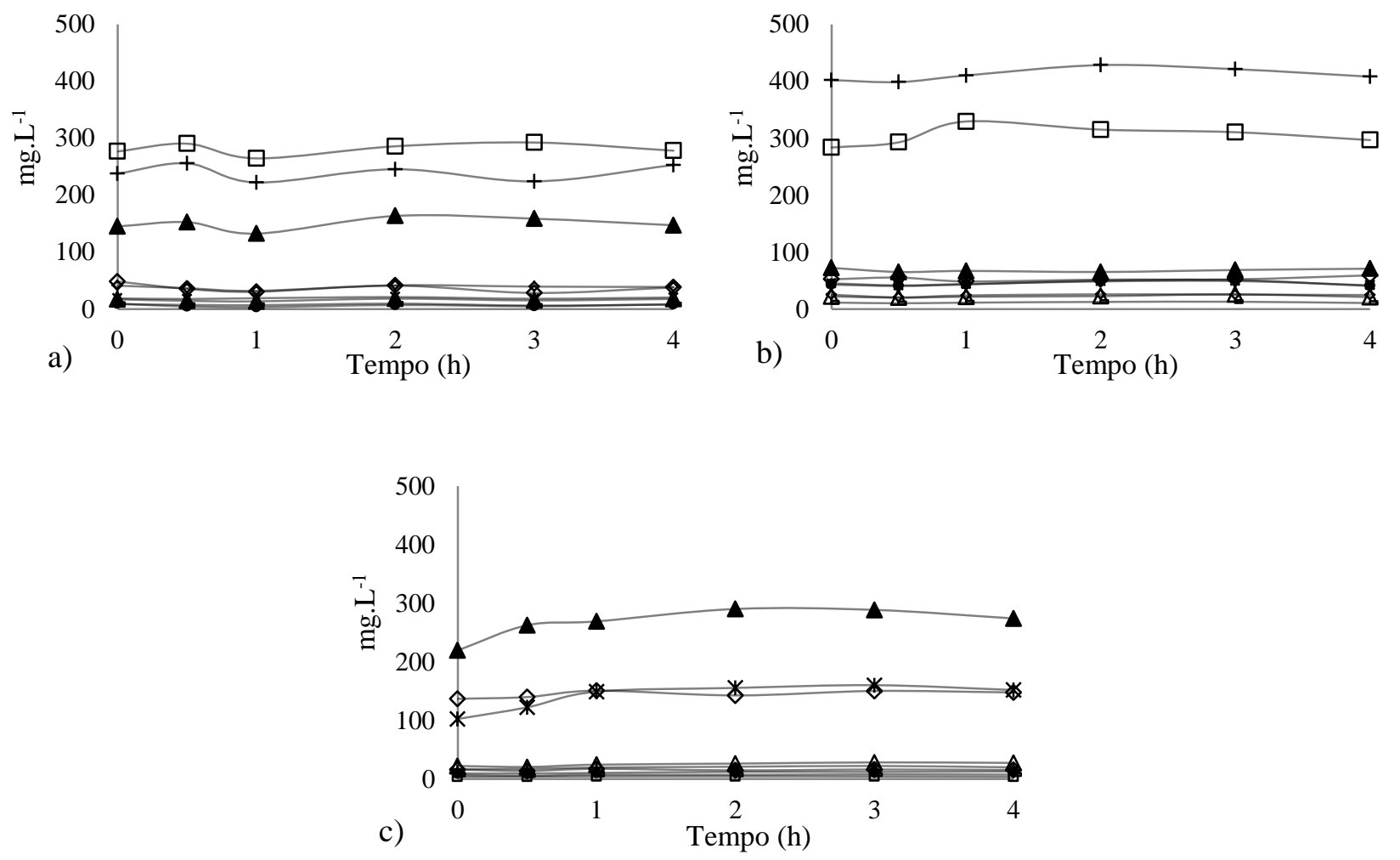

Figura 5.23 - Perfil de ácidos voláteis produzidos ao longo de cada ciclo das condições a) CBST, b) CIII e c) CGB.

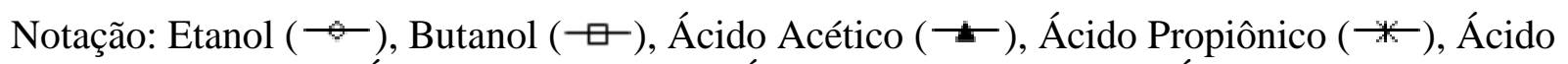
Isso-butírico $(-\bullet)$, Ácido Butírico $(\neg)$, Ácido Iso-valérico $(-)$, Ácido Valérico $\left({ }^{-}\right)$, Ácido Capróico $(\multimap)$ 


\subsubsection{Produção de hidrogênio}

\section{a) Indicadores de produção}

Na Tabela 5.14 são apresentadas as médias dos indicadores de produção de hidrogênio e das cargas orgânicas volumétricas aplicadas nas condições CIII, CBST e CGB. Como é possível se observar a condição CIII manteve um aproveitamento da carga orgânica aplicada levemente superior com relação à produção de hidrogênio em todos os indicadores calculados em comparação à condição CBST. A maior e a menor produtividade molar (PrM) registrada na condição CBST foi 32,6 e 73,3 molH ${ }_{2} \cdot \mathrm{m}^{-3} \cdot \mathrm{d}^{-1}$, respectivamente. Os valores correspondentes à condição CIII foram 60,7 e $75,9 \mathrm{molH}_{2} \cdot \mathrm{m}^{-3} \cdot \mathrm{d}^{-1}$, respectivamente. A média da produtividade molar da condição CIII foi $16 \%$ maior do que a produtividade molar da condição CBST.

A condição CGB, por outro lado, mostrou-se inferior em relação a todos os indicadores de produção de hidrogênio em comparação as outras condições como é observado na Tabela 5.14.

Tabela 5.14 - Medias de indicadores de produção de hidrogênio e das cargas orgânicas envolvidas na operação do reator durante a "Fase experimental".

\begin{tabular}{ccccc}
\hline & & \multicolumn{3}{c}{ Condições } \\
\cline { 3 - 5 } Parâmetro & Unidade & CIII & CBST & CGB \\
\hline COVA $_{\mathrm{ST}}$ & $\left(\mathrm{mgDQO} \cdot \mathrm{L}^{-1} \cdot \mathrm{d}^{-1}\right)$ & 12911 & 12330 & 12779 \\
COVR $_{\mathrm{SF}}$ & $\left(\mathrm{mgDQO} \cdot \mathrm{L}^{-1} \cdot \mathrm{d}^{-1}\right)$ & 3171 & 3311 & 5539 \\
COEA $_{\mathrm{ST}}$ & $\left(\mathrm{mgDQO} \cdot \mathrm{g}-\mathrm{SVT}^{-1} \cdot \mathrm{d}^{-1}\right)$ & 13936 & 5656 & 1173 \\
COER $_{\mathrm{SF}}$ & $\left(\mathrm{mgDQO} \cdot \mathrm{g}-\mathrm{SVT}^{-1} \cdot \mathrm{d}^{-1}\right)$ & 3422 & 1519 & 508 \\
$\mathrm{~V}_{\mathrm{H} 2}$ & $\left(\mathrm{~L}-\mathrm{CNTP} \cdot \mathrm{d}^{-1}\right)$ & 5,6 & 4,1 & 1,7 \\
$\mathrm{n}_{\mathrm{H} 2}$ & $\left(\mathrm{mmolH}_{2} \cdot \mathrm{d}^{-1}\right)$ & 248 & 184 & 31 \\
PrM & $\left(\mathrm{molH}_{2} \cdot \mathrm{m}^{-3} \cdot \mathrm{d}^{-1}\right)$ & 67,5 & 58,5 & 8,3 \\
PrME & $\left(\mathrm{molH}_{2} \cdot \mathrm{kgSVT}^{-1} \cdot \mathrm{d}^{-1}\right)$ & 19,8 & 7,3 & 1,0 \\
$\mathrm{RMCA}_{\mathrm{S}, \mathrm{m}}$ & $\left(\mathrm{molH}_{2} \cdot \mathrm{kgDQO}^{-1}\right)$ & 5,2 & 4,7 & 0,7 \\
$\mathrm{RMCR}_{\mathrm{S}, \mathrm{m}}$ & $\left(\mathrm{molH}_{2} \cdot \mathrm{kgDQO}^{-1}\right)$ & 21,1 & 17,6 & 1,5 \\
\hline
\end{tabular}

A composição percentual do biogás produzido na condição CBST foi similar à condição CIII como se observa na Figura 5.24. Na condição CBST predominou o hidrogênio na 
composição do biogás, diferente da condição CGB que mostrou uma predominância de dióxido de carbono e aproximadamente $20 \%$ menos de hidrogênio do que a condição CBST.

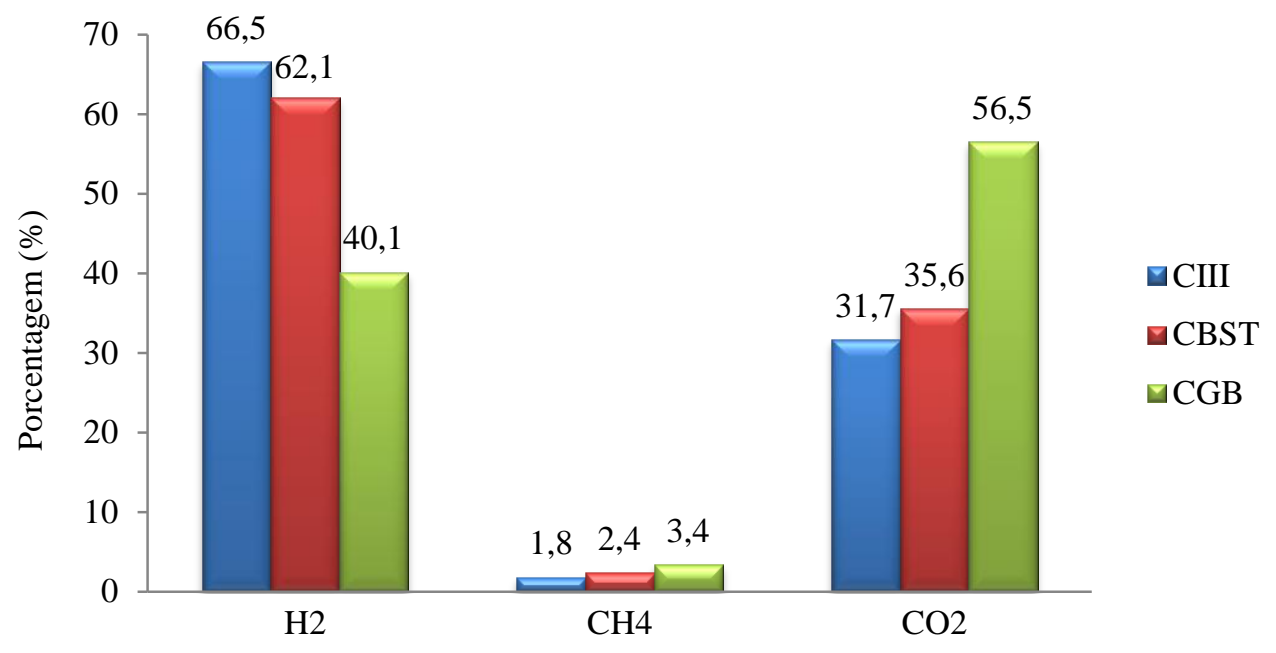

Figura 5.24 - Composição percentual do biogás produzido pelas condições CBST e CIII.

As produtividades molares atingidas também foram similares para as condições CIII e CBST como é observado na Figura 5.25. A produtividade molar de hidrogênio foi o indicador que apresentou a maior diferença entre as duas condições. A condição CGB atingiu uma produtividade molar média consideravelmente menor.

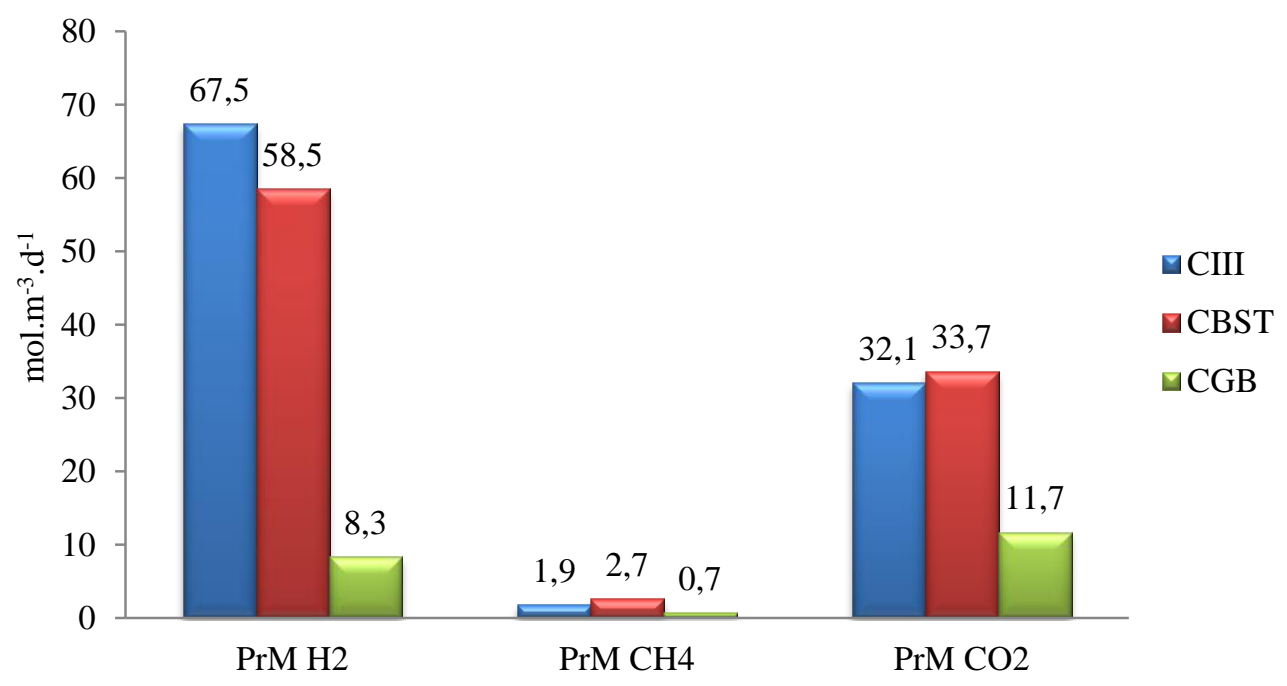

Figura 5.25 - Produtividades molares de hidrogênio, metano e dióxido de carbono das condições CBST e CIII. 
Na Tabela 5.15 são apresentadas as produções volumétricas acumuladas ao final dos ciclos monitorados. Como pode ser observado, a condição CBST começou com uma baixa produção volumétrica que com o tempo superou a condição CIII. Este fato poderia ser um indicativo de que o pré-tratamento acelera o processo biológico mediante o qual é produzido o hidrogênio devido à pré-seleção de microrganismo, porém eventualmente a biomassa não tratada poderia igualar ou superar a produção da biomassa tratada. É importante ressaltar que mesmo produzindo maior volume de biogás, a condição CBST apresentou uma menor porcentagem de hidrogênio na composição deste como foi mostrado na Figura 5.24. É por esta razão que em média a condição CIII registrou maior produção de hidrogênio.

Tabela 5.15 - Produção volumétrica de biogás ao longo da experimentação das condições CIII, CBST e CGB.

\begin{tabular}{|c|c|c|c|c|c|}
\hline \multicolumn{2}{|c|}{ CIII } & \multicolumn{2}{|c|}{ CBST } & \multicolumn{2}{|c|}{ CGB } \\
\hline $\begin{array}{l}\text { Biogás } \\
\text { mL.ciclo }^{-1}\end{array}$ & $\begin{array}{c}\mathrm{H}_{2} \\
\text { mL.ciclo }\end{array}$ & $\begin{array}{l}\text { Biogás } \\
\text { mL.ciclo }^{-1}\end{array}$ & $\begin{array}{c}\mathrm{H}_{2} \\
\text { mL.ciclo }\end{array}$ & $\begin{array}{l}\text { Biogás } \\
\text { mL.ciclo }^{-1}\end{array}$ & $\begin{array}{c}\mathrm{H}_{2} \\
\mathrm{~mL} \text { ciclo }^{-1}\end{array}$ \\
\hline 1248 & 833 & 719 & 446 & 259 & 99 \\
\hline 1353 & 893 & 1040 & 666 & 262 & 103 \\
\hline 1425 & 919 & 1189 & 777 & 236 & 93 \\
\hline 1494 & 1041 & 1530 & 985 & 236 & 97 \\
\hline \multirow[t]{3}{*}{1430} & 941 & 1725 & 1006 & 341 & 140 \\
\hline & & 1602 & 934 & 395 & 162 \\
\hline & & & & 262 & 106 \\
\hline
\end{tabular}

Como tem sido observado e discutido até o momento, as condições CBST e CIII apresentaram características similares tanto no comportamento ao longo da operação como na produção de hidrogênio. Com o objetivo de estabelecer se a diferença observada nas produtividades molares destas duas condições foi estatisticamente significativa se realizou uma Análise de Variância (ANOVA) para um fator, usando a versão estudantil gratuita do programa InfoStat versão 2013e. 
Antes de realizar a análise, os pressupostos da ANOVA foram verificados. Na Figura 5.26 é apresentada a tabela resultado da ANOVA gerada pelo programa. Como se observa, o valor de significância $(p>0,05)$ mostra que não existe diferença significativa estatisticamente entre a produtividade molar obtida pré-tratando a biomassa com aquela atingida sem pré-tratamento.

\begin{tabular}{|c|c|c|c|c|c|}
\hline Quadro de & nálise da & riầ & a (SC & tipo III) & \\
\hline F.V. & $\mathrm{SC}$ & gl & $\mathrm{CM}$ & $F$ & p-valor \\
\hline Modelo. & 218,89 & 1 & 218,89 & 1,42 & 0,2643 \\
\hline Columna1 & 218,89 & 1 & 218,89 & 1,42 & 0,2643 \\
\hline Error & 1389,92 & 9 & 154,44 & & \\
\hline Total & 1608,82 & 10 & & & \\
\hline $\begin{array}{l}\text { Test: Tuke } \\
\text { Error: } 1\end{array}$ & $\begin{array}{l}\text { Alfa }=0,05 \\
4357 \mathrm{gl}:\end{array}$ & $S=1$ & 8757 & & \\
\hline Columna1 & Medias & $\mathrm{n}$ & E.E. & & \\
\hline CBST & 58,52 & 6 & 5,07 & A & \\
\hline CIII & 67,48 & 5 & 5,56 & A & \\
\hline
\end{tabular}

Figura 5.26 - Resultados da ANOVA aplicada gerados pelo programa InfoStat.

\section{b) Produtos intermediários na produção de hidrogênio}

Como foi mencionado anteriormente no item de comportamento do reator, as três condições em análise apresentaram prevalências de diferentes produtos intermediários nas suas operações. A Tabela 5.16 mostra a composição percentual dos produtos intermediários quantificados. Observa-se que a condição CBST produziu mais ácido acético que a condição de referência CIII. Como foi mencionado anteriormente, o produto intermediário relacionado à maior produção teórica de hidrogênio é o ácido acético $\left(3 \mathrm{molH}_{2} \cdot \mathrm{molglicerol}^{-1}\right)$ seguido pelo ácido butírico e butanol $\left(2 \mathrm{molH}_{2} \cdot \mathrm{molglicerol}^{-1}\right)$ e etanol $\left(1 \mathrm{molH}_{2} \cdot \mathrm{molglicerol}^{-1}\right)$. Devido ao fato das duas condições apresentarem produções baixas e similares de metano, com uma crescente 
produção de hidrogênio, pode-se inferir que o ácido acético observado na condição CBST é em sua maioria originado da produção de hidrogênio e não do consumo por homoacetogênese.

Na Figura 5.27 (b), na qual são apresentadas as quantidades molares de hidrogênio e metano produzidas e os produtos intermediários de maior presença produzidos ao longo do perfil, feito no último dia de monitoramento. Observa-se que a condição CBST produziu mais hidrogênio do que foi produzido no perfil da condição CIII. Adicionalmente, observa-se a clara diferença existente na concentração dos principais produtos intermediários gerados, ressaltando a alta produção de ácido acético.

Entretanto, na condição CGB prevaleceu a produção de ácido acético seguida pelo ácido propiônico e do etanol como se observa na Figura 5.27 (c). De acordo com Hawkes et al. (2007), o ácido propiônico pode ser produzido tanto por clostridios como por enterobacterias e está relacionado com uma menor produção de hidrogênio. O etanol por outro lado, está relacionado com a produção de hidrogênio, porém com o um rendimento teórico de apenas 1 $\mathrm{molH}_{2}$.molglicerol ${ }^{-1}$. A produção de ácido acético observada poderia estar relacionada mais com o consumo de hidrogênio do que com a sua produção, já que mesmo apresentando a maior eficiência em remoção de matéria orgânica em comparação às outras duas condições, a condição CGB manteve produções extremamente baixas de hidrogênio. Adicionalmente, como foi mostrado na Figura 5.24, na qual foram apresentadas as porcentagens de composição do biogás, os microrganismos dispuseram de altas concentrações de dióxido de carbono, um composto usado na homoacetogênese para produzir ácido acético.

Os resultados evidenciam que a glicerina bruta usada como substrato na operação do reator AnSBBR em batelada poderia constituir um melhor substrato para a obtenção de ácido acético, etanol e ácido propiônico do que para hidrogênio. É claro que as impurezas da glicerina 
bruta exerceram um efeito negativo na produção de hidrogênio, possivelmente não pela toxicidade como tem sido levantado por vários trabalhos da literatura, mas por sua contribuição em relação à reprodução da biomassa como será discutido mais tarde.

Tabela 5.16 - Porcentagem e concentração total dos compostos intermediários das condições CBST, CGB e CIII.

\begin{tabular}{cccc}
\hline & \multicolumn{3}{c}{ Condições } \\
\cline { 2 - 4 } Espécies & CIII & CBST & CGB \\
\hline Acetona (\%) & 0 & 0 & 0 \\
Metanol (\%) & 0 & 0 & 0 \\
Etanol (\%) & 3 & 5 & 22 \\
Butanol (\%) & 30 & 34 & 1 \\
Ácido Acético (\%) & 7 & 18 & 42 \\
Ácido Propiônico (\%) & 4 & 3 & 23 \\
Ácido Iso-Butírico (\%) & 4 & 1 & 2 \\
Ácido Butírico (\%) & 42 & 31 & 3 \\
Ácido Iso-Valérico (\%) & 1 & 1 & 1 \\
Ácido Valérico (\%) & 2 & 2 & 4 \\
Ácido Capróico (\%) & 6 & 5 & 2 \\
Total (mg.L L $^{-1}$ ) & 978,9 & 809,4 & 659,5 \\
\hline
\end{tabular}



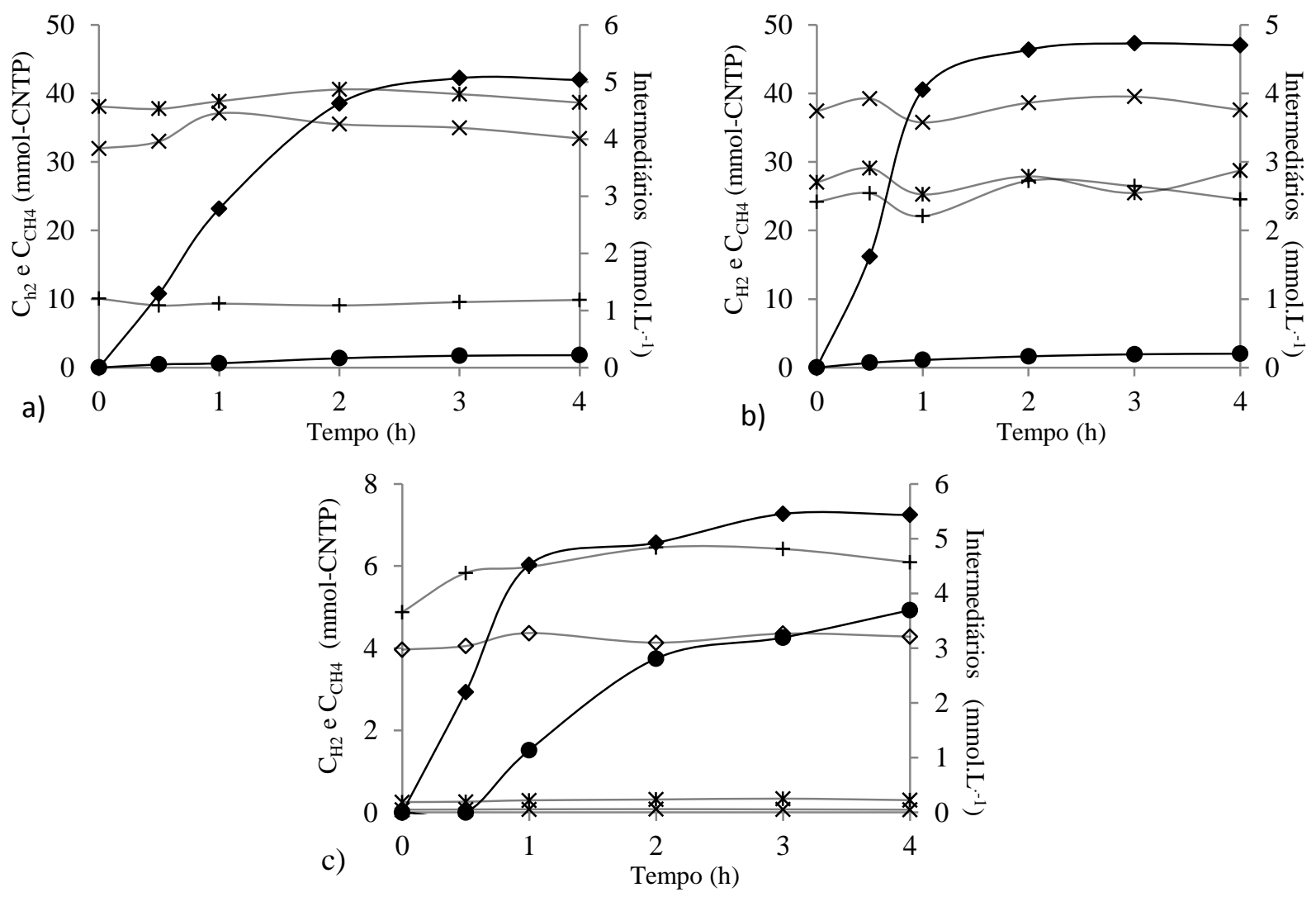

Figura 5.27 - Produção molar de hidrogênio $(-\bullet)$ e metano $(-\bullet)$, e concentração molar ácido acético $\left({ }^{+}\right)$, ácido butírico $\left({ }^{*}\right)$, butanol $\left({ }^{\star}\right)$ e etanol $\left({ }^{-}\right)$, ao longo do ciclo das condições a) CIII, b) CBST e c) CGB.

\section{c) Aproveitamento da glicerina na produção de hidrogênio}

Na Tabela 5.14 foram apresentados os rendimentos molares de hidrogênio por carga orgânica aplicada $\left(\mathrm{RMCA}_{\mathrm{s}, \mathrm{m}}\right)$ e removida $\left(\mathrm{RMCR}_{\mathrm{s}, \mathrm{m}}\right)$ mostrando a superioridade da condição CIII em relação a esses parâmetros. Porém, os rendimentos médios atingidos pela condição CBST não foram muito diferentes. A condição CGB, por outro lado, atingiu rendimentos visivelmente inferiores.

De forma similar à realizada na "Fase experimental" foram calculadas as porcentagens de glicerina consumida e os fatores de rendimento entre hidrogênio produzido e glicerina consumida $\left(\mathrm{Y}_{\mathrm{H} 2}\right)$, sendo os resultados apresentados na Tabela 5.17. Observa-se que o consumo de glicerina 
foi similar nas três condições com exceção do fator de rendimento $\mathrm{Y}_{\mathrm{H} 2}$ que foi maior na condição CIII. O fator de rendimento atingido pela condição CBST foi similar ao da condição CII alimentada com um afluente de $4000 \mathrm{mgDQO} . \mathrm{L}^{-1}$. Com relação à condição CGB observou-se um rendimento baixo na produção de hidrogênio, mesmo apresentado um consumo similar de glicerina.

Tabela 5.17 - Fator de rendimento entre hidrogênio produzido e glicerina consumida, e porcentagens médias de glicerol consumido (CG) das condições CIII, CBST e CGB.

\begin{tabular}{|c|c|c|c|c|c|c|c|c|c|}
\hline $\mathrm{C}$ & Intermediários totais & $\mathrm{C}_{\mathrm{SAFTL}}$ & $\mathrm{C}_{\mathrm{ST}}$ & GC & GC & GC & GC & PrM & $\mathrm{Y}_{\mathrm{H} 2}$ \\
\hline & $\mathrm{mgDQO} \cdot \mathrm{L}^{-1}$ & $\mathrm{mgDQO} . \mathrm{L}^{-1}$ & mgDQO. $L^{-1}$ & $\operatorname{mgDQO} \cdot \mathrm{L}^{-1} \cdot \mathrm{d}^{-1}$ & mgglicerol. $\mathrm{L}^{-1} \cdot \mathrm{d}^{-1}$ & molglicerol. $\mathrm{L}^{-1} \cdot \mathrm{d}^{-1}$ & $\%$ & $\mathrm{molH}_{2} \cdot \mathrm{L}^{-1} \cdot \mathrm{d}^{-1}$ & $\mathrm{molH}_{2} \cdot \mathrm{molGC}^{-1}$ \\
\hline CIII & 1950 & 5265 & 4105 & 10170 & 8136 & 0,09 & 59 & 0,0678 & 0,405 \\
\hline CBST & 1564 & 5028 & 3821 & 11808 & 9444 & 0,102 & 55 & 0,0564 & 0,286 \\
\hline CGB & 883 & 5211 & 3208 & 15030 & 12024 & 0,132 & 55 & 0,0084 & 0,054 \\
\hline
\end{tabular}

\section{d) Concentração de biomassa e produção de hidrogênio}

Ao comparar as três condições com relação à produção de hidrogênio e a concentração de biomassa observou-se uma relação inversamente proporcional. Como é mostrado na Tabela 5.18, quanto menor a quantidade de biomassa maior o rendimento molar de hidrogênio por matéria orgânica removida $\left(\mathrm{RMCR}_{\mathrm{S}, \mathrm{m}}\right)$. A condição CBST apresentou uma quantidade de biomassa três vezes maior do que a condição CIII e o rendimento de hidrogênio por matéria orgânica removida foi levemente inferior. Porém, já que os resultados de produção de hidrogênio foram similares para estas duas condições, a diferença observada poderia estar relacionada mais com o tipo de microrganismos selecionados do que com a quantidade de biomassa no reator.

A condição que apresentou maior reprodução de biomassa foi a CGB operada com glicerina bruta, com uma massa total quase doze vezes maior do que a condição CIII. A alta 
produção de biomassa poderia ter alguma relação com o consumo de hidrogênio por homoacetogênese, já que esta condição apresentou uma alta produção de ácido acético, um rendimento molar de hidrogênio por carga orgânica removida mínimo e a maior eficiência de remoção de matéria orgânica.

Um comportamento similar foi observado nas condições operadas com três horas de tempo de ciclo na "Fase experimental" que também foram relacionadas com altos consumos de hidrogênio. Ni et al. (2011) experimentam com dois reatores conectados operados em batelada para estudar a degradação do substrato e a produção de ácido acético por homoacetogênese, usando glucose como fonte de carbono. Eles observaram que a degradação do substrato e a produção de ácido acético estavam intimamente ligadas à concentração de biomassa ativa no sistema. Quanto maiores às concentrações de biomassa no reator, maiores as produções de ácido acético por homoacetogênese e maior o consumo de substrato. Resultados similares foram observados na operação desta condição. Existe então evidencia de que altas concentrações de biomassa no reator podem contribuir ao consumo de hidrogênio por homoacetogênese.

De acordo com Chatzfragkou e Papanikolaou (2012) e Petitdemange et al. (1995), as impurezas da glicerina bruta poderiam ter um efeito inibitório sobre o crescimento da biomassa. Os resultados da operação da condição CGB demostram que o efeito das impurezas sobre a biomassa não é inibitório no crescimento. Ao contrario, aparenta-se que as impurezas contribuíram positivamente com a reprodução da biomassa e na aceleração das rotas metabólicas que usam o hidrogênio para produção de ácidos e álcoois. Este efeito de alta reprodução poderia estar associado aos nutrientes presentes na glicerina bruta. Thompson e He (2006) mencionam que a glicerina bruta é composta por uma variedade de elementos nutricionais como cálcio, magnésio, fósforo e enxofre independentemente da origem do biodiesel. Estes nutrientes somados 
aos nutrientes adicionados puderam fazer com que o meio apresentasse uma grande oferta nutricional e como consequência tenha provocado uma rápida reprodução da biomassa.

$\mathrm{Na}$ "Fase preliminar" foi observada a necessidade de nutrientes adicionais no meio de alimentação para melhorar a produção de hidrogênio. Porém, as baixas produtividades obtidas nessa fase podem estar relacionadas especificamente à necessidade de ferro no meio (um nutriente ausente na glicerina bruta) ou a outros fatores adicionas como a adaptação ou préseleção inadequada da biomassa.

Uma vez mais é vista a necessidade de estudos mais profundos que contribuam para o esclarecimento da relação entre a quantidade de biomassa no suporte do reator e a produção de hidrogênio, a qual parece ser inversamente proporcional.

Tabela 5.18 - Massa total de biomassa no reator, produtividade molar específica e rendimento $\mathrm{H}_{2}$ /glicerina das condições CBST e CIII.

\begin{tabular}{cccc}
\hline Condição & $\mathrm{M}_{\mathrm{SVT}}$ & $\mathrm{RMCR}_{\mathrm{S}, \mathrm{m}}$ & PrME \\
\hline & $(\mathrm{g})$ & $\left(\mathrm{molH}_{2} \cdot \mathrm{kgDQO}^{-1}\right)$ & $\left(\mathrm{molH}_{2} \cdot \mathrm{kgSVT}^{-1} \cdot \mathrm{d}^{-1}\right)$ \\
\hline CIII & 3,4 & 21,1 & 19,8 \\
$\mathrm{CBST}$ & 8,0 & 17,6 & 7,3 \\
$\mathrm{CGB}$ & 39,0 & 1,5 & 1,0 \\
\hline
\end{tabular}

\subsubsection{Considerações adicionais}

A presente fase permitiu estudar o efeito do pré-tratamento da biomassa sobre a produção de hidrogênio. Em geral foi observado que a diferença das produtividades molares obtidas prétratando e não pré-tratando termicamente a biomassa não foi estatisticamente significativa. Ao analisar os produtos intermediários observou-se que a quantidade de ácido acético produzida na 
condição CBST foi quase três vezes maior do que na condição CIII, atingindo em maior proporção o máximo valor teórico de produção de $3 \mathrm{molH}_{2} \cdot \mathrm{molglicerol}^{-1}$. Esta geração de ácido acético produziu mais do que consumiu hidrogênio.

Adicionalmente, esta fase permitiu observar que os compostos da glicerina bruta tem um efeito negativo na produção de hidrogênio possivelmente relacionado à alta reprodução da biomassa e à aceleração das rotas metabólicas que contribuem para a produção de ácido acético, etanol e ácido propiônico. Por esta razão, a glicerina bruta usada como fonte de carbono nas condições do estudo aparentou ser um melhor substrato para a obtenção destes produtos intermediários, mais do que para hidrogênio.

Outro fator de influência negativa sobre a produção de hidrogênio na condição CGB poderia estar relacionada à alta alcalinidade ao bicarbonato, que também foi observada na "Fase preliminar”. Estudos mais profundos seriam requeridos para obter conclusões específicas.

\section{$5.4 O$ reator AnSBBR em batelada na obtenção de hidrogênio usando glicerol como substrato}

A presente pesquisa mostrou que o reator AnSBBR operado em batelada com biomassa imobilizada em suporte inerte tem um grande potencial na obtenção de hidrogênio usando glicerol como única fonte de carbono. Na Tabela 5.19 são apresentados os resultados de algumas pesquisas que trabalharam usando o reator AnSBBR em batelada com biomassa imobilizada em suporte inerte e recirculação da fase líquida. Os substratos usados foram águas residuárias industriais visando obter hidrogênio. Também são apresentados os melhores resultados do trabalho de Santos et al. (2012), cuja pesquisa foi desenvolvida no mesmo laboratório que o 
presente trabalho, usando o mesmo reator e condições similares. Adicionalmente, todos os trabalhos mostrados apresentam os indicadores de produção de hidrogênio com base na matéria orgânica aplicada e removida, tal como foi feito na presente pesquisa. Os resultados mostrados na Tabela 5.19 correspondem aos quantificados no final do ciclo de operação das pesquisas.

Como se observa na Tabela 5.19, o presente trabalho obteve a maior produtividade molar de hidrogênio superando inclusive à produtividade molar atingida por Santos et al. (2012) na que utilizaram uma maior carga orgânica volumétrica e sacarose como única fonte de carbono. Para comparar o consumo de substrato do trabalho de Santos et al (2012) e da presente pesquisa foi calculado o rendimento molar de hidrogênio por sacarose (RMSC) em termos de DQO equivalente. Como se observa na Tabela 5.19, o presente trabalho apresentou mais do dobro do rendimento obtido pelos autores.

Da mesma forma, este trabalho apresentou o melhor rendimento molar de hidrogênio por matéria orgânica removida e a melhor produção molar de hidrogênio por dia. Estes resultados são um indicativo de que o reator AnSBBR operado em batelada pode apresentar no futuro aplicações promissórias para a obtenção de hidrogênio usando glicerol como única fonte de carbono. 
Tabela 5.19 - Pesquisas que usaram o reator AnSBBR em batelada com biomassa imobilizada em suporte inerte para a obtenção de hidrogênio.

\begin{tabular}{|c|c|c|c|c|c|c|c|}
\hline Autores & Unidade & $\begin{array}{c}\text { Venkata et al. } \\
(2007) \text { (a) }\end{array}$ & $\begin{array}{c}\text { Venkata } \text { et al. } \\
\text { (2007) (b) }\end{array}$ & $\begin{array}{c}\text { Venkata et al. } \\
\text { (2008) (a) }\end{array}$ & $\begin{array}{l}\text { Venkata et al. } \\
\text { (2008) (b) }\end{array}$ & $\begin{array}{c}\text { Santos et al. } \\
\text { (2012) }\end{array}$ & $\begin{array}{l}\text { Presente } \\
\text { pesquisa }\end{array}$ \\
\hline Reator & & AnSBBR & AnSBBR & AnSBBR & AnSBBR & AnSBBR & AnSBBR \\
\hline Substrato & - & $\begin{array}{c}\text { Água residuária } \\
\text { química }\end{array}$ & $\begin{array}{l}\text { Água residuária } \\
\text { química }\end{array}$ & $\begin{array}{l}\text { Água residuária } \\
\text { de destilaria }\end{array}$ & Água residuária & Sacarose & Glicerol \\
\hline $\begin{array}{c}\text { Temperatur } \\
\mathrm{a} \\
\end{array}$ & ${ }^{\circ} \mathrm{C}$ & 28 & 28 & 28 & 28 & 30 & 30 \\
\hline Inóculo & - & $\begin{array}{c}\text { Biomassa } \\
\text { UASB } \\
\text { resistente a } \\
\text { canamicina }\end{array}$ & $\begin{array}{l}\text { Biomassa } \\
\text { anaeróbia }\end{array}$ & $\begin{array}{c}\text { Biomassa } \\
\text { UASB } \\
\text { laboratório }\end{array}$ & $\begin{array}{c}\text { Biomassa } \\
\text { acidogênica }\end{array}$ & $\begin{array}{c}\text { Biomassa } \\
\text { acidogênica }\end{array}$ & $\begin{array}{c}\text { Biomassa } \\
\text { UASB }\end{array}$ \\
\hline $\begin{array}{c}\text { Pré- } \\
\text { tratamento } \\
\text { Biomassa }\end{array}$ & - & $\begin{array}{l}100^{\circ} \mathrm{C}, 2 \mathrm{~h} \\
\mathrm{pH} 3,24 \mathrm{~h}\end{array}$ & $\begin{array}{l}100^{\circ} \mathrm{C}, 2 \mathrm{~h} \\
\mathrm{pH} 3,24 \mathrm{~h}\end{array}$ & $\begin{array}{l}100^{\circ} \mathrm{C}, 2 \mathrm{~h} \\
\mathrm{pH} 3,24 \mathrm{~h}\end{array}$ & $\begin{array}{l}100^{\circ} \mathrm{C}, 2 \mathrm{~h} \\
\mathrm{pH} 3,24 \mathrm{~h}\end{array}$ & - & $\begin{array}{c}90^{\circ} \mathrm{C}, 15 \\
\min \end{array}$ \\
\hline Tc & $\mathrm{h}$ & 24 & 24 & 24 & 24 & 2 & 4 \\
\hline $\mathrm{V}_{\mathrm{R}}$ & $\mathrm{L}$ & 2 & 2 & 0,8 & 1,4 & 4,5 & 3,67 \\
\hline $\mathrm{Va}$ & $\mathrm{L}$ & 1,4 & 1,5 & 0,8 & 1,4 & 1,9 & 1,5 \\
\hline COVA & kgDQO. $\mathrm{m}^{-3} \cdot \mathrm{d}^{-1}$ & 6,3 & 5,6 & 9,6 & 4,75 & 28,7 & 12,91 \\
\hline $\mathrm{nH}_{2}$ & $\mathrm{mmol}^{\mathrm{d}} \mathrm{d}^{-1}$ & 2,5 & 26 & 13,13 & 6,52 & 200 & 248 \\
\hline PrM & mol. $\mathrm{m}^{-3} \cdot \mathrm{d}^{-1}$ & 1,3 & 6,7 & 32,5 & 4,7 & 27,9 & 67,5 \\
\hline $\mathrm{RMCA}_{\mathrm{s}, \mathrm{m}}$ & $\left(\mathrm{molH}_{2} \cdot \mathrm{kgDQO}^{-1}\right)$ & 0,2 & 0,9 & 2,7 & 2,3 & 1,58 & 5,2 \\
\hline $\mathrm{RMCR}_{\mathrm{S}, \mathrm{m}}$ & $\left(\mathrm{molH}_{2} \cdot \mathrm{kgDQO}^{-1}\right)$ & 0,483 & 0,1 & 6,985 & - & 8,92 & 21,1 \\
\hline RMSC & $\left(\mathrm{molH}_{2} \cdot \mathrm{kgDQO}^{-1}\right)$ & & & & & 1,63 & 3,6 \\
\hline
\end{tabular}

\subsection{Análise Microbiológica}

Ao final da operação da condição CGB alimentada com glicerina bruta foi realizada uma microscopia por luz comum. Os resultados são apresentados na Figura 5.28. Observa-se uma alta presença de uma substância extracelular de composição desconhecida cuja função poderia estar relacionada à fixação das células ao suporte. Esta substancia dificulta a visibilidade das células, porém, é clara a presença de estreptobacilos com endósporos, endósporos e microrganismos filamentosos. 

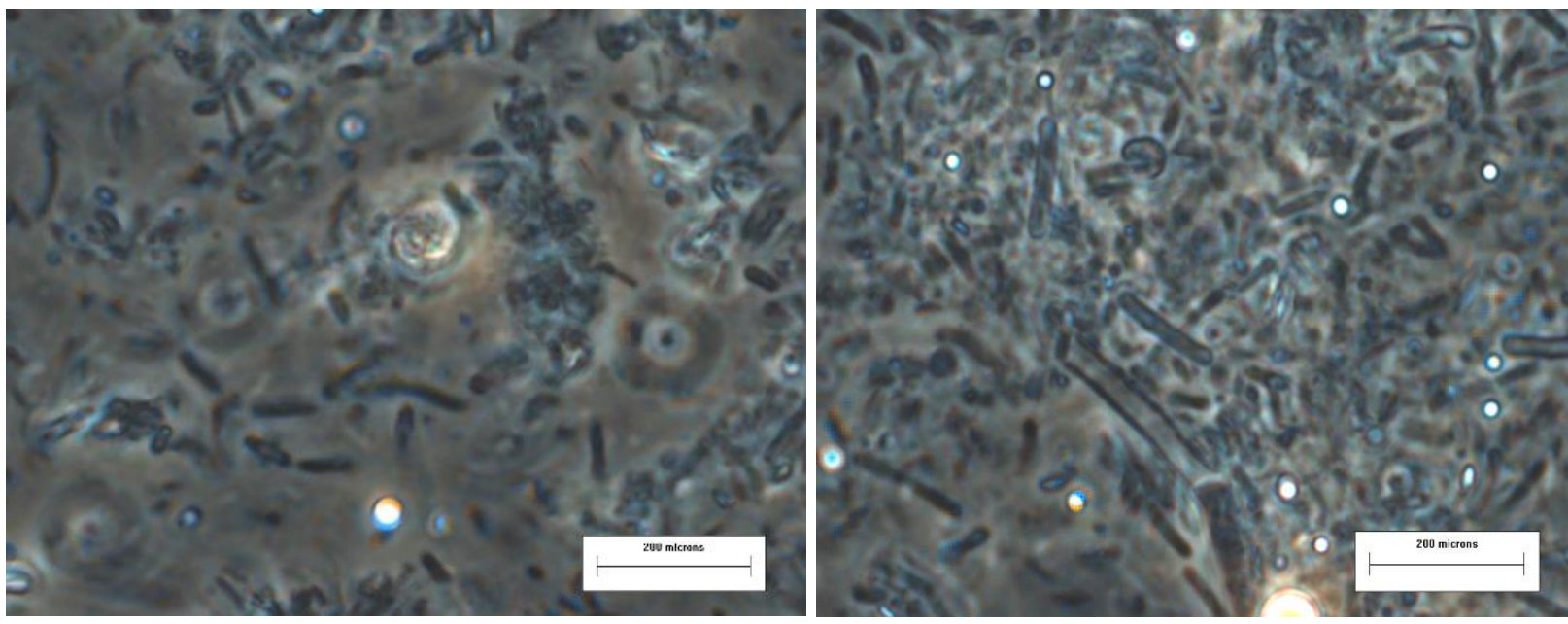

Figura 5.28 - Microscopia por luz comum de biomassa no reator operado na condição CGB. 


\section{CONCLUSÕES}

Os resultados obtidos no estudo da aplicação do reator AnSBBR com biomassa imobilizada em suporte inerte (polietileno de baixa densidade) e operado em batelada sequencial, sendo alimentado com água residuária usando glicerol e glicerina bruta como fonte de carbono visando a obtenção de hidrogênio possibilitaram as seguintes conclusões:

\section{a) Fase preliminar}

- A operação do reator com glicerol-PA como única fonte de carbono com biomassa prétratada termicamente, apresentaou melhores resultados do que a operação com glicerina bruta industrial;

- O uso de sacarose nos primeiros dias de operação com o objetivo de enriquecer a biomassa não teve um efeito postivo na produção de hidrogênio, quando o reator era alimentado com glicerina bruta industrial, de laboratório ou glicerol-PA;

- Quanto maior foi a concentração de matéria orgânica na forma de DQO no afluente maio foi a produção de hidrogênio;

- Ainda que a produção de hidrogênio tivesse sido baixa nas condições operadas com glicerina bruta industrial e de laboratório, o consumo na forma de DQO foi maior em comparação as condições operadas com glicerol. 


\section{b) Fase experimental}

- Todas as condições apresentaram baixas remoções de matéria orgânica na faixa de 19 a $30 \%$

- A diminuição do tempo de ciclo de 4 a 3 horas fez com que aumentasse a produção de metano e, portanto, o consumo de hidrogênio;

- Não foi observada uma relação clara entre a produção de hidrogênio e a carga orgânica volumétrica, porém o reator apresentou o melhor desempenho na obtenção de hidrogênio quanto à produção volumétrica de hidrogênio $\left(\mathrm{V}_{\mathrm{H} 2}: 5,6 \mathrm{~L} \cdot \mathrm{d}^{-1}\right)$, produtividade molar $(\operatorname{PrM}$ : 67,5 $\mathrm{molH}_{2} \cdot \mathrm{m}^{-3} \cdot \mathrm{d}^{-1}$ ) e específica de hidrogênio (PrME: 19,8 $\mathrm{molH}_{2} \cdot \mathrm{SVT}^{-1} \cdot \mathrm{d}^{-1}$ ), rendimento molar de hidrogênio por carga orgânica aplicada $\left(\mathrm{RMCA}_{\mathrm{S}, \mathrm{m}}: 5,2 \mathrm{molH}_{2} \cdot \mathrm{kgDQO}^{-1}\right)$ e por carga orgânica removida $\left(\mathrm{RMCR}_{\mathrm{S}, \mathrm{m}}: 21,1 \mathrm{molH}_{2} \cdot \mathrm{kgDQO}^{-1}\right)$ na condição com 4 horas de tempo de ciclo e uma concentração afluente de $5000 \mathrm{mgDQO} \cdot \mathrm{L}^{-1} \cdot \mathrm{L}^{-1}$ de COVA 12911 mgDQO.L $L^{-1} \cdot \mathrm{d}^{-1}$ (condição CIII). Também foi quantificada uma baixa produção de metano de $0,15 \mathrm{LCH}_{4} \cdot \mathrm{d}^{-1}$;

- Durante a operação predominou a produção de ácido butírico, butanol e ácido acético, porém a condição CIII produziu a menor quantidade de ácido acético que nas outras condições.

\section{c) Fase final}

- A Análise da Variância (ANOVA) realizada com as produtividades molares de hidrogênio das condições CIII e CBST as quais foram operadas com biomassas pré-tratada e sem prétratamento térmico, respectivamente, mostrou que não existiu diferença estatisticamente 
significativa entre as produtividades molares de hidrogênio nestas duas condições, apesar da formação de ácido acético da condição CBST ter sido $11 \%$ maior que a condição CIII;

- O uso de glicerina bruta industrial em comparação ao uso de glicerol-PA teve um efeito negativo na produção de hidrogênio, possivelmente, devido às impurezas da sua constituição. 


\section{REFERÊNCIAS BIBLIOGRÁFICAS}

Angenent, L.T.; Sung, S.; Raskin, L. Methanogenic population dynamics during startup of a fullscale anaerobic sequencing batch reactor treating swine waste. Water Research, 36, 4648-4654, 2002.

Angenent, L.; Karim, K.; Al-Dahhan, M.; Wrenn, B.; Domingues, R. Production of bioenergy and biochemicals from industrial and agricultural wastewater. Trends in Biotechnology, 22(9), 477-485, 2004.

Babu, L.; Mohan, S.; Sarm, P. Influence of reactor configuration on fermentative hydrogen. International Journal of Hydrogen Energy, 34, 3305-3312, 2009.

Ballongue, J.; Maison, E.; Amine, J. Petitdemange, H., Gay, R. Inhibitor effects of products of metabolism on growth of Clostridium acetobutylicum. Applied Microbiology and Biotechnology, 26, 568-573, 1987.

Bergamo, C.M.; Monaco, R.; Ratusznei, S.M.; Rodrigues, J.A.D.; Zaiat, M.; Foresti, E. Effects of Temperature at Different Organic Loading Levels on The Performance of a FluidizedBed Anaerobic Sequencing Batch Bioreactor. Chemical Engineering and Processing, 48, 789-796, 2009.

Bernal, M.; Tinoco, L.; Torres, L.; Malagón, D.; Montoya, D. Evaluation colombian Clostridium spp. strains hydrogen production using glycerol as substrate. Electronic Journal of Biotechnology, 16 (2), Doi 10.2225, 2013

Bezerra, R.A.; Rodrigues, J.A.D.; Ratusznei, S.M.; Zaiat, M.; Foresti, E. Effects of Feed Time, Organic Loading and Shock Loads in the Anaerobic Whey Treatment by an AnSBBR with Circulation. Applied Biochemistry and Biotechnology, 157(02), 140-158, 2009.

Biebl, H.; Zeng, A.; Menzel, K.; Decwer, W. Fermentation fo glicerol to 13-propanediol and 23butanediol by Klebsiella pneumania. Applied Microbiology and Biotechnology, 50, 2429, 1998.

Biodiesel America's Advanced Bioful. Production. National Biodiesel Board [on line]. Estados Unidos 2013. Disponível em: www.biodiesel.org. Acesso em: 5 de abril de 2013. 
Brito, A.; Rodrigues, A.; Melo, F. Feasibility of a pulsed sequencing batch reactor with an anaerobic aggregated biomass for the treatment of low strength wastewaters. Water Science and Technology, 35, 193-198, 1997.

Camargo, E.; Ratusznei, S.; Rodrigues, J.; Zaiat, M.; Borzani, W. Treatment of low-strength wastewater using immobilized biomass in a sequencing batch external loop reactor: influence of the medium superficial velocity on the stability and performance. Brazilian Journal of Chemical Engineering, 19, 267-275, 2002.

Chang, F; Lin, C. Biohydrogen production using an up-flow anaerobic sludge blanket reactor. International Journal of Hydrogen Energy, 29 (1):33-39, 2004

Chatzifragkou, A.; Papanikolaou, S. Effect of impurities in biodiesel-derivel waste glycerol on the performance and feasibility of biotechnological processes. Applied Microbiology and Biotechnology, 95, 13-27, 2012.

Chaudhary, N.; Ngadi, M.; Simpson, B.; Kassama, L. Biosynthesis of Ethanol and Hydrogen by Glycerol Fermentation Using Escherichia coli . Advances en Chemical Engineering and Science, 1, 83-89, 2011.

Chen, C.; Lin, C.; Lin, M. Acid-base enrichment enhances anaerobic hydrogen production process. Applied Microbiological Biotechnology, 8, 224-228, 2002.

Chen, C.; Lin, C. Using sucrose as a substrate in an anaerobic hydrogen-producing reactor. Advanced Environmental Research, 7, 695-699, 2003.

Dague, R.; Habben, R.; Pidaparti, S. Initial studies on anaerobic sequential batch reactor. Water Science Technology, 26(9-11), 2429-2432, 1992.

Damasceno, L.; Rodrigues, J.; Ratusznei, S.; Zaiat, M.; Foresti, E. Effect of Mixing Mode on the Behavior of an ASBBR with Immobilized Biomass in the Treatment of Cheese Whey. Brazilian Journal of Chemical Engineering, 25, 291-298, 2008.

Dinamarca, C. e Bakker, R. (2009) Apparent hydrogen consumption in acid reactors: observations and implications. Water Science and Technology, 59(7),1441-1447.

Doremus, M.; Linden, J.; Moreira, A. Agitation and pressure effects on acetone-butanol fermentation. Biotechnology and Bioengineering, 27, 852-860, 1985.

Doyle, M. 1989. Foodborne Bacterial Pathogens, Décima edição. Marcel Dekker, Inc., Nova York, Estados Unidos de América. 
Duangmanee, T.; Padmasiri, S.I.; Simmons, J.J.; Raskin, L.; Sung, S. Hydrogen production by anaerobic microbial communities exposed to repeated heat treatments. Water Environmental Research, 79(9), 975-83, 2007.

Duffey, A. Estudio regional sobre la economía de los biocombustibles 2010: temas clave para los países de América Latina y el Caribe. Dialogo de políticas sobre desarrollo interinstitucional e innovación en biocombustibles en América Latina y el Caribe, (pág. 100). Santiago de Chile. 2010.

El-Bery, H.; Tawfik, A.; Kumari, S.; Bux, F. Effect of thermal pre-treatment on inoculum sludge to enhance bio-hydrogen production from alkali hydrolysed rice straw in a mesophilic anaerobic baffled reactor . Environmetal Technology, 34, 1965-1972, 2013.

El Manssouri, M. (2012). Influencia da carga orgânica na produção de biohidrogenio em ASBBR com agitação tratando água residuária sintética. Tese de Mestrado. Brasil. Universidade de São Paulo.

Fang, H.; Liu, H. Effect of $\mathrm{pH}$ on hydrogen production from glucose by a mixed culture. Bioresource Technology, 82, 87-93, 2002.

Fang, H.H.P.; Liu, H. Effect of $\mathrm{pH}$ on hydrogen production from glucose by a mixed culture. Bioresource Technology, 82, 87-93, 2002.

Fang, G.; Li, Cl.; Zhang, T. Acidophilic biohydrogen production from rice slurry. International Journal of Hydrogen Energy, 31, 683-692, 2006.

Federación Nacional de Biocombustibles de Colombia. Lento crecimiento de biodiesel en 2013 [on line]. Colombia 2013. Disponível em: http://www.fedebiocombustibles.com. Acceso em: 07 de janeiro de 2014.

Fernandes, B.; Peixoto, G.; Albrecht, F.; Saavedra, N; Zaiat, M. Potencial to produce biohydrogen from various wastewaters. Energy for Susteinable Development, 14, 143$148,2010$.

Ginkel, S.; Oh, S.; Logan, B. Biohydrogen gas production from food processing and domestic wastewaters. International Journal of Hydrogen Energy, 30, 1535-1542, 2005.

Gonzales, R.; Murarka, A.; Dharmadi, Y; Yazdani, S. A new model for the anaerobic fermentation fo glucerol in enteric bacteria: Trunk and auxiliary pathways in Escherichia coli. Metabolic Engineering, 10, 234-245, 2008. 
Hafez, H.; Nakhla, G.; El Naggar, M.; Elbeshbishy, E.; Baghchehsaraee, B. Effect of organic loading on a novel hydrogen bioreactor. International Journal of Hydrongen Energy, 35(1), 81-92, 2010.

Han, S.; Shin, H. Biohydrogen production by anaerobic fermentation of food waste. International Journal of Hydrogen Energy, 29, 569-577, 2004.

Han, S.; Shin, H. Performance of an innovative two-stage process converting food waste to hydrogen and methane. Journal of the air and waste management, 54, 242-249, 2004.

Hawkes, F.; Dinsdale, R.; Hawkes, D.; Hussy, I. Sustainable fermentative hydrogen production: challenges for process optimisation. International journal of Hydrogen Energy, 27, 1339-1347, 2004.

Hawkes, F.; Hussi, I.; Kiazze, C.; Dinsdale, R.; Hawkes, D. Continuos dark fermentative hydrogen production by mesophilic microflora: Principles and progress. International Journal of Hydrogen Energy, 32, 172-184, 2007.

He B.; Thomson J. Characterization of crude glycerol from biodiesel production from multiple feedstocks . Applied Engineering in Agriculture, 22(2), 261-265, 2006.

Horiuchi, J. I.; Shimizu, T.; Tada, K.; Kanno, T.; Kobayashi, M. Selective production of organic acids in anaerobic acid reactor by $\mathrm{pH}$ control. Bioresource Technology, 82, 209-213. 2002.

Hu, H.; Wood, T. An envolved Escherichia coli strain for producing hydrogen and ethanol from glycerol. Biochemical and Biophysical Research Communications, 391,1033-1038, 2010.

Hussy, I.; Hawkes, FR.; Dinsdale, R.; Hawkes, D.L. Continuos fermentative hydrogen production from a wheat starch co-product by mixed microflora. Biotechnology Bioengineering, 84, 619-629, 2003.

Hussy, I.; Hawkes, R.; van Deursen, A.; van Andel, J. Continuos fermentative hydrogen production from sucrose and sugarbeet. International journal of Hydrogen Energy, 30, 471-483, 2005. 
Ito, T.; Nakashimadda, Y.; Senba, K.; Natsui, T.; Nishio, N. Hydrogen and ethanol production from glycerol containing waste discharged after biodiesel manufacturing process. Journal of Bioscience and Bioengineering, 100, 260-265, 2005.

Jou, C. G.; Huang, G. A pilot study for oil refinery wastewater treatment using a fixed film bioreactor. Advances in Environmental Research, 7, 463-469, 2003

Kapdan, I.; Kargi, F. Bio-hydrogen production from waste materials. Enzyme and Microbial Technology, 38, 589-592, 2006.

Khanal, S.K.; Chen, W.H.; Li, L.; Sung, S. Biological hydrogen production:effects of $\mathrm{pH}$ and intermediate products. International Journal of Hydrogen Energy, 29 (11), 1123-1131, 2004.

Khanal, S.; Chen, W.; Li, H.; Sung, S. Biohydrogen production in continuous flow reactor using mixed microbial culture. Water Environmental Research, 78(2), 110-117, 2006.

Kumar, S. 2008. Anaerobic Biotechnology for Bioenergy Production. Principles and Aplications. Primeira edição. Wiley-Blackwell. Nova Deli. India.

Kyazze, G.; Martinez, N.; Dinsdale, R.; Premier, G.; Hawkes, F.; Guwy, A. Influence of substrate concentration on the stability and yield of continuos biohydrogen production . Biotechnology and Bioengineering, 93 (5), 971-979, 2006.

Lay, J.; Lee, Y.; Noike, T. Feasibility of biological hydrogen production from organic fraction of municipal solid waste. Water Research, 33 (11), 2579-2586, 1999.

Lay, J. Modeling and optimization of anaerobic digested sludge converting starch to hydrgogen. Biotechnology Bioengineering, 60(3), 269-278, 2000.

Lay, J.; Fan, K.; Chang, J.; Ku, C. Influence of chemical nature of organic wastes on their conversion to hydrogen by heat-shock digested sludge. International Journal of Hydrogen Energy, 28, 1361-1367, 2003.

Lay, J.; Tsai, C.; Huang, C.; Chang, J.; Chou, C.; Fan, K.; Chang, J.; Hsu, P. Influence of pH and hydraulic retention time on anaerobes converting beer processing wastes. Water Science Technology, 52, 123-129, 2005.

Lay, J. Modeling and optimization of anaerobic digested sludge converting starch to hydrogen. Biotechnology and Bioengineering, 68(3), 269-278, 2000. 
Lee, Y.; Miyahara, T.; Noike, T. Effect of iron concentration on hydrogen fermentation. Bioresource Technology, 80(3), 227-231, 2001.

Lee, K.; Hsu, Y.; Lo, Y.; Lin, P.; Lin, C.; Chang, J. Exploring optimal environmental factors for fermentative hydrogen production from starch using mixed anaerobic microflora. International Journal of Hydrogen Energy, 33, 1565-1572, 2008.

Levin, D.; Islam, R.; Cicek N.; Sparling, R. Hydrogen production by Clostridium thermocellum 27405 from cellulosic biomass substrates. International journal of Hydrogen Energy, 31, 1496-1503, 2006.

Li, C.; Fang, H. Fermentative hydrogen production from wastewater and solid wastes by mixed cultures. Critical Review of Environmental Science and Technology, 37(1), 1-39, 2007.

Lin, C.; Chang, R. Hydrogen production during the anaerobic acidogenic conversion of glucose. Journal of Chemical Technology and Biotechnology, 74, 498-500, 1999.

Lin, C.; Jo, C. Hydrogen production from sucrose using an anaerobic sequencing batch reactor process. Journal of Chemical Technology and Biotechnology, 78, 678-684, 2003.

Lin, C.; Lay, C. Carbon/nitrogen ratio effect on fermentative hydrogen production by mixed microflora. International Journal of Hydrogen Energy, 29(1), 41-45, 2004.

Lin, C.; Lee, C.; Tseng, J.; Shaio, I. Biohydrogen production from sucrose using base-enriched anaerobic mixed microflora. Process Biochemistry, 41, 915-919, 2006.

Liu, G.; Shen, J. Effects of culture and medium conditions on hydrogen production from starch using anaerobic bacteria. Journal of Bioscience and Bioengineering, 98(4), 251-256, 2004.

Luo, G.; Karakashev, D.; Xie, L.; Zhou, Q.; Angelidaki, I. Long-term effect of inoculum pretreatment on fermentative hydrogen production by repeated batch cultivations: Homo acetogenesis and methanogenesis as competitors to hydrogen production. Biotechnology and Bioengineering, 108(8), 1816-1827, 2011.

Mandal, B.; Nath, K. Improvement of biohydrogen production under decreased partial pressure of H2 by Enterobacter cloacae. Biotechnology Letters Journal, 28, 831-835, 2006. 
Mangayil, R.; Karp, M.; Santala, V. Bioconversion of crude glycerol from biodiesel production to hydrogen. International Journal of Hydrogen Energy, 37, 12198-12204, 2012.

Marques, P.; Bartolomeu, M.; Tomé, M.; Neves, L. Bio-hydrogen production from glycerol by a strain of Enterobacter aerogenes. Hyphotesis VIII, 1-3, 2009.

Maru, B.; Stchigel, A.; Medina, F.; Sueiras, J. Bio-hydrogen production by dark fermentation of glycerol using Enterobacter and Citrobacter Sp. American Institute of Chemical Engineers, 29 (1), 31-38, 2012.

Michelan, R.; Zimmer, T.; Rodrigues, J.; Ratusznei, S.; Moraes, D.; Zaiat, M.; Foresti E. Effect of Impeller Type and Mechanical Agitation on the Mass Transfer and Power Consumption Aspects of ASBR Operation Treating Synthetic Wastewater. Journal of Environmental Management, 90, 1357-1364, 2009.

Mizuno, O.; Dinsdale, R.; Hawkes, F.; Hawkes, D.; Noike, T. Enhancement of hydrogen production from glucose by nitrogen gas sparging. Bioresource Technology, 73, 59-65, 2000.

Morimoto, M.; Atsuko, M.; Atif, A.; Ngan, M.; Fakhru'1-Razi, A.; Iyuke, S.; Bakir, A. Biological hydrogen production from glucose using natural anaerobic microflora. International Journal of Hydrogen Energy, 29(7), 709-713, 2004.

$\mathrm{Mu}, \mathrm{Y}$;; Yu, H. Biological hydrogen production in a UASB reactor with granules I: physicochemical characteristics of hydrogen-producing granules. Biotechnology Bioengineering, 94(5), 980-987, 2006.

Mu, Y.; Zheng, X.; Yu, H.; Zhu, R. Biological hydrogen production by anaerobic sludge at various temperatures. International Journal of Hydrogen Energy, 31,780-785, 2006.

Nakashimada, Y.; Rachman, M.; Kakizono, T.; Nishio, N. Hydrogen production of enterobacter aerogenes altered by extracellular and intracellular redox states. International Journal oh Hydrogen Energy, 27, 1399-1405, 2002.

Nath, K.; Das, D. Improvement of fermentaative hydrogen production: Various approaches. Applied Microbiology and Biotecnology, 65, 520-529, 2004.

Ngo, T.; Kim, M.; Sim, S. High-yield biohydrogen production from biodiesel manufacturing waste by Thermogata neapolitana. International Journal of Hydrogen Energy, 36, 58365842, 2011. 
Ni, B.; Liu, H.; Nie, Y.; Zeng, R.; Du, G.; Chen, J.; Yu, H. Coupling glucose fermentation and homoacetogenesis for elevated acetate production: experimental and mathematical approaches. Biotechnology and Bioengineering, 108, 345-353, 2011.

Nissilä, M.; Tähti H.; Rintala J.; Puhakka J. Effects of heat treatment on hydrogen production potential and microbial community of thermophilic compost enrichment cultures. Bioresource Technology, 102(6), 4501-6, 2011.

Noike, T.; Mizuno, O. Hydrogen fermentation of organic municipal wastes. Water Science Technology, 42 (12), 155-162, 2000.

Oh, S.; Van Ginkel, S.; Logan, B. The relative effectiveness of $\mathrm{pH}$ control and heat treatment for enhancing biohydrogen gas production. Environmental Science Technology. 37, 51865190, 2003.

Okamoto, M.; Miyahara, T.; Mizuno, O.; Noike, T. Biological hydrogen potential of materials characteristics of the organic fraction of municipal solid wastes. Water Science Technology. 37 (22), 5186-5190, 2000.

Petitdemange, E.; Durr, C.; Abbad, A.; Raval, G. Fermentation of raw glycerol to 1,3propanediol by new strains of Clostridium butyricum. Journal of Industrial Microbiology and Biotechnology. 15, 498-502, 1995.

Ren, N.; Wnag, B.; Ma, F. Hydrogen bio-production of carbohydrate fermentation by anaerobic activated sludge process. In: Water environment $68^{\text {th }}$ annual conference, Miami Beach; 1995. p.145-153.

Rittman, B.; McCarty, P. 2001. Biotecnología del Medio Ambiente: Principios y Aplicaciones. Primeira edição. McGraw-Hill. Nova York. Estados Unidos de América.

Roychowdhury, S. Process for production of hydrogen from anaerobically decomposed organic materials. U.S. Patent. US 006090266A. 2000. 
Ruralcentro. Biodiesel: Brasil ocupa $3^{\mathrm{a}}$ posição no ranking mundial de produtores [on line]. Brasil 8 de março de 2013. Disponível em: http://ruralcentro.uol.com.br/noticias/biodiesel-brasil-ocupa-3-posicao-no-ranking-undialde-produtores-65925\#y=0.

Santos, D. Estudo da produção de biohidrogênio em AnSBBR com recirculação da fase líquida tratando água residuária sintética - efeito da carga orgânica. Dissertação (Mestrado) Escola de Engenharia de São Carlos - Departamento de Hidráulica e Saneamento, Universidade de São Paulo, 2012.

Sarma, S.; Brar, S.; Sydney E.; Bihan, Y.; Buelna, G.; Socol, C. Microbial hydrogen production by bioconversion of crude glycerol: A review. International Journal of Hydrogen Energy, 37, 6473-6490, 2012.

Sarty, A.; Pozzi, E.; Chinalia, F.; Zaiat, M.; Foresti, E. The performance of an anaerobic sequencing batch biofilm reactor treating domestic sewage colonized by anoxygenic phototrophic bacteria. Chemosphere, 62, 1437-1443, 2006.

Selembo, P.; Perez, J.; Lloyd, W.; Logan, B. Enhanced Hydrogen and 1,3-Propanediol Production from Glycerol by Fermentation Using Mixed Cultures. Biotechnology and Bioengineering, 104 (6), 1098-1106, 2006.

Ueno, Y.; Otsuka, S.; Morimoto, M. Hydrogen Production from Industrial Wastewater by Anaerobic Microflora in Chemostat Culture. Journal of Hydrogen and Bioengineering, 82 (2), 194-197, 1996.

van Ginkel, S.; Sung, S.; Lay, J. Biohydrogen production as a function of $\mathrm{pH}$ and substrate concentration. Environmental Science Technology, 35(24), 4726-4730, 2001.

van Ginkel, S.; Logan, B. Inhibition of biohydrogen production by undissociated acetic and butyric acids. Environmental Science of Technology, 39, 9351-9356, 2005.

van Groenestijn, J.; Hazewinkel, J.; Niernoord, M.; Bussmann, P. Energy aspects of biological hudrogen production in high rate bioreactor operated in the thermophilic temperature range. International Journal of Hydrogen Energy, 27(11-12), 1141-1147, 2002.

van Haandel, A.; Letinga, G. 1994. Anaerobic Sewage Treatment: A practical guide for regions with a hot climate. John Wiley \& Sons, Chester, Inglaterra.

Venkata, S.; Mohanakrishna, G.; Raghavulu, V.; Sarma P. Enhanching biohydrogen production from chemical wastewater treatmen in anaerobic sequencing batch biofilm reactor 
(AnSBBR) by bioaugmenting with selectively enriched kanamycin resistant anaerobic mixed consortia. International Journal of Hydrogen Energy, 32, 3284-3292, 2007 (a).

Venkata, S.; Bhaskar, Y.; Sarma P. Biohydrogen production from chemical wastewater treatment in biofilm configured reactor operated in periodic discontiniuos batch mode by selesctively enriched anaerobic mixed consortia. Water Research, 41, 2652-2664, 2007 (b).

Venkata, S.; Mohanakrishna, G.; Ramanaiah, S.; Sarma P. Simultaneous biohydrogen production and wastewater treatment in biofilm configured anaerobic periodic discontinuos batch reactor using destilery wastewater. International Journal of Hydrogen Energy, 33, 550558, 2008 (a).

Ventaka, S.; Mohanakrishna, G.; Sarma P. Integration of acidogenic and methanogenic processes for similtaneous production of biohydrogen and methane form wastewater treatment. International Journal of Hydrogen Energy, 33, 2156-2166, 2008 (b).

Viana, M.; Freitas, A.; Leitão, R.; Santaella, S. Biodegradability and methane production potential of glycerol generated by biodiesel industry. Water Science and Technology, 66(10), 2217-22, 2012.

Vlassis, T.; Antonopoulou, G.; Stamatelatou, K.; Lyberatos, G. Anaerobic treatment of glycerol for methane and hydrogen production . Global NEST Journal, 14 (2), 149-156, 2012.

Wang, C.; Chang, C.; Chu, C.; Lee, D.; Chang, B.; Liao, C.; Tay, J. Using filtrate of waste biosolids to effectively produce bio-hydrogen by anaerobic fermentation. Water Research, 37, 2789-2793, 2003.

Wang, C.; Chang, C.; Chu, C.; Lee, D.; Chang, B.; Liao, C. Producing hydrogen from wastewater sludge by Clostridium bifermentans. Journal of Biotechnology, 102, 83-92, 2003.

Wang, G.; Mu, Y.; Yu, H. Response surface analusis to evalute the influence of $\mathrm{pH}$, temperature and substrate concentration on the cidogenesis of sucrose-rich wastewater. Biochememical Engineering Journal, 23, 175-184, 2005.

Wu, S.; Hung, C.; Lin, C.; Chen, H.; Lee, A.; Chang, J. Fermentative hydrogen production and bacterial community structure in high rate anaerobic bioreactors containing siliconeimmobilised and self. flocculationg sludge. Ciotechnology and Bioengineering, 93 (5), 934-946, 2006. 
Wu, K.; Lin, Y.; Lo, Y.; Chen, C.; Chen, W. Converting glycerol into hydrogen athanol and diol with a Klebsiella sp. HE1 strain via anaerobic fermentation. Journal of Taiwan Institute of Chemical Engineers, 42, 20-25, 2011.

Youn, J.; Shin, H. Comparative performance between temperature phased and conventional mesophilic two-phased processes in terms of anaerobically produced bionergy from food waste. Waste Management Research, 23, 32-38, 2005.

$\mathrm{Yu}, \mathrm{H}$.; Zhu, Z.; Hu, W.; Zhang, H. Hydrogen production from rice winery wastwater in an upflow anaerobic reactor by using mixed anaerobic cultures. International Journal of Hydrogen Energy, 27, 1359-1365, 2002.

Yuwa-amornpitak, T. Bio-hydrogen Production from Biodiesel Glycerol Waste from Used Oil by Bacterium Isolated from Waste Water Sludge. Journal fo Environmental Science and Technology, 5 (5), 373-380, 2012.

Zaiat, M.; Rodrigues, J.; Ratusznei, S.; Camargo, F.; Borzani, W. Anaerobic sequencing batch reactors for wastewater treatment: a developing technology. Applied. Microbiology. Biotechnology. 55, 29-35, 2001.

Zhang, T.; Liu, H.; Fang, H. Biohydrogen production from starche in wastewater under thermophilic condition. Jornal of Environmental Management, 69, 149-156, 2003.

Zhang, J.; Li, X.; Oh, S.; Logan, B. Physical and hydrodynamic properties of flocs produced during biological hydrogen production. Biotechnology and Bioengineering, 88 (7), 854$860,2004$.

Zhang, Y.; Shen, J. Effect of temperature and iron concentration on the growth and hydrogen production of mixed bacteria. International Journal of Hydrogen Energy, 31, 441-446, 2006.

Zhu H.; Suzuki T.; Tsygankov A.; Asada Y.; Miyake J. Hydrogen production from tofu wastewater by Rhodobacter sphaeroides immobilized in agar gels. International Journal of Hydrogen Energy, 24 (4), 305-310, 1999.

Zoetemeyer, R.; Van de Heuvel JC.; Cohen, A. pH influence on acidogenic dissimilation of glucose in an anaerobic digester. Water Research, 16, 303-311, 1982. 
Zoetemeyer, R.; Arnoldy, P.; Cohen, A.; Boelhouwer, C. Influence of temperature on the anaerobic acidification of glucose in a mixed culture forming part of a two-stage distion process. Water Research, 16, 313-321, 1982. 


\section{ANEXO I}

Tabela AI - Concentração de matéria orgânica (DQO) afluente e efluente da "Fase preliminar".

\begin{tabular}{|c|c|c|c|c|c|c|}
\hline Condição & Tempo & $\mathrm{C}_{\text {SAFTL }}\left(\mathrm{mgDQO} \cdot \mathrm{L}^{-1}\right)$ & $\mathrm{C}_{\mathrm{ST}}\left(\mathrm{mgDQO} \cdot \mathrm{L}^{-1}\right)$ & $\mathrm{C}_{\mathrm{SF}}\left(\mathrm{mgDQO} \cdot \mathrm{L}^{-1}\right)$ & $\varepsilon_{\mathrm{ST}}(\%)$ & $\varepsilon_{\mathrm{SF}}(\%)$ \\
\hline A1 & 2 & 2996 & 2729 & 2217 & 8,9 & 26,0 \\
\hline A1 & 3 & 3161 & 2198 & 1599 & 30,5 & 49,4 \\
\hline A1 & 4 & 2980 & 2242 & 2016 & 24,7 & 32,4 \\
\hline A1 & 5 & 3030 & 2043 & 1856 & 32,6 & 38,8 \\
\hline A1 & 9 & 2814 & 2233 & 2065 & 20,6 & 26,4 \\
\hline A1 & 10 & 2951 & 2077 & 2072 & 29,6 & 28,4 \\
\hline A1 & 11 & 2979 & 2249 & 2112 & 24,5 & 27,2 \\
\hline A1 & 12 & 3063 & 2371 & 2168 & 22,6 & 29,2 \\
\hline A1 & 16 & 2976 & 2242 & 2235 & 24,9 & 24,9 \\
\hline A1 & 17 & 3112 & 2253 & 2185 & 29,8 & 29,8 \\
\hline A1 & 18 & 3030 & 2718 & 2285 & 24,6 & 24,6 \\
\hline A1 & 19 & 3114 & 2745 & 2306 & 26,0 & 26,0 \\
\hline B1 & 23 & 3303 & 2224 & 1960 & 32,7 & 40,7 \\
\hline B1 & 24 & 3385 & 2063 & 1805 & 39,0 & 46,7 \\
\hline $\mathrm{C} 1$ & 25 & 3453 & 2071 & 1861 & 40,0 & 46,1 \\
\hline $\mathrm{C} 1$ & 26 & 3445 & 2403 & 1960 & 30,2 & 43,1 \\
\hline D1 & 27 & 3092 & 2169 & 1685 & 29,8 & 45,5 \\
\hline D1 & 30 & 3087 & 2048 & 1727 & 33,7 & 44,1 \\
\hline D1 & 31 & 2954 & 1820 & 1657 & 38,4 & 43,9 \\
\hline E1 & 32 & 2968 & 2230 & 1832 & 24,9 & 38,3 \\
\hline E1 & 37 & 3164 & 1938 & 1683 & 38,8 & 46,8 \\
\hline E1 & 38 & 2982 & 2036 & 1656 & 31,7 & 44,5 \\
\hline $\mathrm{F} 1$ & 39 & 2988 & 2197 & 1939 & 26,5 & 35,1 \\
\hline $\mathrm{F} 1$ & 40 & 2919 & 1981 & 1789 & 32,1 & 38,7 \\
\hline $\mathrm{F} 1$ & 44 & 3141 & 2296 & 2014 & 26,9 & 35,9 \\
\hline G1 & 45 & 3250 & 1761 & 1646 & 45,8 & 49,3 \\
\hline $\mathrm{A} 2$ & 51 & 2948 & 2555 & 2500 & 13,3 & 15,2 \\
\hline B2 & 52 & 2851 & 2334 & 2248 & 18,1 & 21,2 \\
\hline B2 & 53 & 3097 & 2457 & 2114 & 20,7 & 31,7 \\
\hline B2 & 54 & 3128 & 2543 & 2138 & 18,7 & 31,7 \\
\hline B2 & 58 & 2847 & 2451 & 2095 & 13,9 & 35,9 \\
\hline $\mathrm{C} 2$ & 59 & 3028 & 2511 & 1826 & 17,1 & 51,2 \\
\hline $\mathrm{C} 2$ & 60 & 3283 & 2163 & 1478 & 34,1 & 55,8 \\
\hline $\mathrm{C} 2$ & 61 & 2906 & 2145 & 1453 & 26,2 & 50,0 \\
\hline $\mathrm{C} 2$ & 65 & 3705 & 1905 & 1685 & 54,5 & 54,5 \\
\hline $\mathrm{C} 2$ & 66 & 3105 & 1504 & 1465 & 52,8 & 52,8 \\
\hline $\mathrm{C} 2$ & 68 & 2940 & 1674 & 1592 & 45,9 & 45,9 \\
\hline A3 & 87 & 3145 & 2478 & 2469 & 21,3 & 21,6 \\
\hline
\end{tabular}


Tabela AI - Concentração de matéria orgânica (DQO) afluente e efluente da "Fase preliminar".

\begin{tabular}{ccccccc}
\hline Condição & Tempo & $\mathrm{C}_{\mathrm{SAFTL}}\left(\mathrm{mgDQO} . \mathrm{L}^{-1}\right)$ & $\mathrm{C}_{\mathrm{ST}}\left(\mathrm{mgDQO} . \mathrm{L}^{-1}\right)$ & $\mathrm{C}_{\mathrm{SF}}\left(\mathrm{mgDQO} . \mathrm{L}^{-1}\right)$ & $\varepsilon_{\mathrm{ST}}(\%)$ & $\varepsilon_{\mathrm{SF}}(\%)$ \\
\hline $\mathrm{A} 3$ & 88 & 3286 & 2204 & 2115 & 33,0 & 35,6 \\
$\mathrm{~A} 3$ & 89 & 2972 & 2271 & 2192 & 23,6 & 26,3 \\
$\mathrm{~B} 3$ & 93 & 2796 & 2207 & 2099 & 21,1 & 24,9 \\
$\mathrm{C} 3$ & 94 & 2604 & 1730 & 1649 & 33,6 & 36,7 \\
$\mathrm{C} 3$ & 100 & 3204 & 2229 & 2219 & 30,5 & 30,7 \\
$\mathrm{C} 3$ & 101 & 2769 & 2097 & 2084 & 24,3 & 24,8 \\
$\mathrm{D} 3$ & 102 & 3515 & 2414 & 2411 & 31,3 & 31,4 \\
$\mathrm{D} 3$ & 103 & 3452 & 2587 & 2402 & 25,1 & 30,4 \\
E3 & 107 & 3153 & 2640 & 1982 & 16,3 & 37,1 \\
$\mathrm{~A} 4$ & 109 & 3802 & 3568 & 3140 & 6,2 & 17,4 \\
$\mathrm{~A} 4$ & 110 & 4068 & 3440 & 3127 & 15,4 & 23,1 \\
$\mathrm{~A} 4$ & 114 & 3967 & 3446 & 3246 & 13,1 & 18,2 \\
$\mathrm{~A} 4$ & 115 & 4016 & 3434 & 3285 & 14,4 & 18,2 \\
$\mathrm{~B} 4$ & 116 & 3882 & 3783 & 3702 & 2,6 & 4,6 \\
$\mathrm{~A} 5$ & 157 & 1120 & 739 & 735 & 34,0 & 34,4 \\
$\mathrm{~A} 5$ & 158 & 879 & 800 & 778 & 9,0 & 11,5 \\
$\mathrm{~A} 5$ & 159 & 1017 & 836 & 771 & 17,8 & 24,2 \\
B5 & 163 & 1998 & 1508 & 1484 & 24,5 & 25,7 \\
B5 & 164 & 2062 & 1578 & 1544 & 23,5 & 25,1 \\
\hline
\end{tabular}




\section{ANEXO II}

Tabela AII - Concentração de carboidrato afluente e efluente das condições operadas com sacarose ou mistura de glicerina com sacarose da "Fase preliminar".

\begin{tabular}{|c|c|c|c|c|c|c|}
\hline Condição & Tempo & $\mathrm{C}_{\mathrm{CAFTL}}\left(\mathrm{mgSAC} . \mathrm{L}^{-1}\right)$ & $\mathrm{C}_{\mathrm{CT}}\left(\mathrm{mgSAC} \cdot \mathrm{L}^{-1}\right)$ & $\mathrm{C}_{\mathrm{CF}}\left(\mathrm{mgSAC} \cdot \mathrm{L}^{-1}\right)$ & $\varepsilon_{\mathrm{CT}}(\%)$ & $\varepsilon_{\mathrm{CF}}(\%)$ \\
\hline A1 & 2 & 3523 & 702 & 187 & 80,1 & 94,7 \\
\hline A 1 & 3 & 3822 & 44 & 0 & 98,9 & 100,0 \\
\hline A1 & 4 & 3278 & 71 & 31 & 97,8 & 99,1 \\
\hline A1 & 5 & 3875 & 77 & 4 & 98,0 & 99,9 \\
\hline $\mathrm{A} 1$ & 9 & 3192 & 36 & 29 & 98,9 & 99,1 \\
\hline A 1 & 10 & 3206 & 63 & 59 & 98,0 & 98,2 \\
\hline A1 & 11 & 2873 & 65 & 45 & 97,7 & 98,4 \\
\hline A1 & 12 & 2758 & 58 & 38 & 97,9 & 98,6 \\
\hline A1 & 16 & 2878 & 53 & 11 & 98,2 & 99,6 \\
\hline $\mathrm{A} 1$ & 17 & 2865 & 81 & 26 & 97,2 & 99,1 \\
\hline $\mathrm{A} 2$ & 51 & 3150 & 216 & 121 & 93,1 & 96,2 \\
\hline $\mathrm{B} 2$ & 52 & 1422 & 112 & 53 & 92,1 & 96,3 \\
\hline $\mathrm{B} 2$ & 53 & 1355 & 92 & 32 & 93,2 & 97,7 \\
\hline B2 & 54 & 1620 & 71 & 32 & 95,6 & 98,0 \\
\hline B2 & 58 & 1447 & 67 & 13 & 95,4 & 99,1 \\
\hline $\mathrm{A} 2$ & 51 & 3150 & 216 & 121 & 93,1 & 96,2 \\
\hline B2 & 52 & 1422 & 112 & 53 & 92,1 & 96,3 \\
\hline B2 & 53 & 1355 & 92 & 32 & 93,2 & 97,7 \\
\hline B2 & 54 & 1620 & 71 & 32 & 95,6 & 98,0 \\
\hline B2 & 58 & 1447 & 67 & 13 & 95,4 & 99,1 \\
\hline A3 & 87 & 3147 & 434 & 418 & 86,2 & 86,7 \\
\hline A3 & 88 & 2599 & 41 & 0 & 98,4 & 100,0 \\
\hline A3 & 89 & 2358 & 8 & 0 & 99,7 & 100,0 \\
\hline B3 & 93 & 3431 & 32 & 12 & 99,0 & 99,7 \\
\hline $\mathrm{C} 3$ & 94 & 1377 & 59 & 35 & 95,7 & 97,5 \\
\hline C3 & 100 & 2013 & 30 & 15 & 98,5 & 99,3 \\
\hline $\mathrm{C} 3$ & 101 & 1471 & 32 & 20 & 97,8 & 98,7 \\
\hline D3 & 102 & 1699 & 39 & 31 & 97,7 & 98,2 \\
\hline D3 & 103 & 2060 & 28 & 22 & 98,7 & 98,9 \\
\hline E3 & 107 & 1763 & 50 & 41 & 97,1 & 97,7 \\
\hline A4 & 110 & 85 & 82 & 1612 & 95,0 & 95,2 \\
\hline A4 & 111 & 113 & 57 & 1497 & 92,8 & 96,3 \\
\hline A4 & 115 & 29 & 14 & 1814 & 98,4 & 99,2 \\
\hline A4 & 116 & 46 & 44 & 1916 & 97,7 & 97,8 \\
\hline
\end{tabular}




\section{ANEXO III}

Tabela AIII - Valores de pH, alcalinidade parcial, alcalinidade intermediária, alcalinidade total, alcalinidade a bicarbonato e ácidos voláteis totais no afluente em todas as condições da "Fase preliminar".

\begin{tabular}{|c|c|c|c|c|c|c|c|}
\hline Condição & Tempo (d) & $\mathrm{pH}$ inicial & $\begin{array}{c}\mathrm{AP} \\
\left(\mathrm{mgCaCO}_{3} \cdot \mathrm{L}^{-1}\right)\end{array}$ & $\begin{array}{c}\mathrm{AI} \\
\left(\mathrm{mgCaCO}_{3} \cdot \mathrm{L}^{-1}\right)\end{array}$ & $\begin{array}{c}\mathrm{AT} \\
\left(\mathrm{mgCaCO}_{3} \cdot \mathrm{L}^{-1}\right)\end{array}$ & $\begin{array}{c}\mathrm{AB} \\
\left(\mathrm{mgCaCO}_{3} \cdot \mathrm{L}^{-1}\right)\end{array}$ & $\begin{array}{c}\mathrm{AVT} \\
\left(\mathrm{mgCaCO}_{3} \cdot \mathrm{L}^{-1}\right)\end{array}$ \\
\hline A1 & 1 & 7,92 & 324,6 & 84,3 & 408,9 & 365,7 & 60,9 \\
\hline $\mathrm{A} 1$ & 2 & 7,98 & 339,1 & 82,1 & 421,3 & 405,6 & 22,0 \\
\hline A1 & 3 & 7,9 & 312,7 & 109,1 & 421,7 & 407,1 & 20,6 \\
\hline A1 & 4 & 7,88 & 329,9 & 104,7 & 434,5 & 420,3 & 20,0 \\
\hline A1 & 8 & 8,03 & 298,3 & 107,4 & 405,7 & 391,5 & 19,9 \\
\hline $\mathrm{A} 1$ & 9 & 8,05 & 296,2 & 97,4 & 393,6 & 377,0 & 23,4 \\
\hline A1 & 10 & 7,93 & 291,2 & 104,9 & 396,1 & 381,3 & 20,8 \\
\hline A1 & 11 & 8,01 & 293,7 & 114,1 & 407,8 & 395,3 & 17,5 \\
\hline A1 & 15 & 8,40 & 310,6 & 84,7 & 395,3 & 383,0 & 17,3 \\
\hline A1 & 16 & 8,27 & 303,9 & 83,5 & 387,4 & 364,4 & 32,4 \\
\hline A1 & 17 & 7,95 & 265,1 & 79,3 & 344,4 & 328,9 & 21,8 \\
\hline A1 & 18 & 7,86 & 299,3 & 79,3 & 378,6 & 364,8 & 19,5 \\
\hline $\mathrm{B} 1$ & 22 & 7,9 & 341,9 & 133,2 & 475,0 & 402,0 & 102,9 \\
\hline $\mathrm{B} 1$ & 23 & 7,82 & 326,4 & 144,0 & 470,4 & 394,5 & 107,0 \\
\hline $\mathrm{C} 1$ & 24 & 7,58 & 237,1 & 70,1 & 307,2 & 236,7 & 99,4 \\
\hline $\mathrm{C} 1$ & 25 & 7,87 & 164,1 & 93,9 & 258,0 & 191,6 & 93,4 \\
\hline D1 & 28 & 7,76 & 166,1 & 62,2 & 228,3 & 162,9 & 92,2 \\
\hline D1 & 29 & 7,55 & 209,6 & 81,4 & 291,0 & 219,0 & 101,4 \\
\hline D1 & 30 & 7,85 & 180,1 & 66,9 & 247,0 & 182,0 & 91,6 \\
\hline E1 & 31 & 7,52 & 87,5 & 23,9 & 111,4 & 55,4 & 78,9 \\
\hline E1 & 36 & 7,69 & 113,2 & 36,0 & 149,2 & 85,5 & 89,7 \\
\hline E1 & 37 & 7,05 & 87,9 & 24,3 & 112,1 & 58,7 & 75,3 \\
\hline $\mathrm{F} 1$ & 38 & 7,33 & 88,2 & 48,9 & 137,1 & 81,3 & 78,6 \\
\hline $\mathrm{F} 1$ & 39 & 7,33 & 91,9 & 36,8 & 128,7 & 75,1 & 75,4 \\
\hline $\mathrm{F} 1$ & 43 & 7,8 & 66,2 & 21,7 & 87,9 & 42,2 & 64,3 \\
\hline G1 & 44 & 10,21 & 101,1 & 14,7 & 115,8 & 96,6 & 27,0 \\
\hline A2 & 50 & 8,21 & 267,2 & 65,4 & 332,6 & 318,5 & 19,9 \\
\hline B2 & 51 & 8,77 & 167,6 & 57,0 & 224,6 & 203,5 & 29,6 \\
\hline B2 & 52 & 8,88 & 193,0 & 57,3 & 250,3 & 223,8 & 37,3 \\
\hline B2 & 53 & 8,7 & 202,9 & 51,5 & 254,4 & 227,9 & 37,6 \\
\hline B2 & 57 & 8,61 & 192,6 & 51,5 & 244,1 & 223,3 & 29,3 \\
\hline $\mathrm{C} 2$ & 58 & 9,52 & 144,6 & 30,6 & 175,1 & 152,6 & 31,7 \\
\hline $\mathrm{C} 2$ & 59 & 9,22 & 133,8 & 38,7 & 172,5 & 147,5 & 35,2 \\
\hline $\mathrm{C} 2$ & 60 & 9,68 & 107,6 & 23,2 & 130,8 & 105,8 & 35,2 \\
\hline $\mathrm{C} 2$ & 64 & 9,47 & 146,3 & 29,3 & 175,5 & 133,8 & 58,8 \\
\hline
\end{tabular}


Tabela AIII - Valores de pH, alcalinidade parcial, alcalinidade intermediária, alcalinidade total, alcalinidade a bicarbonato e ácidos voláteis totais no afluente em todas as condições da "Fase preliminar".

\begin{tabular}{cccccccc}
\hline Condição & Tempo (d) & $\mathrm{pH}$ inicial & $\begin{array}{c}\mathrm{AP} \\
\left(\mathrm{mgCaCO}_{3} \cdot \mathrm{L}^{-1}\right)\end{array}$ & $\begin{array}{c}\mathrm{AI} \\
\left(\mathrm{mgCaCO}_{3} \cdot \mathrm{L}^{-1}\right)\end{array}$ & $\begin{array}{c}\mathrm{AT} \\
\left(\mathrm{mgCaCO}_{3} \cdot \mathrm{L}^{-1}\right)\end{array}$ & $\begin{array}{c}\mathrm{AB} \\
\left(\mathrm{mgCaCO}_{3} \cdot \mathrm{L}^{-1}\right)\end{array}$ & $\begin{array}{c}\mathrm{AVT} \\
\left(\mathrm{mgCaCO}_{3} \cdot \mathrm{L}^{-1}\right)\end{array}$ \\
\hline $\mathrm{C} 2$ & 65 & 9,40 & 130,4 & 25,0 & 155,3 & 124,5 & 43,5 \\
$\mathrm{C} 2$ & 67 & 9,75 & 136,0 & 28,8 & 164,8 & 142,2 & 31,9 \\
$\mathrm{~A} 3$ & 86 & 7,90 & 167,8 & 87,8 & 255,6 & 246,9 & 12,2 \\
$\mathrm{~A} 3$ & 87 & 7,55 & 126,2 & 73,1 & 199,3 & 187,8 & 16,3 \\
$\mathrm{~A} 3$ & 88 & 7,50 & 134,6 & 65,0 & 199,6 & 187,7 & 16,7 \\
$\mathrm{~B} 3$ & 92 & 7,75 & 144,6 & 61,8 & 206,5 & 190,1 & 23,1 \\
$\mathrm{C} 3$ & 93 & 8,57 & 127,6 & 50,8 & 178,4 & 156,5 & 30,9 \\
$\mathrm{C} 3$ & 99 & 7,51 & 145,7 & 61,3 & 207,0 & 171,8 & 49,6 \\
$\mathrm{C} 3$ & 100 & 8,49 & 161,1 & 20,6 & 181,7 & 164,0 & 24,9 \\
D3 & 101 & 8,75 & 144,3 & 64,1 & 208,4 & 173,9 & 48,6 \\
D3 & 102 & 8,49 & 148,7 & 33,0 & 181,7 & 156,8 & 35,2 \\
E3 & 106 & 7,13 & 90,9 & 35,5 & 126,4 & 106,3 & 28,2 \\
A4 & 108 & 7,56 & 94,2 & 39,7 & 133,8 & 123,0 & 15,3 \\
A4 & 109 & 7,57 & 94,6 & 33,9 & 128,4 & 118,1 & 14,5 \\
A4 & 113 & 7,62 & 114,7 & 39,0 & 153,7 & 140,0 & 19,3 \\
A4 & 114 & 7,56 & 71,1 & 29,6 & 100,8 & 88,5 & 17,3 \\
B4 & 115 & 7,53 & 88,3 & 34,8 & 123,1 & 111,5 & 16,3 \\
A5 & 156 & 7,68 & 112,8 & 40,1 & 152,9 & 141,8 & 15,7 \\
A5 & 157 & 7,47 & 116,8 & 38,9 & 155,7 & 145,2 & 14,7 \\
A5 & 158 & 7,60 & 93,8 & 33,4 & 127,2 & 116,7 & 14,7 \\
B5 & 162 & 7,96 & 110,9 & 34,2 & 145,1 & 133,4 & 16,4 \\
B5 & 163 & 7,60 & 124,7 & 37,6 & 162,3 & 150,1 & 17,3 \\
\hline & & & & & & &
\end{tabular}




\section{ANEXO IV}

Tabela AIV - Valores de pH, alcalinidade parcial, alcalinidade intermediária, alcalinidade total, alcalinidade a bicarbonato e ácidos voláteis totais no efluente em todas as condições da "Fase preliminar".

\begin{tabular}{|c|c|c|c|c|c|c|c|}
\hline Condição & Tempo (d) & $\mathrm{pH}$ inicial & $\begin{array}{c}\mathrm{AP} \\
\left(\mathrm{mgCaCO}_{3} \cdot \mathrm{L}^{-1}\right)\end{array}$ & $\begin{array}{c}\mathrm{AI} \\
\left(\mathrm{mgCaCO}_{3} \cdot \mathrm{L}^{-1}\right)\end{array}$ & $\begin{array}{c}\mathrm{AT} \\
\left(\mathrm{mgCaCO}_{3} \cdot \mathrm{L}^{-1}\right)\end{array}$ & $\begin{array}{c}\mathrm{AB} \\
\left(\mathrm{mgCaCO}_{3} \cdot \mathrm{L}^{-1}\right)\end{array}$ & $\begin{array}{c}\mathrm{AVT} \\
\left(\mathrm{mgCaCO}_{3} \cdot \mathrm{L}^{-1}\right)\end{array}$ \\
\hline A1 & 2 & 4,51 & 0,0 & 70,7 & 70,7 & 0,0 & 968,2 \\
\hline A1 & 3 & 4,59 & 0,0 & 104,7 & 104,7 & 0,0 & 1014,9 \\
\hline A1 & 4 & 4,55 & 0,0 & 106,9 & 106,9 & 0,0 & 889,0 \\
\hline A1 & 5 & 4,53 & 0,0 & 104,7 & 104,7 & 0,0 & 872,8 \\
\hline A1 & 9 & 4,6 & 0,0 & 113,6 & 113,6 & 0,0 & 759,9 \\
\hline A1 & 10 & 4,64 & 0,0 & 124,5 & 124,5 & 0,0 & 793,3 \\
\hline A1 & 11 & 4,62 & 0,0 & 128,7 & 128,7 & 0,0 & 799,2 \\
\hline A1 & 12 & 4,69 & 0,0 & 146,2 & 146,2 & 0,0 & 746,2 \\
\hline A1 & 16 & 4,94 & 0,0 & 194,1 & 194,1 & 0,0 & 686,4 \\
\hline A1 & 17 & 5,00 & 0,0 & 216,6 & 216,6 & 0,0 & 680,3 \\
\hline A1 & 18 & 4,92 & 0,0 & 188,3 & 188,3 & 0,0 & 692,5 \\
\hline A1 & 19 & 4,96 & 0,0 & 195,8 & 195,8 & 0,0 & 627,5 \\
\hline B1 & 23 & 6,50 & 117,3 & 225,8 & 343,1 & 0,0 & 207,8 \\
\hline B1 & 24 & 6,18 & 89,8 & 264,7 & 354,4 & 0,0 & 361,5 \\
\hline $\mathrm{C} 1$ & 25 & 6,05 & 22,1 & 206,6 & 228,8 & 0,0 & 397,0 \\
\hline $\mathrm{C} 1$ & 26 & 5,45 & 0,0 & 184,9 & 184,9 & 0,0 & 397,0 \\
\hline D1 & 29 & 5,16 & 0,0 & 145,3 & 145,3 & 0,0 & 426,7 \\
\hline D1 & 30 & 5,59 & 0,0 & 165,0 & 165,0 & 0,0 & 347,6 \\
\hline D1 & 31 & 5,28 & 0.0 & 145,9 & 145,9 & 0,0 & 363,3 \\
\hline E1 & 32 & 4,83 & 0,0 & 89,3 & 89,3 & 0,0 & 393,0 \\
\hline E1 & 37 & 4,71 & 0,0 & 65,8 & 65,8 & 0,0 & 394,7 \\
\hline E1 & 38 & 4,55 & 0,0 & 41,2 & 41,2 & 0,0 & 365,0 \\
\hline $\mathrm{F} 1$ & 39 & 4,60 & 0,0 & 53,7 & 53,7 & 0,0 & 398,2 \\
\hline $\mathrm{F} 1$ & 40 & 4,46 & 0,0 & 36,7 & 36,8 & 0,0 & 401,7 \\
\hline $\mathrm{F} 1$ & 44 & 4,11 & 0,0 & 0,0 & 0,0 & 0,0 & 419,2 \\
\hline G1 & 45 & 4,20 & 0,0 & 0,0 & 0,0 & 0,0 & 455,9 \\
\hline $\mathrm{A} 2$ & 51 & 4,40 & 0,0 & 48,9 & 48,9 & 0,0 & 1020,5 \\
\hline B2 & 52 & 4,60 & 0,0 & 76,5 & 76,5 & 0,0 & 607,9 \\
\hline B2 & 53 & 4,68 & 0,0 & 91,9 & 91,9 & 0,0 & 665,5 \\
\hline B2 & 54 & 4,70 & 0,0 & 97,8 & 97,8 & 0,0 & 654,4 \\
\hline B2 & 58 & 4,68 & 0,0 & 113,6 & 113,6 & 0,0 & 612,4 \\
\hline $\mathrm{C} 2$ & 59 & 4,92 & 0,0 & 92,5 & 92,5 & 0,0 & 326,6 \\
\hline $\mathrm{C} 2$ & 60 & 4,82 & 0,0 & 86,9 & 86,9 & 0,0 & 357,2 \\
\hline $\mathrm{C} 2$ & 61 & 4,57 & 0,0 & 51,2 & 51,2 & 0,0 & 343,0 \\
\hline $\mathrm{C} 2$ & 65 & 4,56 & 0,0 & 58,1 & 58,1 & 0,0 & 390,1 \\
\hline
\end{tabular}


Tabela AIV - Valores de pH, alcalinidade parcial, alcalinidade intermediária, alcalinidade total, alcalinidade a bicarbonato e ácidos voláteis totais no efluente em todas as condições da "Fase preliminar".

\begin{tabular}{cccccccc}
\hline Condição & Tempo (d) & $\mathrm{pH}$ inicial & $\begin{array}{c}\mathrm{AP} \\
\left(\mathrm{mgCaCO}_{3} \cdot \mathrm{L}^{-1}\right)\end{array}$ & $\begin{array}{c}\mathrm{AI} \\
\left(\mathrm{mgCaCO}_{3} \cdot \mathrm{L}^{-1}\right)\end{array}$ & $\begin{array}{c}\mathrm{AT} \\
\left(\mathrm{mgCaCO}_{3} \cdot \mathrm{L}^{-1}\right)\end{array}$ & $\begin{array}{c}\mathrm{AB} \\
\left(\mathrm{mgCaCO}_{3} \cdot \mathrm{L}^{-1}\right)\end{array}$ & $\begin{array}{c}\mathrm{AVT} \\
\left(\mathrm{mgCaCO}_{3} \cdot \mathrm{L}^{-1}\right)\end{array}$ \\
\hline $\mathrm{C} 2$ & 67 & 4,53 & 0,0 & 50,8 & 50,8 & 0,0 & 436,5 \\
$\mathrm{C} 2$ & 68 & 4,46 & 0,0 & 36,1 & 36,1 & 0,0 & 408,7 \\
$\mathrm{~A} 3$ & 87 & 4,29 & 0,0 & 0,0 & 0,0 & 0,0 & 468,6 \\
$\mathrm{~A} 3$ & 88 & 4,09 & 0,0 & 0,0 & 0,0 & 0,0 & 664,7 \\
$\mathrm{~A} 3$ & 89 & 4,10 & 0,0 & 0,0 & 0,0 & 0,0 & 613,8 \\
$\mathrm{~B} 3$ & 93 & 4,14 & 0,0 & 0,0 & 0,0 & 0,0 & 579,5 \\
$\mathrm{C} 3$ & 94 & 4,35 & 0,0 & 9,3 & 9,3 & 0,0 & 359,2 \\
$\mathrm{C} 3$ & 100 & 4,38 & 0,0 & 22,4 & 22,4 & 0,0 & 534,5 \\
$\mathrm{C} 3$ & 101 & 4,40 & 0,0 & 28,8 & 28,8 & 0,0 & 517,3 \\
$\mathrm{D} 3$ & 102 & 4,34 & 0,0 & 10,1 & 10,1 & 0,0 & 592,4 \\
$\mathrm{D} 3$ & 103 & 4,28 & 0,0 & 0,0 & 0,0 & 0,0 & 605,4 \\
E3 & 107 & 4,12 & 0,0 & 0,0 & 0,0 & 0,0 & 620,2 \\
A4 & 109 & 3,95 & 0,0 & 0,0 & 0,0 & 0,0 & 462,1 \\
A4 & 110 & 4,18 & 0,0 & 0,0 & 0,0 & 0,0 & 489,9 \\
A4 & 114 & 4,33 & 0,0 & 11,2 & 11,2 & 0,0 & 474,8 \\
A4 & 115 & 4,04 & 0,0 & 0,0 & 0,0 & 0,0 & 459,3 \\
B4 & 116 & 4,85 & 0,0 & 56,4 & 56,4 & 0,0 & 155,5 \\
A5 & 157 & 7,07 & 51,8 & 76,7 & 128,5 & 64,4 & 89,8 \\
A5 & 158 & 7,18 & 59,1 & 69,0 & 128,2 & 67,1 & 85,5 \\
A5 & 159 & 7,03 & 55,7 & 67,0 & 122,7 & 71,9 & 71,6 \\
B5 & 163 & 5,99 & 5,7 & 109,7 & 115,3 & 0,0 & 163,3 \\
B5 & 164 & 6,22 & 12,5 & 114,2 & 126,7 & 8,1 & 167,1 \\
\hline
\end{tabular}




\section{ANEXO V}

Tabela AV - Volume e concentração do biogás no final do ciclo em todas as condições da "Fase preliminar".

\begin{tabular}{|c|c|c|c|c|c|}
\hline Condição & $\begin{array}{l}\text { Tempo } \\
\text { (d) }\end{array}$ & $\begin{array}{c}\mathrm{V}_{\mathrm{G}} \\
\left(\mathrm{mL}^{-1} \text { ciclo }^{-1}\right)\end{array}$ & $\begin{array}{c}\mathrm{H}_{2} \\
\left(\mathrm{mmol} . \mathrm{L}^{-1}\right)\end{array}$ & $\begin{array}{c}\mathrm{CH}_{4} \\
\left(\mathrm{mmol} . \mathrm{L}^{-1}\right)\end{array}$ & $\begin{array}{c}\mathrm{CO}_{2} \\
\left(\mathrm{mmol} . \mathrm{L}^{-1}\right)\end{array}$ \\
\hline A1 & 10 & 773 & 6,65 & 0,00 & 6,20 \\
\hline $\mathrm{A} 1$ & 16 & 1005 & 8,10 & 0,00 & 6,08 \\
\hline A1 & 17 & 808 & 5,47 & 0,00 & 6,30 \\
\hline A1 & 18 & 84 & 5,04 & 0,00 & 6,05 \\
\hline A1 & 19 & 785 & 4,62 & 0,00 & 8,73 \\
\hline B1 & 23 & 31 & 0,00 & 0,00 & 2,24 \\
\hline B1 & 24 & 62 & 0,00 & 0,00 & 2,74 \\
\hline $\mathrm{C} 1$ & 25 & 39 & 0,00 & 0,00 & 2,59 \\
\hline $\mathrm{C} 1$ & 26 & 36 & 0,26 & 0,00 & 2,95 \\
\hline D1 & 30 & 62 & 0,00 & 0,00 & 2,07 \\
\hline D1 & 31 & 74 & 0,34 & 0,00 & 2,26 \\
\hline E1 & 37 & 28 & 0,20 & 0,00 & 1,92 \\
\hline E1 & 38 & 3 & 0,00 & 0,00 & 1,63 \\
\hline $\mathrm{F} 1$ & 39 & 49 & 0,20 & 0,00 & 1,24 \\
\hline $\mathrm{F} 1$ & 40 & 15 & 0,00 & 0,00 & 0,00 \\
\hline $\mathrm{F} 1$ & 44 & 0 & 0,00 & 0,00 & 0,00 \\
\hline G1 & 45 & 26 & 0,00 & 0,00 & 1,49 \\
\hline $\mathrm{A} 2$ & 51 & 2085 & 12,59 & 0,00 & 8,46 \\
\hline B2 & 52 & 490 & 3,85 & 0,00 & 3,24 \\
\hline B2 & 53 & 459 & 3,40 & 0,00 & 3,70 \\
\hline B2 & 54 & 467 & 3,24 & 0,00 & 3,34 \\
\hline B2 & 58 & 546 & 4,51 & 0,00 & 1,56 \\
\hline $\mathrm{C} 2$ & 59 & 69 & 0,19 & 0,00 & 1,56 \\
\hline $\mathrm{C} 2$ & 60 & 56 & 0,00 & 0,00 & 1,30 \\
\hline $\mathrm{C} 2$ & 61 & 67 & 0,22 & 0,00 & 0,00 \\
\hline $\mathrm{C} 2$ & 65 & 80 & 0,24 & 0,00 & 1,34 \\
\hline $\mathrm{C} 2$ & 67 & 49 & 0,00 & 0,00 & 0,00 \\
\hline A3 & 87 & 1003 & 7,90 & 0,39 & 5,19 \\
\hline A3 & 88 & 918 & 13,77 & 0,18 & 7,57 \\
\hline A3 & 89 & 921 & 13,40 & 0,19 & 7,87 \\
\hline B3 & 93 & 916 & 14,08 & 0,18 & 9,41 \\
\hline $\mathrm{C} 3$ & 94 & 444 & 4,55 & 0,00 & 4,88 \\
\hline C3 & 100 & 395 & 1,41 & 0,36 & 4,67 \\
\hline C3 & 101 & 333 & 1,09 & 0,53 & 4,67 \\
\hline D3 & 102 & 410 & 1,50 & 0,90 & 4,53 \\
\hline
\end{tabular}


Tabela AV - Volume e concentração do biogás no final do ciclo em todas as condições da "Fase

\begin{tabular}{|c|c|c|c|c|c|}
\hline Condição & $\begin{array}{l}\text { Tempo } \\
\text { (d) }\end{array}$ & $\begin{array}{c}\mathrm{V}_{\mathrm{G}} \\
\left(\mathrm{mL}^{\left.- \text {ciclo }^{-1}\right)}\right)\end{array}$ & $\begin{array}{c}\mathrm{H}_{2} \\
\left(\mathrm{mmol} \cdot \mathrm{L}^{-1}\right)\end{array}$ & $\begin{array}{c}\mathrm{CH}_{4} \\
\left(\mathrm{mmol} . \mathrm{L}^{-1}\right)\end{array}$ & $\begin{array}{c}\mathrm{CO}_{2} \\
\left(\mathrm{mmol} . \mathrm{L}^{-1}\right)\end{array}$ \\
\hline E3 & 107 & 485 & 1,32 & 1,81 & 5,82 \\
\hline A4 & 109 & 572 & 7,41 & 0,00 & 4,38 \\
\hline A4 & 114 & 659 & 8,51 & 0,00 & 4,86 \\
\hline B4 & 115 & 118 & 7,16 & 0,00 & 4,15 \\
\hline B4 & 116 & 141 & 0,32 & 0,00 & 3,23 \\
\hline A5 & 157 & 0 & 0,00 & 0,00 & 1,32 \\
\hline A5 & 158 & 0 & 0,00 & 0,00 & 1,35 \\
\hline A5 & 159 & 0 & 0,15 & 0,00 & 1,41 \\
\hline B5 & 163 & 87 & 0,32 & 0,00 & 1,97 \\
\hline B5 & 164 & 88 & 0,35 & 0,00 & 2,15 \\
\hline
\end{tabular}




\section{ANEXO VI}

Tabela AVI - Produção volumétrica acumulada do biogás em mL-CNTP ao longo do ciclo em todas as condições da "Fase preliminar"

\begin{tabular}{|c|c|c|c|c|c|c|c|c|c|}
\hline Condição & Tempo (d) & $0,00(\mathrm{~h})$ & $0,50(\mathrm{~h})$ & $1,00(\mathrm{~h})$ & $1,50(\mathrm{~h})$ & $2,00(\mathrm{~h})$ & $2,50(\mathrm{~h})$ & $3,00(\mathrm{~h})$ & $3,50(\mathrm{~h})$ \\
\hline A1 & 10 & 0,0 & 721,6 & 964,3 & 974,1 & 974,2 & 974,2 & 974,2 & 974,2 \\
\hline A1 & 16 & 0,0 & 692,1 & 839,7 & 1266,1 & 1266,1 & 1266,1 & 1266,1 & 1266,1 \\
\hline A1 & 17 & 0,0 & 684,8 & 991,6 & 1017,5 & 1017,5 & 1017,5 & 1017,5 & 1017,5 \\
\hline A1 & 18 & 0,0 & 642,8 & 1017,5 & 1059,4 & 1059,4 & 1059,4 & 1059,4 & 1059,4 \\
\hline A1 & 19 & 0,0 & 281,0 & 759,1 & 985,2 & 988,4 & 988,4 & 988,4 & 988,4 \\
\hline B1 & 23 & 0,0 & 12,9 & 16,2 & 22,6 & 29,1 & 35,5 & 38,8 & 38,8 \\
\hline B1 & 24 & 0,0 & 29,1 & 48,5 & 58,1 & 71,1 & 77,5 & 77,5 & 77,5 \\
\hline $\mathrm{C} 1$ & 25 & 0,0 & 25,8 & 35,5 & 38,8 & 48,5 & 48,5 & 48,5 & 48,5 \\
\hline $\mathrm{C} 1$ & 26 & 0,0 & 6,5 & 12,9 & 25,8 & 38,8 & 45,2 & 45,2 & 45,2 \\
\hline D1 & 30 & 0,0 & 9,7 & 22,6 & 22,6 & 54,9 & 64,6 & 77,5 & 77,5 \\
\hline D1 & 31 & 0,0 & 9,7 & 29,1 & 51,7 & 71,1 & 93,7 & 93,7 & 93,7 \\
\hline E1 & 37 & 0,0 & 19,4 & 19,4 & 32,3 & 35,5 & 35,5 & 35,5 & 35,5 \\
\hline $\mathrm{F} 1$ & 39 & 0,0 & 0,0 & 0,0 & 0,0 & 12,9 & 35,5 & 58,1 & 61,4 \\
\hline G1 & 40 & 0,0 & 0,0 & 0,0 & 3,2 & 9,7 & 16,2 & 19,4 & 19,4 \\
\hline G1 & 45 & 0,0 & 0,0 & 12,9 & 19,4 & 25,8 & 25,8 & 29,1 & 29,1 \\
\hline $\mathrm{A} 2$ & 51 & 0,0 & 361,6 & 671,8 & 969,3 & 1256,5 & 1530,9 & 1800,1 & 2084,8 \\
\hline B2 & 52 & 0,0 & 82,1 & 174,4 & 256,4 & 333,4 & 397,5 & 451,3 & 489,8 \\
\hline B2 & 53 & 0,0 & 87,2 & 182,1 & 269,3 & 343,6 & 402,6 & 441,1 & 459,0 \\
\hline B2 & 54 & 0,0 & 94,9 & 223,1 & 325,7 & 397,5 & 443,6 & 464,1 & 466,7 \\
\hline B2 & 58 & 0,0 & 107,7 & 241,0 & 348,7 & 430,8 & 487,2 & 525,7 & 546,2 \\
\hline $\mathrm{C} 2$ & 59 & 0,0 & 23,1 & 35,90 & 46,2 & 53,9 & 61,5 & 66,7 & 69,2 \\
\hline $\mathrm{C} 2$ & 60 & 0,0 & 20,5 & 33,34 & 41,0 & 46,2 & 51,3 & 53,9 & 56,4 \\
\hline $\mathrm{C} 2$ & 61 & 0,0 & 15,4 & 28,21 & 35,9 & 46,2 & 53,9 & 61,5 & 66,7 \\
\hline $\mathrm{C} 2$ & 65 & 0,0 & 18,0 & 35,90 & 48,7 & 56,4 & 66,8 & 74,4 & 79,5 \\
\hline $\mathrm{C} 2$ & 67 & 0,0 & 25,6 & 33,34 & 41,0 & 46,2 & 48,7 & 48,7 & 48,7 \\
\hline A3 & 87 & 0,0 & 1468,0 & 3042,8 & 4617,6 & 6139,1 & 7767,3 & 9021,8 & 10303,0 \\
\hline A3 & 88 & 0,0 & 1895,1 & 4350,7 & 6566,1 & 8568,0 & 9368,7 & 9502,2 & 9555,6 \\
\hline A3 & 89 & 0,0 & 2375,6 & 5391,7 & 7847,3 & 9128,5 & 9475,5 & 9582,3 & 9582,3 \\
\hline B3 & 93 & 0,0 & 3283,1 & 6859,7 & 8674,8 & 9342,1 & 9528,9 & 9528,9 & - \\
\hline $\mathrm{C} 3$ & 94 & 0,0 & 2322,2 & 3977,1 & 4377,4 & 4591,0 & 4617,6 & 4617,6 & - \\
\hline $\mathrm{C} 3$ & 100 & 0,0 & 2482,3 & 3523,3 & 4030,4 & 4110,5 & 4110,5 & 4110,5 & - \\
\hline $\mathrm{C} 3$ & 101 & 0,0 & 2108,6 & 3149,6 & 3416,5 & 3469,9 & 3469,9 & 3469,9 & - \\
\hline D3 & 102 & 0,0 & 2455,6 & 3923,7 & 4244,0 & 4270,7 & 4270,7 & 4270,7 & - \\
\hline E3 & 107 & 0,0 & 2295,5 & 4110,5 & 4564,3 & 4831,2 & 5044,7 & 5044,7 & - \\
\hline A4 & 109 & 0,0 & 135,9 & 266,7 & 379,5 & 479,5 & 571,8 & 571,8 & - \\
\hline A4 & 110 & 0,0 & 148,7 & 323,1 & 469,3 & 584,7 & 633,4 & 633,4 & - \\
\hline
\end{tabular}


Tabela AVI - Produção volumétrica acumulada do biogás em mL-CNTP ao longo do ciclo em todas as condições da "Fase preliminar"

\begin{tabular}{cccccccccc}
\hline Condição & Tempo $(\mathrm{d})$ & $0,00(\mathrm{~h})$ & $0,50(\mathrm{~h})$ & $1,00(\mathrm{~h})$ & $1,50(\mathrm{~h})$ & $2,00(\mathrm{~h})$ & $2,50(\mathrm{~h})$ & $3,00(\mathrm{~h})$ & $3,50(\mathrm{~h})$ \\
\hline A4 & 114 & 0,0 & 251,3 & 484,7 & 582,1 & 628,3 & 659,0 & 659,0 & - \\
B4 & 115 & 0,0 & 43,6 & 71,8 & 92,3 & 107,7 & 118,0 & 118,0 & - \\
B4 & 116 & 0,0 & 43,6 & 74,4 & 100,0 & 118,0 & 141,0 & 141,0 & - \\
A5 & 157 & 0,0 & 0,0 & 0,0 & 0,0 & 0,0 & 0,0 & 0,0 & 0,0 \\
A5 & 158 & 0,0 & 0,0 & 0,0 & 0,0 & 0,0 & 0,0 & 0,0 & 0,0 \\
A5 & 159 & 0,0 & 0,0 & 0,0 & 0,0 & 0,0 & 0,0 & 0,0 & 0,0 \\
B5 & 163 & 0,0 & 98,6 & 203,8 & 223,6 & 223,6 & 223,6 & 223,6 & 223,6 \\
B5 & 164 & 0,0 & 78,9 & 210,4 & 223,6 & 223,6 & 223,6 & 223,6 & 223,6 \\
\hline
\end{tabular}


ANEXO VII

Tabela AVII - Concentração de matéria orgânica (DQO) afluente e efluente da "Fase experimental".

\begin{tabular}{|c|c|c|c|c|c|c|}
\hline Condição & Tempo & $\mathrm{C}_{\text {SAFTL }}\left(\mathrm{mgDQO} \cdot \mathrm{L}^{-1}\right)$ & $\mathrm{C}_{\mathrm{ST}}\left(\mathrm{mgDQO} \cdot \mathrm{L}^{-1}\right)$ & $\mathrm{C}_{\mathrm{SF}}\left(\mathrm{mgDQO} . \mathrm{L}^{-1}\right)$ & $\varepsilon_{\mathrm{ST}}(\%)$ & $\varepsilon_{\mathrm{SF}}(\%)$ \\
\hline CI & 4 & 3577 & 2889 & 2637 & 19,2 & 26,3 \\
\hline CI & 5 & 3176 & 2711 & 2365 & 14,6 & 25,5 \\
\hline CI & 6 & 3205 & 2557 & 2445 & 20,2 & 23,7 \\
\hline CI & 7 & 2973 & 2359 & 2243 & 20,7 & 24,6 \\
\hline CI & 11 & 2881 & 2379 & 2307 & 17,4 & 19,9 \\
\hline $\mathrm{CI}$ & 12 & 2915 & 2213 & 2163 & 24,1 & 25,8 \\
\hline CI & 13 & 2868 & 2434 & 2313 & 15,2 & 19,4 \\
\hline CII & 18 & 4270 & 3165 & 3039 & 25,9 & 28,8 \\
\hline CII & 19 & 4076 & 3557 & 3335 & 12,7 & 18,2 \\
\hline CII & 20 & 4042 & 3300 & 3211 & 18,4 & 20,6 \\
\hline CII & 24 & 4006 & 3125 & 3066 & 22,0 & 23,5 \\
\hline CII & 25 & 3694 & 2781 & 2652 & 24,7 & 28,2 \\
\hline CII & 26 & 3750 & 2883 & 2875 & 23,1 & 23,3 \\
\hline CII & 27 & 4034 & 2967 & 2905 & 26,5 & 28,0 \\
\hline CIII & 32 & 5073 & 4019 & 4013 & 20,8 & 20,9 \\
\hline CIII & 33 & 5209 & 4092 & 3881 & 21,4 & 25,5 \\
\hline CIII & 34 & 5325 & 4077 & 4010 & 23,4 & 24,7 \\
\hline CIII & 35 & 5543 & 4279 & 4087 & 22,8 & 26,3 \\
\hline CIII & 39 & 5346 & 4137 & 3941 & 22,6 & 26,3 \\
\hline CIII & 40 & 5094 & 4029 & 3900 & 20,9 & 23,4 \\
\hline CIV & 46 & 2912 & 2341 & 2155 & 19,6 & 26,0 \\
\hline CIV & 47 & 2909 & 2502 & 2458 & 14,0 & 15,5 \\
\hline CIV & 48 & 3151 & 2279 & 2143 & 27,7 & 32,0 \\
\hline CIV & 49 & 2938 & 2391 & 2226 & 18,6 & 24,2 \\
\hline CIV & 53 & 4090 & 2133 & 1926 & 47,8 & 52,9 \\
\hline CIV & 54 & 2934 & 2177 & 2039 & 25,8 & 30,5 \\
\hline $\mathrm{CV}$ & 60 & 5304 & 4753 & 4100 & 10,4 & 22,7 \\
\hline $\mathrm{CV}$ & 61 & 4090 & 3408 & 3041 & 16,7 & 25,7 \\
\hline $\mathrm{CV}$ & 62 & 4007 & 3410 & 3010 & 14,9 & 24,9 \\
\hline $\mathrm{CV}$ & 63 & 4201 & 3215 & 2914 & 23,5 & 30,6 \\
\hline $\mathrm{CV}$ & 67 & 3018 & 2178 & 2129 & 27,8 & 29,5 \\
\hline $\mathrm{CV}$ & 68 & 4207 & 2986 & 2961 & 29,0 & 29,6 \\
\hline $\mathrm{CV}$ & 69 & 3874 & 3109 & 3023 & 19,8 & 22,0 \\
\hline CVI & 74 & 4762 & 3801 & 3472 & 20,2 & 27,1 \\
\hline CVI & 75 & 4796 & 4375 & 3642 & 8,8 & 24,1 \\
\hline CVI & 76 & 4973 & 4027 & 3768 & 19,0 & 24,3 \\
\hline CVI & 77 & 5075 & 3853 & 3654 & 24,1 & 28,0 \\
\hline CVI & 81 & 5067 & 3861 & 3855 & 23,8 & 23,9 \\
\hline CVI & 82 & 5083 & 3955 & 3832 & 22,2 & 24,6 \\
\hline
\end{tabular}




\section{ANEXO VIII}

Tabela AVIII - Valores de pH, alcalinidade parcial, alcalinidade intermediária, alcalinidade total, alcalinidade a bicarbonato e ácidos voláteis totais no afluente em todas as condições da "Fase experimental".

\begin{tabular}{|c|c|c|c|c|c|c|c|}
\hline Condição & Tempo (d) & $\mathrm{pH}$ inicial & $\begin{array}{c}\mathrm{AP} \\
\left(\mathrm{mgCaCO}_{3} \cdot \mathrm{L}^{-1}\right)\end{array}$ & $\begin{array}{c}\mathrm{AI} \\
\left(\mathrm{mgCaCO}_{3} \cdot \mathrm{L}^{-1}\right)\end{array}$ & $\begin{array}{c}\mathrm{AT} \\
\left(\mathrm{mgCaCO}_{3} \cdot \mathrm{L}^{-1}\right)\end{array}$ & $\begin{array}{c}\mathrm{AB} \\
\left(\mathrm{mgCaCO}_{3} \cdot \mathrm{L}^{-1}\right)\end{array}$ & $\begin{array}{c}\mathrm{AVT} \\
\left(\mathrm{mgCaCO}_{3} \cdot \mathrm{L}^{-1}\right)\end{array}$ \\
\hline $\mathrm{CI}$ & 4 & 7,57 & 139,6 & 38,4 & 178,0 & 163,3 & 20,7 \\
\hline CI & 5 & 7,65 & 125,7 & 41,1 & 166,7 & 152,3 & 20,4 \\
\hline $\mathrm{CI}$ & 6 & 7,64 & 103,6 & 31,1 & 134,6 & 120,3 & 20,2 \\
\hline CI & 7 & 7,69 & 97,7 & 14,2 & 111,9 & 96,8 & 21,3 \\
\hline $\mathrm{CI}$ & 11 & 7,79 & 90,0 & 28,1 & 118,2 & 104,6 & 19,0 \\
\hline CI & 12 & 7,47 & 85,7 & 28,1 & 113,7 & 100,2 & 19,1 \\
\hline CI & 13 & 7,81 & 111,1 & 31,3 & 142,3 & 128,7 & 19,3 \\
\hline CII & 18 & 7,5 & 116,1 & 26,8 & 142,9 & 126,3 & 23,3 \\
\hline CII & 19 & 7,57 & 131,1 & 26,1 & 157,2 & 140,2 & 23,9 \\
\hline CII & 20 & 7,5 & 117,2 & 27,3 & 144,5 & 125,8 & 26,3 \\
\hline CII & 24 & 7,5 & 117,8 & 31,6 & 149,4 & 130,3 & 26,8 \\
\hline CII & 25 & 7,62 & 160,7 & 35,2 & 195,9 & 178,6 & 24,4 \\
\hline CII & 26 & 7,52 & 156,0 & 37,5 & 193,6 & 174,7 & 26,5 \\
\hline CII & 27 & 7,66 & 147,1 & 35,2 & 182,3 & 161,9 & 28,8 \\
\hline CIII & 32 & 7,53 & 127,9 & 35,4 & 163,3 & 146,7 & 23,5 \\
\hline CIII & 33 & 7,47 & 123,8 & 24,7 & 148,5 & 133,2 & 21,7 \\
\hline CIII & 34 & 7,53 & 110,7 & 25,8 & 136,5 & 119,6 & 23,8 \\
\hline CIII & 35 & 7,5 & 111,3 & 29,9 & 141,1 & 123,9 & 24,3 \\
\hline CIII & 39 & 7,55 & 138,6 & 30,4 & 169,0 & 152,8 & 22,8 \\
\hline CIII & 40 & 7,65 & 131,6 & 31,8 & 163,3 & 145,5 & 25,0 \\
\hline CIV & 46 & 7,57 & 127,8 & 27,6 & 155,3 & 140,1 & 21,4 \\
\hline CIV & 47 & 7,66 & 135,2 & 26,7 & 161,8 & 145,7 & 22,8 \\
\hline CIV & 48 & 7,6 & 136,9 & 24,7 & 161,6 & 146,1 & 21,9 \\
\hline CIV & 49 & 7,66 & 138,3 & 15,2 & 153,4 & 137,2 & 22,9 \\
\hline CIV & 53 & 7,96 & 125,4 & 26,2 & 151,9 & 136,0 & 21,9 \\
\hline CIV & 54 & 7,74 & 126,5 & 25,8 & 152,3 & 138,0 & 20,2 \\
\hline $\mathrm{CV}$ & 60 & 7,55 & 131,1 & 27,6 & 158,6 & 146,8 & 16,7 \\
\hline $\mathrm{CV}$ & 61 & 7,5 & 133,1 & 30,6 & 163,7 & 149,2 & 20,4 \\
\hline $\mathrm{CV}$ & 62 & 7,5 & 132,7 & 30,4 & 163,1 & 147,4 & 22,2 \\
\hline $\mathrm{CV}$ & 63 & 7,5 & 134,5 & 30,9 & 165,5 & 151,3 & 19,9 \\
\hline $\mathrm{CV}$ & 67 & 7,62 & 126,9 & 25,1 & 151,9 & 137,9 & 19,7 \\
\hline $\mathrm{CV}$ & 68 & 7,52 & 126,3 & 30,8 & 157,1 & 141,7 & 21,7 \\
\hline $\mathrm{CV}$ & 69 & 7,66 & 130,4 & 28,4 & 158,8 & 143,2 & 22,0 \\
\hline CVI & 74 & 7,55 & 111,4 & 26,8 & 138,3 & 120,6 & 24,9 \\
\hline CVI & 75 & 7,69 & 120,9 & 20,6 & 141,5 & 122,3 & 27,1 \\
\hline CVI & 76 & 7,59 & 126,0 & 27,6 & 153,6 & 136,4 & 24,2 \\
\hline
\end{tabular}


Tabela AVIII - Valores de pH, alcalinidade parcial, alcalinidade intermediária, alcalinidade total, alcalinidade a bicarbonato e ácidos voláteis totais no afluente em todas as condições da "Fase experimental".

\begin{tabular}{cccccccc}
\hline Condição & Tempo (d) & pH inicial & $\begin{array}{c}\mathrm{AP} \\
\left(\mathrm{mgCaCO}_{3} \cdot \mathrm{L}^{-1}\right)\end{array}$ & $\begin{array}{c}\mathrm{AI} \\
\left(\mathrm{mgCaCO}_{3} \cdot \mathrm{L}^{-1}\right)\end{array}$ & $\begin{array}{c}\mathrm{AT} \\
\left(\mathrm{mgCaCO}_{3} \cdot \mathrm{L}^{-1}\right)\end{array}$ & $\begin{array}{c}\mathrm{AB} \\
\left(\mathrm{mgCaCO}_{3} \cdot \mathrm{L}^{-1}\right)\end{array}$ & $\begin{array}{c}\mathrm{AVT} \\
\left(\mathrm{mgCaCO}_{3} \cdot \mathrm{L}^{-1}\right)\end{array}$ \\
\hline CVI & 77 & 7,53 & 123,9 & 26,8 & 150,8 & 134,5 & 22,9 \\
CVI & 81 & 7,59 & 124,6 & 27,3 & 151,9 & 135,0 & 23,8 \\
CVI & 82 & 7,64 & 124,8 & 28,3 & 153,1 & 137,2 & 22,4 \\
\hline
\end{tabular}




\section{ANEXO VIX}

Tabela AVIX - Valores de pH, alcalinidade parcial, alcalinidade intermediária, alcalinidade total, alcalinidade a bicarbonato e ácidos voláteis totais no efluente em todas as condições da "Fase experimental".

\begin{tabular}{|c|c|c|c|c|c|c|c|}
\hline Condição & Tempo (d) & $\mathrm{pH}$ inicial & $\begin{array}{c}\mathrm{AP} \\
\left(\mathrm{mgCaCO}_{3} \cdot \mathrm{L}^{-1}\right)\end{array}$ & $\begin{array}{c}\mathrm{AI} \\
\left(\mathrm{mgCaCO}_{3} \cdot \mathrm{L}^{-1}\right)\end{array}$ & $\begin{array}{c}\mathrm{AT} \\
\left(\mathrm{mgCaCO}_{3} \cdot \mathrm{L}^{-1}\right) \\
\end{array}$ & $\begin{array}{c}\mathrm{AB} \\
\left(\mathrm{mgCaCO}_{3} \cdot \mathrm{L}^{-1}\right)\end{array}$ & $\begin{array}{c}\mathrm{AVT} \\
\left(\mathrm{mgCaCO}_{3} \cdot \mathrm{L}^{-1}\right)\end{array}$ \\
\hline CI & 4 & 4,88 & 0,0 & 105,8 & 105,8 & 0,0 & 420,1 \\
\hline CI & 5 & 4,97 & 0,0 & 115,3 & 115,3 & 0,0 & 378,4 \\
\hline $\mathrm{CI}$ & 6 & 4,81 & 0,0 & 88,4 & 88,4 & 0,0 & 376,0 \\
\hline $\mathrm{CI}$ & 7 & 4,61 & 0,0 & 48,6 & 48,6 & 0,0 & 355,7 \\
\hline $\mathrm{CI}$ & 11 & 4,33 & 0,0 & 4,1 & 4,1 & 0,0 & 367,1 \\
\hline $\mathrm{CI}$ & 12 & 4,33 & 0,0 & 3,8 & 3,8 & 0,0 & 369,8 \\
\hline CI & 13 & 4,41 & 0,0 & 25,9 & 25,9 & 0,0 & 385,8 \\
\hline CII & 18 & 4,39 & 0,0 & 19,8 & 19,8 & 0,0 & 455,9 \\
\hline CII & 19 & 4,41 & 0,0 & 27,1 & 27,1 & 0,0 & 472,4 \\
\hline CII & 20 & 4,4 & 0,0 & 18,9 & 18,9 & 0,0 & 515,0 \\
\hline CII & 24 & 4,42 & 0,0 & 30,3 & 30,3 & 0,0 & 478,0 \\
\hline CII & 25 & 4,47 & 0,0 & 41,8 & 41,8 & 0,0 & 575,5 \\
\hline CII & 26 & 4,61 & 0,0 & 83,9 & 83,9 & 0,0 & 580,1 \\
\hline CII & 27 & 4,52 & 0,0 & 62,4 & 62,4 & 0,0 & 585,5 \\
\hline CIII & 32 & 4,32 & 0,0 & 10,1 & 10,1 & 0,0 & 543,1 \\
\hline CIII & 33 & 4,34 & 0,0 & 8,5 & 8,5 & 0,0 & 537,6 \\
\hline CIII & 34 & 4,2 & 0,0 & 0,0 & 0,0 & 0,0 & 501,2 \\
\hline CIII & 35 & 4,28 & 0,0 & 0,0 & 0,0 & 0,0 & 510,3 \\
\hline CIII & 39 & 4,35 & 0,0 & 12,9 & 12,9 & 0,0 & 516,3 \\
\hline CIII & 40 & 4,41 & 0,0 & 25,6 & 25,6 & 0,0 & 545,0 \\
\hline CIV & 46 & 4,57 & 0,0 & 58,8 & 58,8 & 0,0 & 451,2 \\
\hline CIV & 47 & 4,68 & 0,0 & 79,5 & 79,5 & 0,0 & 471,4 \\
\hline CIV & 48 & 4,76 & 0,0 & 90,6 & 90,6 & 0,0 & 459,1 \\
\hline CIV & 49 & 4,7 & 0,0 & 83,9 & 83,9 & 0,0 & 477,6 \\
\hline CIV & 53 & 4,76 & 0,0 & 88,2 & 88,2 & 0,0 & 429,7 \\
\hline CIV & 54 & 4,72 & 0,0 & 83,3 & 83,3 & 0,0 & 449,7 \\
\hline $\mathrm{CV}$ & 60 & 4,43 & 0,0 & 34,5 & 34,5 & 0,0 & 503,2 \\
\hline $\mathrm{CV}$ & 61 & 4,45 & 0,0 & 36,4 & 36,4 & 0,0 & 504,8 \\
\hline $\mathrm{CV}$ & 62 & 4,46 & 0,0 & 40,2 & 40,2 & 0,0 & 484,7 \\
\hline $\mathrm{CV}$ & 63 & 4,5 & 0,0 & 45,8 & 45,8 & 0,0 & 452,3 \\
\hline $\mathrm{CV}$ & 67 & 4,8 & 0,0 & 86,4 & 86,4 & 0,0 & 383,1 \\
\hline $\mathrm{CV}$ & 68 & 4,65 & 0,0 & 83,2 & 83,2 & 0,0 & 550,2 \\
\hline $\mathrm{CV}$ & 69 & 4,64 & 0,0 & 77,0 & 77,0 & 0,0 & 519,4 \\
\hline CVI & 74 & 4,34 & 0,0 & 14,1 & 14,1 & 0,0 & 609,1 \\
\hline CVI & 75 & 4,37 & 0,0 & 18,4 & 18,4 & 0,0 & 646,0 \\
\hline CVI & 76 & 4,39 & 0,0 & 23,7 & 23,7 & 0,0 & 625,5 \\
\hline CVI & 77 & 4,48 & 0,0 & 48,7 & 48,7 & 0,0 & 682,9 \\
\hline
\end{tabular}


Tabela AVIX - Valores de pH, alcalinidade parcial, alcalinidade intermediária, alcalinidade total, alcalinidade a bicarbonato e ácidos voláteis totais no efluente em todas as condições da "Fase experimental".

\begin{tabular}{cccccccc}
\hline Condição & Tempo (d) & $\mathrm{pH}$ inicial & $\begin{array}{c}\mathrm{AP} \\
\left(\mathrm{mgCaCO}_{3} \cdot \mathrm{L}^{-1}\right)\end{array}$ & $\begin{array}{c}\mathrm{AI} \\
\left(\mathrm{mgCaCO}_{3} \cdot \mathrm{L}^{-1}\right)\end{array}$ & $\begin{array}{c}\mathrm{AT} \\
\left(\mathrm{mgCaCO}_{3} \cdot \mathrm{L}^{-1}\right)\end{array}$ & $\begin{array}{c}\mathrm{AB} \\
\left(\mathrm{mgCaCO}_{3} \cdot \mathrm{L}^{-1}\right)\end{array}$ & $\begin{array}{c}\mathrm{AVT} \\
\left(\mathrm{mgCaCO}_{3} \cdot \mathrm{L}^{-1}\right)\end{array}$ \\
\hline $\mathrm{CVI}$ & 81 & 4,39 & 0,0 & 26,5 & 26,5 & 0,0 & 646,0 \\
$\mathrm{CVI}$ & 82 & 4,33 & 0,0 & 8,7 & 8,7 & 0,0 & 554,9 \\
\hline
\end{tabular}




\section{ANEXO X}

Tabela AX - Volume e concentração do biogás no final do ciclo em todas as condições da "Fase experimental".

\begin{tabular}{|c|c|c|c|c|c|}
\hline Condição & $\begin{array}{c}\text { Tempo } \\
\text { (d) }\end{array}$ & $\begin{array}{c}\mathrm{V}_{\mathrm{G}} \\
\left(\mathrm{mL}^{\left.- \text {ciclo }^{-1}\right)}\right.\end{array}$ & $\begin{array}{c}\mathrm{H}_{2} \\
\left(\mathrm{mmol} . \mathrm{L}^{-1}\right)\end{array}$ & $\begin{array}{c}\mathrm{CH}_{4} \\
\left(\mathrm{mmol} . \mathrm{L}^{-1}\right)\end{array}$ & $\begin{array}{c}\mathrm{CO}_{2} \\
\left(\mathrm{mmol} . \mathrm{L}^{-1}\right)\end{array}$ \\
\hline CI & 4 & 290 & 1,97 & 0,00 & 2,83 \\
\hline CI & 5 & 275 & 2,13 & 0,00 & 3,12 \\
\hline CI & 7 & 270 & 1,75 & 0,00 & 2,82 \\
\hline CI & 11 & 198 & 1,44 & 0,82 & 3,29 \\
\hline $\mathrm{CI}$ & 12 & 347 & 1,55 & 0,79 & 2,42 \\
\hline CII & 18 & 603 & 5,25 & 0,00 & 3,70 \\
\hline CII & 19 & 591 & 7,22 & 0,00 & 5,29 \\
\hline CII & 20 & 642 & 5,85 & 0,00 & 4,10 \\
\hline CII & 24 & 742 & 7,14 & 0,00 & 4,74 \\
\hline CII & 25 & 1466 & 7,43 & 0,00 & 4,76 \\
\hline CII & 26 & 1220 & 9,42 & 0,18 & 4,76 \\
\hline CIII & 32 & 1248 & 13,03 & 0,25 & 6,25 \\
\hline CIII & 33 & 1353 & 11,63 & 0,24 & 5,75 \\
\hline CIII & 34 & 1425 & 11,95 & 0,31 & 6,27 \\
\hline CIII & 35 & 1494 & 12,43 & 0,34 & 5,08 \\
\hline CIII & 39 & 1430 & 12,30 & 0,53 & 5,87 \\
\hline CIV & 46 & 490 & 4,55 & 0,29 & 3,45 \\
\hline CIV & 47 & 570 & 4,86 & 0,35 & 3,33 \\
\hline CIV & 48 & 626 & 5,38 & 0,76 & 4,44 \\
\hline CIV & 49 & 745 & 6,28 & 0,86 & 4,64 \\
\hline CIV & 52 & 745 & 5,85 & 0,98 & 4,81 \\
\hline CIV & 53 & 583 & 4,66 & 0,89 & 3,67 \\
\hline CIV & 54 & 524 & 3,89 & 0,98 & 3,84 \\
\hline $\mathrm{CV}$ & 60 & 583 & 4,27 & 0,17 & 4,06 \\
\hline $\mathrm{CV}$ & 61 & 760 & 5,17 & 0,19 & 4,40 \\
\hline $\mathrm{CV}$ & 62 & 840 & 6,46 & 0,26 & 4,31 \\
\hline $\mathrm{CV}$ & 63 & 804 & 7,93 & 0,17 & 4,73 \\
\hline $\mathrm{CV}$ & 67 & 598 & 7,46 & 0,73 & 4,61 \\
\hline CVI & 74 & 1089 & 9,09 & 0,52 & 6,32 \\
\hline CVI & 75 & 1053 & 12,88 & 1,03 & 6,46 \\
\hline CVI & 76 & 1112 & 10,41 & 1,51 & 6,54 \\
\hline CVI & 77 & 1009 & 10,02 & 2,61 & 6,70 \\
\hline CVI & 81 & 868 & 8,64 & 4,58 & 6,77 \\
\hline CVI & 82 & 923 & 8,60 & 4,34 & 6,69 \\
\hline
\end{tabular}




\section{ANEXO XI}

Tabela AXI - Produção volumétrica acumulada do biogás em $\mathrm{mL}$ ao longo do ciclo em todas as condições da "Fase preliminar"

\begin{tabular}{|c|c|c|c|c|c|c|c|c|c|}
\hline Condição & Tempo (d) & $0,00(\mathrm{~h})$ & $0,50(\mathrm{~h})$ & $1,00(\mathrm{~h})$ & $1,50(\mathrm{~h})$ & $2,00(\mathrm{~h})$ & $2,50(\mathrm{~h})$ & $3,00(\mathrm{~h})$ & $3,82(\mathrm{~h})$ \\
\hline CI & 4 & 0,00 & 87,2 & 164,1 & 179,5 & 205,1 & 243,6 & 276,9 & 289,8 \\
\hline CI & 5 & 0,00 & 87,2 & 174,4 & 184,6 & 215,4 & 235,9 & 269,3 & 274,4 \\
\hline CI & 6 & 0,00 & 82,1 & 164,1 & 179,5 & 207,71 & 241,0 & 261,6 & 269,3 \\
\hline CI & 12 & 0,00 & 92,3 & 174,4 & 192,3 & 297,5 & 310,3 & 341,1 & 346,2 \\
\hline CII & 20 & 0,00 & 166,7 & 305,2 & 500,0 & 538,5 & 615,4 & 638,5 & 641,1 \\
\hline CII & 21 & 0,00 & 187,2 & 405,2 & 569,3 & 677,0 & 733,4 & 741,1 & 741,1 \\
\hline CII & 25 & 0,00 & 205,1 & 441,1 & 815,4 & 1130,8 & 1351,4 & 1451,4 & 1464,2 \\
\hline CII & 26 & 0,00 & 374,4 & 753,9 & 1018,0 & 1166,7 & 1210,3 & 1218,0 & 1218,0 \\
\hline CIII & 32 & 0,00 & 248,7 & 543,6 & 810,3 & 1025,7 & 1166,7 & 1230,9 & 1246,2 \\
\hline CIII & 33 & 0,00 & 279,5 & 600,0 & 871,9 & 1110,3 & 1264,2 & 1338,6 & 1351,4 \\
\hline CIII & 34 & 0,00 & 315,4 & 651,3 & 953,9 & 1187,3 & 1343,7 & 1412,9 & 1423,2 \\
\hline CIII & 35 & 0,00 & 330,8 & 674,4 & 1000,1 & 1248,8 & 1423,2 & 1482,2 & 1489,8 \\
\hline CIII & 39 & 0,00 & 371,8 & 764,2 & 1094,9 & 1312,2 & 1415,5 & 1428,3 & 1428,3 \\
\hline CIV & 46 & 0,00 & 182,1 & 377,0 & 477,0 & 487,2 & 489,8 & 489,8 & - \\
\hline CIV & 47 & 0,00 & 233,4 & 466,7 & 561,6 & 569,3 & 569,3 & 569,3 & - \\
\hline CIV & 48 & 0,00 & 315,4 & 556,5 & 625,7 & 625,7 & 625,7 & 625,7 & - \\
\hline CIV & 49 & 0,00 & 371,8 & 677,0 & 743,6 & 743,6 & 743,6 & 743,6 & - \\
\hline CIV & 52 & 0,00 & 459,0 & 743,6 & 743,6 & 743,6 & 743,6 & 743,6 & - \\
\hline CIV & 53 & 0,00 & 297,5 & 538,5 & 582,1 & 582,1 & 582,1 & 582,1 & - \\
\hline CIV & 54 & 0,00 & 246,2 & 471,8 & 528,2 & 528,2 & 528,2 & 528,2 & - \\
\hline CIV & 46 & 0,00 & 182,1 & 377,0 & 477,0 & 487,2 & 489,8 & 489,8 & - \\
\hline $\mathrm{CV}$ & 60 & 0,00 & 130,8 & 294,9 & 425,7 & 525,7 & 582,1 & 582,1 & - \\
\hline $\mathrm{CV}$ & 61 & 0,00 & 218,0 & 453,9 & 633,4 & 733,4 & 759,0 & 759,0 & - \\
\hline $\mathrm{CV}$ & 62 & 0,00 & 251,3 & 523,1 & 718,0 & 818,0 & 838,5 & 838,5 & - \\
\hline $\mathrm{CV}$ & 63 & 0,00 & 282,1 & 551,3 & 725,7 & 797,5 & 802,6 & 802,6 & - \\
\hline $\mathrm{CV}$ & 67 & 0,00 & 346,2 & 559,0 & 597,5 & 597,5 & 597,5 & 597,5 & - \\
\hline CVI & 74 & 0,00 & 246,2 & 482,1 & 697,5 & 897,5 & 1087,3 & 1087,3 & - \\
\hline CVI & 75 & 0,00 & 235,9 & 512,9 & 759,0 & 951,4 & 1051,4 & 1051,4 & - \\
\hline CVI & 76 & 0,00 & 307,7 & 643,6 & 907,8 & 1061,6 & 1110,3 & 1110,3 & - \\
\hline CVI & 77 & 0,00 & 315,4 & 646,2 & 894,9 & 1000,1 & 1007,8 & 1007,8 & - \\
\hline CVI & 81 & 0,00 & 269,3 & 592,4 & 810,3 & 866,7 & 866,7 & 866,7 & - \\
\hline CVI & 82 & 0,00 & 343,6 & 694,9 & 889,8 & 923,1 & 923,1 & 923,1 & - \\
\hline
\end{tabular}




\section{ANEXO XII}

Tabela XII.1 - Sólidos suspendidos e sólidos totais do afluente da "Fase experimental".

\begin{tabular}{cccccc}
\hline Condição & $\begin{array}{c}\text { Tempo } \\
(\mathrm{d})\end{array}$ & $\begin{array}{c}\text { SST } \\
(\mathrm{mg} / \mathrm{L})\end{array}$ & $\begin{array}{c}\text { SSV } \\
(\mathrm{mg} / \mathrm{L})\end{array}$ & $\begin{array}{c}\text { ST } \\
(\mathrm{mg} / \mathrm{L})\end{array}$ & $\begin{array}{c}\text { STV } \\
(\mathrm{mg} / \mathrm{L})\end{array}$ \\
\hline CI & 4 & 18 & 4 & 462 & 222 \\
CI & 6 & 20 & 0 & 336 & 230 \\
CI & 11 & 32 & 2 & 358 & 188 \\
CII & 19 & 28 & 22 & 558 & 292 \\
CII & 21 & 22 & 26 & 456 & 346 \\
CII & 26 & 0 & 32 & 596 & 298 \\
CIII & 32 & 8 & 18 & 478 & 188 \\
CIII & 34 & 36 & 38 & 548 & 340 \\
CIII & 38 & 70 & 4 & 622 & 340 \\
CIV & 46 & 14 & 18 & 392 & 194 \\
CIV & 48 & 38 & 24 & 452 & 332 \\
CIV & 54 & 12 & 38 & 584 & 282 \\
CV & 60 & 32 & 26 & 550 & 246 \\
CV & 62 & 4 & 34 & 518 & 288 \\
CV & 67 & 20 & 20 & 630 & 398 \\
CVI & 74 & 10 & 24 & 538 & 390 \\
CVI & 76 & 38 & 0 & 516 & 274 \\
CVI & 81 & 26 & 0 & 506 & 264 \\
\hline
\end{tabular}

Tabela XII.2 - Sólidos suspendidos e sólidos totais do efluente da "Fase experimental".

\begin{tabular}{cccccc}
\hline Condição & $\begin{array}{c}\text { Tempo } \\
(\mathrm{d})\end{array}$ & $\begin{array}{c}\text { SST } \\
(\mathrm{mg} / \mathrm{L})\end{array}$ & $\begin{array}{c}\text { SSV } \\
(\mathrm{mg} / \mathrm{L})\end{array}$ & $\begin{array}{c}\text { ST } \\
(\mathrm{mg} / \mathrm{L})\end{array}$ & $\begin{array}{c}\text { STV } \\
(\mathrm{mg} / \mathrm{L})\end{array}$ \\
\hline CI & 4 & 74 & 58 & 604 & 376 \\
CI & 6 & 30 & 18 & 522 & 378 \\
CI & 11 & 58 & 28 & 474 & 316 \\
CI & 13 & 54 & 20 & 420 & 236 \\
CII & 19 & 98 & 92 & 644 & 428 \\
CII & 21 & 70 & 82 & 734 & 590 \\
CII & 26 & 96 & 108 & 874 & 618 \\
CII & 28 & 72 & 42 & 680 & 482 \\
CIII & 32 & 76 & 94 & 814 & 588 \\
CIII & 34 & 104 & 96 & 772 & 640 \\
CIII & 38 & 136 & 88 & 850 & 586 \\
CIV & 46 & 66 & 66 & 604 & 376 \\
CIV & 48 & 84 & 64 & 522 & 378 \\
CIV & 54 & 150 & 162 & 474 & 316 \\
CV & 60 & 92 & 98 & 964 & 658 \\
CV & 62 & 112 & 118 & 986 & 768 \\
CV & 67 & 84 & 82 & 840 & 678 \\
CV & 69 & 84 & 70 & 976 & 858 \\
CVI & 74 & 64 & 44 & 1004 & 908 \\
CVI & 76 & 52 & 52 & 988 & 784 \\
CVI & 81 & 20 & 0 & 886 & 690 \\
CVI & 83 & 48 & 38 & 862 & 722 \\
\hline
\end{tabular}




\section{ANEXO XIII}

Tabela XIII.1 - Concentração de matéria orgânica (DQO) ao longo do ciclo nas condições da "Fase experimental"

\begin{tabular}{cccccccc}
\hline Condição & Tempo & $0 \mathrm{~h}$ & $0,5 \mathrm{~h}$ & $1 \mathrm{~h}$ & $2 \mathrm{~h}$ & $3 \mathrm{~h}$ & 3,82 \\
\hline CI & 13 & 2593,9 & 2384,5 & 2444,6 & 2187,8 & 2258,7 & 2130,2 \\
CII & 27 & 3573,1 & 3286,8 & 2566,9 & 2989,1 & 2952,5 & 3009,4 \\
CIII & 40 & 4381,9 & 4217,6 & 4123,8 & 3801,9 & 3901,4 & 3982,9 \\
CIV & 54 & 2311,2 & 2447,0 & 2011 & 2155,1 & 2032 & - \\
CV & 70 & 3111,6 & 3135,6 & 2936,9 & 3010,9 & 3035,5 & - \\
CVI & 82 & 4049,1 & 3985,9 & 3884,1 & 3810,4 & 4085,5 & - \\
\hline
\end{tabular}

Tabela XIII.2 - Valores de pH, alcalinidade parcial, alcalinidade intermediária, alcalinidade total, alcalinidade a bicarbonato e ácidos voláteis totais ao longo do ciclo da condição I da "Fase experimental".

\begin{tabular}{ccccccc}
$\begin{array}{c}\text { Tempo } \\
(\mathrm{h})\end{array}$ & $\mathrm{pH}$ & $\begin{array}{c}\mathrm{AP}(\mathrm{mg} / \mathrm{L} \\
\mathrm{CaCO} 3)\end{array}$ & $\begin{array}{c}\mathrm{AI}(\mathrm{mg} / \mathrm{L} \\
\mathrm{CaCO} 3)\end{array}$ & $\begin{array}{c}\mathrm{AT}(\mathrm{mg} / \mathrm{L} \\
\mathrm{CaCO} 3)\end{array}$ & $\begin{array}{c}\mathrm{AB}(\mathrm{mg} / \mathrm{L} \\
\mathrm{CaCO} 3)\end{array}$ & $\begin{array}{c}\mathrm{AVT}(\mathrm{mg} / \mathrm{L} \\
\mathrm{HAC})\end{array}$ \\
\hline 0 & 4,68 & 0,0 & 67,3 & 67,3 & 0,0 & 171,1 \\
0,5 & 4,62 & 0,0 & 52,7 & 52,7 & 0,0 & 204,6 \\
1 & 4,52 & 0,0 & 38,6 & 38,6 & 0,0 & 325,3 \\
2 & 4,46 & 0,0 & 31,0 & 31,0 & 0,0 & 392,3 \\
3 & 4,38 & 0,0 & 19,5 & 19,5 & 0,0 & 389,1 \\
3,82 & 4,37 & 0,0 & 21,7 & 21,7 & 0,0 & 336,1 \\
\hline
\end{tabular}

Tabela XIII.3 - Valores de pH, alcalinidade parcial, alcalinidade intermediária, alcalinidade total, alcalinidade a bicarbonato e ácidos voláteis totais ao longo do ciclo da condição II da "Fase experimental".

\begin{tabular}{ccccccc}
$\begin{array}{c}\text { Tempo } \\
(\mathrm{h})\end{array}$ & $\mathrm{pH}$ & $\begin{array}{c}\mathrm{AP}(\mathrm{mg} / \mathrm{L} \\
\mathrm{CaCO} 3)\end{array}$ & $\begin{array}{c}\mathrm{AI}(\mathrm{mg} / \mathrm{L} \\
\mathrm{CaCO} 3)\end{array}$ & $\begin{array}{c}\mathrm{AT}(\mathrm{mg} / \mathrm{L} \\
\mathrm{CaCO} 3)\end{array}$ & $\begin{array}{c}\mathrm{AB}(\mathrm{mg} / \mathrm{L} \\
\mathrm{CaCO} 3)\end{array}$ & $\begin{array}{c}\mathrm{AVT}(\mathrm{mg} / \mathrm{L} \\
\mathrm{HAC})\end{array}$ \\
\hline 0 & 4,95 & 0,0 & 116,7 & 116,7 & 0,0 & 388,1 \\
0,5 & 4,7 & 0,0 & 90,9 & 90,9 & 0,0 & 488,6 \\
1 & 4,61 & 0,0 & 85,6 & 85,6 & 0,0 & 519,2 \\
2 & 4,51 & 0,0 & 60,1 & 60,1 & 0,0 & 598,1 \\
3 & 4,51 & 0,0 & 68,6 & 68,6 & 0,0 & 647,3 \\
3,82 & 4,47 & 0,0 & 51,9 & 51,9 & 0,0 & 630,1 \\
\hline
\end{tabular}


Tabela XIII.4 - Valores de pH, alcalinidade parcial, alcalinidade intermediária, alcalinidade total, alcalinidade a bicarbonato e ácidos voláteis totais ao longo do ciclo da condição III da "Fase experimental".

\begin{tabular}{ccccccc}
\hline $\begin{array}{c}\text { Tempo } \\
(\mathrm{h})\end{array}$ & $\mathrm{pH}$ & $\begin{array}{c}\mathrm{AP}(\mathrm{mg} / \mathrm{L} \\
\mathrm{CaCO} 3)\end{array}$ & $\begin{array}{c}\mathrm{AI}(\mathrm{mg} / \mathrm{L} \\
\mathrm{CaCO} 3)\end{array}$ & $\begin{array}{c}\mathrm{AT}(\mathrm{mg} / \mathrm{L} \\
\mathrm{CaCO} 3)\end{array}$ & $\begin{array}{c}\mathrm{AB}(\mathrm{mg} / \mathrm{L} \\
\mathrm{CaCO} 3)\end{array}$ & $\begin{array}{c}\mathrm{AVT}(\mathrm{mg} / \mathrm{L} \\
\mathrm{HAC})\end{array}$ \\
\hline 0 & 4,69 & 0,0 & 98,5 & 98,5 & 0,0 & 361,0 \\
0,5 & 4,56 & 0,0 & 76,7 & 76,7 & 0,0 & 454,4 \\
1 & 4,45 & 0,0 & 72,2 & 72,2 & 0,0 & 482,9 \\
2 & 4,45 & 0,0 & 50,7 & 50,7 & 0,0 & 556,3 \\
3 & 4,39 & 0,0 & 57,9 & 57,9 & 0,0 & 602,0 \\
3,82 & 4,34 & 0,0 & 43,8 & 43,8 & 0,0 & 586,0 \\
\hline
\end{tabular}

Tabela XIII.5 - Valores de pH, alcalinidade parcial, alcalinidade intermediária, alcalinidade total, alcalinidade a bicarbonato e ácidos voláteis totais ao longo do ciclo da condição IV da "Fase experimental"'.

\begin{tabular}{ccccccc}
$\begin{array}{c}\text { Tempo } \\
(\mathrm{h})\end{array}$ & $\mathrm{pH}$ & $\begin{array}{c}\mathrm{AP}(\mathrm{mg} / \mathrm{L} \\
\mathrm{CaCO} 3)\end{array}$ & $\begin{array}{c}\mathrm{AI}(\mathrm{mg} / \mathrm{L} \\
\mathrm{CaCO} 3)\end{array}$ & $\begin{array}{c}\mathrm{AT}(\mathrm{mg} / \mathrm{L} \\
\mathrm{CaCO} 3)\end{array}$ & $\begin{array}{c}\mathrm{AB}(\mathrm{mg} / \mathrm{L} \\
\mathrm{CaCO} 3)\end{array}$ & $\begin{array}{c}\mathrm{AVT}(\mathrm{mg} / \mathrm{L} \\
\mathrm{HAC})\end{array}$ \\
\hline 0 & 4,87 & 0,0 & 105,4 & 105,4 & 0,0 & 408,9 \\
0,5 & 4,83 & 0,0 & 100,2 & 100,2 & 0,0 & 411,3 \\
1 & 4,77 & 0,0 & 91,2 & 91,2 & 0,0 & 403,7 \\
2 & 4,7 & 0,0 & 84,5 & 84,5 & 0,0 & 459,7 \\
3 & 4,68 & 0,0 & 89,4 & 89,4 & 0,0 & 468,5 \\
\hline
\end{tabular}

Tabela XIII.6 - Valores de pH, alcalinidade parcial, alcalinidade intermediária, alcalinidade total, alcalinidade a bicarbonato e ácidos voláteis totais ao longo do ciclo da condição V da "Fase experimental"'.

\begin{tabular}{ccccccc}
$\begin{array}{c}\text { Tempo } \\
(\mathrm{h})\end{array}$ & $\mathrm{pH}$ & $\begin{array}{c}\mathrm{AP}(\mathrm{mg} / \mathrm{L} \\
\mathrm{CaCO} 3)\end{array}$ & $\begin{array}{c}\mathrm{AI}(\mathrm{mg} / \mathrm{L} \\
\mathrm{CaCO} 3)\end{array}$ & $\begin{array}{c}\mathrm{AT}(\mathrm{mg} / \mathrm{L} \\
\mathrm{CaCO} 3)\end{array}$ & $\begin{array}{c}\mathrm{AB}(\mathrm{mg} / \mathrm{L} \\
\mathrm{CaCO} 3)\end{array}$ & $\begin{array}{c}\mathrm{AVT}(\mathrm{mg} / \mathrm{L} \\
\mathrm{HAC})\end{array}$ \\
\hline 0 & 4,86 & 0,0 & 98,0 & 98,0 & 0,0 & 416,1 \\
0,5 & 4,51 & 0,0 & 55,7 & 55,7 & 0,0 & 427,6 \\
1 & 4,67 & 0,0 & 72,3 & 72,3 & 0,0 & 398,8 \\
2 & 4,6 & 0,0 & 73,9 & 73,9 & 0,0 & 513,7 \\
3 & 4,61 & 0,0 & 71,2 & 71,2 & 0,0 & 466,7 \\
\hline
\end{tabular}

Tabela XIII.7 - Valores de pH, alcalinidade parcial, alcalinidade intermediária, alcalinidade total, alcalinidade a bicarbonato e ácidos voláteis totais ao longo do ciclo da condição V da "Fase experimental".

\begin{tabular}{ccccccc}
$\begin{array}{c}\text { Tempo } \\
(\mathrm{h})\end{array}$ & $\mathrm{pH}$ & $\begin{array}{c}\mathrm{AP}(\mathrm{mg} / \mathrm{L} \\
\mathrm{CaCO} 3)\end{array}$ & $\begin{array}{c}\mathrm{AI}(\mathrm{mg} / \mathrm{L} \\
\mathrm{CaCO} 3)\end{array}$ & $\begin{array}{c}\mathrm{AT}(\mathrm{mg} / \mathrm{L} \\
\mathrm{CaCO} 3)\end{array}$ & $\begin{array}{c}\mathrm{AB}(\mathrm{mg} / \mathrm{L} \\
\mathrm{CaCO} 3)\end{array}$ & $\begin{array}{c}\mathrm{AVT}(\mathrm{mg} / \mathrm{L} \\
\mathrm{HAC})\end{array}$ \\
\hline 0 & 4,69 & 0,0 & 98,5 & 98,5 & 0,0 & 361,0 \\
0,5 & 4,56 & 0,0 & 76,7 & 76,7 & 0,0 & 454,4 \\
1 & 4,45 & 0,0 & 72,2 & 72,2 & 0,0 & 482,9 \\
2 & 4,45 & 0,0 & 50,7 & 50,7 & 0,0 & 556,3 \\
3 & 4,39 & 0,0 & 57,9 & 57,9 & 0,0 & 602,0 \\
\hline
\end{tabular}


Tabela XIII.8 - Volume acumulado de biogás ao longo do ciclo das condições da "Fase experimental".

\begin{tabular}{ccccccc}
\hline & \multicolumn{7}{c}{ Tempo (h) } \\
\hline Condição & 0,0 & 0,5 & 1,0 & 2,0 & 3,0 & 4,0 \\
\hline CI $(\mathrm{mL})$ & 0,0 & 92,4 & 174,6 & 297,8 & 341,5 & 346,6 \\
CII $(\mathrm{mL})$ & 0,0 & 374,9 & 754,9 & 1168,2 & 1219,6 & 1219,6 \\
CIII (mL) & 0,0 & 372,3 & 765,1 & 1314,6 & 1430,1 & 1430,1 \\
CIV (mL) & 0,0 & 459,6 & 744,6 & 744,6 & 744,6 & - \\
CV $(\mathrm{mL})$ & 0,0 & 282,4 & 552,0 & 798,5 & 803,6 & - \\
CVI $(\mathrm{mL})$ & 0,0 & 344,1 & 695,8 & 924,3 & 924,3 & - \\
\hline
\end{tabular}

Tabela XIII.9 - Concentração dos compostos do biogás ao longo do ciclo das condições da "Fase experimental".

\begin{tabular}{cccccccc}
\hline & \multicolumn{7}{c}{ Tempo (h) } \\
\hline & Condição & $\mathbf{0 , 0}$ & $\mathbf{0 , 5}$ & $\mathbf{1 , 0}$ & $\mathbf{2 , 0}$ & $\mathbf{3 , 0}$ & $\mathbf{4 , 0}$ \\
\hline & CI & 0,00 & 0,35 & 0,98 & 1,46 & 1,54 & 1,55 \\
& CII & 0,00 & 1,79 & 5,60 & 9,24 & 9,37 & 9,42 \\
$\mathrm{C}_{\mathrm{H} 2}$ & CIII & 0,00 & 4,19 & 8,45 & 10,85 & 12,12 & 12,30 \\
$\left(\mathrm{mmol} \cdot \mathrm{L}^{-1}\right)$ & CIV & 0,00 & 0,21 & 4,97 & 5,31 & 5,85 & - \\
& CV & 0,00 & 1,49 & 3,16 & 5,12 & 7,26 & - \\
& CVI & 0,00 & 2,28 & 4,34 & 8,01 & 8,60 & - \\
\hline \multirow{5}{*}{$\mathrm{C}_{\mathrm{CH} 4}$} & CI & 0,00 & 0,00 & 0,21 & 0,44 & 0,66 & 0,79 \\
$\left(\mathrm{mmol} \cdot \mathrm{L}^{-1}\right)$ & CII & 0,00 & 0,00 & 0,00 & 0,00 & 0,00 & 0,18 \\
& CIII & 0,00 & 0,18 & 0,23 & 0,39 & 0,50 & 0,53 \\
& CIV & 0,00 & 0,00 & 0,34 & 0,71 & 0,98 & - \\
& CV & 0,00 & 0,00 & 0,30 & 0,62 & 0,73 & - \\
& CVI & 0,00 & 1,74 & 2,81 & 3,98 & 4,34 & - \\
\hline $\mathrm{C}_{\mathrm{CO} 2}$ & CI & 0,00 & 0,00 & 1,46 & 2,01 & 2,49 & 2,42 \\
$\left(\mathrm{mmol} . \mathrm{L}^{-1}\right)$ & CII & 0,00 & 1,72 & 3,21 & 4,62 & 4,71 & 4,76 \\
& CIII & 0,00 & 2,08 & 3,77 & 5,28 & 5,70 & 5,87 \\
& CIV & 0,00 & 1,48 & 3,20 & 4,46 & 4,81 & - \\
& CV & 0,00 & 1,72 & 2,82 & 3,45 & 4,70 & - \\
& CVI & 0,00 & 1,82 & 3,13 & 5,62 & 6,69 & - \\
\hline
\end{tabular}




\section{ANEXO XIV}

Tabela XIV - concentração de compostos intermediários ao longo do ciclo das condições da "Fase experimental"

\begin{tabular}{|c|c|c|c|c|c|c|c|c|c|c|}
\hline Condição & Tempo & Etanol & Butanol & Ac. Acético & Ac. Propiônico & Ac. Iso-butírico & Ac.Butírico & Ac.Iso-valérico & Ac.Valérico & Ac.Capróico \\
\hline & (mg.L) & (mg.L) & (mg.L) & (mg.L) & (mg.L) & (mg.L) & (mg.L) & (mg.L) & (mg.L) & (mg.L) \\
\hline \multirow[t]{6}{*}{$\mathrm{CI}$} & 0 & 20,1 & 15,2 & 73,1 & 38,6 & 7,4 & 284,6 & 9,6 & 23,4 & 32,9 \\
\hline & 0,5 & 24,3 & 16,5 & 76,2 & 41,6 & 9,2 & 339,9 & 10,2 & 26,3 & 37,2 \\
\hline & 1 & 22,7 & 15,9 & 85,9 & 29,8 & 8,1 & 278,9 & 8,4 & 24,6 & 30,1 \\
\hline & 2 & 23,2 & 18,7 & 81,9 & 36,3 & 6,5 & 246,8 & 8,5 & 20,5 & 28,2 \\
\hline & 3 & 21,1 & 20,5 & 101,8 & 40,6 & 4,8 & 239,4 & 8,1 & 20,9 & 26,9 \\
\hline & 4 & 19,9 & 20,1 & 108,2 & 37,4 & 2,6 & 210,6 & 7,8 & 18,8 & 24,1 \\
\hline \multirow[t]{6}{*}{ CII } & 0 & 15,1 & 255,1 & 64,9 & 31,8 & 12,2 & 366,4 & 9,8 & 20,6 & 26,7 \\
\hline & 0,5 & 14,2 & 234,6 & 66,1 & 30,7 & 9,2 & 340,2 & 7,4 & 17,9 & 24,9 \\
\hline & 1 & 17,5 & 251,1 & 68,8 & 28,7 & 8 & 362,8 & 7 & 16,8 & 22,6 \\
\hline & 2 & 19,1 & 281,4 & 70,2 & 40,8 & 11,4 & 402,4 & 10,4 & 21,5 & 28,7 \\
\hline & 3 & 15,1 & 222,1 & 73,7 & 33,6 & 8,8 & 3984,4 & 7,8 & 19,9 & 29,4 \\
\hline & 4 & 17,2 & 257,2 & 71,8 & 36,3 & 10,2 & 417,1 & 9,1 & 20,1 & 31,2 \\
\hline \multirow[t]{6}{*}{ CII } & 0 & 25,4 & 283,8 & 72,5 & 45,4 & 43,1 & 402,1 & 11,7 & 22,5 & 52,4 \\
\hline & 0,5 & 20,8 & 292,9 & 65,3 & 41,8 & 40,7 & 398,6 & 10,4 & 20,1 & 55,5 \\
\hline & 1 & 24,2 & 329,5 & 67,2 & 44,2 & 43,4 & 410,2 & 11,5 & 21,8 & 48,8 \\
\hline & 2 & 26,1 & 315,2 & 65,3 & 48,8 & 50,1 & 428,4 & 12,8 & 22,9 & 51,9 \\
\hline & 3 & 25,6 & 310,6 & 68,8 & 49,4 & 51,2 & 421,2 & 13,1 & 26,1 & 52,4 \\
\hline & 4 & 24,9 & 296,8 & 71,1 & 41,9 & 40,7 & 408,1 & 10,8 & 21,2 & 59,4 \\
\hline \multirow[t]{5}{*}{ CIV } & 0 & 47,9 & 82,3 & 119,2 & 39,8 & 9,2 & 214,5 & 7,9 & 22,4 & 24,8 \\
\hline & 0,5 & 51,2 & 89,8 & 111,2 & 43,7 & 10,7 & 207,4 & 8,1 & 20,8 & 29,8 \\
\hline & 1 & 45,6 & 96,8 & 107,4 & 38,7 & 8,2 & 198,4 & 6,7 & 24,2 & 21,2 \\
\hline & 2 & 44,2 & 99,6 & 117,1 & 37,9 & 7,9 & 219,1 & 7,1 & 20,9 & 19,9 \\
\hline & 3 & 47,8 & 91,4 & 118,3 & 31,5 & 6,8 & 198,8 & 6,5 & 21,2 & 18,8 \\
\hline \multirow[t]{5}{*}{$\mathrm{CV}$} & 0 & 17,9 & 208,5 & 129,7 & 45,3 & 5,5 & 313,2 & 8,4 & 18,2 & 29,4 \\
\hline & 0,5 & 17 & 205,7 & 117,8 & 44,8 & 8,1 & 382,6 & 9,5 & 20,1 & 36,9 \\
\hline & 1 & 18,2 & 217,8 & 110,8 & 49,9 & 9,9 & 365,2 & 10,2 & 21,2 & 38,2 \\
\hline & 2 & 16,4 & 225,5 & 109,5 & 38,5 & 6,1 & 376,4 & 8,1 & 16,7 & 28,6 \\
\hline & 3 & 14,6 & 210,4 & 126,1 & 33,2 & 5,9 & 349,2 & 7,1 & 14,9 & 26,4 \\
\hline \multirow[t]{5}{*}{ CVI } & 0 & 19,6 & 310,2 & 136,8 & 59,5 & 31,7 & 449,8 & 10,1 & 19,7 & 44,1 \\
\hline & 0,5 & 15,5 & 298,4 & 125,1 & 51,3 & 29,5 & 422,6 & 7,9 & 15,8 & 33,8 \\
\hline & 1 & 20,2 & 289,9 & 119,9 & 65,1 & 28,5 & 407,1 & 12,5 & 23,1 & 36,1 \\
\hline & 2 & 22,6 & 300,7 & 121,2 & 68,6 & 30,1 & 418,4 & 10,7 & 20,7 & 41,2 \\
\hline & 3 & 18,9 & 281,1 & 131,6 & 54,6 & 32,8 & 422,1 & 12,8 & 17,9 & 39,8 \\
\hline
\end{tabular}




\section{ANEXO XV}

Tabela XV.1 - Concentração de matéria orgânica (DQO) afluente e efluente da condição operada sem pré-tratamento da biomassa CSBT.

\begin{tabular}{ccccccc}
\hline Condição & Tempo & $\mathrm{C}_{\mathrm{SAFTL}}\left(\mathrm{mgDQO} . \mathrm{L}^{-1}\right)$ & $\mathrm{C}_{\mathrm{ST}}\left(\mathrm{mgDQO} . \mathrm{L}^{-1}\right)$ & $\mathrm{C}_{\mathrm{SF}}\left(\mathrm{mgDQO} . \mathrm{L}^{-1}\right)$ & $\varepsilon_{\mathrm{ST}}(\%)$ & $\varepsilon_{\mathrm{SF}}(\%)$ \\
\hline CBST & 88 & 4974 & 4095 & 3989 & 17,7 & 19,8 \\
CBST & 89 & 5029 & 3908 & 3611 & 22,3 & 28,2 \\
CBST & 90 & 5093 & 3713 & 3662 & 27,1 & 28,1 \\
CBST & 91 & 4980 & 3790 & 3723 & 23,9 & 25,2 \\
CBST & 96 & 5027 & 3676 & 3352 & 26,9 & 33,3 \\
CBST & 97 & 5064 & 3745 & 3728 & 26,1 & 26,4 \\
\hline
\end{tabular}

Tabela XV.2 - Valores de pH, alcalinidade parcial, alcalinidade intermediária, alcalinidade total, alcalinidade a bicarbonato e ácidos voláteis totais no afluente da condição operada sem prétratamento da biomassa CSBT.

\begin{tabular}{|c|c|c|c|c|c|c|c|}
\hline $\begin{array}{l}\text { Condiç } \\
\text { ão }\end{array}$ & $\begin{array}{l}\text { Tempo } \\
\text { (d) }\end{array}$ & $\mathrm{pH}$ & $\begin{array}{c}\mathrm{AP}\left(\mathrm{mg} \cdot \mathrm{L}^{-1}\right. \\
\mathrm{CaCO} 3)\end{array}$ & $\begin{array}{c}\mathrm{AI}\left(\mathrm{mg} \cdot \mathrm{L}^{-1}\right. \\
\mathrm{CaCO})\end{array}$ & $\begin{array}{l}\text { AT (mg. } L^{-1} \\
\text { CaCO3) }\end{array}$ & $\begin{array}{c}\mathrm{AB}\left(\mathrm{mg} \cdot \mathrm{L}^{-1}\right. \\
\mathrm{CaCO} 3)\end{array}$ & $\begin{array}{c}\text { AVT (mg.. } .^{-1} \\
\text { HAC) }\end{array}$ \\
\hline CBST & 88 & $\begin{array}{c}7,7 \\
3\end{array}$ & 111,4 & 20,8 & 132,2 & 117,6 & 20,7 \\
\hline CBST & 89 & 7,7 & 134,5 & 21,9 & 156,4 & 136,6 & 27,9 \\
\hline CBST & 90 & $\begin{array}{c}7,7 \\
3\end{array}$ & 107,9 & 23,4 & 131,3 & 113,1 & 25,6 \\
\hline CBST & 91 & $\begin{array}{c}7,7 \\
5\end{array}$ & 116,5 & 28,4 & 144,9 & 127,9 & 24,0 \\
\hline CBST & 96 & $\begin{array}{l}7,7 \\
4\end{array}$ & 134,6 & 25,4 & 160,0 & 142,0 & 25,4 \\
\hline CBST & 97 & $\begin{array}{l}7,7 \\
3\end{array}$ & 114,3 & 31,2 & 145,5 & 128,3 & 24,2 \\
\hline
\end{tabular}

Tabela XV.3 - Valores de pH, alcalinidade parcial, alcalinidade intermediária, alcalinidade total, alcalinidade a bicarbonato e ácidos voláteis totais no efluente em todas as condições da condição operada sem pré-tratamento da biomassa CSBT.

\begin{tabular}{cccccccc}
\hline Condição & $\begin{array}{c}\text { Tempo } \\
(\mathrm{d})\end{array}$ & $\mathrm{pH}$ & $\begin{array}{c}\mathrm{AP}\left(\mathrm{mg} . \mathrm{L}^{-1}\right. \\
\mathrm{CaCO} 3)\end{array}$ & $\begin{array}{c}\mathrm{AI}\left(\mathrm{mg} . \mathrm{L}^{-1}\right. \\
\mathrm{CaCO} 3)\end{array}$ & $\begin{array}{c}\mathrm{AT}\left(\mathrm{mg} . \mathrm{L}^{-1}\right. \\
\mathrm{CaCO} 3)\end{array}$ & $\begin{array}{c}\mathrm{AB}\left(\mathrm{mg} . \mathrm{L}^{-1}\right. \\
\mathrm{CaCO} 3)\end{array}$ & $\begin{array}{c}\text { AVT }\left(\mathrm{mg} . \mathrm{L}^{-1}\right. \\
\text { HAC) }\end{array}$ \\
\hline CBST & 88 & 4,26 & 0,0 & 0,0 & 0,0 & 0,0 & 837,0 \\
CBST & 89 & 4,38 & 0,0 & 18,1 & 18,1 & 0,0 & 741,9 \\
CBST & 90 & 4,36 & 0,0 & 20,1 & 20,1 & 0,0 & 815,7 \\
CBST & 91 & 4,22 & 0,0 & 0,0 & 0,0 & 0,0 & 734,1 \\
CBST & 96 & 4,32 & 0,0 & 5,8 & 5,8 & 0,0 & 670,1 \\
CBST & 97 & 4,36 & 0,0 & 17,5 & 17,5 & 0,0 & 631,7 \\
\hline
\end{tabular}


Tabela XV.4 - Produção volumétrica acumulada do biogás em $\mathrm{mL}$ ao longo do ciclo da condição operada sem pré-tratamento da biomassa CSBT.

\begin{tabular}{cccccccccc}
\cline { 3 - 10 } & & \multicolumn{8}{c}{ Tempo (h) } \\
\hline Condição & Tempo (d) & 0,0 & 0,5 & 1,0 & 1,5 & 2,0 & 2,5 & 3,0 & 4,0 \\
\hline CBST & 88 & 0,00 & 148,7 & 307,7 & 456,4 & 589,8 & 677,0 & 715,4 & 718,0 \\
CBST & 89 & 0,00 & 259,0 & 541,1 & 782,1 & 948,8 & 1028,2 & 1038,5 & 1038,5 \\
CBST & 90 & 0,00 & 343,6 & 712,9 & 1002,6 & 1153,9 & 1184,7 & 1187,3 & 1187,3 \\
CBST & 91 & 0,00 & 387,2 & 876,9 & 1264,2 & 1477,0 & 1528,3 & 1528,3 & 1528,3 \\
CBST & 96 & 0,00 & 720,6 & 1364,2 & 1677,0 & 1723,2 & 1723,2 & 1723,2 & 1723,2 \\
\hline
\end{tabular}

Tabela XV.5 - Volume e concentração do biogás no final do ciclo da condição operada com biomassa sem pré-tratamento CBST.

\begin{tabular}{cccccc}
\hline Condição & $\begin{array}{c}\text { Tempo } \\
(\mathrm{d})\end{array}$ & $\begin{array}{c}\mathrm{V}_{\mathrm{G}} \\
\left(\mathrm{mL} . \text { ciclo }^{-1}\right)\end{array}$ & $\begin{array}{c}\mathrm{H}_{2} \\
\left(\mathrm{mmol.L} \mathrm{L}^{-1}\right)\end{array}$ & $\begin{array}{c}\mathrm{CH}_{4} \\
\left(\mathrm{mmol} \cdot \mathrm{L}^{-1}\right)\end{array}$ & $\begin{array}{c}\mathrm{CO}_{2} \\
\left(\mathrm{mmol} \cdot \mathrm{L}^{-1}\right)\end{array}$ \\
\hline CBST & 88 & 719 & 7,97 & 0,00 & 4,87 \\
CBST & 89 & 1040 & 9,75 & 0,20 & 5,28 \\
CBST & 90 & 1189 & 10,24 & 0,22 & 5,20 \\
CBST & 91 & 1530 & 10,49 & 0,27 & 5,54 \\
CBST & 96 & 1725 & 10,81 & 0,91 & 6,82 \\
\hline
\end{tabular}

Tabela XV.6 - Sólidos suspendidos e sólidos totais do afluente da condição operada com biomassa sem pré-tratamento CBST.

\begin{tabular}{cccccc}
\hline Condição & $\begin{array}{c}\text { Tempo } \\
(\mathrm{d})\end{array}$ & $\begin{array}{c}\text { SST } \\
\left(\mathrm{mg} . \mathrm{L}^{-1}\right)\end{array}$ & $\begin{array}{c}\text { SSV } \\
\left(\mathrm{mg} . \mathrm{L}^{-1}\right)\end{array}$ & $\begin{array}{c}\text { ST } \\
\left(\mathrm{mg} . \mathrm{L}^{-1}\right)\end{array}$ & $\begin{array}{c}\text { STV } \\
\left(\mathrm{mg} . \mathrm{L}^{-1}\right)\end{array}$ \\
\hline CBST & 88 & 32 & 32 & 462 & 214 \\
CBST & 90 & 52 & 12 & 554 & 372 \\
CBST & 96 & 14 & 42 & 408 & 160 \\
\hline
\end{tabular}

Tabela XV.7 - Sólidos suspendidos e sólidos totais do efluente da condição operada com biomassa sem pré-tratamento CBST.

\begin{tabular}{cccccc}
\hline Condição & $\begin{array}{c}\text { Tempo } \\
(\mathrm{d})\end{array}$ & $\begin{array}{c}\text { SST } \\
\left(\mathrm{mg} . \mathrm{L}^{-1}\right)\end{array}$ & $\begin{array}{c}\text { SSV } \\
\left(\mathrm{mg} . \mathrm{L}^{-1}\right)\end{array}$ & $\begin{array}{c}\text { ST } \\
\left(\mathrm{mg} . \mathrm{L}^{-1}\right)\end{array}$ & $\begin{array}{c}\text { STV } \\
\left(\mathrm{mg} . \mathrm{L}^{-1}\right)\end{array}$ \\
\hline CBST & 88 & 30 & 52 & 958 & 696 \\
CBST & 90 & 34 & 32 & 942 & 760 \\
CBST & 96 & 26 & 56 & 958 & 744 \\
CBST & 97 & 24 & 8 & 908 & 773 \\
\hline
\end{tabular}

Tabela XV.8 - Concentração de matéria orgânica (DQO) ao longo do ciclo da condição operada com biomassa sem pré-tratamento CBST.

\begin{tabular}{cccccccc}
\hline & & \multicolumn{6}{c}{ Tempo (h) } \\
\hline Condição & Tempo (d) & 0 & 0,5 & 1,0 & 2,0 & 3,0 & 4,0 \\
\hline CBST & 97 & 4583,7 & 321,9 & 3844,1 & 3462,3 & 3650,3 & 3685,4 \\
\hline
\end{tabular}


Tabela XV.9 - Valores de pH, alcalinidade parcial, alcalinidade intermediária, alcalinidade total, alcalinidade a bicarbonato e ácidos voláteis totais ao longo do ciclo da condição CBST.

\begin{tabular}{ccccccc}
\hline $\begin{array}{c}\text { Tempo } \\
(\mathrm{h})\end{array}$ & $\mathrm{pH}$ & $\begin{array}{r}\mathrm{AP}\left(\mathrm{mg} . \mathrm{L}^{-1}\right. \\
\mathrm{CaCO} 3)\end{array}$ & $\begin{array}{r}\mathrm{AI}\left(\mathrm{mg} . \mathrm{L}^{-1}\right. \\
\mathrm{CaCO} 3)\end{array}$ & $\begin{array}{r}\mathrm{AT}\left(\mathrm{mg} . \mathrm{L}^{-1}\right. \\
\mathrm{CaCO} 3)\end{array}$ & $\begin{array}{c}\mathrm{AB}\left(\mathrm{mg} . \mathrm{L}^{-1}\right. \\
\mathrm{CaCO} 3)\end{array}$ & $\begin{array}{c}\text { AVT }\left(\mathrm{mg} . \mathrm{L}^{-1}\right. \\
\text { HAC })\end{array}$ \\
\hline 0 & 4,59 & 0 & 58,5 & 58,5 & 0,0 & 393,5 \\
0,5 & 4,42 & 0 & 25,8 & 25,8 & 0,0 & 473,1 \\
1 & 4,4 & 0 & 22,1 & 22,1 & 0,0 & 566,4 \\
2 & 4,4 & 0 & 26,5 & 26,5 & 0,0 & 584,8 \\
3 & 4,29 & 0 & 0,00 & 0,00 & 0,0 & 582,6 \\
3,82 & 4,3 & 0 & 0,00 & 0,00 & 0,0 & 503,7 \\
\hline
\end{tabular}

Tabela XV.10 - Volume acumulado e concentração dos compostos do biogás ao longo do ciclo da condição CBST.

\begin{tabular}{ccccccc}
\hline & \multicolumn{7}{c}{ Tempo (h) } \\
\hline & $\mathbf{0 , 0}$ & $\mathbf{0 , 5}$ & $\mathbf{1 , 0}$ & $\mathbf{2 , 0}$ & $\mathbf{3 , 0}$ & $\mathbf{4 , 0}$ \\
\hline $\mathrm{C}_{\mathrm{H} 2}\left(\mathrm{mmol} . \mathrm{L}^{-1}\right)$ & 0,00 & 3,41 & 7,13 & 9,60 & 10,02 & 10,81 \\
$\mathrm{C}_{\mathrm{CH} 4}\left(\mathrm{mmol} . \mathrm{L}^{-1}\right)$ & 0,00 & 0,25 & 0,43 & 0,58 & 0,79 & 0,91 \\
$\mathrm{C}_{\mathrm{CO} 2}\left(\mathrm{mmol} . \mathrm{L}^{-1}\right)$ & 0,00 & 3,30 & 4,80 & 5,87 & 6,77 & 6,82 \\
$\mathrm{~V}_{\mathrm{G}}(\mathrm{mL})$ & 0,0 & 721,5 & 1365,94 & 1679,2 & 1725,4 & 1725,4 \\
\hline
\end{tabular}

Tabela XV.11 - Concentração de compostos intermediários ao longo do ciclo da condição CBST.

\begin{tabular}{|c|c|c|c|c|c|c|}
\hline & \multicolumn{6}{|c|}{ Tempo (h) } \\
\hline & $\mathbf{0 , 0}$ & 0,5 & $\mathbf{1 , 0}$ & 2,0 & $\mathbf{3 , 0}$ & 4,0 \\
\hline Acetona (mg. $\left.\mathrm{L}^{-1}\right)$ & 0,00 & 3,41 & 7,13 & 9,60 & 10,02 & 10,81 \\
\hline Metanol (mg. $\left.\mathrm{L}^{-1}\right)$ & 0,00 & 0,25 & 0,43 & 0,58 & 0,79 & 0,91 \\
\hline Etanol (mg. $\left.\mathrm{L}^{-1}\right)$ & 41,1 & 36,6 & 32,1 & 41,7 & 39,5 & 38,8 \\
\hline Butanol (mg.L $\left.{ }^{-1}\right)$ & 276,8 & 290,4 & 264,6 & 285,8 & 292,4 & 278,1 \\
\hline Ácido Acético (mg.L $\left.{ }^{-1}\right)$ & 145,1 & 152,6 & 132,5 & 163,5 & 158,7 & 147,2 \\
\hline Ácido Propiônico (mg.L $\left.{ }^{-1}\right)$ & 18,7 & 17,8 & 19,1 & 21,1 & 18,2 & 20,4 \\
\hline Ácido Iso-Butírico (mg.L $\left.{ }^{-1}\right)$ & 9,4 & 4,6 & 3,4 & 7,1 & 5,2 & 8,2 \\
\hline Ácido Butírico (mg.L $\left.\mathrm{L}^{-1}\right)$ & 237,8 & 255,9 & 222,3 & 245,5 & 224,2 & 252,9 \\
\hline Ácido Iso-Valérico (mg.L $\left.\mathrm{L}^{-1}\right)$ & 8,8 & 7,4 & 6,9 & 9,6 & 6,1 & 8,1 \\
\hline Ácido Valérico (mg.L $\left.\mathrm{L}^{-1}\right)$ & 17,1 & 14,5 & 13,6 & 18,3 & 15,2 & 17,8 \\
\hline Ácido Capróico (mg.L $\left.{ }^{-1}\right)$ & 48,4 & 35,5 & 30,4 & 41,1 & 28,3 & 37,9 \\
\hline
\end{tabular}




\section{ANEXO XVI}

Tabela XVI.1 - Concentração de matéria orgânica (DQO) afluente e efluente da condição operada com glicerina bruta CGB.

\begin{tabular}{ccccccc}
\hline Condição & Tempo & $\mathrm{C}_{\mathrm{SAFTL}}\left(\mathrm{mgDQO} . \mathrm{L}^{-1}\right)$ & $\mathrm{C}_{\mathrm{ST}}\left(\mathrm{mgDQO} . \mathrm{L}^{-1}\right)$ & $\mathrm{C}_{\mathrm{SF}}\left(\mathrm{mgDQO} . \mathrm{L}^{-1}\right)$ & $\varepsilon_{\mathrm{ST}}(\%)$ & $\varepsilon_{\mathrm{SF}}(\%)$ \\
\hline $\mathrm{CGB}$ & 102 & 5658 & 3664 & 3340 & 35,2 & 41,0 \\
$\mathrm{CGB}$ & 103 & 5660 & 3623 & 3290 & 36,0 & 41,9 \\
$\mathrm{CGB}$ & 104 & 4987 & 3096 & 2880 & 37,9 & 42,2 \\
$\mathrm{CGB}$ & 105 & 5140 & 3047 & 3042 & 40,7 & 40,8 \\
$\mathrm{CGB}$ & 109 & 5192 & 3142 & 2681 & 39,5 & 48,4 \\
$\mathrm{CGB}$ & 110 & 5109 & 3209 & 2938 & 37,2 & 42,5 \\
$\mathrm{CGB}$ & 111 & 4871 & 2911 & 2726 & 40,2 & 44,0 \\
$\mathrm{CGB}$ & 112 & 5072 & 2970 & 2724 & 41,4 & 46,3 \\
\hline
\end{tabular}

Tabela XVI.2 - Valores de pH, alcalinidade parcial, alcalinidade intermediária, alcalinidade total, alcalinidade a bicarbonato e ácidos voláteis totais no afluente da condição operada com glicerina bruta CGB.

\begin{tabular}{cccccccc} 
Condição & Tempo (d) & $\mathrm{pH}$ inicial & $\begin{array}{c}\mathrm{AP} \\
\left(\mathrm{mgCaCO}_{3} \cdot \mathrm{L}^{-1}\right)\end{array}$ & $\begin{array}{c}\mathrm{AI} \\
\left(\mathrm{mgCaCO}_{3} \cdot \mathrm{L}^{-1}\right)\end{array}$ & $\begin{array}{c}\mathrm{AT} \\
\left(\mathrm{mgCaCO}_{3} \cdot \mathrm{L}^{-1}\right)\end{array}$ & $\begin{array}{c}\mathrm{AB} \\
\left(\mathrm{mgCCO}_{3} \cdot \mathrm{L}^{-1}\right)\end{array}$ & $\begin{array}{c}\mathrm{AVT} \\
\left(\mathrm{mgCaCO}_{3} \cdot \mathrm{L}^{-1}\right)\end{array}$ \\
\hline CGB & 102 & 8,37 & 213,9 & 67,0 & 283,9 & 193,9 & 126,7 \\
CGB & 103 & 8,13 & 236,7 & 71,2 & 307,8 & 218,7 & 125,6 \\
CGB & 104 & 8,06 & 224,5 & 69,1 & 293,6 & 203,7 & 126,6 \\
CGB & 105 & 7,99 & 227,7 & 71,6 & 299,3 & 202,4 & 136,5 \\
CGB & 109 & 8,00 & 216,8 & 64,7 & 281,4 & 195,2 & 121,5 \\
CGB & 110 & 8,12 & 221,6 & 72,0 & 293,6 & 200,5 & 131,1 \\
CGB & 111 & 8,12 & 181,0 & 62,6 & 243,6 & 160,1 & 117,6 \\
CGB & 112 & 8,03 & 178,1 & 94,8 & 272,9 & 179,4 & 131,7 \\
\hline
\end{tabular}

Tabela XVI.3 - Valores de pH, alcalinidade parcial, alcalinidade intermediária, alcalinidade total, alcalinidade a bicarbonato e ácidos voláteis totais no efluente da condição operada com glicerina bruta CGB.

\begin{tabular}{cccccccc}
\hline Condição & Tempo (d) & $\mathrm{pH}$ inicial & $\begin{array}{c}\mathrm{AP} \\
\left(\mathrm{mgCaCO}_{3} \cdot \mathrm{L}^{-1}\right)\end{array}$ & $\begin{array}{c}\mathrm{AI} \\
\left(\mathrm{mgCaCO}_{3} \cdot \mathrm{L}^{-1}\right)\end{array}$ & $\begin{array}{c}\mathrm{AT} \\
\left(\mathrm{mgCaCO}_{3} \cdot \mathrm{L}^{-1}\right)\end{array}$ & $\begin{array}{c}\mathrm{AB} \\
\left(\mathrm{mgCCO}_{3} \cdot \mathrm{L}^{-1}\right)\end{array}$ & $\begin{array}{c}\mathrm{AVT} \\
\left(\mathrm{mgCaCO}_{3} \cdot \mathrm{L}^{-1}\right)\end{array}$ \\
\hline CGB & 102 & 5,85 & 0,0 & 268,0 & 268,0 & 0,0 & 647,3 \\
CGB & 103 & 5,54 & 0,0 & 242,0 & 242,0 & 0,0 & 614,9 \\
CGB & 104 & 5,63 & 0,0 & 226,9 & 226,9 & 0,0 & 556,3 \\
CGB & 105 & 5,47 & 0,0 & 234,2 & 234,2 & 0,0 & 590,6 \\
CGB & 109 & 5,61 & 0,0 & 242,8 & 242,8 & 0,0 & 574,3 \\
CGB & 110 & 5,42 & 0,0 & 226,9 & 226,9 & 0,0 & 614,2 \\
CGB & 111 & 5,12 & 0,0 & 187,9 & 187,9 & 0,0 & 578,3 \\
CGB & 112 & 5,04 & 0,0 & 184,2 & 184,2 & 0,0 & 600,2 \\
\hline
\end{tabular}


Tabela XVI.4 - Produção volumétrica acumulada do biogás em $\mathrm{mL}$ ao longo do ciclo da condição operada com glicerina bruta CGB.

\begin{tabular}{cccccccccc} 
& & \multicolumn{7}{c}{ Tempo (h) } \\
\hline Condição & Tempo (d) & 0,0 & 0,5 & 1,0 & 1,5 & 2,0 & 2,5 & 3,0 & 4,0 \\
\hline CGB & 102 & 0,0 & 120,5 & 218,0 & 253,9 & 259,0 & 259,0 & 259,0 & 259,0 \\
CGB & 103 & 0,0 & 141,0 & 230,8 & 256,4 & 261,6 & 261,6 & 261,6 & 261,6 \\
CGB & 104 & 0,0 & 120,5 & 210,3 & 230,8 & 235,9 & 235,9 & 235,9 & 235,9 \\
CGB & 105 & 0,0 & 105,1 & 164,1 & 235,9 & 235,9 & 235,9 & 235,9 & - \\
CGB & 109 & 0,0 & 146,2 & 289,8 & 338,5 & 338,5 & 338,5 & 338,5 & - \\
CGB & 111 & 0,0 & 125,6 & 238,5 & 261,6 & 261,6 & 261,6 & 261,6 & - \\
\hline
\end{tabular}

Tabela XVI.5 - Volume e concentração do biogás no final do ciclo da condição operada com glicerina bruta CGB.

\begin{tabular}{cccccc}
\hline Condição & $\begin{array}{c}\text { Tempo } \\
(\mathrm{d})\end{array}$ & $\begin{array}{c}\mathrm{V}_{\mathrm{G}} \\
\left(\mathrm{mL} . \mathrm{ciclo}^{-1}\right)\end{array}$ & $\begin{array}{c}\mathrm{H}_{2} \\
\left(\mathrm{mmol} . \mathrm{L}^{-1}\right)\end{array}$ & $\begin{array}{c}\mathrm{CH}_{4} \\
\left(\mathrm{mmol}^{-1} \mathrm{~L}^{-1}\right)\end{array}$ & $\begin{array}{c}\mathrm{CO}_{2} \\
\left(\mathrm{mmol} . \mathrm{L}^{-1}\right)\end{array}$ \\
\hline CGB & 102 & 259 & 1,79 & 0,00 & 2,87 \\
CGB & 103 & 262 & 1,98 & 0,00 & 3,07 \\
CGB & 104 & 236 & 1,91 & 0,19 & 2,76 \\
CGB & 105 & 236 & 1,90 & 0,27 & 2,46 \\
CGB & 109 & 341 & 2,23 & 0,22 & 2,97 \\
CGB & 110 & 395 & 2,20 & 0,28 & 2,87 \\
CGB & 111 & 262 & 2,17 & 0,26 & 2,92 \\
\hline
\end{tabular}

Tabela XVI.6 - Sólidos suspendidos e sólidos totais do afluente da condição operada com glicerina bruta CGB.

\begin{tabular}{cccccc}
\hline Condição & $\begin{array}{c}\text { Tempo } \\
(\mathrm{d})\end{array}$ & $\begin{array}{c}\text { SST } \\
\left(\mathrm{mg} . \mathrm{L}^{-1}\right)\end{array}$ & $\begin{array}{c}\text { SSV } \\
\left(\mathrm{mg} . \mathrm{L}^{-1}\right)\end{array}$ & $\begin{array}{c}\text { ST } \\
\left(\mathrm{mg} . \mathrm{L}^{-1}\right)\end{array}$ & $\begin{array}{c}\text { STV } \\
\left(\mathrm{mg} . \mathrm{L}^{-1}\right)\end{array}$ \\
\hline CGB & 102 & 303 & 284 & 2222 & 1654 \\
CGB & 104 & 453 & 426 & 1792 & 1154 \\
CGB & 109 & 296 & 223 & 2312 & 1722 \\
CGB & 111 & 276 & 288 & 1954 & 1412 \\
\hline
\end{tabular}

Tabela XVI.7 - Sólidos suspendidos e sólidos totais do efluente da condição operada com glicerina bruta CGB.

\begin{tabular}{cccccc}
\hline Condição & $\begin{array}{c}\text { Tempo } \\
(\mathrm{d})\end{array}$ & $\begin{array}{c}\text { SST } \\
\left(\mathrm{mg} . \mathrm{L}^{-1}\right)\end{array}$ & $\begin{array}{c}\mathrm{SSV} \\
\left(\mathrm{mg} . \mathrm{L}^{-1}\right)\end{array}$ & $\begin{array}{c}\mathrm{ST} \\
\left(\mathrm{mg} . \mathrm{L}^{-1}\right)\end{array}$ & $\begin{array}{c}\mathrm{STV} \\
\left(\mathrm{mg} . \mathrm{L}^{-1}\right)\end{array}$ \\
\hline CGB & 102 & 78 & 52 & 1654 & 1074 \\
CGB & 104 & 96 & 76 & 1482 & 886 \\
CGB & 109 & 112 & 80 & 1644 & 1142 \\
CGB & 111 & 84 & 80 & 1740 & 1212 \\
\hline
\end{tabular}


Tabela XVI.8 - Concentração de matéria orgânica (DQO) ao longo do ciclo da condição operada com glicerina bruta CGB.

\begin{tabular}{cccccccc}
\hline & & \multicolumn{7}{c}{ Tempo (h) } \\
\hline Condição & Tempo (d) & 0 & 0,5 & 1,0 & 2,0 & 3,0 & 4,0 \\
\hline CGB & 112 & 3279 & 3093 & 2934 & 2676 & 2766 & 2848 \\
\hline
\end{tabular}

Tabela XVI.9 - Valores de pH, alcalinidade parcial, alcalinidade intermediária, alcalinidade total, alcalinidade a bicarbonato e ácidos voláteis totais ao longo do ciclo da condição CGB.

\begin{tabular}{ccccccc}
$\begin{array}{c}\text { Tempo } \\
(\mathrm{h})\end{array}$ & $\mathrm{pH}$ & $\begin{array}{c}\mathrm{AP}\left(\mathrm{mg} . \mathrm{L}^{-1}\right. \\
\mathrm{CaCO} 3)\end{array}$ & $\begin{array}{c}\mathrm{AI}\left(\mathrm{mg} . \mathrm{L}^{-1}\right. \\
\mathrm{CaCO} 3)\end{array}$ & $\begin{array}{c}\mathrm{AT}\left(\mathrm{mg} . \mathrm{L}^{-1}\right. \\
\mathrm{CaCO} 3)\end{array}$ & $\begin{array}{c}\mathrm{AB}\left(\mathrm{mg} . \mathrm{L}^{-1}\right. \\
\mathrm{CaCO} 3)\end{array}$ & $\begin{array}{c}\text { AVT }\left(\mathrm{mg} . \mathrm{L}^{-1}\right. \\
\mathrm{HAC})\end{array}$ \\
\hline 0 & 5,40 & 0,0 & 179,9 & 179,9 & 0,0 & 500,3 \\
0,5 & 5,24 & 0,0 & 195,2 & 195,2 & 0,0 & 525,7 \\
1 & 5,20 & 0,0 & 194,2 & 194,2 & 0,0 & 594,2 \\
2 & 5,00 & 0,0 & 190,1 & 190,1 & 0,0 & 629,9 \\
3 & 5,01 & 0,0 & 176,9 & 176,9 & 0,0 & 605,3 \\
3,82 & 4,94 & 0,0 & 170,8 & 170,8 & 0,0 & 481,5 \\
\hline
\end{tabular}

Tabela XVI.10 - Volume acumulado e concentração dos compostos do biogás ao longo do ciclo da condição CGB.

\begin{tabular}{ccccccc}
\hline & \multicolumn{7}{c}{ Tempo (h) } \\
\hline & 0,0 & 0,5 & 1,0 & 2,0 & 3,0 & 4,0 \\
\hline $\mathrm{C}_{\mathrm{H} 2}\left(\mathrm{mmol} . \mathrm{L}^{-1}\right)$ & 0,00 & 0,81 & 1,55 & 1,89 & 2,09 & 2,20 \\
$\mathrm{C}_{\mathrm{CH} 4}\left(\mathrm{mmol} . \mathrm{L}^{-1}\right)$ & 0,00 & 0,00 & 0,10 & 0,22 & 0,24 & 0,28 \\
$\mathrm{C}_{\mathrm{CO} 2}\left(\mathrm{mmol} . \mathrm{L}^{-1}\right)$ & 0,00 & 1,12 & 2,08 & 2,74 & 2,74 & 2,87 \\
$\mathrm{~V}_{\mathrm{G}}(\mathrm{mL})$ & 0,0 & 146,2 & 289,8 & 338,5 & 338,5 & 338,5 \\
\hline
\end{tabular}

Tabela XVI.11 - Concentração de compostos intermediários ao longo do ciclo da condição CGB.

\begin{tabular}{|c|c|c|c|c|c|c|}
\hline & \multicolumn{6}{|c|}{ Tempo (h) } \\
\hline & 0,0 & 0,5 & 1,0 & 2,0 & 3,0 & 4,0 \\
\hline Acetona $\left(\mathrm{mg} . \mathrm{L}^{-1}\right)$ & 0,00 & 3,41 & 7,13 & 9,60 & 10,02 & 10,81 \\
\hline Metanol (mg.L $\left.{ }^{-1}\right)$ & 0,00 & 0,25 & 0,43 & 0,58 & 0,79 & 0,91 \\
\hline Etanol $\left(\mathrm{mg} \cdot \mathrm{L}^{-1}\right)$ & 136,8 & 139,8 & 150,7 & 142,6 & 150,2 & 147,7 \\
\hline Butanol (mg.L $\left.\mathrm{L}^{-1}\right)$ & 3,7 & 3,9 & 4,2 & 4,4 & 4,1 & 3,6 \\
\hline Ácido Acético (mg.L $\left.\mathrm{L}^{-1}\right)$ & 219,6 & 262,5 & 269,1 & 290,3 & 288,7 & 274,1 \\
\hline Ácido Propiônico (mg.L $\left.\mathrm{L}^{-1}\right)$ & 102,4 & 122,3 & 149,1 & 155,4 & 160,1 & 151,9 \\
\hline Ácido Iso-Butírico (mg.L $\left.{ }^{-1}\right)$ & 9,3 & 9,4 & 10,2 & 12,1 & 11,9 & 12,7 \\
\hline Ácido Butírico (mg.L $\left.\mathrm{L}^{-1}\right)$ & 16,6 & 17,2 & 19,4 & 20,7 & 22,1 & 19,7 \\
\hline Ácido Iso-Valérico (mg.L $\left.\mathrm{L}^{-1}\right)$ & 6,7 & 5,4 & 7,1 & 6,9 & 7,7 & 7,3 \\
\hline Ácido Valérico $\left(\mathrm{mg} . \mathrm{L}^{-1}\right)$ & 22,1 & 20,4 & 24,3 & 26,1 & 28,2 & 27,3 \\
\hline Ácido Capróico (mg.L $\left.{ }^{-1}\right)$ & 15,8 & 13,7 & 17,1 & 14,6 & 16,1 & 15,2 \\
\hline
\end{tabular}

